- तै-

\title{
O Open Access
}

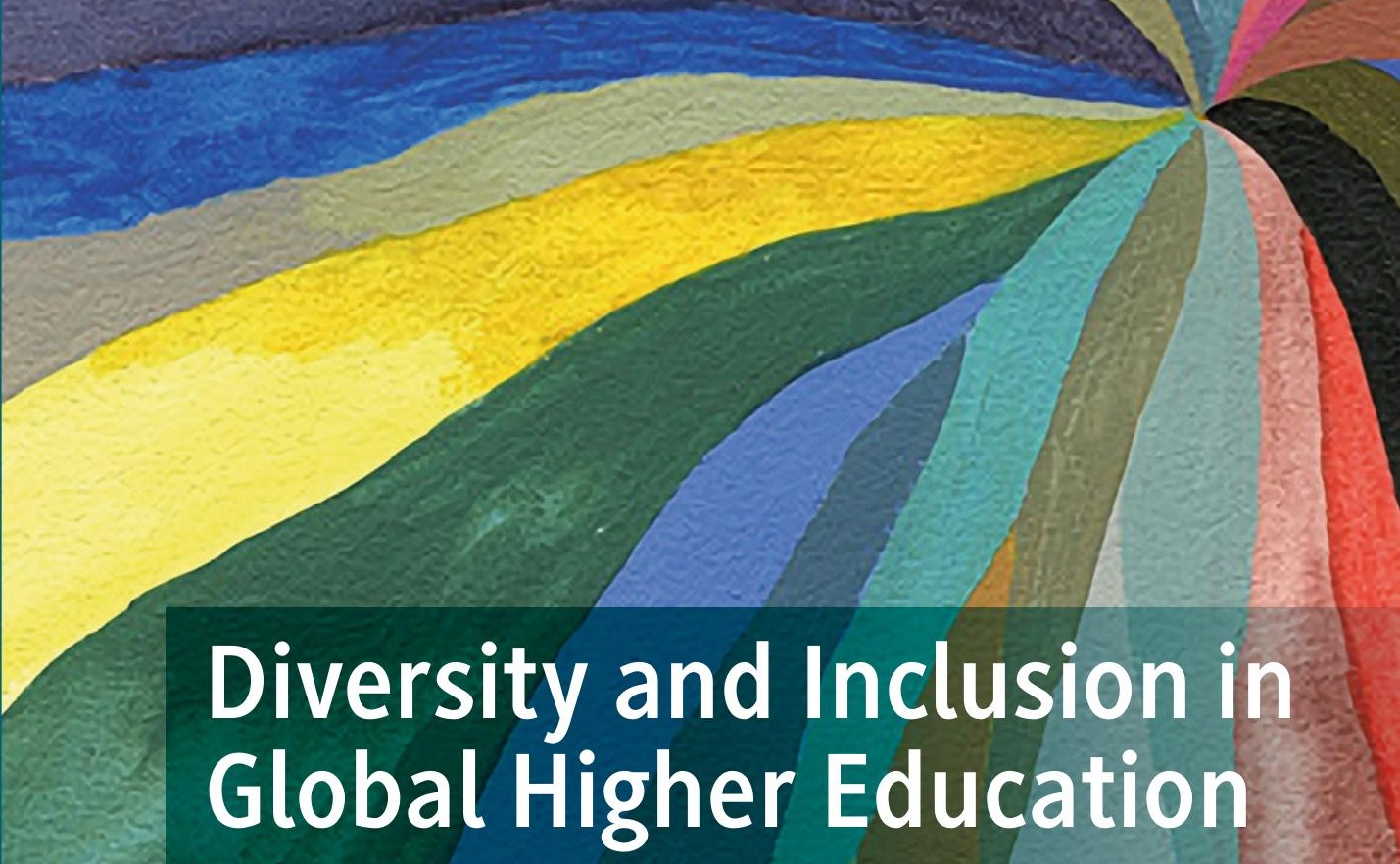

Lessons from Across Asia

Edited by

Catherine Shea Sanger

Nancy W. Gleason 
Diversity and Inclusion in Global Higher Education 
Catherine Shea Sanger - Nancy W. Gleason Editors

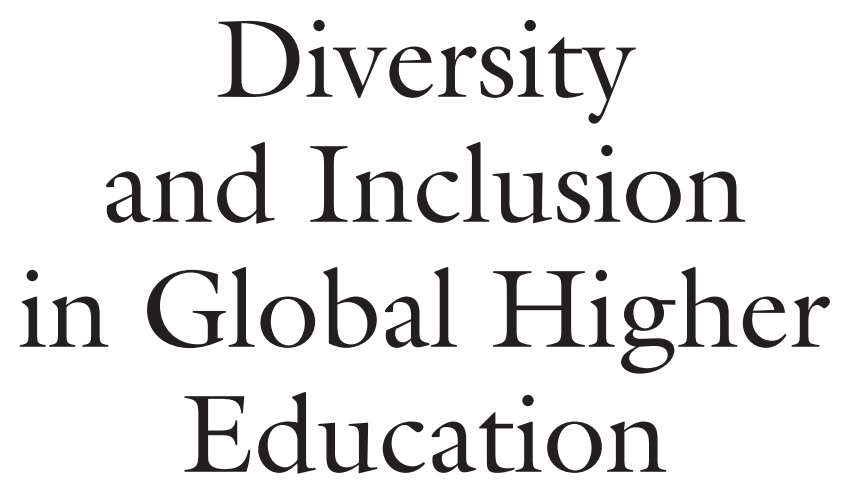

Lessons from Across Asia

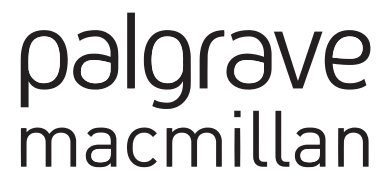


Editors

Catherine Shea Sanger

Yale-NUS College

Singapore, Singapore
Nancy W. Gleason

New York University Abu Dhabi

Abu Dhabi, United Arab Emirates

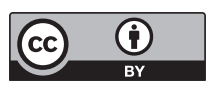

ISBN 978-981-15-1627-6 ISBN 978-981-15-1628-3 (eBook) https://doi.org/10.1007/978-981-15-1628-3

(C) The Editor(s) (if applicable) and The Author(s) 2020. This book is an open access publication.

Open Access This book is licensed under the terms of the Creative Commons Attribution 4.0 International License (http://creativecommons.org/licenses/by/4.0/), which permits use, sharing, adaptation, distribution and reproduction in any medium or format, as long as you give appropriate credit to the original author(s) and the source, provide a link to the Creative Commons license and indicate if changes were made.

The images or other third party material in this book are included in the book's Creative Commons license, unless indicated otherwise in a credit line to the material. If material is not included in the book's Creative Commons license and your intended use is not permitted by statutory regulation or exceeds the permitted use, you will need to obtain permission directly from the copyright holder.

The use of general descriptive names, registered names, trademarks, service marks, etc. in this publication does not imply, even in the absence of a specific statement, that such names are exempt from the relevant protective laws and regulations and therefore free for general use. The publisher, the authors and the editors are safe to assume that the advice and information in this book are believed to be true and accurate at the date of publication. Neither the publisher nor the authors or the editors give a warranty, expressed or implied, with respect to the material contained herein or for any errors or omissions that may have been made. The publisher remains neutral with regard to jurisdictional claims in published maps and institutional affiliations.

Cover credit: beastfromeast

This Palgrave Macmillan imprint is published by the registered company Springer Nature Singapore Pte Ltd.

The registered company address is: 152 Beach Road, \#21-01/04 Gateway East, Singapore 189721, Singapore 


\section{FOREWORD}

For the last fifteen years, I have held administrative and academic leadership roles in liberal arts institutions across the United States, Australia, Asia, and the Middle East. But my journey in higher education began at age 18 when I attended a small, Christian, liberal arts college in the Midwestern United States. Moving away from home for the first time; taking classes that challenged my world view about religion and culture; navigating relationships with peers from different backgrounds and family structures; and discovering my intellectual passion for philosophy after several failed attempts at other majors created a transformative educational experience that changed the course of my personal and professional trajectories.

Yet my own experience with liberal arts education seems distinctively and, perhaps, conventionally American. I did not acquire a passport until nearly a decade after finishing my bachelor's degree; nearly zero of my classmates came from outside the United States; and most faculty members oriented their teaching exclusively on Western philosophies. Instead, what made this education enriching was that it stretched my intellectual and social capacities at the time, and challenged my preconceived ideas in ways that were both possible and contextual to a small-town, Midwestern, Christian school.

The rise of liberal arts education across Asia and the Middle East is encouraging for its potential to promote critical discourse and an engaged citizenry, and so it is worth reflecting on what the words "liberal arts" actually mean in these contexts. Notions of studying 
"depth and breadth", seeking one's passion when selecting a course of study, or even whether or not to ask questions in a classroom environment are culturally and geographically constructed. And the underlying assumptions that faculty, administrators, government officials, and industry stakeholders often make about liberal arts education require reimagination and adaptation to truly be accessible for all students.

At New York University, Abu Dhabi, I oversee our division of student affairs, which brings together several functional areas of the student experience including career development, health and wellness, spiritual life, intercultural education, residential life, student involvement, community outreach, athletics, and cultural engagement. With a population of 1500 undergraduates from $120+$ countries, each of these administrative units require thoughtful leadership regarding diversity and inclusion in order to facilitate an environment that harnesses this rich array of cultures toward a greater sense of understanding and connection across difference.

Shaping this environment that moves us from demographic diversity to intercultural pluralism is not solely the task of administrators, as students do not draw the same boundary lines between their experiences in the classroom, laboratory, studio, athletic field, residential building, and dining hall. Faculty, alongside students themselves, are vital partners in creating the kind of community that can draw upon each students' different identities and perspectives to foster a more complete, textured understanding of both the intellectual and social experiences that underpin a liberal arts education.

Further, to realize the full potential of diversity within higher education-whether that is at a small Midwestern US religious school or a cosmopolitan international campus of Abu Dhabi-is to appreciate and grapple with the fact that this is a messy project, rife with complexity and cultural "blind spots" that inhibit our efforts to create an educational experience that is inclusive and accessible. For example, in some Asian nations, promoting tolerance of minority groups is the preferred approach while in other locations, fostering harmony among cultures is paramount. And for others still, local legal and policy frameworks impact how diversity may be pursued in educational institutions. The context and distinctive characteristics of every institution and country matter, but this book offers a set of thoughtful reflections that can enhance the teaching and learning environment across Asia and the world. 
Advancing an inclusive campus community is exceedingly difficult and as leaders in higher education, we will not always get it right. Indeed, it will often be students who help us address gaps in our own perspective. In this edited volume, Dr. Sanger and Dr. Gleason have curated a group of experts on issues of inclusion that address multiple touch-points across the student experience. This holistic approach to delivering inclusive pedagogy acknowledges the full extent of student experiences beyond the boundaries of the classroom, and provides faculty and administrators alike with a valuable resource for advancing an inclusive campus community.

This volume presents ideas and examples that offer a way forward for faculty, administrators, and students to work together to support not only diversity in concept, but the practice and implementation of strategies and approaches that can help us all appreciate the potential it offers higher education in Asia and around the world.

August 2019

Kyle Farley, Ph.D. Associate Vice Chancellor for Student Affairs and Dean of Students New York University Abu Dhabi Abu Dhabi, United Arab Emirates 


\section{Contents}

1 Diversity, Inclusion, and Context in Asian Higher Education

Catherine Shea Sanger

Part I Pedagogy for Inclusion

2 Inclusive Pedagogy and Universal Design Approaches for Diverse Learning Environments Catherine Shea Sanger

3 Beyond Fairness and Consistency in Grading:

The Role of Rubrics in Higher Education

Kiruthika Ragupathi and Adrian Lee

4 Educating Adult Learners: Bridging Learners'

Characteristics and the Learning Sciences

Ho Yan Yin and Wei Ying Rebekah Lim

5 Culture and Learning: Confucian Heritage

Learners, Social-Oriented Achievement, and Innovative Pedagogies

Shelen Ho 
Part II Liberal Arts Curricula in Asia Through the Diversity and Inclusion Lens

6 Diversifying the Liberal Arts Curriculum in an Asian Context

Charles Bailyn

7 Service-Learning as a Means to Understand Socio-Economic Privilege, Inequality, and Social Mobility

Mikiko Nishimura and Hitomi Yokote

8 Building a Center for Writing and Communication: Inclusion, Diversity and Writing in the Indian Context Kanika Singh

Part III Supporting Historically Marginalized Populations

9 Gender and Sexual Diversity in Asian Universities Khoo Hoon Eng and Daryl W. J. Yang

10 Higher Education for Women in Asia Solveig Olson-Strom and Nirmala Rao

Part IV Leadership for Inclusion

11 Conclusion: Strategic Leadership for Diversity and Inclusion in Higher Education Nancy W. Gleason 


\section{Notes on Contributors}

Charles Bailyn is the A. Bartlett Giamatti Professor of Astronomy and Physics at Yale University, and from 2011-2016 served as the inaugural Dean of Faculty at Yale-NUS College in Singapore. He is currently Head of College of Benjamin Franklin College, one of Yale's fourteen residential colleges. He served on the steering committee of the Committee on Yale College Education, which carried out a complete review of the Yale undergraduate curriculum in 2001-2003. He has been the director of undergraduate studies and department chair in Astronomy at Yale and has served two terms as chair of the Yale College committee on Teaching, Learning and Advising. He has been awarded the Dylan Hixon Prize, Yale's highest honor for teaching in the natural sciences, and the Bruno Rossi prize for research in high-energy astrophysics from the American Astronomical Society.

Khoo Hoon Eng is Associate Professor of Life Sciences at Yale-NUS College and Associate Professor of Biochemistry at the Yong Loo Lin School of Medicine, NUS (NUSMedicine). She has published articles and books in medical education and liberal arts education. Her administrative experience in higher education include being a Vice Dean at NUSMedicine and Associate Dean of Faculty at Yale-NUS College. She was the inaugural Provost and Acting Vice Chancellor at the Asian University for Women, a liberal arts institution located in Bangladesh. She is a cofounder of SAFE Singapore (Supporting and Affirming and Empowering our LGBTQ friends and family) and faculty adviser to 
G-Spot, a Yale-NUS student organization that seeks to raise awareness on issues of gender, sexuality, and feminism, including their intersections.

Dr. Nancy W. Gleason is inaugural director of the Hilary Ballon Center for Excellence in Teaching and Learning and NYU-Abu Dhabi in the United Arab Emirates. Previously, she directed the Centre for Teaching Excellence at Yale-NUS College in Singapore. Her research has focused on climate change policy and the Fourth Industrial Revolution's implications for higher education and the future of work. She is the editor of Higher Education in the Era of the Fourth Industrial Revolution (Springer, 2018).

Shelen Ho is an Associate Professor in International Business and Strategy at the University of Reading Malaysia and leads the flexible executive MBA program at the Henley business school. She is also a global supervisor of live business projects for the MBA programs at the Manchester Business School. She has previously taught master programs with Manchester Business School (UK), Maastricht School of Management (The Netherlands), University of Stirling (UK), University of Hertfordshire (UK), and Royal Melbourne Institute of Technology (Australia). Shelen has over two decades of broad-based business consultancy experiences in the ASEAN region specializing in SME restructuring and development. She researches actively in SMEs' settings, community capacity building, and shared value creation with socioeconomic innovations. She also conducts action research on innovative pedagogic practices in different cultural contexts. Findings from her field studies have been presented in various international conferences and published in regional journals.

Adrian Lee is currently the Deputy Director of the Centre for Development of Teaching and Learning (CDTL) at the National University of Singapore (NUS). His primary responsibility is overseeing professional development programs. Adrian's background is in the Sciences-he holds a Ph.D. in Chemistry. His interests in education are wide-ranging and include technology-enhanced learning, especially blended learning, interdisciplinary education (he was the Director of the Special Programme in Science from 2011 to 2016), and student livinglearning experiences. In academic development, Adrian looks to build programs within a collegial culture and further a conversation that is both evidence-based and research-informed that becomes part of an academic's scholarly reflective teaching practice. 
Dr. Wei Ying Rebekah Lim is Associate Professor and Director of the Teaching and Learning Centre and Singapore University of Social Sciences. Dr. Lim leads innovative pedagogical scholarship and professional development across Southeast Asia. Her research focuses on the learning sciences, digital learning, professional development, teacher learning, and the broader issues of higher education. She holds a Ph.D. in Education from Nanyang Technological University in Singapore.

Mikiko Nishimura is a Senior Associate Professor of Sociology of Education at the College of Liberal Arts and the Graduate School of Arts and Sciences, International Christian University in Japan. Prior to the current position, she was an Associate Professor at the Graduate School of International Cooperation Studies, Kobe University. Her research interests focus on empirical studies of education reforms and issues of institutionalized disparities and stratification in education. She has worked extensively in education planning and research as an Associate Specialist of Japan International Cooperation Agency. As a researcher and freelance consultant, she has been involved in project formulation, implementation, and evaluation in education and poverty alleviation in fourteen countries, in Asia, Africa, and Latin America. She holds an M.Phil. in Development Studies from University of Sussex and Ed.D. in International Educational Development from Teachers College, Columbia University.

Solveig Olson-Strom is a Writing Center Fellow at the Asian University for Women in Chittagong, Bangladesh. She previously studied Linguistics at Pomona College in Claremont, California. Her interests lie in cross-cultural education, multilingualism, and gender studies.

Kiruthika Ragupathi is an Associate Director of the Centre for Development of Teaching and Learning (CDTL) at the National University of Singapore (NUS) and has been with the Centre since 1997. In her current role, she co-leads the continuing professional development programs and oversees the centralized teaching quality instruments at NUS - student feedback and peer review. She also designs and conducts training on various topics including technology-enhanced learning, student engagement, and assessment. Her research work, past and present, focuses on academic development, educational technology, student learning experiences, assessment, and evaluation. Kiruthika was awarded the Commendation Medal at the Singapore's National Day Awards in 2014. 
Nirmala Rao, OBE, FAcSS is the Vice Chancellor of the Asian University for Women in Chittagong, Bangladesh. She has been a champion of gender equality in teaching and learning in higher education throughout her career. She served as the Pro-Director (Learning and Teaching) of SOAS, University of London from 2008 to 2016. She holds a Ph.D. from Queen Mary and Westfield College, University of London. She served in the Politics Department at Goldsmiths College where she was elected Fellow of the Academy of Social Sciences in 2003. She has published extensively in the field of urban governance and has served as an advisor to a range of bodies including the UK Audit Commission and the Office of the Deputy Prime Minister (ODPM). She currently serves as a Trustee of the Learning from Experience Trust, and is a member of the Governing Body of Trinity Laban Conservatoire of Music and Dance, and of the Council of the Association of Commonwealth Universities (ACU).

Dr. Catherine Shea Sanger is Interim Director of the Centre for Teaching and Learning, and Lecturer in Global Affairs, at Yale-NUS College in Singapore. Her work operates at the intersection of liberal arts education, student life, and faculty pedagogy development. Dr. Sanger joined the College in 2014 as the inaugural Assistant Dean of Students for Cendana Residential College, one of three Residential Colleges at Yale-NUS. In 2017, she took on the new post of Deputy Director of the Centre for Teaching \& Learning at Yale-NUS College. She works with both faculty and students to facilitate transformative student learning and empowered faculty teaching. Dr. Sanger has particular responsibility for managing student learning accommodations, peer tutoring, syllabus design, and pedagogy development for junior faculty. She is especially interested in supporting faculty to develop inclusive teaching strategies for a diverse educational community. She holds a Ph.D. in International Affairs from the University of Virginia, where she served as an instructor for many years before moving to South East Asia.

Kanika Singh is the Director, Centre for Writing \& Communication, Ashoka University. She has experience creating learning material for museums, school students, neo-literates, and in distance education. She is a historian working on heritage and museums in India and her current research is on Sikh museums. She is the cofounder of Delhi Heritage Walks, a group engaging with heritage of the city of Delhi. She studied 
at University of Delhi, Jawaharlal Nehru University, and Ambedkar University Delhi. She has taught at CEPT University, Ahmedabad and Ambedkar University, Delhi.

Daryl W. J. Yang holds a B.A. with Honours (Liberal Arts) with a minor in Anthropology at Yale-NUS College and an LLB (First Class Honours) from the National University of Singapore's Faculty of Law. $\mathrm{He}$ co-founded and served as the inaugural Executive Director of Singapore's Inter-University LGBT Network and previously interned with the National Center for Lesbian Rights and the International Lesbian, Gay, Bisexual, Trans and Intersex Association (ILGA). Daryl's writing has been published in the Singapore Law Review and various online publications.

Dr. Ho Yan Yin is a Lecturer at the Teaching and Learning Centre at the Singapore University of Social Sciences where she delivers curricular design and faculty advancement. She holds a Ph.D. in Psychology from the National University of Singapore. Prior to her current position, she served for several years at a Lecturer, within the School of Humanities \& Social Sciences, at Ngee Ann Polytechnic in Singapore. Her research focuses on adult learning, microlearning, psychological assessment, and learning potential.

Hitomi Yokote is a lecturer and program coordinator of ServiceLearning, International Christian University (ICU), Tokyo, Japan since August 2018. Prior to joining ICU, she held various executive positions in business and nonprofit organizations, and also the government. Hitomi holds an MBA from Graduate School of Management, Keio University, Japan, and holds a BA from Sophia University, Japan. 


\section{List of Figures}

Fig. 3.1 Rubric development as part of course design (adapted from Huba and Freed, 2000) 83

Fig. 4.1 Adult learners' rating of their preferred lesson delivery methods 106

Fig. 4.2 The time periods for when adult learners reported they most likely have time to study

Fig. 4.3 Average number of hours (per week) spent by adult learners on self-studying (excluding time spent on assignment preparation)

Fig. 4.4 Average number of hours spent by adult learners to complete one assignment

Fig. 5.1 Flipped learning

Fig. 5.2 Pedagogic strategies for strategic management in classrooms 


\section{List of TABLES}

$\begin{array}{lll}\text { Table 3.1 Single-point rubric as an instructional scaffold } & 85\end{array}$

Table 3.2 Teacher summary rubric for teaching improvement 90

Table 4.1 Demographic information 104

Table 7.1 ICU's service-learning program development phase 192

Table 9.1 Various institutional approaches towards gender and sexual diversity 246

Table 11.1 Tertiary enrolment statistics in selected Asian countries 290 


\section{Diversity, Inclusion, and Context in Asian Higher Education}

\section{Catherine Shea Sanger}

Diversity in the classroom is a valuable opportunity to enrich student learning. Significant trends impacting the Asian higher education environment are creating new prospects and imperatives to harness diversity for learning. ${ }^{l}$ Student and faculty mobility continues apace. New institutions of higher education are being forged through international

${ }^{1}$ Sun Hee Kim Gertz, Betsy Huang, and Lauren Cyr, eds., Diversity and Inclusion in Higher Education and Societal Contexts: International and Interdisciplinary Approaches (New York: Palgrave Macmillan, 2018); Paloma Castro, Jane Woodin, Ulla Lundgren, and Michael Byram, "Student Mobility and Internationalisation in Higher Education: Perspectives from Practitioners," Language and Intercultural Communication 16, no. 3 (2016): 418-436; Peter D. Hershock, "Equity and Higher Education in the Asia-Pacific," in The Palgrave Handbook of Asia Pacific Higher Education, edited by C. Collins, M. Lee, J. Hawkins, and D. Neubauer (New York: Palgrave Macmillan, 2016), 331-344.

\section{S. Sanger $(\bowtie)$}

Yale-NUS College, Singapore, Singapore

e-mail: catherine.sanger@yale-nus.edu.sg

(C) The Author(s) 2020

C. S. Sanger and N. W. Gleason (eds.),

Diversity and Inclusion in Global Higher Education, https://doi.org/10.1007/978-981-15-1628-3_1 
and intra-regional partnerships, while older institutions are experimenting with innovative pedagogies. At the same time, instructors and education scholars are moving past limiting cultural assumptions and false dichotomies of "Asian" and "Western" to understand and support students' full learning potential. As a result, faculty are teaching more diverse students in more diverse formats. For all these reasons, it is an important moment to center diversity and inclusion in Asian higher education institutions.

The literature on diversity in higher education has created a substantial foundation for many of the contributions in this volume, but it also has some important limitations. First, too often the existing literature frames student diversity as a challenge to be overcome for faculty teaching, rather than an opportunity to advance student learning. Second, much of the literature drawn from the North American educational context uses "diversity" as code for "race." This literature is therefore often less holistic in its approach to inclusive pedagogy and curricular design that it could be. It makes sense that US-focused literature is highly attentive to the intersections of race, socio-economic status, and educational background that are specific to the American context. However, the result is that lessons do not always travel well to other settings. Lastly, and most importantly for this volume, diversity and inclusion literature is often not very connected or attentive to Asia, a region where higher education institutions and opportunities are expanding and diversifying in hugely exciting and important ways.

The contributions in this volume reflect and build on these observations, synthesizing international research, best practice literature, and greater responsiveness to the local context. Together the authors explore different dimensions of diversity and inclusion across varied higher education environments.

This introductory chapter sets the scene for the larger volume, explaining how diversity enhances learning for all students when matched with proactive inclusion in the classroom and curriculum. First, it highlights regional and global trends that are increasing attention to diversity across Asian higher education contexts. The chapter then considers the distinction between diversity and inclusion, and how that distinction is salient for pedagogy and curriculum design. It concludes with an overview of the goals and contents of the book. 


\section{Diversity and Inclusion in Asian Higher Education ConTEXTS}

Diversity means variety and range, a significant degree of variation within a particular group or community across a range of characteristics. In educational settings, diversity often connotes the bringing together of individuals with differences, and sometimes unexpected similarities. Diversity involves all aspects of identity and experience, including nationality, ethnicity, language, gender, sexuality, value system, socio-economic context, family structure, age, ability, educational background, and learning styles. Diversity is also found in the personalities, backgrounds, and teaching approaches of individual faculty members. Some classrooms are more diverse than others, but all classrooms are diverse in ways that can enhance learning if properly harnessed. Students stand to learn more when they feel secure sharing their different perspectives and identities with each other. Attention to diversity is also important as we prepare future graduates for a changing world. Diversity in pedagogy, curricula, and student identities helps enable critical thinking, communication, and problemsolving competencies required to impart impactful learning for presentday students. For all these reasons, and especially when teaching in very diverse contexts, it is important to proactively anticipate and deliberately incorporate students' different backgrounds and strengths into pedagogy and course design.

This volume uses the term "Asia" in its title to highlight shared concerns and considerations that are particularly relevant in many Asian higher education contexts. That said, this book is not an encyclopedic account. Asia is a geographic domain with a multitude of cultures, subcultures, political systems, social institutions, and educational contexts. We have not attempted to "cover" all the countries in the region. Most of the chapters in the volume, to the extent that they focus on a particular geographic-political area, focus on Northeast, Southeast, and South Asia. Institutions and higher education trends in North Asia, the Caucuses, Central Asia, and the Middle East do not feature prominently in this volume.

Additionally, a novel contribution of this book is that it speaks to the challenges and opportunities facing internationally minded institutions of higher education. All of the institutions that serve as case studies in this volume have one or more of the following traits: they were forged 
through formal international partnerships, they broadly emphasize international engagement, they have highly multi-national faculties, and/or they enroll significant numbers of international students. Most chapters in this volume describe and draw lessons from institutions that are distinctive, competitive, innovative, and often new to their given context. Several chapters present case studies of institutions that have been operating for roughly a decade or less, including Yale-NUS College, Ashoka University, Asian Women's University (AUW), University of Reading Malaysia, and Singapore University of Social Sciences (SUSS). At the same time, the volume has contributors from very established, older institutions including the National University of Singapore, which is consistently ranked as one of the very best universities in the Asia Pacific region. Several chapters highlight interdisciplinary programs and liberal arts institutions (e.g. Yale-NUS, Ashoka, AUW, and Tokyo Christian University), while others draw case studies from pre-professional and discipline-specific institutions (University of Reading Malaysia, SUSS). Together, the chapters signal that diversity is as important for established as for newer institutions, and for broad and more specific curricular programs alike.

Of course it would be wonderful to have a broader representation of institutional and national contexts from across Asia in the book. However, geographic coverage is not the primary aim here. To take that approach would be to perpetuate the oversimplification that there is one Indian, one Chinese, one South Korean, or one Indonesian higher education context. Moreover, enrolment in higher education among university-age students varies considerably across Asia, so that the very topics explored here will be of more or less relevance to different enclaves within and across countries. $^{2}$ In this sense, the volume brings together case studies from widely different settings, and some themes that will emerge will be as relevant for non-Asian contexts as for many environments in Asia. Nonetheless, although "Asia" (and even eastern Asia and southern Asia) is a broad and somewhat amorphous term, we think it is still worthwhile to dedicate attention to Asian higher education. It represents proximate geographic and in some cases cultural communities and those working in higher education in the region are likely to share some common opportunities, constraints, and influences.

\footnotetext{
${ }^{2}$ Max Roser and Esteban Ortiz-Ospina, "Tertiary Education," https://ourworldindata. org/tertiary-education.
} 
Four trends of particular relevance for discussions of diversity in eastern and southern Asia are described below and include student and faculty mobility; educational experimentation, international partnerships, and branch campuses; socio-economic transformation; and more complex and nuanced understandings of diversity in popular and scholarly discourse. Together, these trends are opening up new possibilities for inclusive pedagogy and institutional leadership in the higher education sphere.

\section{Intra-Regional and International Mobility}

Within Asia, increasing levels of intra-regional mobility by students lead to diverse classrooms in terms of nationality, culture, religion, and prior learning environment. As students move across education systems and cultural contexts, new opportunities to learn from each others' differences emerge, as do unanticipated sources of conflict and alienation. ${ }^{3}$ Further, the tremendous flow of students from Asia to colleges and universities in North America, Australasia, Europe, and beyond makes it important for educators and administrators worldwide to have a more nuanced

\footnotetext{
${ }^{3}$ Thu T. Do and Duy N. Pham, "Challenges of Student Mobility in Southeast Asia," International Higher Education, no. 84 (2016): 24-26; Jenny Lee, Jae-Eun Jon, and Kiyong Byun, "Neo-Racism and Neo-Nationalism Within East Asia: The Experiences of International Students in South Korea," Journal of Studies in International Education 21, no. 2 (2017): 136-155; Peter Kell and Gillian Vogl, eds., Global Student Mobility in the Asia Pacific: Mobility, Migration, Security and Wellbeing of International Students (Cambridge: Cambridge Scholars Publishing, 2010); Die Wen and Jie Hao Hu, "International Students' Experiences in China: Does the Planned Reverse Mobility Work?," International Journal of Educational Development 61 (2018): 204-212; Shin Gi-Wook, Oh Yeon-Cheon, and Rennie J. Moon, eds., Internationalizing Higher Education in Korea: Challenges and Opportunities in Comparative Perspective (New York: Brookings Institution Press, 2016); Ken Lau and Chia-Yen Lin, "Internationalization of Higher Education and Language Policy: The Case of a Bilingual University in Taiwan," Higher Education 74, no. 3 (2017): 437-454; Chan Sheng-Ju, "Shifting Patterns of Student Mobility in Asia," Higher Education Policy 25, no. 2 (2012): 207-224; Miki Horie, "Internationalization of Japanese Universities: Learning from the CAMPUS Asia Experience," International Higher Education 78 (2014): 19-21; Kazuo Kuroda, "Regionalization of Higher Education in Asia," in The Palgrave Handbook of Asia Pacific Higher Education, 141-156; Jane Knight, "Regionalization of Higher Education in Asia: Functional, Organizational, and Political Approaches," in The Palgrave Handbook of Asia Pacific Higher Education, 113-127; Peidong Yang, "Compromise and Complicity in International Student Mobility: The Ethnographic Case of Indian Medical Students at a Chinese University," Discourse: Studies in the Cultural Politics of Education 39, no. 5 (2018): 694-708.
} 
understanding of Asian students' backgrounds and prior educational contexts. Alongside student mobility, we see a great deal of faculty mobility within Asian universities. Student and faculty mobility together creates a greater need to cultivate appreciation for diversity in the classroom. Gaps in understanding arise not only when foreign faculty are brought to new countries to teach but also when professors teaching in their homeland have increasingly diverse students in their classrooms. Faculty are not always intuitively familiar with the educational background and expectations of their students. This, in turn, can diminish teaching effectiveness and serve as a barrier to learning. ${ }^{4}$

\section{International Partnerships, Branch Campuses, and Pedagogical Innovation}

One reason we see so much international faculty mobility is the uptick in international partnerships. The establishment of campuses between Asian universities and institutions of higher education from other parts of the region and world has been a notable feature of the contemporary higher education landscape. Some examples in eastern and southern

\footnotetext{
${ }^{4}$ Louise Morley, Nafsika Alexiadou, Stela Garaz, José González-Monteagudo, and Marius Taba, "Internationalisation and Migrant Academics: The Hidden Narratives of Mobility," Higher Education 76, no. 3 (2018): 537-554; Rajika Bhandari and Alessia Lefébure, eds., Asia: The Next Higher Education Superpower? (New York: Institute of International Education, 2015); Stephanie K. Kim, "Western Faculty 'Flight Risk' at a Korean University and the Complexities of Internationalisation in Asian Higher Education," Comparative Education 52, no. 1 (2016): 78-90; Sauwakon Ratanawijitrasin, "The Evolving Landscape of South-East Asian Higher Education and the Challenges of Governance," in The European Higher Education Area, edited by Adrian Curaj, Liviu Matei, Remus Pricopie, Jamil Salmi, and Peter Scott (New York: Springer, 2015), 221-238; Philip G. Altbach and Maria Yudkevich, "Twenty-First Century Mobility: The Role of International Faculty," International Higher Education 90 (2017): 8-10; Futao Huang, Martin J. Finkelstein, and Michele Rostan, eds., The Internationalization of the Academy: Changes, Realities and Prospects (Dordrecht: Springer, 2014); Terri Kim, "Shifting Patterns of Transnational Academic Mobility: A Comparative and Historical Approach," Comparative Study 45, no. 3 (2009): 387-403; Maria Yudkevich, Philip G. Altbach, and Laura E. Rumbley, eds., International Faculty in Higher Education: Comparative Perspectives on Recruitment, Integration, and Impact (New York: Routledge, 2017); Futao Huang, "International Faculty at Japanese Universities: Their Demographic Characteristics and Work Roles," Asia Pacific Education Review 19, no. 2 (2018): 263-272; Akiyoshi Yonezawa, Hugo Horta, and Aki Osawa, "Mobility, Formation and Development of the Academic Profession in Science, Technology, Engineering and Mathematics in East and South East Asia," Comparative Education 52, no. 1 (2016), 44-61.
} 
Asia include Yale-NUS College, NYU-Shanghai, Duke-Kunshan, Monash University Malaysia, Xi'an Jiaotong-Liverpool University, University of Reading Malaysia, James Cook University in Singapore, the Savannah College of Art and Design in Hong Kong, and Fulbright University Vietnam. In the Persian Gulf region, there has also been a surge of international partnerships over the past decade with universities from Philippines, Australia, India, Canada, the US, the UK, France, Germany, and elsewhere, establishing branch campuses in Education City Qatar, Abu Dhabi, and elsewhere. ${ }^{5}$ These partnerships often bring in foreign-educated faculty and administrators to help these new institutions get established. A lack of understanding of local educational contexts and students' identities can impede the success of these new institutions.

Additionally, many of these partnership programs emphasize curricula and pedagogies that are novel in their local contexts. At the same time, established institutions at the tertiary and secondary level are experimenting with new pedagogies, integrating liberal arts curricular requirements as well as active learning and experimental pedagogies that are sometimes described as more "Western" approaches. Understanding of local educational context can help ensure that students-and their parents-recognize the intended value of these curricular and pedagogical approaches.

\section{Globalization and Economic Transformation}

Students are leaving university and entering into increasingly globalized professional and personal contexts. Learning to excel in a diverse undergraduate setting prepares students to thrive in their postgraduate plans and fosters the resilience necessary for success. At the same time, due to rapid economic development and transformation in the education sector of many Asian nations, students are now attending universities that are radically different from what their parents may have experienced. The rate of change is so high that students may also be receiving an education that is very different from what they themselves were prepared for in primary and secondary school. This can lead students to feel ill-equipped and isolated once in university and to underperform academically as a result.

${ }^{5}$ Michael Lanford and William G. Tierney, "The International Branch Campus: Cloistered Community or Agent of Social Change?," in The Palgrave Handbook of Asia Pacific Higher Education, 157-172; Bhandari and Lefébure, Asia. 
As my co-editor Nancy Gleason has argued elsewhere, the goals of contemporary higher education need to involve developing students' habits of mind, to question what is already known, and to learn how to learn across seemingly separate disciplines and contexts. ${ }^{6}$ In this age of automation, climate change, and significant demographic shifts, higher education graduates need to be adaptive to new environments and be able to utilize knowledge from one situation in another. Simple information transfer no longer constitutes adequate advanced education and has become instead a necessary first step. Students need to know how to apply - and adapt - the knowledge they possess in ever-changing situations. These forces combine to elevate the importance of intercultural learning and active inclusion efforts in many Asian higher education contexts, both to ensure students get the most gain from their education, and to help students apply that education and thrive in times of tremendous change. ${ }^{7}$

\section{Moving Toward More Complex Understandings of Diversity}

Together, these trends call to the fore more complex understandings of diversity and highlight the importance of centering diversity and inclusion efforts in Asian universities, especially those that have experienced significant shifts in student and faculty demographics, pedagogies, or curriculum.

${ }^{6}$ Nancy W. Gleason, ed., "Introduction" and "Singapore's Higher Education Systems in The Era of the Fourth Industrial Revolution: Preparing Lifelong Learners," in Higher Education in the Era of the Fourth Industrial Revolution (Singapore: Palgrave Macmillan, 2018), 1-11, 145-169.

${ }^{7}$ Mark Heyward, "From International to Intercultural: Redefining the International School for a Globalized World," Journal of Research in International Education 1, no. 1 (2002): 9-32; Gundula G. Hiller and Maja Wozniak, "Developing an Intercultural Competence Programme at an International Cross-Border University," Intercultural Education 20, no. 4 (2009): 113-124; Leda Kamenopoulou, ed., Inclusive Education and Disability in the Global South (New York: Palgrave, 2018); Miki Sugimura, "Transformation of Higher Education Systems in the Dynamics of Contemporary Globalization: The Case of Japan," in The Palgrave Handbook of Asia Pacific Higher Education, 183-193; Christopher Ziguras, "Globalization and the Transformation of Asian Higher Education," in The Palgrave Handbook of Asia Pacific Higher Education, 73-88; Deanne E. Neubauer and John Hawkins, "Prospects for Higher Education in the Midst of Globalization," in The Palgrave Handbook of Asia Pacific Higher Education, 57-72. 
One sometimes hears or reads in popular discourse that Chinese or Asian students - and these two terms are unfortunately often conflatedare only trained to engage in rote-learning, memorization, and regurgitation. Asian students are often stereotyped as having been trained since birth to be deferential to authority and parrot back to teachers, and as a result struggle when asked to engage with critical thinking or active learning. Though it is true that some education systems and institutions emphasize deference and memorization, we need to move past such oversimplified generalizations. Many of us teaching and researching education in institutions across Asia observe that contemporary students are exposed to a much more varied set of pedagogies and can absolutely thrive when asked to engage in active and complex learning. ${ }^{8}$ There is a growing body of literature demonstrating that "Asian" students cannot be lumped together as a learning type and that Asian students are not uniformly different in their learning preferences, motivations, and habits than American, European, or Australian students. More recent and more nuanced literature on the interaction between national origin, culture, and learning is helping scholars and practitioners move past cultural essentialism and narrow assumptions about "Asian learning styles" that dominated the literature in the past. ${ }^{9}$ There is no single Eastern and no single Western learner type, and supposed differences in learning styles between groups

\footnotetext{
${ }^{8}$ For more nuanced and critical studies of the ways country and culture of origin may impact learning see Megan Watkins, Christina Ho, and Rose Butler, "Asian Migration and Education Cultures in the Anglo-Sphere," Journal of Ethnic and Migration Studies 43, no. 14 (2017): 2283-2299; AKM Ahsan Ullah and Muhammad Azizuddin, "South Asian Student Migration to Nordic Countries: Changing Initial Motivations," Asian Profile 46, no. 1 (2018); Rahul Choudaha, "Three Waves of International Student Mobility (1999-2020)," Studies in Higher Education 42, no. 5 (2017): 825-832; Choy Siew Chee, Daljeet Singh, Yow Lin Liew, Mun Yee Lee, Audrey Malenee, and Norkhadirah Anuar, "Influence of Culture on Students' Awareness of How and Why They Learn," Malaysian Journal of Learning and Instruction 12 (2015): 49-67; Joseph Kee-Kuok Wong, "Are the Learning Styles of Asian International Students Culturally or Contextually Based?," International Education Journal 4, no. 4 (2004): 154-166; David Kember, "Why Do Chinese Students Out-Perform Those from the West? Do Approaches to Learning Contribute to the Explanation?," Cogent Education 3, no. 1 (2016): 1248187; David Kember, "Misconceptions About the Learning Approaches, Motivation and Study Practices of Asian Students." Higher Education 40, no. I (2000): 99-121.

${ }^{9}$ E. Sadler-Smith and F. Tsang, "A Comparative Study of Approaches to Studying in Hong Kong and the United Kingdom," British Journal of Educational Psychology 68, no. 1 (1998): 81-93; Doris Y. P. Leung, Paul Ginns, and David Kember, "Examining the Cultural Specificity of Approaches to Learning in Universities in Hong Kong and Sydney,"
} 
are still very much up for debate. ${ }^{10}$ Even in studies that argue culture or national origin play a role in shaping how students learn, individual agency and adaptability are also shown to be important inputs. ${ }^{11}$

Recent scholarship of teaching and learning in international contexts also highlights the important recognition that diversity is more than race, nationality, and religion. Even in seemingly heterogeneous learning environments where all students share a common ethnicity or citizenship, new research shows that greater awareness of students' manifold differences can enhance teaching effectiveness. ${ }^{12}$ The forms of diversity that

Journal of Cross-Cultural Psychology 39, no. 3 (2008): 251-266; Chang Zhu, Martin Valcke, and Tammy Schellens, "A Cross-Cultural Study of Chinese and Flemish University Students: Do They Differ in Learning Conceptions and Approaches to Learning?," Learning and Individual Differences 18, no. 1 (2008): 120-127; F. Sushila Niles, "Cultural Differences in Learning Motivation and Learning Strategies: A Comparison of Overseas and Australian Students at an Australian University," International Journal of Intercultural Relations 19, no. 3 (1995): 369-385; Prem Ramburuth and John McCormick, "Learning Diversity in Higher Education: A Comparative Study of Asian International and Australian Students," Higher Education 42, no. 3 (2001): 333-350; Haoda Sun and John E. Richardson, "Perceptions of Quality and Approaches to Studying in Higher Education: A Comparative Study of Chinese and British Postgraduate Students at Six British Business Schools," Higher Education 63, no. 3 (2012): 299-316; David Kember, "International Students from Asia," in The Routledge International Handbook of Higher Education, edited by Malcom Tight, Ka Ho Mok, Jeroen Huisman, and Christopher Morphew (Florence: Routledge, 2009), 47-60.

${ }^{10}$ Some studies do find salient differences in the learning approaches or preferences of students according to country of origin, but often at modest degrees. Yusuke Sakurai, Anna Parpala, Kirsi Pyhältö, and Sari Lindblom-Ylänne, "Engagement in Learning: A Comparison Between Asian and European International University Students," Compare: A Journal of Comparative and International Education 46, no. 1 (2016): 24-47; Yusuke Sakurai, Kirsi Pyhältö, and Sari Lindblom-Ylänne, “Are Chinese University Students More Likely to Exhibit a Surface Approach to Learning Than Other International Students in Finland?," Journal of Research in International Education 13, no. 2 (2014): 135-148; Teklu Abate Bekele, "Context in Comparative and International Education Studies," in Annual Review of Comparative and International Education 2017 (International Perspectives on Education and Society, Vol. 34), edited by A. Wiseman (Bingley: Emerald Publishing Limited, 2018), 275-299; Chunyan Yang and Li Bai, "The Use of Metacognitive Strategies by Chinese Phd Students of Social Sciences in Australian Universities," International Journal of Educational Research 97 (2019): 43-52.

${ }^{11}$ Sakurai, Parpala, Pyhältö, and Lindblom-Ylänne, "Engagement in Learning"; Swee Noi Smith, "Approaches to Study of Three Chinese National Groups," British Journal of Educational Psychology 71, no. 3 (2001): 429-441.

12 W. James Jacob and Weiyan Xiong, "Higher Education Capacity for What? Balancing Issues of Equity, Efficiency, Choice, and Excellence," in The Palgrave Handbook of Asia Pacific Higher Education, 345-363; M. N. N. Lee, "Regional Trends in Asian Higher 
are salient for educators to consider will vary across contexts because Asia is a very diverse place. Inclusion in a highly multi-ethnic, multi-religious environment like Singapore will probably look different than in an ethnically and religiously more homogeneous country like Cambodia. In some university contexts within India or China, heterogeneity of language and dialect will be of primary importance. In other contexts, such as many Japanese universities, linguistic diversity may not feature as prominently, but socio-economic diversity could be very important for students' learning experience. Moreover, and very importantly, not all students from the same country or educational context learn in the same ways. ${ }^{13}$ Within the same country, some students may have attended streamed schools where they only studied math and science for several years, whereas others may have attended International Baccalaureate schools and studied a range of subjects simultaneously. Some students may be accustomed to small classes and active learning methods, whereas others come from institutions that emphasized memorization and relatively passive learning. Students are also not stagnant and without agency. They bring certain cultural expectations and practices with them to university, but those change and are molded by new contexts with time. ${ }^{14}$

Together, these trends and shifting understandings of the higher education landscape have brought diversity into the foreground of teaching and learning discourse. It would be a mistake, however, to strive for student diversity, and then stop. Diversity facilitates powerful learning, but to be fully realized needs to be matched with intentional strategies of inclusion. This conviction underpins much of the edited volume.

\section{How Diversity With Inclusion Promotes Learning}

Some classrooms are visibly and audibly very diverse, with students of different nationalities, ethnic groups, ages, gender identities, and languages.

Education," in The Palgrave Handbook of Asia Pacific Higher Education, 129-139; Cora Lingling Xu, "Identity and Cross-Border Student Mobility: The Mainland China-Hong Kong Experience," European Educational Research Journal 14, no. 1 (2015): 65-73.

${ }^{13}$ Qi Wu, "Re-examining the 'Chinese Learner': A Case Study of Mainland Chinese Students' Learning Experiences at British Universities," Higher Education 70, no. 4 (2015): 753-766.

${ }^{14}$ Tang T. Heng, "Different Is Not Deficient: Contradicting Stereotypes of Chinese International Students in US Higher Education," Studies in Higher Education 43, no. 1 (2018): 22-36. 
But almost every classroom has important varieties of diversity that can amplify learning when recognized, and hinder learning when overlooked. For example, variation in prior educational experience is not easily seen, but nonetheless significant. When instructors recognize that their students come from different economic and educational contexts, they can use that diversity to expand the perspectives and learning that occurs in class. When instructors fail to recognize this form of diversity they can do unintentional harm to student learning.

Diversity among students and faculty deepens learning in a multitude of ways. Learning in diverse environments enhances students' communication, argumentation, and problem-solving skills. Diverse classrooms also contribute to students' emotional intelligence, improving empathy and perspective-taking in ways that prepare them to thrive personally and professionally. ${ }^{15}$ Learning among diverse peers and professors inculcates critical thinking abilities, prompting students to challenge their own received wisdom and culturally-bounded assumptions. Properly cultivated, diversity in the classroom expands students' interpretive capacity, showing how particular content can be approached from multiple angles. Diverse classrooms promote listening and expression, as students engage in critical analysis and teamwork across different communication styles. ${ }^{16} \mathrm{Stu}^{-}$ dent diversity also contributes to professional growth and satisfaction

${ }^{15}$ P. Christopher Earley and Soon Ang, Cultural Intelligence: Individual Interactions Across Cultures (Stanford: Stanford University Press, 2003).

${ }^{16}$ On the value of diversity for learning see Jiaxian Zhou and Kurt W. Fischer, "Culturally Appropriate Education: Insights From Educational Neuroscience," Mind, Brain, and Education 7, no. 4 (2013): 225-231; Milton J. Bennett, "Defining, Measuring, and Facilitating Intercultural Learning: A Conceptual Introduction to the Intercultural Education Double Supplement," Intercultural Education 20, no. S1-S2 (2009): 1-13; Susan Ambrose, Michael Bridges, Michele DiPietro, Marsha Lovett, and Marie Norman, How Learning Works: Seven Research-Based Principles for Smart Teaching (San Francisco: Wiley, 2010); Victor Savicki, ed., Developing Intercultural Competence and Transformation: Theory, Research and Application in International Education (Sterling: Stylus, 2008), 13-31; Margery Ginsberg and Raymond Wlodkowski, Diversity and Motivation: Culturally Responsive Teaching in College (New York: Wiley, 2009); Myron Lustig and Jolene Koester, Intercultural Competence: Interpersonal Communication Across Cultures, 8th ed. (Boston: Pearson, 2017); Scott Page, The Difference: How the Power of Diversity Creates Better Groups, Firms, Schools, and Societies (Princeton: Princeton University Press, 2007); Laura B. Perry and Leonie Southwell, "Developing Intercultural Understanding and Skills: Models and Approaches," Intercultural Education 22, no. 6 (2011): 453-466; Ruanni Tupas, "Intercultural Education in Everyday Practice," Intercultural Education 25, no. 4 (2014): 243-254. 
for faculty. Faculty enjoy opportunities to learn new things about the world, about teaching, and about their own areas of expertise by seeing it through their students' varied lenses. Teaching a diverse group of students keeps the teaching experience fresh and invigorating. Student diversity can ideally prompt faculty to develop new pedagogical approaches and think creatively about how to provide an excellent education to all students, across varied backgrounds. ${ }^{17}$

For these reasons, we should be enthusiastic about the diversity among our students and proactive in seizing opportunities to harness that diversity in pursuit of deeper learning for all.

The "for all" is important to emphasize. At the same time that diversity enhances learning, differences between the backgrounds and identities of faculty and students can pose barriers to learning. When students feel isolated and alienated in class, when they feel they do not belong, it impedes engagement and trust in the professor, which in turn diminishes learning. ${ }^{18}$ Students, especially those from minoritized groups, experience educational alienation from two common pathways: 1) when they are made to feel invisible and 2) when they are exoticized by their professors or their peers. ${ }^{19}$

${ }^{17}$ On the ways diversity enhance faculty teaching and experiences, see Bidisha Biswas and Shirin Deylami, "Finding Agency in the Margins: Lessons from Teaching as Immigrant Women of Color," PS: Political Science \& Politics 50, no. 4 (2017): 1011-1014; Stephen Brookfield, Becoming a Critically Reflective Teacher (New York: Wiley, 2017); Choy Siew Chee and Phaik Kin Cheah, "Teacher Perceptions of Critical Thinking Among Students and its Influence on Higher Education," International Journal of Teaching and Learning in Higher Education 20, no. 2 (2008): 198-206.

${ }^{18}$ On the relationship between belonging, learning, and academic success see Terrell L. Strayhorn, College Students' Sense of Belonging: A Key to Educational Success for All Students (New York: Routledge, 2012); Pyong-sik Yi, "Institutional Climate and Student Departure: A Multinomial Multilevel Modeling Approach," Review of Higher Education 31, no. 2 (2008): 161-183. See also Roderick Ferguson, The Reorder of Things: The University and Its Pedagogies of Minority Difference (Minneapolis: University of Minnesota Press, 2012); Diane Goodman, Promoting Diversity and Social Justice: Educating People from Privileged Groups (New York: Routledge, 2011); Mark Hearn, "Positionality, Intersectionality, and Power: Socially Locating the Higher Education Teacher in Multicultural Education," Multicultural Education Review 4, no. 2 (2012): 38-59.

${ }^{19}$ Isabel Moallem, "A Meta-Analysis of School Belonging and Academic Success and Persistence” (PhD diss., Loyola University Chicago, 2013), 726; Steven J. Spencer, Claude M. Steele, and Dianne M. Quinn, "Stereotype Threat and Women's Math Performance," Journal of Experimental Social Psychology 35, no. 1 (1999): 4-28; Joshua Aronson and 
Students can be made to feel invisible when teachers and peers overlook their identities, backgrounds, or learning needs. This happens, for example, when professors draw on illustrations and analogies from a very specific cultural context without self-awareness, or when textbooks always use the same gender pronouns to describe leadership positions, or when peers from more affluent families assume all students have experienced world travel. These actions, even when not intentional or malicious, can lead to feelings of exclusion that obstruct engagement and learning. The flip side of the coin is when students from minority or marginalized groups are exoticized and tokenized, perhaps being asked to represent their entire culture, region, or other identities. This can happen when professors expect minority students to educate the majority of the class about "their people." For example, when a professor turns to the one student from Vietnam and asks them to explain Southeast Asian culture, as if there was such a singular concept. Such attempts to bring student experience and diversity into the classroom are often well-intentioned, but can reinforce minoritized students' feelings of isolation.

The distinction between minority and minoritized helps to illustrate these points. ${ }^{20}$ The term "minority" in the education context is often

Michael Inzlicht, "The Ups and Downs of Attributional Ambiguity: Stereotype Vulnerability and the Academic Self-Knowledge of African-American students," Psychological Science 15, no. 12 (2004): 829-836; Joshua Aronson, Carrie B. Fried, and Catherine Good, "Reducing the Effects of Stereotype Threat on African American College Students By Shaping Theories of Intelligence," Journal of Experimental Social Psychology 38, no. 2 (2002): 113-125.

${ }^{20}$ For more on the use of minoritized as an illuminating concept in higher education studies, see: Michael Benitez, "Resituating Culture Centers Within a Social Justice Framework: Is There Room for Examining Whiteness?," in Culture Centers in Higher Education: Perspectives on Identity, Theory, and Practice, edited by Lori D. Patton (Sterling: Stylus, 2010), 119-134; Nana Osei-Kofi, Riyad A. Shahjahan, and Lori D. Patton, "Centering Social Justice in the Study of Higher Education: The Challenges and Possibilities for Institutional Change," Equity \& Excellence in Education 43, no. 3 (2010): 326-340; Sharon Lee, "Over-Represented and De-minoritized: The Racialization of Asian Americans in Higher Education," InterActions: UCLA Journal of Education and Information Studies 2, no. 2 (2006); Dafina-Lazarus Stewart, "Racially Minoritized Students at U.S. Four Year Institutions," The Journal of Negro Education 82, no. 2 (2013): 184197; Jodi L. Linley, "We Are (Not) All Bulldogs: Minoritized Peer Socialization Agents' Meaning-Making About Collegiate Contexts,"Journal of College Student Development 58, no. 5 (2017): 643-656; Koen Leurs and Sandra Ponzanesi, "Norms and Contestations: Ethnicized and Minoritized Students as Space Invaders in Dutch Higher Education," Etnofoor 25, no. 2 (2013): 73-97; Marlee M. Spafford, Vicki L. Nygaard, Fran Gregor, and Marcia A. Boyd, "Navigating the Different Spaces': Experiences of Inclusion 
used to describe groups whose members are few in number. For example, we might reference the Indonesian student minority at an Australian university or a Muslim minority at a majority-Hindu Indian college. In many cases, however, use of the term minority obscures the reality that many groups are numerically less represented at universities because they have been structurally excluded, or minoritized. In some cases these groups have faced historical and institutional barriers to higher education within their own country. A historically marginalized ethnic or religious group may make up a sizeable percentage of a country's population, but be a minority in university classrooms. Similarly, in many academic disciplines women are a numerical minority in the classroom, but certainly not in the population at large. In other cases, post-colonial and developmental asymmetries in educational opportunities across states lead students to travel abroad for university. To be a minority in an educational environment, then, sometimes reflects historical and social-structural forms of inequality at the international level.

In this sense, the term "minoritized" draws our attention to the forces of exclusion from higher education that make certain groups and individuals "minorities" in our universities and in our classrooms. This understanding, in turn, illuminates educators' responsibility for taking more proactive measures of inclusion.

Faculty have the power to serve as models for how to engage with and learn from diversity and intercultural exchange. Sometimes diversity in the classroom can give rise to misunderstandings and disagreements. Students will look to faculty for leadership - intellectual and ethical-in difficult and uncomfortable situations. Pejorative or offensive words in one country might not be taboo in another. Faculty may have to mediate conflict and intercultural friction among students. Faculty themselves may unintentionally offend their students. A faculty member's reaction or inaction in response to "hot moments" of intercultural misunderstanding

and Isolation among Racially Minoritized Faculty in Canada," The Canadian Journal of Higher Education 36, no. 1 (2006): 1-27. Minoritization and higher education have been written about extensively in the North American context but more recently also in Asian higher education contexts. Ngo Thi Hang Nga, "Access and Equity in Higher Education: A Case of Minority Students in Northwest Vietnam," Global Education Colloquium, April 3, 2019, https://drexel.edu/soe/resources/event-series/gec/April-3-2019-Event/; Vu Hoang Linh, Le Viet Thuy, and Giang Thanh Long, "Equity and Access to Tertiary Education: The Case of Vietnam" (Working Paper 10, Development and Policies Research Center [DEPOCEN], Vietnam, April 2010). 
and conflict is of paramount importance. Naming sources of inequality and correcting unintentionally ignorant or hurtful comments during class is especially important when faculty members hold privileged identities in their teaching context, either because they represent the dominant majority or a privileged minority identity. The more you know about your students and their educational context, the more likely you are to anticipate challenges that will arise and respond in productive ways that maximize student learning. ${ }^{21}$

Even faculty who are committed to creating supportive environments can inadvertently foster feelings of isolation and exclusion. For example, for most of us it is easier to learn students' names that are familiar, and we may struggle to differentiate Dave and Dan or Hee Yi and Li Yi if we are unfamiliar with those names. This understandable limitation becomes problematic when it leads faculty to disproportionately call on the students whose names they can pronounce, and avoid calling on those with names they are afraid of mispronouncing or confusing. To promote a feeling of belonging among students - to move from diversity to inclusion-faculty can take action to pronounce names correctly (e.g. using a pronunciation guide like http://hearnames.com/). These steps will give professors the confidence to call on students evenly, which invites all students equally into the learning environment.

This is but one example that illustrates how diversity on its own does not equal inclusion, and can even lead to feelings of exclusion. Having diversity in a classroom does not guarantee that students will listen to or learn from each other's different perspectives and strengths. In fact, the distinction between diversity and inclusion shows that faculty inaction can cause real harm. As Tienda explains, inclusion requires intentionality. It involves institutional and instructor-level "strategies and practices that promote meaningful social and academic interactions among students

${ }^{21}$ Sara Ahmed, On Being Included: Racism and Diversity in Institutional Life (Durham: Duke University Press, 2012); Alexander W. Astin, "Diversity and Multiculturalism on Campus: How Are Students Affected?," Change 25, no. 2 (2013): 44-49; Patricia Gurin, Eric Dey, Sylvia Hurtado, and Gerald Gurin, "Diversity and Higher Education: Theory and Impact on Educational Outcomes," Harvard Educational Review 72, no. 3 (2002): 330-367; Josipa Roska, Cindy Kilgo, Teniell Trolian, and Ernest Pascarella, "Engaging with Diversity: How Positive and Negative Experiences Shape Student's Cognitive Outcomes," The Journal of Higher Education 88, no. 3 (2017): 297-322. 
who differ in their experiences, views, and traits." 22 Inclusive pedagogy and curriculum promote access to learning and belonging for all. One could even conceive of inclusion as seeking to dismantle the privileging of certain differences or identities over others. ${ }^{23}$

In sum, for diversity to enhance learning for all, it needs to go handin-hand with deliberate and enthusiastic inclusion. ${ }^{24}$

\section{Overarching Goals and Chapter Overview}

At the same time that there is interest in diversity and inclusion, there is also faculty burnout and sometimes resistance. The demands on university faculty and administrators have shifted with time and expanded beyond being experts in a particular subject and discipline. Faculty in many institutions are increasingly expected to use novel pedagogies, create inclusive learning spaces, and facilitate positive intercultural interactions in their classes. Similarly, administrators are facing new pressures to be responsive to student voices and create inclusive curricula and campus communities. Being deliberately inclusive takes work, and not all educators have a clear sense of where to start or expand their efforts in this area. Indeed, many faculty members receive little to no pedagogical training in graduate school, let alone specific training in inclusive teaching and curricular leadership.

This book exists to showcase different ways of cultivating more inclusive classrooms and institutions across diverse contexts and identity groups. It will be valuable to many categories of faculty, administrators,

${ }^{22}$ Marta Tienda, "Diversity $\neq$ Inclusion: Promoting Integration in Higher Education," Educational Researcher 42, no. 9 (2013): 467. See also Rennie J. Moon, "Internationalisation Without Cultural Diversity? Higher Education in Korea," Comparative Education 52, no. l (2016): 91-108.

${ }^{23}$ Maurianne Adams, Lee Anne Bell, and Pat Griffin, eds., Teaching for Diversity and Social Justice, 2nd ed. (New York: Routledge, 2007); Asia McCleary-Gaddy, "Be Explicit: Defining the Difference Between the Office of Diversity \& Inclusion and the Office of Diversity \& Equity," Medical Teacher (2019): 1-2.

${ }^{24}$ Kimberly D. Tanner, "Structure Matters: Twenty-One Teaching Strategies to Promote Student Engagement and Cultivate Classroom Equity," CBE Life Sciences Education 12, no. 3 (2013): 322-331. On the importance of proactive engagement with different ideas for effective democratic deliberation, see Mary F. Scudder, "The Ideal of Uptake in Democratic Deliberation," Political Studies, no. 1962 (2019). 
education scholars, and those interested in education trends. We developed this book for educators who are new to Asia, for those who are familiar with their local context but experiencing demographic and curricular changes; and for those who are working in diverse settings outside of Asia as well. The book provides both broad frameworks and specific strategies to help faculty, administrators, students, and policy-makers make their own diverse higher education contexts more inclusive. The goal is not to paint all diversity-or all of Asian higher education-with one large brush. On the contrary, the goal here is to identify certain pedagogical, curricular, and institutional strategies that promote inclusivity across highly dissimilar contexts. ${ }^{25}$

It is for this reason that we have solicited a mix of contributions to this volume. As editors, we have tried to include diverse voices and analytic approaches, as well as give windows into different institutional and national contexts across Asia. Some chapters speak to specific populations of learners, including Confucian heritage learners, adults, women, and LGBTQ+ students. Some chapters emphasize inclusive pedagogical strategies that are relevant across Asia and the world-such as rubrics-while others are rooted in specific institutional and national contexts, including Singapore, Malaysia, Japan, and India. Many of the contributors to this volume hail from the country in which they are teaching or writing. Several authors, including the editors, do not. Some of the authors in this volume suggest that there are distinctive cultures within Asia that can influence the ways students react to different pedagogies. Other authors take less cultural approaches, focusing on economic or institutional forces that exert influence over learning and teaching in different Asian contexts. Other authors focus on the individual level, investigating the experience of individual students in specific educational contexts.

The book takes a holistic approach to the study of diversity and inclusion, looking at pedagogy, curriculum, and institutional design.

Part I emphasizes Pedagogy for Inclusion.

In Chapter 2, "Inclusive Pedagogy and Universal Design Approaches for Diverse Learning Environments" Catherine Sanger offers an overview

\footnotetext{
${ }^{25}$ Nguyen, Terlouw, and Pilot have noted the hubris and the deleterious effects of mapping pedagogical practices from one context onto another without attention to indigenous local pedagogies and effective practices. Mai Nguyen Phuong Mai, Cees Terlouw, and Albert Pilot, "Cooperative Learning in Vietnam and the West-East educational transfer," Asia Pacific Journal of Education 32, no. 2 (2012): 137-152.
} 
of two broad approaches to inclusive education before detailing a number of specific pedagogical strategies to promote learning across diverse contexts. This chapter will be especially relevant for those teaching outside their own cultural context, and/or teaching very diverse groups of students.

In Chapter 3, "Beyond Fairness and Consistency in Grading: The Role of Rubrics in Higher Education" Kiruthika Ragupathi and Adrian Lee introduce readers to an essential technique for inclusive assessment and provide very detailed information on why, when, and how to use rubrics. The chapter highlights the ways that rubrics enhance not only assessment but also improves student learning outcomes, teaching effectiveness, and course design.

Chapter 4, "Educating Adult Learners: Bridging Learners' Characteristics and the Learning Sciences" addresses a population of students that is increasingly important in the Asian higher education context. Authors Yan Yin Ho and Rebekah Lim Wei Ying describe how, as birth rates fall and the population ages, schools need to enroll adults to stay in business. Many Asian governments and education sectors are also focusing on re-skilling adults in response to rapid economic change and anticipated workforce needs for the Fourth Industrial Revolution. This chapter helps practitioners move past unfounded assumptions about what adult learners need to thrive, and offers evidence-based strategies for supporting adults in higher education.

Chapter 5, "Culture and Learning: Confucian Heritage Learners, Social-Oriented Achievement, and Innovative Pedagogies" argues that understanding students' cultural context can help faculty implement innovative pedagogies in ways that maximize student learning. Author Shelen Ho confronts the perception that certain pedagogies-specifically TeamBased Learning and Flipped Classrooms-are inappropriate in Asian contexts, demonstrating instead that sensitivity to local context can enhance the effectiveness of these techniques.

Part II, Liberal Arts Curricula in Asia Through the Diversity and Inclusion Lens, presents different case studies of how institutions have embedded diversity into curricula in different Asian liberal arts institutions.

In Chapter 6, "Diversifying the Liberal Arts Curriculum in an Asian Context," Charles Bailyn calls our attention to the absence of a serious engagement with Asian traditions and texts in the US liberal arts model. The author draws on personal experience designing a new curriculum for 
a Singapore-based liberal arts college, and how the strengths of a traditional liberal arts approach were enhanced by serious engagement with Asian content and sensitivity to local context.

In Chapter 7, "Service Learning as a Means to Understand SocioEconomic Privilege, Inequality, and Social Mobility," Mikiko Nishimura and Hitomi Yokote describe a multi-national service learning program hosted by a Japanese liberal arts university. The program was designed to promote not only greater awareness of diversity in socio-economic privilege but also to actively upend entrenched inequalities. The program brought together students from very different contexts within and beyond Asia to engage in significant intercultural and experiential learning.

In Chapter 8, "Inclusive Pedagogy and Writing Centres in Asian Higher Education," Kanika Singh shares her experience and lessons from directing the Centre for Writing and Communication at Ashoka University, India. The chapter highlights strategies for supporting learning as students are exposed to new pedagogies and asked to communicate across different dialects and languages.

Part III, Supporting Historically Marginalized Populations, includes two chapters.

Chapter 9, "Gender \& Sexual Diversity in Asian Universities" alerts readers to overt and subtler forms of discrimination and alienation experienced by LGBTQ+ students across many Asian higher education contexts. Authors Daryl WJ Yang and Khoo Hoon Eng identify a range of practices that enhance inclusion and present a typology for Asian universities in terms of their institutional approaches and levels of support toward LGBTQ students.

In Chapter 10, "Higher Education for Women in Asia," Solveig OlsonStrom and Nirmala Rao address historical and institutional forces that have led women to be under-served across many higher education contexts. Drawing on the experience of the Asian University for Women and other institutions, the authors describe empowering institutional and pedagogical strategies for counteracting historical forms of exclusion.

Lastly, in Part IV, Leadership for Inclusion, Nancy W. Gleason discusses "Strategic Leadership for Diversity and Inclusion in Higher Education," and how university and education leaders can help make diversity an institutional priority, creating broad stakeholder support for inclusive pedagogy and curricular design.

Our desire for this volume is that it will serve as a venue for exploring the diversity within Asia and across the world, not to suggest there 
is some sort of uniform Asian educational environment. We are mindful of Edward Said's much-quoted invocation that "Rather than the manufactured clash of civilizations, we need to concentrate on the slow working together of cultures that overlap, borrow from each other, and live together in far more interesting ways than any abridged or inauthentic mode of understanding can allow." 26 These processes are at work in diverse, collaborative higher education programs throughout Asia. We hope that each chapter instigates and contributes to existing conversations about how inclusive higher education can further develop across diverse contexts within Asia and beyond.

Acknowledgements It was very important to us as editors and educators that a volume on the topic of diversity and inclusion should be as widely available as possible to all readers, everywhere. We are therefore very happy to be offering this book Open Access, such that every chapter is available free of cost to all potential readers with Internet access. We are grateful to Yale-NUS College for sponsoring Open Access, and in particular the support of our Dean of Faculty Jeannette Ickovics and Vice President of Academic Affairs Joanne Roberts for facilitating this process. We want to thank Calvin Yeo Jing Xun who worked miracles under tight deadlines to format, reference-check, and copy-edit this entire volume and Lily Seah who provided administrative support for this project, without which it would not have come to fruition. For this particular chapter, my great thanks to Brandon Yoder, Laura Severin, and Shruti Tewari for edits, suggestions, and encouragement.

\section{BIBLIOGRAPHY}

Adams, Maurianne, Lee Anne Bell, and Pat Griffin, eds. Teaching for Diversity and Social Justice. 2nd ed. New York: Routledge, 2007.

Ahmed, Sara. On Being Included: Racism and Diversity in Institutional Life. Durham: Duke University Press, 2012.

Altbach, Philip G., and Maria Yudkevich. "Twenty-First Century Mobility: The Role of International Faculty." International Higher Education 90 (2017): $8-10$.

Ambrose, Susan, Michael Bridges, Michele DiPietro, Marsha Lovett, and Marie Norman. How Learning Works: Seven Research-Based Principles for Smart Teaching. San Francisco: Wiley, 2010.

${ }^{26}$ Edward W. Said, Orientalism (London: Penguin, 2003), xxii. 
Aronson, Joshua, and Michael Inzlicht. "The Ups and Downs of Attributional Ambiguity: Stereotype Vulnerability and the Academic Self-Knowledge of African-American students.” Psychological Science 15, no. 12 (2004): 829836.

Aronson, Joshua, Carrie B. Fried, and Catherine Good. "Reducing the Effects of Stereotype Threat on African American College Students by Shaping Theories of Intelligence." Journal of Experimental Social Psychology 38, no. 2 (2002): $113-125$.

Astin, Alexander W. "Diversity and Multiculturalism on Campus: How Are Students Affected?" Change 25, no. 2 (2013): 44-49.

Bekele, Teklu Abate. "Context in Comparative and International Education Studies." In Annual Review of Comparative and International Education 2017 (International Perspectives on Education and Society, Vol. 34), edited by A. Wiseman, 275-299. Bingley: Emerald Publishing Limited, 2018.

Benitez, Michael. "Resituating Culture Centers Within a Social Justice Framework: Is There Room for Examining Whiteness?" In Culture Centers in Higher Education: Perspectives on Identity, Theory, and Practice, edited by Lori D. Patton, 119-134. Sterling: Stylus, 2010.

Bennett, Milton J. "Defining, Measuring, and Facilitating Intercultural Learning: A Conceptual Introduction to the Intercultural Education Double Supplement." Intercultural Education 20, no. S1-S2 (2009): 1-13.

Bhandari, Rajika, and Alessia Lefébure, eds. Asia: The Next Higher Education Superpower? New York: Institute of International Education, 2015.

Biswas, Bidisha, and Shirin Deylami. "Finding Agency in the Margins: Lessons from Teaching as Immigrant Women of Color.” PS: Political Science \& Politics 50, no. 4 (2017): 1011-1014.

Brookfield, Stephen. Becoming a Critically Reflective Teacher. New York: Wiley, 2017.

Castro, Paloma, Jane Woodin, Ulla Lundgren, and Michael Byram. "Student Mobility and Internationalisation in Higher Education: Perspectives from Practitioners." Language and Intercultural Communication 16, no. 3 (2016): $418-436$.

Chan, Sheng-Ju. "Shifting Patterns of Student Mobility in Asia." Higher Education Policy 25, no. 2 (2012): 207-224.

Chee, Choy Siew, Daljeet Singh, Yow Lin Liew, Mun Yee Lee, Audrey Malenee, and Norkhadirah Anuar. "Influence of Culture on Students' Awareness of How and Why They Learn." Malaysian Journal of Learning and Instruction 12 (2015): 49-67.

Choudaha, Rahul. "Three Waves of International Student Mobility (19992020)." Studies in Higher Education 42, no. 5 (2017): 825-832.

Choy, Siew Chee, and Phaik Kin Cheah. "Teacher Perceptions of Critical Thinking Among Students and Its Influence on Higher Education." International 
Journal of Teaching and Learning in Higher Education 20, no. 2 (2008): 198-206.

Collins, C. M. Lee, J. Hawkins, and D. Neubauer, eds. The Palgrave Handbook of Asia Pacific Higher Education. New York: Palgrave Macmillan, 2016.

Earley, P. Christopher, and Soon Ang. Cultural Intelligence: Individual Interactions Across Cultures. Stanford: Stanford University Press, 2003.

Ferguson, Roderick. The Reorder of Things: The University and Its Pedagogies of Minority Difference. Minneapolis: University of Minnesota Press, 2012.

Gertz, Sun Hee Kim, Betsy Huang, and Lauren Cyr, eds. Diversity and Inclusion in Higher Education and Societal Contexts: International and Interdisciplinary Approaches. New York: Palgrave Macmillan, 2018.

Ginsberg, Margery, and Raymond Wlodkowski. Diversity and Motivation: Culturally Responsive Teaching in College. New York: Wiley, 2009.

Gleason, Nancy W., ed. Higher Education in the Era of the Fourth Industrial Revolution. Singapore: Palgrave Macmillan, 2018.

Goodman, Diane. Promoting Diversity and Social Justice: Educating People from Privileged Groups. New York: Routledge, 2011.

Gurin, Patricia, Eric Dey, Sylvia Hurtado, and Gerald Gurin. "Diversity and Higher Education: Theory and Impact on Educational Outcomes." Harvard Educational Review 72, no. 3 (2002): 330-367.

Hearn, Mark. "Positionality, Intersectionality, and Power: Socially Locating the Higher Education Teacher in Multicultural Education." Multicultural Education Review 4, no. 2 (2012): 38-59.

Heyward, Mark. "From International to Intercultural: Redefining the International School for a Globalized World." Journal of Research in International Education 1, no. 1 (2002): 9-32.

Hiller, Gundula G., and Maja Wozniak. "Developing an Intercultural Competence Programme at an International Cross-Border University." Intercultural Education 20, no. 4 (2009): 113-124.

Horie, Miki. "Internationalization of Japanese Universities: Learning from the CAMPUS Asia Experience.” International Higher Education 78 (2014): 1921.

Huang, Futao. "International Faculty at Japanese Universities: Their Demographic Characteristics and Work Roles." Asia Pacific Education Review 19, no. 2 (2018): 263-272.

Huang, Futao, Martin J. Finkelstein, and Michele Rostan, eds. The Internationalization of the Academy: Changes, Realities and Prospects. Dordrecht: Springer, 2014.

Kamenopoulou, Leda, ed. Inclusive Education and Disability in the Global South. New York: Palgrave, 2018. 
Kell, Peter, and Gillian Vogl, eds. Global Student Mobility in the Asia Pacific: Mobility, Migration, Security and Wellbeing of International Students. Cambridge: Cambridge Scholars Publishing, 2010.

Kember, David. "Misconceptions About the Learning Approaches, Motivation and Study Practices of Asian Students." Higher Education 40, no. 1 (2000): 99-121.

- "International Students from Asia." In The Routledge International Handbook of Higher Education, edited by Malcom Tight, Ka Ho Mok, Jeroen Huisman, and Christopher Morphew, 47-60. Florence: Routledge, 2009.

-. "Why Do Chinese Students Out-Perform Those from the West? Do Approaches to Learning Contribute to the Explanation?" Cogent Education 3, no. 1 (2016): 1248187.

Kim, Stephanie K. "Western Faculty 'Flight Risk' at a Korean University and the Complexities of Internationalisation in Asian Higher Education." Comparative Education 52, no. 1 (2016): 78-90.

Kim, Terri. "Shifting Patterns of Transnational Academic Mobility: A Comparative and Historical Approach." Comparative Study 45, no. 3 (2009): 387403.

Lau, Ken, and Chia-Yen Lin. "Internationalization of Higher Education and Language Policy: The Case of a Bilingual University in Taiwan." Higher Education 74, no. 3 (2017): 437-454.

Lee, Jenny, Jae-Eun Jon, and Kiyong Byun. "Neo-Racism and Neo-Nationalism Within East Asia: The Experiences of International Students in South Korea." Journal of Studies in International Education 21, no. 2 (2017): 136-155.

Lee, Sharon. "Over-Represented and De-minoritized: The Racialization of Asian Americans in Higher Education." InterActions: UCLA Journal of Education and Information Studies 2, no. 2 (2006).

Leung, Doris Y. P., Paul Ginns, and David Kember. "Examining the Cultural Specificity of Approaches to Learning in Universities in Hong Kong and Sydney." Journal of Cross-Cultural Psychology 39, no. 3 (2008): 251-266.

Leurs, Koen, and Sandra Ponzanesi. "Norms and Contestations: Ethnicized and Minoritized Students as Space Invaders in Dutch Higher Education." Etnofoor 25, no. 2 (2013): 73-97.

Linley, Jodi L. "We Are (Not) All Bulldogs: Minoritized Peer Socialization Agents' Meaning-Making About Collegiate Contexts." Journal of College Student Development 58, no. 5 (2017) 643-656.

Lustig, Myron, and Jolene Koester. Intercultural Competence: Interpersonal Communication Across Cultures. 8th ed. Boston: Pearson, 2017.

McCleary-Gaddy, Asia. "Be Explicit: Defining the Difference Between the Office of Diversity \& Inclusion and the Office of Diversity \& Equity." Medical Teacher (2019): 1-2. 
Moallem, Isabel. "A Meta-Analysis of School Belonging and Academic Success and Persistence." PhD diss., Loyola University Chicago, 2013.

Moon, Rennie J. "Internationalisation Without Cultural Diversity? Higher Education in Korea." Comparative Education 52, no. 1 (2016): 91-108.

Morley, Louise, Nafsika Alexiadou, Stela Garaz, José González-Monteagudo, and Marius Taba. "Internationalisation and Migrant Academics: The Hidden Narratives of Mobility." Higher Education 76, no. 3 (2018): 537-554.

Ngo, Thi Hang Nga. "Access and Equity in Higher Education: A Case of Minority Students in Northwest Vietnam." Global Education Colloquium, April 3, 2019. https://drexel.edu/soe/resources/event-series/gec/April-3-2019Event/.

Nguyen, Mai Phuong Mai, Cees Terlouw, and Albert Pilot. "Cooperative Learning in Vietnam and the West-East educational transfer." Asia Pacific Journal of Education 32, no. 2 (2012): 137-152.

Niles, F. Sushila. "Cultural Differences in Learning Motivation and Learning Strategies: A Comparison of Overseas and Australian Students at an Australian University." International Journal of Intercultural Relations 19, no. 3 (1995): 369-385.

Osei-Kofi, Nana, Riyad A. Shahjahan, and Lori D. Patton. "Centering Social Justice in the Study of Higher Education: The Challenges and Possibilities for Institutional Change." Equity \& Excellence in Education 43, no. 3 (2010): 326-340.

Page, Scott. The Difference: How the Power of Diversity Creates Better Groups, Firms, Schools, and Societies. Princeton: Princeton University Press, 2007.

Perry, Laura B., and Leonie Southwell. "Developing Intercultural Understanding and Skills: Models and Approaches." Intercultural Education 22, no. 6 (2011): 453-466.

Qi, Wu. "Re-examining the 'Chinese learner': A Case Study of Mainland Chinese Students' Learning Experiences at British Universities.” Higher Education 70, no. 4 (2015): 753-766.

Ramburuth, Prem, and John McCormick. "Learning Diversity in Higher Education: A Comparative Study of Asian International and Australian Students." Higher Education 42, no. 3 (2001): 333-350.

Ratanawijitrasin, Sauwakon. "The Evolving Landscape of South-East Asian Higher Education and the Challenges of Governance." In The European Higher Education Area, edited by Adrian Curaj, Liviu Matei, Remus Pricopie, Jamil Salmi, and Peter Scott, 221-238. New York: Springer, 2015.

Roser, Max, and Esteban Ortiz-Ospina. "Tertiary Education." https:// ourworldindata.org/tertiary-education. 
Roska, Josipa, Cindy Kilgo, Teniell Trolian, and Ernest Pascarella. "Engaging with Diversity: How Positive and Negative Experiences Shape Student's Cognitive Outcomes." The Journal of Higher Education 88, no. 3 (2017): 297322 .

Sadler-Smith, E., and F. Tsang. "A Comparative Study of Approaches to Studying in Hong Kong and the United Kingdom." British Journal of Educational Psychology 68, no. 1 (1998): 81-93.

Said, Edward W. Orientalism. London: Penguin, 2003.

Sakurai, Yusuke, Anna Parpala, Kirsi Pyhältö, and Sari Lindblom-Ylänne. "Engagement in Learning: A Comparison Between Asian and European International University Students." Compare: A Journal of Comparative and International Education 46, no. 1 (2016): 24-47.

Sakurai, Yusuke, Kirsi Pyhältö, and Sari Lindblom-Ylänne. “Are Chinese University Students More Likely to Exhibit a Surface Approach to Learning Than Other International Students in Finland?" Journal of Research in International Education 13, no. 2 (2014): 135-148.

Savicki, Victor, ed. Developing Intercultural Competence and Transformation: Theory, Research and Application in International Education. Sterling: Stylus, 2008.

Scudder, Mary F. “The Ideal of Uptake in Democratic Deliberation." Political Studies, no. 1962 (2019).

Shin, Gi-Wook, Oh Yeon-Cheon, and Rennie J. Moon, eds. Internationalizing Higher Education in Korea: Challenges and Opportunities in Comparative Perspective. New York: Brookings Institution Press, 2016.

Smith, Swee Noi. "Approaches to Study of Three Chinese National Groups." British Journal of Educational Psychology 71, no. 3 (2001): 429-441.

Spafford, Marlee M., Vicki L. Nygaard, Fran Gregor, and Marcia A. Boyd. "Navigating the Different Spaces': Experiences of Inclusion and Isolation Among Racially Minoritized Faculty in Canada." The Canadian Journal of Higher Education 36, no. 1 (2006): 1-27.

Spencer, Steven J., Claude M. Steele, and Dianne M. Quinn. "Stereotype Threat and Women's Math Performance." Journal of Experimental Social Psychology 35, no. 1 (1999): 4-28.

Stewart, Dafina-Lazarus. "Racially Minoritized Students at U.S. Four Year Institutions." The Journal of Negro Education 82, no. 2 (2013): 184-197.

Strayhorn, Terrell L. College Students' Sense of Belonging: A Key to Educational Success for All Students. New York: Routledge, 2012.

Sun, Haoda, and John E. Richardson. "Perceptions of Quality and Approaches to Studying in Higher Education: A Comparative Study of Chinese and British Postgraduate Students at Six British Business Schools." Higher Education 63, no. 3 (2012): 299-316. 
Tang, T. Heng. "Different is Not Deficient: Contradicting Stereotypes of Chinese International Students in US Higher education." Studies in Higher Education 43, no. 1 (2018): 22-36.

Tanner, Kimberly D. "Structure Matters: Twenty-One Teaching Strategies to Promote Student Engagement and Cultivate Classroom Equity." CBE Life Sciences Education 12, no. 3 (2013): 322-331.

Thu, T. Do, and Duy N. Pham. "Challenges of Student Mobility in Southeast Asia.” International Higher Education, no. 84 (2016): 24-26.

Tienda, Marta. "Diversity $\neq$ Inclusion: Promoting Integration in Higher Education." Educational Researcher 42, no. 9 (2013): 467.

Tupas, Ruanni. "Intercultural Education in Everyday Practice." Intercultural Education 25, no. 4 (2014): 243-254.

Ullah, AKM Ahsan, and Muhammad Azizuddin. "South Asian Student Migration to Nordic Countries: Changing Initial Motivations." Asian Profile 46, no. 1 (2018).

$\mathrm{Vu}$, Hoang Linh, Le Viet Thuy, and Giang Thanh Long. "Equity and Access to Tertiary Education: The Case of Vietnam.” Working Paper 10, Development and Policies Research Center (DEPOCEN), Vietnam, April 2010.

Watkins, Megan, Christina Ho, Rose Butler. "Asian Migration and Education Cultures in the Anglo-Sphere." Journal of Ethnic and Migration Studies 43, no. 14 (2017): 2283-2299.

Wen, Die, and Jie Hao Hu. "International Students' Experiences in China: Does the Planned Reverse Mobility Work?" International Journal of Educational Development 61 (2018): 204-212.

Wong, Joseph Kee-Kuok. "Are the Learning Styles of Asian International Students Culturally or Contextually Based?" International Education Journal 4, no. 4 (2004): 154-166.

$\mathrm{Xu}$, Cora Lingling. "Identity and Cross-Border Student Mobility: The Mainland China-Hong Kong Experience." European Educational Research Journal 14, no. 1 (2015): 65-73.

Yang, Chunyan, and Li Ba. "The Use of Metacognitive Strategies by Chinese Phd Students of Social Sciences in Australian Universities." International Journal of Educational Research 97 (2019): 43-52.

Yang, Peidong. "Compromise and Complicity in International Student Mobility: The Ethnographic Case of Indian Medical Students at a Chinese University." Discourse: Studies in the Cultural Politics of Education 39, no. 5 (2018): 694708.

Yi, Pyong-sik. "Institutional Climate and Student Departure: A Multinomial Multilevel Modeling Approach." Review of Higher Education 31, no. 2 (2008): 161-183.

Yonezawa, Akiyoshi, Hugo Horta, and Aki Osawa. "Mobility, Formation and Development of the Academic Profession in Science, Technology, Engineering 
and Mathematics in East and South East Asia." Comparative Education 52, no. 1 (2016): 44-61.

Yudkevich, Maria, Philip G. Altbach, and Laura E. Rumbley, eds. International Faculty in Higher Education: Comparative Perspectives on Recruitment, Integration, and Impact. New York: Routledge, 2017.

Zhou, Jiaxian, and Kurt W. Fischer. "Culturally Appropriate Education: Insights From Educational Neuroscience." Mind, Brain, and Education 7, no. 4 (2013): 225-231.

Zhu, Chang, Martin Valcke, and Tammy Schellens. "A Cross-Cultural Study of Chinese and Flemish University Students: Do They Differ in Learning Conceptions and Approaches to Learning?" Learning and Individual Differences 18 , no. 1 (2008): 120-127.

Open Access This chapter is licensed under the terms of the Creative Commons Attribution 4.0 International License (http://creativecommons.org/licenses/ by $/ 4.0 /$ ), which permits use, sharing, adaptation, distribution and reproduction in any medium or format, as long as you give appropriate credit to the original author(s) and the source, provide a link to the Creative Commons license and indicate if changes were made.

The images or other third party material in this chapter are included in the chapter's Creative Commons license, unless indicated otherwise in a credit line to the material. If material is not included in the chapter's Creative Commons license and your intended use is not permitted by statutory regulation or exceeds the permitted use, you will need to obtain permission directly from the copyright holder.

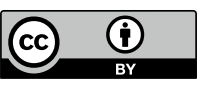


Pedagogy for Inclusion 


\section{Inclusive Pedagogy and Universal Design Approaches for Diverse Learning Environments}

\section{Catherine Shea Sanger}

Diversity presents an opportunity to foster deeper learning for our students and ourselves. The previous chapter argues that for diversity to result in substantial and equitable learning gains, it needs to go hand-inhand with intentional, widespread inclusion. At the same time, working to be inclusive of students who are diverse on multiple and intersecting dimensions can feel challenging and even overwhelming to many educators. Being deliberately inclusive in the classroom takes work, and not all faculty have a clear sense of where to start or expand their efforts in this area.

Building on these insights, this chapter introduces readers to two broad frameworks-Inclusive Pedagogy and Universal Design for Learningand eight specific strategies for promoting inclusion in diverse educational environments. The chapter is designed to be particularly useful to faculty who may be teaching outside their own cultural comfort zone, and those

C. S. Sanger $(\otimes)$

Yale-NUS College, Singapore, Singapore

e-mail: catherine.sanger@yale-nus.edu.sg

(C) The Author(s) 2020

C. S. Sanger and N. W. Gleason (eds.), 
who are teaching students who are very diverse in terms of nationality, ethnicity, communication style, and cultural context, as well as ability, socio-economic circumstance, and educational background. The strategies suggested here are drawn from evidence-based education, psychology, and neuroscience research; practice-based literature on pedagogy and teaching technique; as well as a decade of personal experience teaching, and supporting fellow teaching staff, across different learning environments.

The goal of this chapter is not to present cookie-cutter, all-purpose pedagogy. On the contrary, the goal is to share flexible instructional strategies that promote inclusivity across highly dissimilar contexts. By planning in advance for the multifaceted and vibrant diversity in your classrooms, and responding to student learning needs in an encompassing way, you can enhance inclusivity and teaching quality to the benefit of as many learners as possible.

\section{Inclusive Pedagogy and Universal Design FOR LEARNING}

Inclusive Pedagogy and the Universal Design for Learning framework offer practical tools and big-picture perspectives that help us harness student diversity for learning.

Inclusive Pedagogy is an approach that aims to make learning as accessible and welcoming to all students as possible. ${ }^{1}$ Some authors use the

\footnotetext{
${ }^{1}$ There are many practical guides on inclusive pedagogy, two of the most useful are Shari Saunders and Diana Kardia, Creating Inclusive College Classrooms (Ann Arbor: University of Michigan, 1994); "Guide to Inclusive Teaching at Columbia," Columbia University, accessed December 18, 2018, from https:// ctl.columbia.edu/resources-and-technology/inclusive-teaching-guide/. For more research and philosophical writing on the topic, see Barbara Gross Davis, Tools for Teaching, 2nd ed. (San Francisco: Wiley, 2009); Christine Hockings, "Inclusive Learning and Teaching in Higher Education: A Synthesis of Research," accessed December 18, 2018, from https://www.heacademy.ac.uk/knowledge-hub/inclusive-learningand-teaching-higher-education-synthesis-research; bell hooks, Teaching Community: A Pedagogy of Hope (New York: Routledge, 2003); Donald Mitchell, Charlana Simmons, and Lindsay Greyerhiehl, Intersectionality and Higher Education: Theory, Research, and Praxis (New York: Peter Land Publishing, 2014); Damon Williams, Strategic Diversity Leadership: Activating Change and Transformation in Higher Education (Sterling: Stylus, 2013).
} 
term 'inclusive pedagogy' primarily in the context of racial, gender, cultural, and socio-economic diversity. ${ }^{2}$ Others used it in the context of differently abled or special-needs learners. ${ }^{3}$ Across these different applications, inclusive pedagogy offers a critique of what is sometimes called a 'deficit approach'. The deficit approach assumes or demands that disadvantaged or marginalized students put in extra effort and get any additional support they need beyond the classroom. By contrast, inclusive pedagogy seeks to embed equitable access and opportunity for success within the classroom and curriculum. As articulated by Florian and BlackHawkins, inclusive pedagogy is underpinned by a shift in pedagogical thinking from an approach that works for most learners existing alongside something "additional" or "different" for those (some) who experience difficulties, towards one that involves providing rich learning opportunities that are sufficiently made available for everyone, so that all learners are able to participate in classroom life'. ${ }^{4}$

Although the term inclusive pedagogy has sometimes been applied to specific learner identities or dimensions of diversity, it is applicable across very different types of students and classrooms. From this more encompassing perspective, students with more and less normative cognitive abilities should have full access to course materials, just as students from more and less-resourced secondary schools should have equal understanding of their professors' assessment criteria. For this reason, inclusive pedagogy literature emphasizes equitable access to course materials and the importance of professors being transparent about their expectations of students.

Central to the concept of inclusive pedagogy is belonging, and research showing that feelings of belonging promote student engagement and learning. ${ }^{5}$ We promote a sense of belonging when we select topics, authors, assignments, and activities with student diversity in mind. We

\footnotetext{
${ }^{2}$ On inclusive pedagogy from a race and gender perspective see Hockings, "Inclusive Learning and Teaching."

${ }^{3}$ On inclusive pedagogy in terms of ability/disability see Leda Kamenopoulou, ed., Inclusive Education and Disability in the Global South (New York: Palgrave, 2018); L. Florian and K. Black-Hawkins, "Exploring Inclusive Pedagogy," British Educational Research Journal 37, no. 5 (2011): 813-828.

${ }^{4}$ Florian and Black-Hawkins, "Exploring Inclusive Pedagogy," 826.

${ }^{5}$ On the relationship between belonging, learning, and academic success see Terrell L. Strayhorn, College Students' Sense of Belonging: A Key to Educational Success for All Students, 2nd ed. (New York: Routledge, 2018); Laura D. Pittman and Adeya Richmond, "Academic and Psychological Functioning in Late Adolescence: The Importance
} 
teach students to engage with each other rigorously and with respect when we deliberately articulate class expectations and discussion guidelines. We also instil a sense of belonging when we humble ourselves enough as faculty to solicit student feedback and input as the class unfolds. These actions signal the professor's enthusiasm for the diversity in their class and desire to support all students' learning experience.

Universal Design for Learning (UDL) is similarly a framework that is broadly inclusive, without being hyper-individualized. The concept of UDL was elaborated and popularized by the Center for Applied Special Technology (CAST) in the 1990s and has subsequently become widely disseminated. As conceptualized by CAST, UDL encourages educators to provide: (1) multiple means of engagement-the 'Why' of learning; (2) multiple means of representation - the 'What' of learning; and (3) multiple means of action and expression-the 'How' of learning. ${ }^{6}$

The notion of UDL, as articulated by long-time proponent Sheryl Burgstahler, is 'to maximize the learning of students with a wide range of characteristics by applying UD principles to all aspects of instruction

of School Belonging," The Journal of Experimental Education 75, no. 4 (2007): 270290; Joan M. Ostrove and Susan M. Long, "Social Class and Belonging: Implications for College Adjustment," The Review of Higher Education 30, no. 4 (2007): 363-389; L. R. M. Hausmann, J. W. Schofield, and R. L. Woods, "Sense of Belonging as a Predictor of Intentions to Persist Among African American and White First-Year College Students," Research in Higher Education 48, no. 7 (2007): 803-839; P. Yi, "Institutional Climate and Student Departure: A Multinomial Multilevel Modeling Approach," Review of Higher Education 31, no. 2 (2008): 161-183; Isabel Moallem, "A Meta-Analysis of School Belonging and Academic Success and Persistence" (PhD diss., Loyola University Chicago, 2013), 726; S. J. Spencer, C. M. Steele, and D. M. Quinn, "Stereotype Threat and Women's Math Performance," Journal of Experimental Social Psychology 35 (1999): 4-28; J. Aronson and M. Inzlicht, "The Ups and Downs of Attributional Ambiguity: Stereotype Vulnerability and the Academic Self-Knowledge of African-American Students," Psychological Science 15, no. 12 (2004): 829-836; J. Aronson, C. Fried, and C. Good, "Reducing the Effects of Stereotype Threat on African American College Students by Shaping Theories of Intelligence," Journal of Experimental Social Psychology 38 (2002): $113-125$.

6 "The UDL Guidelines," CAST, udlguidelines.cast.org. See also Thomas J. Tobin and Kirsten T. Behling, Reach Everyone, Teach Everyone: Universal Design for Learning in Higher Education (West Virginia University Press, 2018); Jeanne L. Higbee and Emily Goff, eds., Pedagogy and Student Services for Institutional Transformation: Implementing Universal Design in Higher Education (Minneapolis: University of Minnesota, 2008); Sheryl E. Burgstahler, ed., Universal Design in Higher Education: From Principles to Practice, 2nd ed. (Cambridge: Harvard Education Press, 2015). 
(e.g., delivery methods, physical spaces, information resources, technology, personal interactions, assessments)'. 7 Rather than waiting to learn that a specific student needs additional or specialized support, the UDL approach encourages educators to plan their curriculum and pedagogy to anticipate broad diversity in student learning needs and proclivities. A UDL approach focuses less on the narrow accommodation of specific disabilities or identities, and more on a holistic approach to boosting everyone's learning.

UDL was initially focused on supporting students with varied learning abilities, but lends itself naturally to culturally diverse and international learning contexts. ${ }^{8}$ Most tactics that benefit one group or type of learners benefit others as well. For example, complementing verbal lectures with visual aids helps not only students who may have hearing impairment but also those who are unfamiliar with the professor's accent or vocabulary.

UDL is sometimes misunderstood as advocating hyper-individualized support. This is not the case. The idea behind UDL is not to apply resource-intensive 'spot treatments' for individual student needs. Instead, UDL integrates broader structural changes that make our classes more engaging and accessible for all, regardless of specific student needs or required accommodations.

To illustrate, a 'spot-treatment' approach for helping students with attention deficits or hearing impairments would be to provide a designated note-taker for each individual student who qualifies for assistance. UDL draws our attention to the fact that many other students would benefit from seeing their peers' notes, even if they do not have an official

${ }^{7}$ Sheryl Burgstahler, "Universal Design of Instruction (UDI): Definition, Principles, Guidelines, and Examples," https://www.washington.edu/doit/universal-designinstruction-udi-definition-principles-guidelines-and-examples.

${ }^{8}$ Sean Bracken and Katie Novak, eds., Transforming Higher Education Through Universal Design for Learning: An International Perspective (Routledge: New York, 2019); CAST, "CAST," accessed December 18, 2018, from www.cast.org; "UDL on Campus," Universal Design for Higher Learning in Education, udloncampus.cast.org; "Guide to Creating Accessible Presentations," The Digital Library Federation, accessed December 18, 2018, from www.diglib.org/forums/2016forum/guide-to-creating-accessiblepresentations/; David Rose, Wendy Harbour, Catherine Johnston, Samantha Daley, and Linda Abarbanell, "Universal Design for Postsecondary Education: Reflections on Principles and Their Application," Journal of Postsecondary Education and Disability 19, no. 2 (2004): 135-151; "UDL Center," National Center on Universal Design for Learning, accessed December 18, 2018, from www.udlcenter.org; "Web Accessibility Initiative," accessed December 18, 2018, from www.w3.org. 
'disability' or 'condition' that confers such an accommodation. For example, seeing peers' class notes would be useful for students who are new to the language of instruction, first-year students who are new to collegiate academic habits, or students who are new to the discipline being taught and therefore unfamiliar with the professor's jargon. Given this, a professor might create a low-stakes assignment where students sign-up for a week to be responsible for anonymously sharing their notes with the entire class. Such an assignment will help students who have difficulty taking their own notes, but has the added benefit of exposing all students to different note-taking methods, which could be an important academic skills-builder for the entire class.

There is compelling evidence that taking this holistic, UDL approach to student learning and integrating multiple modes of instruction enhances learning for all. Far from expecting professors to tailor lessons to each individual student and their perceived 'learning styles', new research emphasizes the importance of exposing all students to diverse formats and learning processes. Students may believe they learn best by listening or by using visual aids, but evidence suggests most students do not have a single 'learning style' and in fact learn best when exposed to a range of modalities and representations. ${ }^{9}$

An enthusiastically inclusive approach makes a difference for students in the quality of learning and their interest in learning. In the voice of one student, as reported by UDL practitioner James Lang:

What we don't want is to be made to feel like we are a burden to you because we have requested accommodations. Many of us already have this feeling that we're burdening you, and it really helps if you can treat us like you want us to be in your course. We're not asking for accommodations

${ }^{9}$ Dung C. Bui and Mark A. McDaniel, "Enhancing Learning During Lecture NoteTaking Using Outlines and Illustrative Diagrams," Journal of Applied Research in Memory and Cognition 4, no. 2 (2015): 129-135; Russell N. Carney and Joel R. Levin, "Pictorial Illustrations Still Improve Students' Learning from Text," Educational Psychology Review 14, no. 1 (2002): 5-26; Harold Pashler, Mark Mcdaniel, Doug Rohrer, and Robert Bjork, "Learning Styles: Concepts and Evidence," Psychological Science in the Public Interest 9, no. 3 (2008): 105-119; Youki Terada, "Multiple Intelligences Theory: Widely Used, Yet Misunderstood," October 15, 2018, https://www.edutopia.org/article/ multiple-intelligences-theory-widely-used-yet-misunderstood; F. Coffield, D. Moseley, E. Hall, and K. Ecclestone, Learning Styles and Pedagogy in Post-16 Learning: A Systematic and Critical Review (London: Learning and Skills Research Centre, 2004). 
to make your life difficult, or because we're trying to get away with something. We want to be in your course. We just need your help learning the best we can. ${ }^{10}$

\section{Strategies for Inclusive Teaching}

Teachers can apply the following strategies to diverse higher education settings in order to foster student belonging and learning. Consistent with UDL, the techniques offered here are not organized primarily around types of diversity or difference. Instead, most strategies promote learning and a sense of belonging across multiple dimensions of diversity.

\section{Proactively Learn About Your Environment, Especially Stu- dents' Prior Educational Contexts}

Following the UDL approach, instructors do not need to know each student's personal backstory to be an effective or inclusive teacher. However, especially when faculty are teaching outside their own cultural milieu, and do not have familiarity with their students' educational or social context, it is valuable to learn about the identities and backgrounds in your classroom. For example, when the author relocated from the United States to Singapore, it was important to learn that almost all Singaporean males do two years of National Service prior to attending university, a feature of local context that has implications for pedagogy, especially when teaching first-year students. There are a number of ways of acquiring information about your educational context, from reading up on local history to meeting with Admissions officers to inquire about student demographics and educational backgrounds.

Although UDL is geared towards creating broadly inclusive learning environments, inclusive pedagogy research tells us that students do appreciate having their individual identities and lived experiences acknowledged by professors. You can signal you care about students as individuals by surveying them prior to the start of the term to learn basic information like nationality, languages, prior education system, perceived learning preferences, preferred gender pronouns, etc. Gathering this information allows

${ }^{10}$ James M. Lang, “A Welcoming Classroom," September 27, 2017, https://www. chronicle.com/article/A-Welcoming-Classroom/241294. See also James M. Lang, Small Teaching: Everyday Lessons from the Science of Learning (New York: Jossey-Bass, 2016). 
you to acknowledge diversity in your class, and follow-up with individual students to make sure their needs are being met.

If you are working in a diverse context in terms of nationality and/or socio-economic background, there is likely to be a huge variety of students' prior educational experience in terms of curriculum, pedagogy, and norms of classroom engagement. ${ }^{11}$ Students may not understand why you are assigning a certain activity, or what you expect from essays, problem sets, or presentations. They may have never been asked to speak in class before, or to write an analytical essay. Giving students a way to communicate their prior knowledge, or lack thereof, can help you pitch your class appropriately. Inquiring about prior education also signals to students that you are aware of their diverse backgrounds and that you are looking forward to working with them to succeed in your class. ${ }^{12}$

As such, some inclusive pedagogical strategies do require knowledge about individual students. For example, the following strategies help leverage information about students' backgrounds to enhance learning:

- Meet individually with students and ask about their transition to college and prior educational experiences. Consider mandatory office hours appointments for first-year students. If you are teaching a large class, consider scheduled group office hours to get students accustomed to visiting you outside of class in small batches.

- Administer an anonymous intake survey or reflective writing activity to better understand the prior knowledge of your students. Share the information you received in anonymous form back with the students, which will help them see that while they may all have different personal histories, they probably share some common hopes and fears.

${ }^{11}$ Erin Meyer, The Culture Map: Decoding How People Think, Lead, and Get Things Done Across Cultures (New York: PublicAffairs, 2015); Nicolla Rolls, Andrew Norhedge, and Ellie Chambers, eds., Successful University Teaching in Times of Diversity (New York: Palgrave Teaching and Learning, 2018).

${ }^{12}$ Marlieke van Kesteren, Mark Rijpkema, Dirk J. Ruiter, Richard G. M. Morris, and Guillén Fernández, "Building on Prior Knowledge: Schema-Dependent Encoding Processes Relate to Academic Performance," Journal of Cognitive Neuroscience 26, no. 10 (2014): 2250-2261; Maryellen Weimer, Learner-Centered Teaching: Five Key Changes to Practice (New York: Jossey-Bass, 2013). 
- Give students an opportunity to share relevant personal information without forcing them to reveal information they prefer to keep private. For example, if you are teaching a smaller class, invite information but give students choice over what they share, e.g. 'Please share anything you would like us to know about your name, gender pronouns, educational background, learning needs, and learning goals'. (This approach depends heavily on local context. In an institution or country where being transgender is illegal or highly stigmatized, or where people with special learning needs are ostracized, you may not want to encourage students to share information that could make them vulnerable to violence or exclusion by peers or other professors.)

- When assigning group work activities, intentionally pair students with more and less prior experience so that the more experienced students can help guide their less experienced peers.

Additionally, the following techniques do not require information about specific students but can still contribute to making your classroom inclusive of students with differences in an educational context. ${ }^{13}$

${ }^{13}$ Many of these strategies are drawn from the following resources: Mary Brabeck, Jill Jeffery, and Sara Fry, "Practice for Knowledge Acquisition (Not Drill and Kill)," accessed December 18, 2018, from https://www.apa.org/education/k12/practice-acquisition. aspx; John Bransford, Ann Brown, and Rodney Cocking, "How Experts Differ from Novices," in How People Learn: Brain, Mind, Experience, and School, edited by Ann Brown, Rodney Cocking, M. Suzzanne Donovan, and James W. Pellegrino (Washington, DC: The National Academies Press, 2000), 31-50; Adam Persky and Jennifer Robinson, "Moving form Novice to Experts and its Implications for Instruction," American Journal of Pharmacentical Education 81, no. 9 (2017): 6065; "Strategies to Create an Inclusive Course," Iowa State University, accessed December 18, 2018, from http://www. celt.iastate.edu/wp-content/uploads/2015/10/StrategiestoCreateanInclusiveCourse.pdf; Jessy Ramey, "12 Evidence Based Teaching Strategies to Create a Productive and Inclusive Classroom Climate," accessed December 18, 2018, from https://my.chatham.edu/ documents/documentcenter/12\%20Evidence $\% 20$ Based $\% 20$ Teaching $\% 20$ Strategies $\% 20$ to\% 20Create\%20Productive\%20and\%20Inclusive\%20Classroom\%20Climate\%20.pdf; "Teaching Problem Solving," Vanderbilt University, accessed December 18, 2018, from https:// cft.vanderbilt.edu/guides-sub-pages/problem-solving/; "Facilitating Challenging Conversations in the Classroom," University of Washington in St. Louis, accessed December 18, 2018, from https://teachingcenter.wustl.edu/resources/inclusive-teaching-learning/ facilitating-challenging-conversations-in-the-classroom/. 
- Explicitly acknowledge the various degrees of prior exposure among students, and solicit a discussion of prior learning environments and comfort zones.

- Create reflective activities (discussions, writing activities, silent reflection) throughout the term that prompts students to think about how their prior knowledge has been amplified, disrupted, or applied in the class. These do not need to be graded or even collected by the instructor to have a learning benefit for the students.

- Consider how your speech includes or alienates. Ask yourself if you routinely use words or references that are likely to be alienating to students from different educational backgrounds than you are used to. For example, using a sophisticated vocabulary can help students expand their own linguistic repertoire, but using 'fancy', unfamiliar words can also serve to intimidate and hinder comprehension. If you tend to use more esoteric language, consider telling students at the beginning of the term that they should ask if you use words they do not know, or they should write it down and look the words up after class. You could even give students participation credit for identifying and looking-up new words used during class, which signals that you do not expect students to already know all the words you are using.

\section{Signal Your Confidence in the Potential of Each Student}

Communicating high standards, along with a clear commitment to helping students achieve those standards, signals that all students belong and have the capacity for growth in your class. You can encourage students who may be struggling in your class by sharing your own moments of academic difficulty. Additionally, following the work of Carol Dweck and colleagues Paul O'Keefe and Greg Walton, emphasize a 'growth mindset' that, with effort, people can generally become better and more invested at things that were previously very challenging or even uninteresting. ${ }^{14}$

${ }^{14}$ O'Keefe, Dweck, and Walton, "Having a Growth Mindset Makes It Easier to Develop New Interests," Harvard Business Review, September 10, 2018, https://hbr.org/2018/ 09/having-a-growth-mindset-makes-it-easier-to-develop-new-interests; O'Keefe, Dweck, and Walton, "Implicit Theories of Interest: Finding Your Passion or Developing It?," Psychological Science 29, no. 10 (2018): 1653-1664; Dweck, Mindset: The New Psychology of Success (New York: Ballantine Books, 2016); “Teaching a Growth Mindset," PERTS, 
Other scholars have similarly found that a positive sense of self, paired with supportive individuals, can help students achieve academic success. ${ }^{15}$

Here are some specific suggestions for encouraging effort and signaling confidence in your students' ability to learn.

- Share your own academic struggles and how you managed setbacks and times of uncertainty. Modelling that it is okay to be uncertain, and that learning is a process, may inspire students to be open with you about their struggles so you can help them learn.

- When you see students putting in effort, acknowledge and encourage it. This can be through verbal encouragement in the moment, or even an email after the fact (e.g. 'Hello Jin, I was really impressed with the patience and perseverance you showed today during the lab experiment. Your attitude sets an important example for the whole class. Keep up the effort and good work').

- Ask students to report not only their answers but also the process they took to arrive at those answers. Provide feedback on process as well as final product.

- Make it okay to be unsure. Signal that all students belong and can thrive in your class by suggesting resources that students with less prior knowledge of your discipline or teaching style can use to catch up over the first few weeks. Invite students to meet with you if they feel confused or are looking for additional resources.

\section{Transparency: Be Explicit About Expectations and Strategies for Success}

Many countries in Asia have experienced rapid economic and educational development over the last several decades. As a result, many university-age students today are experiencing a radically different higher

accessed December 18, 2018, from https://www.mindsetkit.org/topics/teaching-growthmindset.

${ }^{15}$ Jairo N. Fuertes, William E. Sedlacek, and William M. Liu, "Using the SAT and Noncognitive Variables to Predict the Grades and Retention of Asian American University Students," Measurement and Evaluation in Counseling and Development 27, no. 2 (1994): 74-84; Terence J. Tracey and William E. Sedlacek, "Prediction of College Graduation from Noncognitive Variables by Race," Measurement and Evaluation in Counseling and Development 19, no. 4 (1987): 177-184. 
education context and job market than what their parents encountered. In this sense, in many Asian contexts university students exhibit some of the qualities that typically get described as 'first-generation student' in a North American context. ${ }^{16}$ This is especially relevant for students enrolled in liberal arts or more novel curricular programmes that were not previously offered in the relevant country or region. In such environments, even students who come from well-educated and affluent families may be the first in their family to attend a liberal arts college where they will be expected to take courses across multiple subjects and actively participate during class discussion. ${ }^{17}$

${ }^{16}$ For more on the obstacles academic success sometimes facing first-generation students, see Terrell L. Strayhorn, "Factors Influencing the Academic Achievement of FirstGeneration College Students," NASPA Journal 43, no. 2 (2006): 82-111; Nicole M. Stephens, Stephanie A. Fryberg, Hazel Rose Markus, Camille S. Johnson, and Rebecca Covarrubias, "Unseen Disadvantage: How American Universities' Focus on Independence Undermines the Academic Performance of First-Generation College Students," Journal of Personality and Social Psychology 102, no. 6 (2012): 1178-1197; Daniel J. Almeida, Andrew M. Byrne, Rachel M. Smith, and Saul Ruiz, "How Relevant Is Grit? The Importance of Social Capital in First-Generation College Students' Academic Success," Journal of College Student Retention: Research, Theory \& Practice (2019); Thai-Huy Nguyen and Bach Mai Dolly Nguyen, "Is the 'First-Generation Student' Term Useful for Understanding Inequality? The Role of Intersectionality in Illuminating the Implications of an Accepted-Yet Unchallenged-Term," Review of Research in Education 42, no. 1 (2018): 146-176; Andrew J. McMurray and Darrin Sorrells, "Bridging the Gap: Reaching FirstGeneration Students in the Classroom," Journal of Instructional Psychology 36, no. 3 (2009): 210-214; Jeffery E. Aspelmeier, Michael M. Love, Lauren A. McGill, Ann N. Elliott, and Thomas W. Pierce, "Self-Esteem, Locus of Control, College Adjustment, and GPA Among First- and Continuing-Generation Students: A Moderator Model of Generational Status," Research in Higher Education 53, no. 7 (2012): 755-781; Ryan D. Padgett, Megan P. Johnson, and Ernest T. Pascarella, "First-Generation Undergraduate Students and the Impacts of the First Year of College: Additional Evidence," Journal of College Student Development 53, no. 2 (2012): 243-266.

${ }^{17}$ Carole J. Elliott and Michael Reynolds, "Participative Pedagogies, Group Work and the International Classroom: An Account of Students' and Tutors' Experiences," Studies in Higher Education 39, no. 2 (2014): 307-320; Yael Sharan, "Cooperative Learning: A Diversified Pedagogy for Diverse Classrooms," Intercultural Education 21, no. 3 (2010): 195-203.

Nguyen Phuong-Mai, “Culturally Appropriate Pedagogy: The Case of Group Learning in a Confucian Heritage Culture Context," Intercultural Education 17, no. 1 (2006): 119.

"Using Roles in Group Work," University of Washington in St. Louis, accessed December 18, 2018, from http://teachingcenter.wustl.edu/resources/teaching-methods/groupwork-in-class/using-roles-in-group-work/. Thank you to Malcolm Keating who has shared these methods with me and many colleagues at Yale-NUS. 
First-generation students, and those who come from very different educational environments from their new university, may be unfamiliar and even feel alienated by the subtle, 'unwritten rules' of higher education. ${ }^{18}$ Expectations around speaking up during class, publicly asking questions, attending office hours, asking friends to proofread papers, and admitting uncertainty to professors may feel particularly challenging. A combination of unfamiliarity, imposter syndrome, shame, and guilt can combine to make first-generation students less likely to take full advantage of academic and emotional support resources such as faculty office hours, tutoring programmes, advising services, and peer support. ${ }^{19}$

This sense of self-doubt and inferiority is compounded if students come from cultural contexts where it is considered weak or unbecoming to ask for help. In such contexts, students cannot get helpful advice from family and may feel they cannot reach out to peers or professors for assistance either. This can lead to feelings of isolation and discouragement.

"Examples of Discussion Guidelines," CRLT, accessed December 18, 2018, from http://www.crlt.umich.edu/examples-discussion-guidelines. Headings and guidelines in brackets are not from the University of Michigan and have been inserted by the author.

${ }^{18}$ Dan Berrett, "The Unwritten Rules of College," The Chronicle of Higher Education, September 21, 2015, https://www.chronicle.com/article/The-Unwritten-Rules-of/ 233245; Ben Galina, "Teaching First-Generation College Students," accessed December 18, 2018, https://cft.vanderbilt.edu/guides-sub-pages/teaching-first-generation-collegestudents/.

${ }^{19}$ Many of the practical pedagogical steps to support first-generation learners are drawn from and inspired by the following resources: Dan Berrett, "The Unwritten Rules of College"; Ben Dedman, "For First-Generation Students, It's All About the Support You Have," Association of American Colleges and Universities, September 2017, https://www.aacu.org/aacu-news/newsletter/2017/september/perspectives; Sarah L. Eddy, and Kelly A. Hogan, "Getting Under the Hood: How and for Whom Does Increasing Course Structure Work?," Life Sciences Education 13, no. 3 (2014): 453-468; Ben Galina, "Teaching First-Generation College Students"; Kelly Hogan and Viji Sathy. "Structuring the Classroom for Inclusive Teaching," accessed December 18, 2018, from https://cfe.unc.edu/initiatives/structuring-the-classroom-for-inclusiveteaching/; Institute for Higher Education Policy, Supporting First-Generation Students Through Classroom-Based Practices (Washington, DC: Institute for Higher Education Policy, 2012); "First Generation College Students," University of Colorado, accessed December 18, 2018, from http://www.ucdenver.edu/faculty_staff/faculty/center-for-facultydevelopment/resources/Teaching\%20resources/firstgen/Pages/default.aspx; Jessica Yorks, "When Parents Can't Help: How Can We support First-Generation College Students?," April 23, 2018, https://Gcci.uconn.edu/2018/04/23/when-parents-cant-help-how-canwe-support-first-generation-college-students/\#. 
This confluence of potentially alienating dynamics makes it important for faculty to proactively explain the rationale and strategies for success in their classes, and reiterate to students the resources that are available to help. For example, rather than just sharing your office hours' time and location, explain what office hours are designed for and how students can use this one-on-one time with you.

Success in college requires effort, but knowing where to focus that effort is not intuitive to all students. Being explicit with students about academic success strategies like closely reading the syllabus, doing outlines and drafts of essays, sample lab notes, and clarifying assignments with faculty during office hours can help.

Here are some more specific tactics for promoting transparency in your teaching.

\section{3a. Be Explicit About Your Expectations}

It may be obvious to you why you have given students a particular activity or assignment, and how it will be evaluated. But for some students, this is not at all clear. To make your classroom inclusive to all, apply the TILT (Transparency in Learning and Teaching) framework and try to be as transparent as possible with your students about what you are asking them to do, why you are asking them to do it (e.g. what will they learn from it), and how you will evaluate their work. ${ }^{20}$ You can also help students transition to college by being explicit about things like email etiquette and how you want them to present themselves in class.

\section{3b. Provide Advice, Promote Resources, and Self-Help Strategies}

Some faculty feel that giving explicit advice on how to do well gives an unfair advantage to lazy students because it provides a short-cut for students who would not take the time to figure out how to succeed on their own. From an inclusive pedagogy perspective, we worry even more about the risk that students from different cultural or educational backgrounds from their professor might learn less because they do not feel empowered to ask the professor for help, and do not understand how to

\footnotetext{
${ }^{20}$ For more information on the TILT framework and research visit https://tilthighered. com.
} 
succeed in class. Failing to coach students for success privileges students from a shared cultural and educational background or better-resourced secondary schools, not students who are inherently more hard working.

When possible provide examples of what you consider to be high quality or exemplary work and, very importantly, the process students can use for achieving those results. Professors sometimes worry that sharing examples will dampen student creativity or lead to copying. If those are concerns, make it clear to students that you will reward intellectual risk-taking and what constitutes productive versus unproductive forms of deviation from the disciplinary norm.

You can help students help themselves by actively encouraging them to take full advantage of all academic support resources including office hours, peers both in the class and out, tutoring, faculty advisors, librarians, counselling centres, etc. If you feel comfortable doing so, you may want to share an example of how you took advantage of such resources during your education or how you have seen it make a difference for other students.

3c. Consider Aspects of Your Course That Might Be Particularly NonIntuitive

Explain in detail why these expectations matter to you and why your students benefit from investing in those skills or knowledge. For example, as more and more universities are moving away from emphasizing rote learning and towards critical thinking and communication skills, inclass participation becomes a more important part of the learning experience. However, many students come from secondary school systems where students were not encouraged to speak during class. Some students come from educational contexts where the students' job is to listen and absorb knowledge, and the professors' job is to impart knowledge. In such educational environments, students ask questions, and professors give answers. If this has been your educational experience since birth it is not at all clear why, once you get to university, the professor would be asking the questions and expecting the students to answer! The value of learner-centric teaching is not intuitive for those inculcated with other educational norms. If you emphasize discussion and active student contributions, be explicit about what that looks like and how students can get better at it. 


\section{Use Varied Teaching Techniques and Formats}

Teaching students using different formats and types of learning activities will help reduce inadvertent bias and give all students opportunities to cultivate and demonstrate learning.

\section{4a. Integrate Verbal, Visual, and Textual Representations}

When designing lessons, consider what barriers might exist for different types of learners in accessing and processing information in your class. How would students with less familiarity with your language, cultural references, or pedagogy engage? How might students with vision impairment, or attention deficits encounter your class? For example:

- If your primary delivery method is visual, consider complementing that with verbal information. Provide verbal descriptions while projecting pictures, graphs, and charts and/or ask students to describe in words or in writing what they see and what it means. This will deepen all students' comprehension of the ideas you are trying to convey, and give them practice in visually processing information. And for students with vision impairment or who are unfamiliar with the representational formats of your discipline, listening to peers describe the visual materials will help them understand the content even if they cannot process it visually the same way as their peers.

- Conversely, if you often transmit information in pure lecture format, consider sharing the transcript of your lecture so that students who may have difficulty integrating verbal information can complement lectures with a written format. This would help students with low hearing or auditory processing disorders, but also those who may be unaccustomed to your accent or jargon in the course. Some faculty are concerned that sharing lecture notes will discourage lecture attendance. However, there are other methods that can be used to boost attendance like implementing low-stakes quizzes or integrating more interactive mid-lecture activities. Moreover, it may be a worthwhile trade-off to give students who really want to learn more ways of understanding the course material by sharing transcripts, even if that means some of the less-motivated students skip 
lecture. Some students may even be able to achieve adequate learning and perform well on assignments without attending lecture, in which case it may be reasonable to let them decide whether or not to attend. But if lecture adds considerable learning value independent of the transcript, then students who are motivated to succeed in the class should also remain motivated to attend. This author's approach is to prioritize making learning as accessible as possible for students who put in effort, over coercing attendance by students who do not value the lecture.

4b. Mix-Up Learning Activities and Modes of Expression

Incorporating different types of activities and teaching methods will make your classroom more inclusive of students with different prior experiences and learning strengths. ${ }^{21}$ Here are several formats that can be integrated into many types of courses.

- Lectures with visual aids like images, charts, graphs, or videos offer an effective combination of visual and auditory learning.

- Lectures with interactive tools like clickers and PollEverywhere prompt students to learn material by taking actions and making decisions, also enhancing student attention.

- Informal discussions of a prompt chosen by the professor or by the class help students think and learn by 'talking things out' and hearing differing perspectives across the class.

- Formal discussions are more structured presentations or debates that may be especially beneficial for students who prefer to develop a script and refine their ideas internally before speaking out loud.

- Small group or paired activities can feel safer or more productive spaces for intellectual exploration than whole-class discussions for some students, especially when students come from secondary

${ }^{21}$ Linda Suskie, Assessing Student Learning: A Common Sense Guide (New York: Wiley, 2018). 
education systems that emphasize collaborative work over speaking aloud during class. ${ }^{22}$

- Writing in real time on a chalk or white board by the professor or by students can enhance and clarify what is being said during a discussion. The writing could take many forms, such as lists, causal diagrams, or mind-maps.

- Writing in real time on an online discussion board projected on a screen creates opportunities for anonymous contributions, which might be useful if teaching students who are unfamiliar and lack confidence contributing verbally to in-class discussions.

- Reflective writing exercises, especially when they are not shared with peers, can serve as a private, more personal exercise to stimulate analysis and critical thinking, and allowing students to take intellectual risks without fear of 'sounding stupid'.

\section{4c. Encourage Peer-to-Peer Learning}

Creating student-to-student learning opportunities helps maximize the gains from a diverse classroom. Create class-time activities and assignments where peers can support each other and bring their different talents together for shared success. Some research has found that peer support is not only important for students' emotional and social transition to college but also a very important factor in academic success. ${ }^{23}$ Peer support is especially important for first-generation college students, who will often feel peer advice is more valuable than family advice on academic matters. ${ }^{24}$ Organize study groups or review sessions for all students, perhaps making attendance mandatory or incentivized. Explicitly creating space for

${ }^{22}$ Prem Ramburuth and John McCormick, "Learning Diversity in Higher Education: A Comparative Study of Asian International and Australian Students," Higher Education 42 , no. 3 (2001): 333-350.

${ }^{23}$ Chun-Mei Zhao and George D. Kuh, "Adding Value: Learning Communities and Student Engagement," Research in Higher Education 45, no. 2 (2004): 115-138.

${ }^{24}$ Jessica M. Dennis, Jean S. Phinney, and Lizette Ivy Chuateco, "The Role of Motivation, Parental Support, and Peer Support in the Academic Success of Ethnic Minority First-Generation College Students," Journal of College Student Development 46, no. 3 (2005): 223-236; R. Richardson and E. Skinner, "Helping First-Generation Minority Students Achieve Degrees," New Directions for Community Colleges 1992, no. 80 (1992): 29-43. 
student-to-student learning signals the importance of collaborating with peers in learning. There are many different approaches and formats that support peer-to-peer learning. ${ }^{25}$

- Think-Pair-Shares: Students are given a prompt to think and possibly write about, then paired with another student and asked to share what they came up with. This combination of individual and interactive processing activates different kinds of learning and can be a more comfortable way for students to express themselves verbally than speaking up during a whole-class discussion. These can be very short activities (1 minute to think, 2 minutes to share) or more drawn-out exercises. These work in large and small classes.

- Jigsaw Activities: For a particular session students are assigned to small groups A, B, and C, with each group given a different task or prompt for discussion. After completing the discussion/task, representatives from each group reconfigure themselves so that new groups are composed of at least one $\mathrm{A}$, one $\mathrm{B}$, and one $\mathrm{C}$ representative. They then share what they learned/produced in their initial groupings. This activity can occur during a single class meeting, or across more than one session.

- Research Exercises: Students can apply and extend course content by engaging in research activities with one or more partner, either in a single class session or over the course of several weeks.

- Field Trips/Experiential Learning Activities: The whole class or small groups can be assigned to venture into the 'field', be that a museum, estuary, or bus station. Pairing or grouping students across diverse identities and backgrounds can make these experiential learning activities more illuminating as students interpret and take actions across diverse lenses.

25 Claire Howell Major, Elizabeth F. Barkley, and K. Patricia Cross, Collaborative Learning Techniques: A Handbook for College Faculty (New York: Jossey-Bass, 2005); Wilbert McKeachie and Marilla Svinicki, McKeachie's Teaching Tips, 14th ed. (Belmont: Wadsworth Publishing, 2013); David A. Kolb, Experiential Learning: Experience as the Source of Learning and Development (New York: Pearson, 1984); Bridget Arend and James R. Davis, Facilitating Seven Ways of Learning: A Resource for More Purposeful, Effective, and Enjoyable College Teaching (New York: Stylus, 2012). 
- Problem-Based Learning: Students work in groups to solve a problem, one that often does not have only one possible answer or resolution. The groups must determine what they need to know and do in order to solve the problem, and members work together to implement a plan of action. Groups may work together over for a short or longer duration. ${ }^{26}$

- Team-Based Learning: When implementing TBL, the class is divided into intentionally diversified teams and members work together over the duration of the course, allowing the group to build capacity, trust, and collaborative skills. When creating teams, it may be advantageous to consider if certain students might feel isolated or overpowered by their peers. If there are students who are underrepresented in the class, for example if there are only two female students, you may want to put them in the same group so they can support each other. In TBL most class-time is dedicated to teamwork. Like PBL, in TBL students gain practice applying course content and skills to novel and complex problems. ${ }^{27}$

\section{Practice Inclusive Assessment Techniques}

To help students progress, you need to know how well they are understanding course material and whether they are gaining competency in relevant skills. Students from diverse educational backgrounds and cultural contexts may shine at different kinds of assessments, building confidence

${ }^{26}$ Cindy E. Hmelo-Silver, "Problem-Based Learning: What and How Do Students Learn?," Educational Psychology Review 16, no. 3 (2004): 235-266; John R. Savery, "Overview of Problem-Based Learning: Definition and Distinctions," The Interdisciplinary Journal of Problem-Based Learning 1, no. 1 (2006): 9-20; Barbara J. Duch, Susan E. Groh, and Deborah E. Allen, eds., The Power of Problem-Based Learning: A Practical "How To" for Teaching Undergraduate Courses in Any Discipline (New York: Stylus, 2001); José A. Amador, Libby Miles, and Calvin B. Peters, The Practice of Problem-Based Learning: A Guide to Implementing PBL in the College Classroom (New York: Jossey-Bass, 2006).

${ }^{27}$ Larry K. Michaelsen and Michael Sweet, "The Essential Elements of Team-Based Learning," New Directions for Teaching and Learning 2008, no. 116 (2008): 7-27; Larry K. Michaelsen, Arletta Bauman Knight, and L. Dee Fink, eds., Team-Based Learning: A Transformative Use of Small Groups in College Teaching (New York: Stylus, 2004). More information is available at the Team Based Learning Collaborative online at http://www. teambasedlearning.org/definition/. I am grateful to colleagues Dave Smith and Matt Stamps who have expanded my understanding of these teaching methods. 
that is important to learning. ${ }^{28}$ To avoid implicitly grading a student's background, rather than their learning in your class, it is essential to employ inclusive assessment designs. ${ }^{29}$

Collectively, the recommendations below support students with disabilities and health impediments, who may be unfamiliar with your discipline or pedagogy, and those from cultural and educational contexts that differ from your own.

\section{5a. Vary Assessment Formats}

Combining different modes of assessment can help you evaluate a wider range of student learning. One possibility is even to give students the option of how they want to demonstrate their learning-through oral presentations, written essays, or visual representations-or to give students the option to complement traditional essays or exams with more personalized submissions as well. Consider, for example, integrating a mix of the following formats.

- Written assignments in traditional academic formats such as descriptive or analytic essays.

- Written assignments in journalistic, fictional, creative, or other formats.

- Verbal presentations (individual or team-based).

- Visual presentations and representations (posters, videos, photographic displays-individual or team-based).

- Online discussion forums or blogs.

${ }^{28}$ Nguyen, "Culturally Appropriate Pedagogy"; Sharan, "Cooperative Learning”; David Killick, Internationalization and Diversity in Higher Education: Implications for Teaching, Learning, and Assessment (New York: Palgrave, 2017); Margery Ginsberg and Raymond Wlodkowski, Diversity and Motivation: Culturally Responsive Teaching in College (New York: Wiley, 2009); Darla K. Deardorff, "Assessing Intercultural Competence in Study Abroad Students," in Living and Studying Abroad: Research and Practice, edited by Michael Bryam and Feng Anwei (Clevedon: Multilingual Matters, 2006), 232-256.

29 "Articulate Your Learning Objectives," Eberly Center, accessed December 18, 2018, from www.cmu.edu/teaching/designteach/design/learningobjectives.htlm; Amy Lee, Robert Roch, Marta Shaw, and Rhiannon Williams, Engaging Diversity in Undergraduate Classrooms: A Pedagogy of Developing Intercultural Competence (San Francisco: Wiley, 2012); Stevens and Levi, Introduction to Rubrics; John Biggs, Teaching for Quality Learning at University, 2nd ed. (Maidenhead: Open University Press, 2003). 
5b. Don't Let the Grade Speak for Itself-Offer Direct, Constructive Feedback

Some faculty will assume that students understand why they did poorly on an assignment, or that they did poorly due to lack of effort. That is not always the case, especially if you are asking students to demonstrate and process learning in novel ways. Students who are unfamiliar with your pedagogy and discipline may not know how to improve upon the work they submitted. Feedback is an essential way to help them advance. Here are some suggestions to enhance the quality of your feedback when teaching in diverse contexts.

- Give honest, direct, and constructive feedback.

- Recommend concrete steps to improve their work.

- Provide feedback promptly so students improve across assignments, thereby building confidence and commitment to continued effort.

- Encourage students to come to your office hours for additional advice as needed.

- When they are available, direct students to additional resources such as tutoring, a writing centre, or library, rather than just saying 'this needs improvement'.

- Share an exemplar with the entire class, and have the class discuss in detail what makes that particular work so successful.

\section{5c. Recognize Possible Barriers to Intercultural Communication}

While being clear and honest in feedback, it is also important to consider your tone and how students from different cultures might receive feedback. Ways of communicating vary considerably across different national and sub-national cultures, and across different personalities. Some communicative styles are more direct, conflict-tolerant, and emotionally expressive while others are more indirect and less overtly emotional. Additionally, some cultures have clearly differentiated formal versus informal communicative modes (one for home, another for work) while 
others adopt an informal communication style in classroom or professional contexts. ${ }^{30}$ These differences in communication style can unintentionally impede faculty from giving students helpful feedback.

For example, faculty members with more conflict-tolerant communication styles than their students might be accustomed to directly disagreeing with or correcting students during a classroom exchange. But for students who are unaccustomed to direct disagreement, who come from cultures that emphasize 'saving face' during public interactions, they may interpret a professor's critique as 'my professor hates me' or 'I must be really stupid'.

Misunderstanding feedback across communication styles can also operate in reverse, for example, if students from more formal educational cultures have instructors with informal, 'friendly' styles of expression. In such a situation, a faculty member who tends to use an encouraging, supportive tone might inadvertently give their students the inaccurate impression they are doing well in the course. Students will subsequently feel betrayed when they get low grades. Explaining your cultural context and feedback style early in the term, and being as clear in feedback as possible, can help students accurately interpret your feedback.

\section{5d. Consider Untimed Exams}

Another method of inclusivity in assessment is to consider untimed exams. Exams are not just opportunities to demonstrate knowledge. The act of taking a test also contributes to learning. For this reason, we want testtaking to be as inclusive as possible, because we want learning to be as inclusive as possible. Two of the most common learning accommodations students receive are extra time on exams and the ability to take exams in private rooms. These accommodations are recommended for students with a range of testing constraints, including dyslexia, attention deficits, and anxiety. Moreover, the individuals who are formally granted learning accommodations are hardly the only students in your class who would be able to learn more and perform better if exams were untimed. Consider

${ }^{30}$ Mitchell R. Hammer, "The Intercultural Conflict Style Inventory: A Conceptual Framework and Measure of Intercultural Conflict Resolution Approaches," International Journal of Intercultural Relations 29, no. 6 (2005): 675-695; Stella Ting-Toomey and Leeva C. Chung, Understanding Intercultural Communication, 2nd ed. (Oxford: Oxford University Press, 2011). 
whether speed is an important skill you are trying to teach, and if so, whether you have taken the time to teach students how to fulfil your expectations quickly. If not, consider letting all students take their exams on their own time.

Admittedly, timed exams are convenient for faculty, as they do not need to proctor long exams or find a time all students can be in a room together for an extended period. It may be worth considering, then, whether your students can take the exam independently, at their own pace and in their own space. This approach has the added benefit of not using up valuable in-class time on testing.

\section{5e. Provide Opportunities for Do-Overs}

Students who come to study from different countries or under-resourced secondary schools may have less practice doing the kinds of assignments that are common at their new university. Consider giving all students the opportunity to submit drafts for peer review, or to redo their first assignment if it is disappointing. This is a way to incentivize students to take your feedback seriously, and signals your commitment to support your most hard-working students. For example, you might give students the opportunity to rewrite a mid-term essay or rerun an experiment for one-third of the original grade. If you primarily assess student learning through exams, consider having a second exam for those who want to try again, and tell students you will give them the average of the two exam scores. Another option is to let students write a reflective memo after receiving their assignment feedback, discussing what they achieved in the assignment, and where they went astray. Admittedly, providing these 'doovers' is a time-consuming practice for faculty, as it requires writing a new exam or grading a new submission. It may not be a realistic option for faculty who have big classes and high teaching loads. But finding ways to encourage students to integrate feedback, such as a small grade boost for simply submitting a revised version of an assignment, may be worthwhile even in large classes.

\section{5f. Minimize Unconscious Bias with Rubrics and Blind Grading}

Bias can sneak its way into grading and assessment despite our best intentions. We might have affection for a student who shares our hobbies or 
seems to be working very hard in our class. We might feel a particular loyalty to a student who has served as a research assistant, or who is especially helpful during lab clean-up. It is of course wonderful when faculty can develop special mentoring relationships with individual students, but assessment should be a bias-free indicator to the student and to the professor of whether learning is being accomplished.

One way to reduce the risk of bias in your grading practices is to use rubrics with transparent and stable evaluative criteria. The act of creating a rubric helps faculty be clear in their own minds about what they assessing. If you are teaching students with varied linguistic backgrounds, consider in particular how much you want the final grade to reflect writing clarity, organization, grammar, etc. Rubrics also promote transparency with students. If you worry that providing a rubric will result in boring, formulaic essays, reports, or presentations, you can add in 'bravery' bonus points to encourage creativity and bold arguments. (See Chapter 3 'Beyond Fairness and Consistency in Grading' for more information on designing rubrics.)

Another helpful practice is to remove students' names from their submissions to keep biases out of your grading practices. Some faculty like to know who they are grading so they can reward progress and hard work by students who may have struggled in the past. It may be safer to grade anonymously initially, and then subsequently take effort and trajectory into account as part of bonus points or participation grades.

\section{5g. Reflect on Whether You Are Grading New or Prior Knowledge}

Students from similar cultural and educational systems to their professor's may be performing better not because they have learned more in the class, but because they are conforming to norms of expression the professor finds familiar and therefore more desirable. To the extent that you want to reward learning and not prior training and privilege, you may need to be very explicit with students about your standards, and provide the resources to help students achieve those standards.

To that end, ask yourself whether you are grading what you yourself have taught, or if you are primarily grading students' prior knowledge and educational background. For example, consider how much you want to penalize a student's grade for poor essay organization if you have not provided any instruction on what constitutes a quality essay for your class. 
Similarly, if you require student presentations but do not offer guidance on what constitutes a good presentation, it may be unfair to significantly penalize a student for speaking too quickly or putting too much text on their slides. This is another reason why rubrics are helpful because they help professors determine and communicate to students what they are assessing and how much weight to give different components of an assignment.

\section{Avoid Projecting Your Professional Goals and Learning Prefer- ences on Students}

It is perfectly natural to extrapolate from our own experience when thinking about how to help students learn. Unfortunately, a professor's personal experience may not be terribly relevant or helpful for all students. Take some time to contemplate whether you have historically rewarded and favoured students who think like you, who share your learning or expression styles, and whether your pedagogy assumes students learn best the same way you do. These unconscious tendencies can disadvantage students with different learning styles, strengths, and educational backgrounds. For example, you may develop your own thoughts by 'talking things out' but other students may achieve greater insights and comprehension through free writing exercises. This is why it is so valuable to integrate many different formats of learning and assessment activities.

What worked for you during university is not necessarily helpful for your students. University professors are a rare breed, and are probably not representative in their interests or intellectual habits of most university students. Rather than projecting your own experience, inquire about how your course fits into students' larger educational path and development goals. Ask them about what has worked best for them in terms of teaching technique and learning style in the past. If you teach a large class, you can even ask these sorts of questions through an anonymous survey at the beginning of the term. These questions will help students reflect on their own learning preferences, which is productive for learning in and of itself.

Additionally, depending on the university type and context, recognize that many (probably most) students do not share your career goals. University faculty are extremely diverse in many ways, except one: almost all faculty members have attended graduate school, earned a doctorate 
or similar advanced degree, and taken up careers as university educators. Your students will pursue a much more diverse set of careers and postgraduate opportunities. Even if students currently aspire to be like you, ten years after they get their degree the economy and job market is likely to have shifted in unpredictable ways.

Consider whether your teaching is designed for students with varied life goals and career aims, or whether you are teaching primarily for future academics like yourself. For example, many faculty default to assigning research essays, but integrating other types of assignments like videos or posters can help develop students' communicative repertoires. Consider how you can design your courses in ways that will benefit students with more diverse career paths ahead.

\section{Represent Diversity in Syllabi and Course Content}

The goal of inclusive pedagogy is to centre multiple viewpoints and identities in your course. Especially if you are teaching students from different countries and cultural traditions, proactively diversifying your syllabus and course content will help students feel that they belong, which in turn will help them learn. ${ }^{31}$

\section{7a. Create Opportunities for Students to Draw on Personal Identities}

Students often appreciate having the opportunity to share their perspectives and background, but typically resent being expected to represent their entire country, continent, or race. This is especially the case for students from less-represented countries, who may be tired of answering

${ }^{31}$ On the value of, and strategies for, using diverse authors, examples, references see Davis, Tools for Teaching; Regan Gurung and Loraeto Prieto, eds., Getting Culture: Incorporating Diversity Across the Curriculum (New York: Stylus, 2009); Hockings, "Inclusive Learning and Teaching"; Lee, Roch, Shaw, and Williams, Engaging Diversity in Undergraduate Classsrooms; Sherrill Sellers, Jean Roberts, Levi Giovanetto, Katherine Friedrich, and Caroline Hammargren, Reaching All Students: A Resource for Teaching in STEM, 2nd ed. (Madison: CIRTL, 2007); Maha Bali and Steve Greenlaw, "Tips for Inclusive Teaching," Chronicle of Higher Education, September 12, 2016, https://www.chronicle.com/ blogs/profhacker/tips-for-inclusive-teaching/62747; Jason Barr, "Developing a Positive Classroom Climate" (paper, The IDEA Center, 2016); Ginsberg and Wlodkowski, Diversity and Motivation; Dorothy M. Steele and Becki Bohn-Vargas, Identity Safe Classrooms: Places to Belong and Learn (New York: Corwin Press, 2013). 
basic and even insulting questions about their country and culture. Creating space for students to share personal experience can deepen learning and student motivation to learn, e.g. 'did this passage resonate with any of you personally?' This is different from demanding a student share from personal experience or on behalf of a particular identity group, e.g. 'Sana, you are Pakistani - tell us what it is like to grow up female in a Muslim country?'

As a professor, you can set an inclusive tone by inviting everyone to share what they know about a given topic. In general, avoid 'tokenizing' students by expecting individual students to speak on behalf of an entire nation, region, race, or culture.

\section{7b. Avoid or Explain Culturally Specific References}

Having students from across the region and the world in your classes also means some references, words, and phrases that might be 'common knowledge' in your context will be foreign to others. For a British professor, illustrating a point by referencing 'the distance across The Channel', might be an obvious reference to the body of water between England and France. But students from other regions might wonder what you are talking about. Chanel, the fashion label? Or the waterway between Singapore and Malaysia? If you catch yourself using a reference or phrase that might be culturally contingent, take a minute to explain what you mean so all students get the benefit of the analogy or point you are trying to make.

\section{7c. Be Inclusive in Authors, References, and Illustrations}

You can contribute to a sense of belonging for students by assigning authors of different gender identities, case studies from a variety of regions, and scholarly perspectives that might be underrepresented in your discipline. If possible given your subjectmatter, use diverse examples and regional references in seminars and lectures. If broad representation is not an option in your discipline, acknowledge these imbalances to your students and invite critique. If an essential textbook only uses male pronouns, or if a historic document uses language which is considered derogatory and hateful in contemporary discourse, acknowledge this and give students an opportunity to discuss and process. If possible, show 
examples of scholars or other figures who can serve as role models to students from a variety of communities. Be conscious of how you use examples of historically marginalized peoples. For example, integrate examples of people in desirable roles and making leadership contributions, not only in positions of oppression and victimization that reinforce negative and demeaning stereotypes.

\section{Recognize Your Power}

You may not have pursued a career in academia in order to make students feel socially included, but that is a power you now have.

Faculty can help students feel included by accepting the leadership role they have in class. Students will look to professors for direction in difficult moments or when they feel alienated by something that happens in class. You can show you care and help maintain a productive learning environment by acknowledging difficult comments and following-up with impacted students outside of class when necessary. When a student makes an insulting or derogatory comment about traditionally marginalized communities, and a professor stays silent it can validate the ignorant comment. Silence by the professor harms the student who made the comment, as they miss the opportunity to become more reflective and inclusive communicators. Silence also harms students from marginalized identities, reinforcing feelings of vulnerability and exclusion.

In research on student perceptions of diversity and learning conducted at Yale-NUS College in Singapore, several students expressed a desire for faculty to be more assertive during class in addressing insensitive comments or stereotypes from fellow students. ${ }^{32}$ Some students from lessrepresented racial and ethnic groups shared that when faculty did not step in to correct unintentionally offensive statements, these minority students felt the weight of educating their peers about why those statements are offensive. This in turn distracts focus from the lesson at hand and makes minoritized students feel alienated in the class. Similarly, students who

\footnotetext{
32 Research conducted by Kristi Lemm and Joanna Lee for the Centre for Teaching and Learning at Yale-NUS College. Reported in "Early Experiences of Diversity in the YaleNUS Classroom," in Diversity and Inclusion in Curriculum and Classroom: A Community Resource for Yale-NUS Faculty and International Liberal Arts Educators (Singapore: YaleNUS College, 2019).
} 
represent minority gender and sexual identities can feel isolated and devalued when faculty do not step in to address a homophobic or transphobic comment, or do not use inclusive language around gender and sexuality themselves. Most students who voiced these concerns acknowledged that offensive comments were almost always unintentional. But faculty can still use their leadership role in the class to correct these unintended slights. ${ }^{33}$

While rooted in an American cultural context, the University of Michigan's Center for Research on Learning and Teaching and the Vanderbilt University Center for Teaching web sites have excellent, generalizable and practical resources to help faculty prepare to respond to difficult classroom situations or 'hot moments' inclusively and in ways that promote student learning. ${ }^{34}$

In diverse learning environments, with students and faculty of such varied backgrounds and identities, it is likely that someone will not realize that what they are saying is offensive or hurtful to those from different backgrounds. Faculty have power in the classroom and can enhance inclusion by taking responsibility for naming such comments, rather than expecting the most vulnerable and underrepresented students to educate and correct each other in these areas.

${ }^{33}$ For strategies for responding to difficult classroom situations or 'hot moments' the following research and resources are often transferable and valuable: Derald Sue, Annie Lin, Gina Torino, Christina Capodilupo, and David Rivera, "Racial Microaggressions and Difficult Dialogues on Race in the Classroom," Cultural Diversity and Ethnic Minority Psychology 15, no. 2 (2009): 183-190; Hanae Tsukada and Amy Perreault, "Complicating How Classroom Climate Works: Advancing the Framework," Transformative Dialogues: Teaching and Learning Journal 9, no. 2 (2016): 1-18; "Hot Moments," University of Michigan, accessed December 18, 2018, from www.crlt.umich.edu/category/tags/hotmoments; Penny Pasque, Mark Chesler, and Jessica Charbeneau, "Pedagogical Approaches to Student Racial Conflict in the Classroom," Journal of Diversity in Higher Education 6, no. 1 (2013): 1-16; Douglas Stone, Bruce Patton, and Sheila Heen, Difficult Conversation: How to Discuss What Matters Most (New York: Penguin, 1999).

${ }^{34}$ Visit "Responding to Difficult Moments," University of Michigan, www.crlt.umich. edu/multicultural-teaching/difficult-moments and "Difficult Dialogues," Vanderbilt University, https://cft.vanderbilt.edu/guides-sub-pages/difficult-dialogues/. On responding to difficult classroom situations see also Kay Landis, ed., Start Talking: A Handbook for Engaging in Difficult Dialogues (Anchorage: The University of Alaska Anchorage and Alaska Pacific University, 2008). 


\section{Conclusion: Reflect, LeARN, AND Listen}

This chapter has highlighted the value of proactively anticipating and incorporating students' diverse backgrounds and interests into pedagogy and course design. The techniques described here are drawn from the Inclusive Pedagogy and Universal Design for Learning approaches, which are designed to enhance belonging and learning for students in diverse higher education contexts.

Perhaps the best way to create an inclusive classroom is to be conscious and critical of your goals as an educator, and on any biases or blind spots you or your discipline may have that would pose barriers for learning in your classes. In particular, it is important to reflect on whether you have historically rewarded and favoured students who think like you, who share your learning or expression styles, and whether your pedagogy assumes students learn best the same way you do. These unconscious tendencies can disadvantage students with different learning needs and educational backgrounds. We have all been exposed to biases and stereotypes that may impact the way we see and operate in the world. The more we come to terms with those biases, the more we can work to prevent them from damaging our teaching. ${ }^{35}$

For example, reflect on whether you tend to call on particular students first, and why. The answer might be straightforward and simple: 'because those students always raise their hands first'. But consider why some students feel more comfortable or emboldened to speak than their peers. It might be because they come from cultures or education systems that emphasize speaking up during class. It might be because they hold privileged identities that empower them to speak, whereas other students have been exposed to subtle but consistent messaging that their voice is not welcome. As a teacher, you have the power to help other students find and use their voice. You can take steps to make speaking up during class more inclusive, and therefore more educationally impactful.

Ask yourself whether students of different genders and nationalities are contributing equally. If not, ask yourself if there is something you can do to invite all voices into the conversation-perhaps starting with group

${ }^{35}$ Mahzarin Banaji and Anthony Greenwald, Blindspot: Hidden Biases of Good People (New York: Delacorte Press, 2013); Claude Steele, Whistling Vivaldi: How Stereotypes Affect Us and What We Can Do (New York: W. W. Norton, 2011); James Jones, John Dovidio, and Deborah Vietze. The Psychology of Diversity: Beyond Prejudice and Racism (New York: Wiley, 2014). 
work, or assigning students specific speaking roles. One tool that might be helpful is to have your class videotaped, and then watch for gender, ethnic, or other dynamics at play in how you teach, and how students operate in the classroom. You can also ask someone to sit-in on your course with particular attention to inclusivity.

Soliciting input directly from students on whether they feel included and supported in the classroom is another powerful tool. The very act of asking is likely to make students feel valued, and motivated in your class. There are many options for this, including office hours, in-class conversations, mid-semester evaluations, and anonymous student feedback via online course management systems. For example, include a question on a mid-term feedback exercise like 'How comfortable do you feel participating in this class?' or 'How inclusive do you find our classroom dynamics to be with regard to nationality, gender, socio-economic background, and other forms of diversity?'

Knowing the popular discourses around diversity, inclusion, and education can also help you to anticipate students' desires and expectations. It is especially valuable to keep in contact with shifting generational discourses on these topics. Students are generally not experts in pedagogy, but they are experts in their own perceptions and personal experience of pedagogy. You may disagree with students about what constitutes desirable teaching or appropriate classroom behaviour, but it is still useful to understand their perspectives and perceived needs. You can monitor evolving ideas about teaching and learning by reading student newspapers, attending community dialogues and events, following the education section of your favourite journals and newspapers, participating in webinars or conferences through the education journals and associations in your area or discipline.

Cultivating an inclusive learning environment facilitates deeper student learning in many dimensions. Thoughtful reflection about where you are teaching, who you are teaching, and how you are teaching will help to harness student diversity for learning and avoid doing unintentional harm. As more research becomes available on mechanisms for inclusion across diverse higher education contexts in Asia, we will have more nuanced and contextual resources for inclusive teaching in the region.

Acknowledgements This chapter has benefited greatly from very thoughtful suggestions and encouragement from Brandon Yoder, Molly Scudder, Jacqueline Su, and Jennifer Silva. The chapter draws on faculty development resources produced at Yale-NUS College in collaboration with many colleagues, including Nancy Gleason, Joanna Lee, Lily Seah, Courtney Carter, Rachel Tan Wei Fen, 
Sahar Kazemini, Sara Amjad, and Matthew Stamps. I am indebted to many former and present mentors and colleagues at Yale-NUS College and the University of Virginia who fostered, deepened, and enabled my exploration into issues of academic inclusion and equity, including Deandra Little, Michael Palmer, Melissa Thomas-Hunt, Kyle Farley, Suyin Chew, Fiona Kanagasingam, Sara Amjad, D Dangaran, Jacqueline Su, Brian McAdoo, Joanne Roberts, and too many students to list by name. Thank you especially to Sara, D, Jackie, and Joanna for being particularly sage, humorous, and generous guides in helping me grapple with shifting expectations of higher education, the complex interplay of generation change, social justice, and academia, and to see the importance of faculty leadership regarding inclusion in the classroom and college.

\section{BIBLIOGRAPHY}

Almeida, Daniel J., Andrew M. Byrne, Rachel M. Smith, and Saul Ruiz. "How Relevant Is Grit? The Importance of Social Capital in First-Generation College Students' Academic Success." Journal of College Student Retention: Research, Theory \& Practice (2019).

Amador, José A., Libby Miles, and Calvin B. Peters. The Practice of ProblemBased Learning: A Guide to Implementing PBL in the College Classroom. New York: Jossey-Bass, 2006.

Arend, Bridget, and James R. Davis. Facilitating Seven Ways of Learning: A Resource for More Purposeful, Effective, and Enjoyable College Teaching. New York: Stylus, 2012.

Aronson, J., and M. Inzlicht. "The Ups and Downs of Attributional Ambiguity: Stereotype Vulnerability and the Academic Self-Knowledge of AfricanAmerican Students." Psychological Science 15, no. 12 (2004): 829-836.

Aronson, J., C. Fried, and C. Good. "Reducing the Effects of Stereotype Threat on African American College Students by Shaping Theories of Intelligence." Journal of Experimental Social Psychology 38 (2002): 113-125.

Aspelmeier, Jeffery E., Michael M. Love, Lauren A. McGill, Ann N. Elliott, and Thomas W. Pierce. "Self-Esteem, Locus of Control, College Adjustment, and GPA Among First- and Continuing-Generation Students: A Moderator Model of Generational Status." Research in Higher Education 53, no. 7 (2012): 755781 .

Bali, Maha, and Steve Greenlaw. "Tips for Inclusive Teaching." Chronicle of Higher Education, September 12, 2016. https://www.chronicle.com/blogs/ profhacker/tips-for-inclusive-teaching/62747.

Banaji, Mahzarin, and Anthony Greenwald. Blindspot: Hidden Biases of Good People. New York: Delacorte Press, 2013. 
Barr, Jason. "Developing a Positive Classroom Climate." Paper \#61, The IDEA Center, Miami, 2016.

Berrett, Dan. "The Unwritten Rules of College." The Chronicle of Higher Education, September 21, 2015. https://www.chronicle.com/article/TheUnwritten-Rules-of/233245.

Biggs, John. Teaching for Quality Learning at University. 2nd ed. Maidenhead: Open University Press, 2003.

Brabeck, Mary, Jill Jeffery, and Sara Fry. "Practice for Knowledge Acquisition (Not Drill and Kill).” Accessed December 18, 2018, from https://www.apa. org/education/k12/practice-acquisition.aspx.

Bracken, Sean, and Katie Novak, eds. Transforming Higher Education Through Universal Design for Learning: An International Perspective. Routledge: New York, 2019.

Bui, Dung C., and Mark A. McDaniel. "Enhancing Learning During Lecture Note-Taking Using Outlines and Illustrative Diagrams." Journal of Applied Research in Memory and Cognition 4, no. 2 (2015): 129-135.

Burgstahler, Sheryl E., ed. Universal Design in Higher Education: From Principles to Practice. 2nd ed. Cambridge: Harvard Education Press, 2015.

- "Universal Design of Instruction (UDI): Definition, Principles, Guidelines, and Examples." https://www.washington.edu/doit/universal-designinstruction-udi-definition-principles-guidelines-and-examples.

Carney, Russell N., and Joel R. Levin. "Pictorial Illustrations Still Improve Students' Learning from Text.” Educational Psychology Review 14, no. 1 (2002): $5-26$.

CAST. "CAST.” Accessed December 18, 2018, from www.cast.org.

—. "The UDL Guidelines.” udlguidelines.cast.org.

Coffield, F. D. Moseley, E. Hall, and K. Ecclestone. Learning Styles and Pedagogy in Post-16 Learning: A Systematic and Critical Review. London: Learning and Skills Research Centre, 2004.

Columbia University. "Guide to Inclusive Teaching at Columbia." Accessed December 18, 2018, from https://ctl.columbia.edu/resources-andtechnology/inclusive-teaching-guide/.

CRLT. "Examples of Discussion Guidelines." Accessed December 18, 2018, from http://www.crlt.umich.edu/examples-discussion-guidelines.

Davis, Barbara Gross. Tools for Teaching. 2nd ed. San Francisco: Wiley, 2009.

Deardorff, Darla K. "Assessing Intercultural Competence in Study Abroad Students." In Living and Studying Abroad: Research and Practice, edited by. Michael Bryam and Feng Anwei, 232-256. Clevedon: Multilingual Matters, 2006. 
Dedman, Ben. "For First-Generation Students, 'It's All About the Support You Have." Association of American Colleges and Universities, September 2017. https://www.aacu.org/aacu-news/newsletter/2017/september/ perspectives.

Dennis, Jessica M., Jean S. Phinney, and Lizette Ivy Chuateco. "The Role of Motivation, Parental Support, and Peer Support in the Academic Success of Ethnic Minority First-Generation College Students." Journal of College Student Development 46, no. 3 (2005): 223-236.

Duch, Barbara J., Susan E. Groh, and Deborah E. Allen, eds. The Power of Problem-Based Learning: A Practical "How To" for Teaching Undergraduate Courses in Any Discipline. New York: Stylus, 2001.

Dweck, Carol S. Mindset: The New Psychology of Success. New York: Ballantine Books, 2016.

Eberly Center. "Articulate Your Learning Objectives." Accessed December 18, 2018, from www.cmu.edu/teaching/designteach/design/learningobjectives. html.

Eddy, Sarah L., and Kelly A. Hogan. "Getting Under the Hood: How and for Whom Does Increasing Course Structure Work?” Life Sciences Education 13, no. 3 (2014): 453-468.

Elliott, Carole J., and Michael Reynolds. "Participative Pedagogies, Group Work and the International Classroom: An Account of Students' and Tutors' Experiences." Studies in Higher Education 39, no. 2 (2014): 307-320.

Florian, L., and K. Black-Hawkins. "Exploring Inclusive Pedagogy." British Educational Research Journal 37, no. 5 (2011): 813-828.

Fuertes, Jairo N., William E. Sedlacek, and William M. Liu. "Using the SAT and Noncognitive Variables to Predict the Grades and Retention of Asian American University Students." Measurement and Evaluation in Counseling and Development 27, no. 2 (1994): 74-84.

Galina, Ben. "Teaching First-Generation College Students." Accessed December 18, 2018, https://cft.vanderbilt.edu/guides-sub-pages/teaching-firstgeneration-college-students/.

Ginsberg, Margery, and Raymond Wlodkowski. Diversity and Motivation: Culturally Responsive Teaching in College. New York: Wiley, 2009.

Gurung, Regan, and Loraeto Prieto, eds. Getting Culture: Incorporating Diversity Across the Curriculum. New York: Stylus, 2009.

Hammer, Mitchell R. "The Intercultural Conflict Style Inventory: A Conceptual Framework and Measure of Intercultural Conflict Resolution Approaches." International Journal of Intercultural Relations 29, no. 6 (2005): 675-695.

Hausmann, L. R. M., J. W. Schofield, and R. L. Woods. "Sense of Belonging as a Predictor of Intentions to Persist Among African American and White First-Year College Students." Research in Higher Education 48, no. 7 (2007): 803-839. 
Higbee, Jeanne L., and Emily Goff, eds. Pedagogy and Student Services for Institutional Transformation: Implementing Universal Design in Higher Education. Minneapolis: University of Minnesota, 2008.

Hmelo-Silver, Cindy E. "Problem-Based Learning: What and How Do Students Learn?" Educational Psychology Review 16, no. 3 (2004): 235-266.

Hockings, Christine. "Inclusive Learning and Teaching in Higher Education: A Synthesis of Research." Accessed December 18, 2018, from https://www.heacademy.ac.uk/knowledge-hub/inclusive-learning-andteaching-higher-education-synthesis-research.

Hogan, Kelly, and Viji Sathy. "Structuring the Classroom for Inclusive Teaching." Accessed December 18, 2018, from https://cfe.unc.edu/initiatives/ structuring-the-classroom-for-inclusive-teaching/.

hooks, bell. Teaching Community: A Pedagogy of Hope. New York: Routledge, 2003.

Institute for Higher Education Policy. Supporting First-Generation Students Through Classroom-Based Practices. Washington, DC: Institute for Higher Education Policy, 2012.

Iowa State University. "Strategies to Create an Inclusive Course." Accessed December 18, 2018, from http://www.celt.iastate.edu/wp-content/ uploads/2015/10/StrategiestoCreateanInclusiveCourse.pdf.

John Bransford, Ann Brown, and Rodney Cocking, "How Experts Differ From Novices." In How People Learn: Brain, Mind, Experience, and School, edited by Ann Brown, Rodney Cocking, M. Suzzanne Donovan, and James W. Pellegrino, 31-50. Washington, DC: The National Academies Press, 2000.

Jones, James, John Dovidio, and Deborah Vietze. The Psychology of Diversity: Beyond Prejudice and Racism. New York: Wiley, 2014.

Kamenopoulou, Leda, ed. Inclusive Education and Disability in the Global South. New York: Palgrave, 2018.

Killick, David. Internationalization and Diversity in Higher Education: Implications for Teaching, Learning, and Assessment. New York: Palgrave, 2017.

Kolb, David A. Experiential Learning: Experience as the Source of Learning and Development. New York: Pearson, 1984.

Landis, Kay, ed., Start Talking: A Handbook for Engaging in Difficult Dialogues. Anchorage: The University of Alaska Anchorage and Alaska Pacific University, 2008.

Lang, James M. “A Welcoming Classroom.” September 27, 2017. https://www. chronicle.com/article/A-Welcoming-Classroom/241294.

- Small Teaching: Everyday Lessons from the Science of Learning. New York: Jossey-Bass, 2016.

Lee, Amy, Robert Roch, Marta Shaw, and Rhiannon Williams. Engaging Diversity in Undergraduate Classrooms: A Pedagogy of Developing Intercultural Competence. San Francisco: Wiley, 2012. 
Major, Claire Howell, Elizabeth F. Barkley, and K. Patricia Cross. Collaborative Learning Techniques: A Handbook for College Faculty. New York: Jossey-Bass, 2005.

McKeachie, Wilbert, and Marilla Svinicki. McKeachie's Teaching Tips. 14th ed. Belmont: Wadsworth Publishing, 2013.

McMurray, Andrew J., and Darrin Sorrells. "Bridging the Gap: Reaching FirstGeneration Students in the Classroom." Journal of Instructional Psychology 36, no. 3 (2009): 210-214.

Meyer, Erin. The Culture Map: Decoding How People Think, Lead, and Get Things Done Across Cultures. New York: PublicAffairs, 2015.

Michaelsen, Larry K., and Michael Sweet. "The Essential Elements of TeamBased Learning." New Directions for Teaching and Learning 2008, no. 116 (2008): 7-27.

Michaelsen, Larry K., Arletta Bauman Knight, L. Dee Fink, eds. Team-Based Learning: A Transformative Use of Small Groups in College Teaching. New York: Stylus, 2004.

Mitchell, Donald, Charlana Simmons, and Lindsay Greyerhiehl. Intersectionality and Higher Education: Theory, Research, and Praxis. New York: Peter Land Publishing, 2014.

Moallem, Isabel. "A Meta-Analysis of School Belonging and Academic Success and Persistence." PhD diss., Loyola University Chicago, 2013.

National Center on Universal Design for Learning. "UDL Center." Accessed December 18, 2018, from www.udlcenter.org.

Nguyen, Phuong-Mai. "Culturally Appropriate Pedagogy: The Case of Group Learning in a Confucian Heritage Culture Context." Intercultural Education 17, no. 1 (2006): 1-19.

Nguyen, Thai-Huy, and Bach Mai Dolly Nguyen. "Is the "First-Generation Student" Term Useful for Understanding Inequality? The Role of Intersectionality in Illuminating the Implications of an Accepted-Yet UnchallengedTerm." Review of Research in Education 42, no. 1 (2018): 146-176.

O'Keefe, Paul A., Carol S. Dweck, and Greg M. Walton. "Having a Growth Mindset Makes It Easier to Develop New Interests." Harvard Business Review, September 10, 2018. https://hbr.org/2018/09/having-a-growthmindset-makes-it-easier-to-develop-new-interests.

- "Implicit Theories of Interest: Finding Your Passion or Developing It?" Psychological Science 29, no. 10 (2018): 1653-1664.

Ostrove, Joan M., and Susan M. Long. "Social Class and Belonging: Implications for College Adjustment." The Review of Higher Education 30, no. 4 (2007): 363-389. 
Padgett, Ryan D., Megan P. Johnson, and Ernest T. Pascarella. "First-Generation Undergraduate Students and the Impacts of the First Year of College: Additional Evidence." Journal of College Student Development 53, no. 2 (2012): 243-266.

Pashler, Harold, Mark Mcdaniel, Doug Rohrer, and Robert Bjork. "Learning Styles: Concepts and Evidence." Psychological Science in the Public Interest 9, no. 3 (2008): 105-119.

Pasque, Penny, Mark Chesler, and Jessica Charbeneau. "Pedagogical Approaches to Student Racial Conflict in the Classroom." Journal of Diversity in Higher Education 6, no. 1 (2013): 1-16.

Persky, Adam, and Jennifer Robinson. "Moving form Novice to Experts and Its Implications for Instruction." American Journal of Pharmaceutical Education 81 , no. 9 (2017): 6065.

PERTS. “Teaching a Growth Mindset." Accessed December 18, 2018, from https://www.mindsetkit.org/topics/teaching-growth-mindset.

Pittman, Laura D., and Adeya Richmond. "Academic and Psychological Functioning in Late Adolescence: The Importance of School Belonging." The Journal of Experimental Education 75, no. 4 (2007): 270-290.

Ramburuth, Prem, and John McCormick. "Learning Diversity in Higher Education: A Comparative Study of Asian International and Australian Students." Higher Education 42, no. 3 (2001): 333-350.

Ramey, Jessy. "12 Evidence Based Teaching Strategies to Create a Productive and Inclusive Classroom Climate." Accessed December 18, 2018, from https://my.chatham.edu/documents/documentcenter/12\%20Evidence $\%$ 20Based $\% 20$ Teaching $\% 20$ Strategies $\% 20$ to $\% 20$ Create $\% 20$ Productive $\% 20$ and $\%$ 20Inclusive $\% 20$ Classroom\%20Climate\%20.pdf.

Richardson, R., and E. Skinner. "Helping First-Generation Minority Students Achieve Degrees." New Directions for Community Colleges 1992, no. 80 (1992): 29-43.

Rolls, Nicolla, Andrew Norhedge, and Ellie Chambers, eds. Successful University Teaching in Times of Diversity. New York: Palgrave Teaching and Learning, 2018.

Rose, David, Wendy Harbour, Catherine Johnston, Samantha Daley, and Linda Abarbanell. "Universal Design for Postsecondary Education: Reflections on Principles and Their Application." Journal of Postsecondary Education and Disability 19, no. 2 (2004): 135-151.

Saunders, Shari, and Diana Kardia. Creating Inclusive College Classrooms. Ann Arbor: University of Michigan, 1994.

Savery, John R. "Overview of Problem-Based Learning: Definition and Distinctions." The Interdisciplinary Journal of Problem-Based Learning 1, no. 1 (2006): 9-20. 
Sellers, Sherrill, Jean Roberts, Levi Giovanetto, Katherine Friedrich, and Caroline Hammargren. Reaching All Students: A Resource for Teaching in STEM. 2nd ed. Madison: CIRTL, 2007.

Sharan, Yael. "Cooperative Learning: A Diversified Pedagogy for Diverse Classrooms." Intercultural Education 21, no. 3 (2010): 195-203.

Spencer, S. J., C. M. Steele, and D. M. Quinn. "Stereotype Threat and Women's Math Performance." Journal of Experimental Social Psychology 35 (1999): 428.

Steele, Claude. Whistling Vivaldi: How Stereotypes Affect Us and What We Can Do. New York: W. W. Norton, 2011.

Steele, Dorothy M., and Becki Bohn-Vargas. Identity Safe Classrooms: Places to Belong and Learn. New York: Corwin Press, 2013.

Stephens, Nicole M., Stephanie A. Fryberg, Hazel Rose Markus, Camille S. Johnson, Rebecca Covarrubias. "Unseen Disadvantage: How American Universities' Focus on Independence Undermines the Academic Performance of First-Generation College Students." Journal of Personality and Social Psychology 102, no. 6 (2012): 1178-1197;

Stevens, Dannelle, and Antonia Levi. Introduction to Rubrics: An Assessment Tool to Save Grading Time, Convey Effective Feedback, and Promote Student Learning. New York: Stylus, 2013.

Stone, Douglas, Bruce Patton, and Sheila Heen. Difficult Conversation: How to Discuss What Matters Most. New York: Penguin, 1999.

Strayhorn, Terrell L. College Students' Sense of Belonging: A Key to Educational Success for All Students. 2nd ed. New York: Routledge, 2018.

- "Factors Influencing the Academic Achievement of First-Generation College Students." NASPA Journal 43, no. 2 (2006): 82-111.

Sue, Derald, Annie Lin, Gina Torino, Christina Capodilupo, and David Rivera. "Racial Microaggressions and Difficult Dialogues on Race in the Classroom." Cultural Diversity and Ethnic Minority Psychology 15, no. 2 (2009): 183-190.

Suskie, Linda. Assessing Student Learning: A Common Sense Guide. New York: Wiley, 2018.

Terada, Youki. "Multiple Intelligences Theory: Widely Used, Yet Misunderstood." October 15, 2018. https://www.edutopia.org/article/multipleintelligences-theory-widely-used-yet-misunderstood.

The Digital Library Federation. "Guide to Creating Accessible Presentations." Accessed December 18, 2018, from www.diglib.org/forums/2016forum/ guide-to-creating-accessible-presentations/.

Ting-Toomey, Stella, and Leeva C. Chung. Understanding Intercultural Communication. 2nd ed. Oxford: Oxford University Press, 2011.

Tobin, Thomas J., and Kirsten T. Behling. Reach Everyone, Teach Everyone: Universal Design for Learning in Higher Education. West Virginia University Press, 2018. 
Tracey, Terence J., and William E. Sedlacek. "Prediction of College Graduation from Noncognitive Variables by Race." Measurement and Evaluation in Counseling and Development 19, no. 4 (1987): 177-184.

Tsukada, Hanae, and Amy Perreault, "Complicating How Classroom Climate Works: Advancing the Framework." Transformative Dialogues: Teaching and Learning Journal 9, no. 2 (2016): 1-18.

Universal Design for Higher Learning in Education. "UDL on Campus." udloncampus.cast.org.

University of Colorado. "First Generation College Students." Accessed December 18, 2018, from http://www.ucdenver.edu/faculty_staff/faculty/centerfor-faculty-development/resources/Teaching\%20resources/firstgen/Pages / default.aspx.

University of Michigan. "Hot Moments." Accessed December 18, 2018, from www.crlt.umich.edu/category/tags/hot-moments.

—. "Responding to Difficult Moments." www.crlt.umich.edu/multiculturalteaching/difficult-moments.

University of Washington in St. Louis. "Facilitating Challenging Conversations in the Classroom." Accessed December 18, 2018, from https:// teachingcenter.wustl.edu/resources/inclusive-teaching-learning/facilitatingchallenging-conversations-in-the-classroom/.

-. "Using Roles in Group Work." Accessed December 18, 2018, from http://teachingcenter.wustl.edu/resources/teaching-methods/groupwork-in-class/using-roles-in-group-work/.

van Kesteren, Marlieke, Mark Rijpkema, Dirk J. Ruiter, Richard G. M. Morris, and Guillén Fernández. "Building on Prior Knowledge: Schema-Dependent Encoding Processes Relate to Academic Performance." Journal of Cognitive Neuroscience 26, no. 10 (2014): 2250-2261.

Vanderbilt University. "Difficult Dialogues.” https://cft.vanderbilt.edu/guidessub-pages/difficult-dialogues/.

—. "Teaching Problem Solving." Accessed December 18, 2018, from https://cft.vanderbilt.edu/guides-sub-pages/problem-solving/.

"Web Accessibility Initiative." Accessed December 18, 2018, from www.w3.org.

Weimer, Maryellen. Learner-Centered Teaching: Five Key Changes to Practice. New York: Jossey-Bass, 2013.

Williams, Damon. Strategic Diversity Leadership: Activating Change and Transformation in Higher Education. Sterling: Stylus, 2013.

Yale-NUS College. Diversity and Inclusion in Curriculum and Classroom: $A$ Community Resource for Yale-NUS Faculty and International Liberal Arts Educators. Singapore: Yale-NUS College, 2019.

Yi, P. "Institutional Climate and Student Departure: A Multinomial Multilevel Modeling Approach." Review of Higher Education 31, no. 2 (2008): 161183. 
Yorks, Jessica. "When Parents Can't Help: How Can We Support FirstGeneration College Students?" April 23, 2018, https://gcci.uconn.edu/ 2018/04/23/when-parents-cant-help-how-can-we-support-first-generationcollege-students/\#.

Zhao, Chun-Mei, and George D. Kuh. "Adding Value: Learning Communities and Student Engagement." Research in Higher Education 45, no. 2 (2004): $115-138$.

Open Access This chapter is licensed under the terms of the Creative Commons Attribution 4.0 International License (http://creativecommons.org/licenses/ by $/ 4.0 /)$, which permits use, sharing, adaptation, distribution and reproduction in any medium or format, as long as you give appropriate credit to the original author(s) and the source, provide a link to the Creative Commons license and indicate if changes were made.

The images or other third party material in this chapter are included in the chapter's Creative Commons license, unless indicated otherwise in a credit line to the material. If material is not included in the chapter's Creative Commons license and your intended use is not permitted by statutory regulation or exceeds the permitted use, you will need to obtain permission directly from the copyright holder.

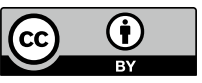




\title{
Beyond Fairness and Consistency in Grading: The Role of Rubrics in Higher Education
}

\author{
Kiruthika Ragupathi and Adrian Lee
}

\section{WHAT Is A RUBRIC?}

Student-centered learning demands progressive means of assessment that enable students to view learning as a process to develop and use strategies to meet or exceed assessment expectations. Such continuous improvement is possible only when students receive continuous, timely, objective, and constructive feedback. However, most assessment tasks provide little or no information to improve or promote student learning, but instead simply provide test scores or grades that merely quantify performance. Students need to have information about the quality of their work while they work on their assessment tasks and need to comprehend what constitutes good performance. They need to understand what excellent work is and what poor work is and be able to know what they can do to improve.

K. Ragupathi $(\bowtie) \cdot A$. Lee

Centre for Development of Teaching and Learning, National University of Singapore, Singapore, Singapore e-mail: kiruthika@nus.edu.sg
A. Lee
e-mail: cdtaml@nus.edu.sg
(C) The Author(s) 2020
C. S. Sanger and N. W. Gleason (eds.),
Diversity and Inclusion in Global Higher Education, https://doi.org/10.1007/978-981-15-1628-3_3 
An increasing emphasis on formative assessment has fueled a push toward the use of rubrics in higher education as they focus on the criteria for quality of student work. ${ }^{1}$ The use of rubrics and scoring guides give students a better understanding of what is being assessed, on what criteria grades are based, and what standards are expected.

Teachers read into the term, rubric, a "variety of meanings' 2 and a 'series of questions. ${ }^{3}$ At its best, a rubric is a carefully wrought expression of the professional judgment of a teacher. In this judgment, the rubric identifies the learning goals and aspirations for performance. A rubric is an assessment tool that explicitly lists the criteria for student work and articulates the levels of quality for each criterion. It is a visual narrative that breaks down the assignment into component parts and provides clear descriptions of the characteristics of the work associated with each component, at varying levels of mastery. In his seminal article on rubrics, Popham was the first to identify the three essential features that a rubric must have: evaluative criteria; quality definitions; and, a scoring strategy. ${ }^{4}$ Evaluative criteria identify the factors that determine the quality of a student's work. Quality definitions, in turn, provide a detailed description of the skills and knowledge for each level that a student must achieve to reach the suggestive levels of performance to distinguish acceptable from unacceptable responses. The scoring strategy is the use of a rating scale to interpret judgments, and these may be scored either holistically or analytically. Rating scales, if used on their own, have only criteria but no performance level descriptions, and are therefore different from rubrics. ${ }^{5}$ Brookhart provides a clear explanation of how rubrics, checklists, and rating scales include criteria but are different in how the scales are used. ${ }^{6}$

${ }^{1}$ Susan M. Brookhart, How to Create and Use Rubrics for Formative Assessment and Grading (Alexandria: ASCD, 2013).

${ }^{2}$ Phillip Dawson, “Assessment Rubrics: Towards Clearer and More Replicable Design, Research and Practice," Assessment \& Evaluation in Higher Education 42, no. 3 (2017): 347-360, https://doi.org/10.1080/02602938.2015.1111294.

${ }^{3}$ W. James Popham, "What's Wrong-And What's Right-With Rubrics," Educational Leadership 55, no. 2 (1997): 72-75.

${ }^{4}$ Popham, "What's Wrong-And What's Right-With Rubrics."

${ }^{5}$ Brookhart, How to Create and Use Rubrics for Formative Assessment and Grading.

${ }^{6}$ Susan M. Brookhart, "Appropriate Criteria: Key to Effective Rubrics," Frontiers in Education 3, no. 22 (2018), https://doi.org/10.3389/feduc.2018.00022. 
Checklists use a simple yes/no, rating scales use a Likert-scale decision while the rubrics actually describe the performance for each criterion.

Rubrics have different meanings and divergent practices-analytic $v s$. holistic; generic vs. task-specific; teacher-centered vs. student-centered. ${ }^{7}$ A holistic rubric requires teachers to score the overall process or product without any targeted, specific feedback to students, while an analytic rubric gets teachers to score separate, individual parts of the product or performance first, then sum the individual scores to obtain a total score. Thus, holistic rubrics are primarily used as scoring rubrics, while analytic rubrics are used as instructional rubrics. Another variation to these rubrics is the single-point rubric that only lists the criteria for proficiency but provides space for teachers to identify where students have exceeded expectations, as well as highlight specific areas of concern upon which students need to focus. ${ }^{8}$ Scoring rubrics focus on the product, while instructional rubrics focus on the process. Andrade proposes using instructional rubrics to clarify learning goals, to design the instruction that address these learning goals, to communicate and clarify teacher expectations of these learning goals, to guide the feedback on students' progress toward the learning goals, and to judge the final products in terms of the degree to which the learning goals were met. ${ }^{9}$ Teacher-centered rubrics are primarily for teachers to quickly and objectively assign accurate grades, while studentcentered rubrics specifically focus on student learning and achievement.

There are many reasons for using rubrics. To support their summative use, Broad identifies 'legitimacy, affordability, and accountability' as key reasons to use rubrics. ${ }^{10}$ Whereas to support their formative use, Reddy and Andrade identify increasing student achievement, improving

${ }^{7}$ Anders Jonsson, and Gunilla Svingby, "The Use of Scoring Rubrics: Reliability, Validity and Educational Consequences," Educational Research Review 2, no. 2 (2007): 130144; D. Royce Sadler, "Transforming Holistic Assessment and Grading into a Vehicle for Complex Learning," in Assessment, Learning and Judgement in Higher Education, edited by Gordon Joughin (Dordrecht: Springer, 2009), 1-19.

${ }^{8}$ David Balch, Robert Blanck, and David H. Balch, "Rubrics-Sharing the Rules of the Game," Journal of Instructional Research 5 (2016): 19-49; Jarene Fluckiger, "Single Point Rubric: A Tool for Responsible Student Self-Assessment," Delta Kappa Gamma Bulletin 76, no. 4 (2010): 18-25.

${ }^{9}$ Heidi G. Andrade, "Teaching with Rubrics: The Good, the Bad, and the Ugly," College Teaching 53, no. 1 (2005): 27-30.

${ }^{10}$ Bob Broad, What We Really Value: Beyond Rubrics in Teaching and Assessing Writing (Logan: Utah State University Press, 2003). 
instruction and evaluating programs as key reasons. ${ }^{11}$ Recently, the focus of rubrics has shifted gradually away from summative grading to formative purposes. A rubric can provide students with informative feedback on their strengths and weaknesses and prompts them to reflect on their own work. While it can be used as a mechanism to specify and communicate the expectations of an assignment to students, it can also be a secret scoring sheet used only by teachers to assess student work fairly, consistently, and efficiently.

Students generally favor the use of rubrics, whereas teachers tend to resist their use due to their limited conception of the purpose of a rubric.' $^{12}$ Some teachers do not see the need for a rubric, and many teachers find them to be too specific, too constraining, or too vague. Reddy and Andrade offer hope that 'teachers might be more receptive if they understand that rubrics can be used to enhance teaching and learning as well as to evaluate.' 13 Among the reasons why students favor the use of rubrics, and in particular instructional rubrics, is because they provide informative feedback about students' strengths and highlight areas for improvement; ultimately, they support learning, good thinking, and the development of understanding and skills. ${ }^{14}$

There is a clear need to shift away from teacher-centered, summative rubrics to student-centered, formative rubrics. In this chapter, we will focus primarily on the use of instructional rubrics to achieve this shift. We will first discuss in more detail why rubrics matter, going beyond their use to achieve fair and consistent grading, to their use as instructional scaffolds. We will then identify and provide a framework for the construction of such rubrics before discussing how these rubrics can be most effectively used and how they impact teaching.

${ }^{11}$ Y. Malini Reddy, and Heidi G. Andrade, "A Review of Rubric Use in Higher Education," Assessment \& Evaluation in Higher Education 35, no. 4 (2010): 435-448, https:// doi.org/10.1080/02602930902862859.

12 Reddy and Andrade, "A Review of Rubric Use in Higher Education."

13 Reddy and Andrade, "A Review of Rubric Use in Higher Education."

${ }^{14}$ Heidi G. Andrade, "Using Rubrics to Promote Thinking and Learning," Educational Leadership 57, no. 5 (2000): 13-18. 


\section{Why Do Rubrics MatTer?}

In many Asian universities, including Singapore, professors often come from different cultural backgrounds from their students. Additionally, far from there being a singular Asian culture, there are many different cultures in most Asian university classrooms in part because students travel to other Asian nations for their education but also because so many Asian nations are themselves highly multicultural. This diversity of the student and teacher population in Asian Universities-culturally, ethnically, socially, and linguistically-makes transparency ever more important to effective teaching. Winkelmes, Boye, and Tapp argue that transparency in assignment design can overcome inequity in students' educational experiences. ${ }^{15}$ The characteristics of transparency and fairness embedded within rubrics make it a valuable tool in diverse higher education contexts such as in Asia.

\section{Rubrics for Monitoring Fairness and Consistency}

Rubrics offer the possibility of objective, consistent evaluation minimizing difference in grades even when multiple raters are involved in evaluating student work. ${ }^{16}$ In Jonsson and Svingby's review paper on rubrics, they conclude that 'reliable scoring of performance assessments can be enhanced by the use of rubrics, especially if they are analytic, topicspecific, and complemented with exemplars and/or rater training., 17

${ }^{15}$ Mary-Anne Winkelmes, Allison Boye, and Suzanne Tapp, eds., Transparent Design in Higher Education Teaching and Leadership: A Guide to Implementing the Transparency Framework Institution-Wide to Improve Learning and Retention (Stirling: Stylus, 2019).

${ }^{16}$ Mary E. Huba and Jann E. Freed, Learner-Centered Assessment on College Campuses: Shifting the Focus from Teaching to Learning (Needham Heights: Allyn and Bacon, 2000); Deborah Crusan, Assessment in the Second Language Writing Classroom (Ann Arbor: University of Michigan Press, 2010); Dannelle D. Stevens and Antonia J. Levi, Introduction to Rubrics: An Assessment Tool to Save Grading Time, Convey Effective Feedback and Promote Student Learning (Sterling: Stylus, 2013); and Brookhart, How to Create and Use Rubrics for Formative Assessment and Grading.

${ }^{17}$ Jonsson and Svingby, "The Use of Scoring Rubrics: Reliability, Validity and Educational Consequences." 
Rubrics offer the necessary transparency in providing students with clear, accessible, and understandable benchmarks for developing and judging their work. They clarify teacher's expectations and performance indicators through explicitly stated criteria, and show students how their work will be evaluated and what is expected of them. ${ }^{18}$ Students agree that the use of rubrics makes the grading process fair as they can easily verify if they have met the criteria or not. ${ }^{19}$ Students further report that they are less anxious and more confident in working on their assignments when expectations are clearly listed in the rubrics. ${ }^{20}$

Rubrics improve students' self-efficacy by helping students identify the key cognitive skills that they need to develop to excel in the assignment. With these skills identified, students can plan and self-assess their work, and thus rubrics can be important tools in supporting students become self-regulated learners. ${ }^{21}$ However, this transparency in supporting students more effectively deliver what the teacher wants can encourage instrumentalism. ${ }^{22}$ Kohn argues that this instrumentalism is likely to narrow students' scope and restrict the development of skills beyond what is explicitly stated in the criteria. ${ }^{23}$ A potential solution to this dilemma,

${ }^{18}$ Robin Tierney and Marielle Simon, "What's Still Wrong with Rubrics: Focusing on the Consistency of Performance Criteria Across Scale Levels," Practical Assessment, Research \& Evaluation 9, no. 2 (2004): 1-7; Anders Jonsson, "Rubrics as a Way of Providing Transparency in Assessment," Assessment \& Evaluation in Higher Education 39, no. 7 (2014): 840-852; and Deborah Crusan, "Dance, Ten; Looks, Three: Why Rubrics Matter," Assessing Writing 26 (2015): 1-4.

${ }^{19}$ Heidi G. Andrade and Ying Du, "Student Perspectives on Rubric-Referenced Assessment," Practical Assessment, Research \& Evaluation 10, no. 5 (2005): 1-11.

${ }^{20}$ Andrade and Du, "Student Perspectives on Rubric-Referenced Assessment."

${ }^{21}$ Ernesto Panadero, "Instructional Help for Self-Assessment and Self-Regulation: Evaluation of the Efficacy of Self-Assessment Scripts vs. Rubrics" (Unpublished PhD diss., Universidad Autónoma de Madrid, 2011); Ernesto Panadero and Anders Jonsson, "The Use of Scoring Rubrics for Formative Assessment Purposes Revisited: A Review," Educational Research Review 9 (2013): 129-144; Anastasia Efklides, "Interactions of Metacognition with Motivation and Affect in Self-Regulated Learning: The MASRL Model," Educational Psychologist 46, no. 1 (2011): 6-25; and Barry J. Zimmerman, "Self-Regulated Learning and Academic Achievement: An Overview," Educational Psychologist 25, no. 1 (1990): 3-17.

${ }^{22}$ Harry Torrance, "Assessment as Learning? How the Use of Explicit Learning Objectives, Assessment Criteria and Feedback in Post-secondary Education and Training Can Come to Dominate Learning," Assessment in Education: Principles, Policy \& Practice 14 (2007): 281-294.

${ }^{23}$ Alfie Kohn, “The Trouble with Rubrics.” English Journal 95, no. 4 (2006): 12-16. 
as noted by Torrance, is to move from summative assessment of learning through formative assessment for learning to experiential assessment as learning. ${ }^{24}$

\section{Rubrics as Scaffolds for Assessment as Learning}

Assessment tasks tend to focus primarily on monitoring and evaluating student learning, but most often provide little or no scaffold to promote learning. Teachers who advocate assessment as learning confirm that rubrics can teach as well as evaluate. ${ }^{25}$ Andrade laments that 'rubrics used only to assign grades represent not only a missed opportunity to teach but also a regrettable instance of the teacher as-sole-judge-of-quality model that puts our students in a position of mindlessness and powerlessness. ${ }^{26}$ Using rubrics, teachers can explicitly list the assessment criteria to enhance the alignment of learning, instruction, and assessment. ${ }^{27}$ In a student-centered approach, the rubric is shared and at times cocreated with students to support student learning. ${ }^{28}$ Students can then use rubrics to plan their assessment task, clarify targets, determine and focus effort where needed, identify issues related to the task, regulate the process in the effort to produce high-quality work. ${ }^{29}$ For example, Broad argues that rubrics 'may have done more good for writing assessment and the teaching of writing than any other concept or technology' when used as a scaffold. ${ }^{30}$

\footnotetext{
${ }^{24}$ Torrance, "Assessment as Learning?"

25 Judith Arter and Jay McTighe, Scoring Rubrics in the Classroom: Using Performance Criteria for Assessing and Improving Student Performance (Thousand Oaks: Sage, 2001); Panadero and Jonsson, "The Use of Scoring Rubrics for Formative Assessment Purposes Revisited"; Reddy and Andrade, "A Review of Rubric Use in Higher Education."

${ }^{26}$ Andrade, "Teaching with Rubrics: The Good, the Bad, and the Ugly."

${ }^{27}$ John Biggs and Catherine Tang, Teaching for Quality Learning at University (Maidenhead: Open University Press, 2007).

28 Jonsson, "Rubrics as a Way of Providing Transparency in Assessment."

${ }^{29}$ Reddy and Andrade, "A Review of Rubric Use in Higher Education"; Fred C. Bolton, "Rubrics and Adult Learners: Andragogy and Assessment," Assessment Update 18, no. 3 (2006): 5-6.
}

${ }^{30}$ Broad, What We Really Value. 
Rubrics act as pre-assessment narratives that set clear expectations and visual cues to allow students to plan their response to a task. With standardized criteria of what constitutes good performance clearly stated, students use rubrics as a self-assessment tool to interrogate the assessment and monitor the quality of their own work. ${ }^{31}$ With continued use of rubrics, students quickly start to notice patterns of recurring problems. This self-discovery and critical reflection of their own learning process can lead to self-improvement. In so doing, rubrics become part of a formative, student-centered approach to assessment. Rubrics initiate this approach by communicating and clarifying the teacher's expectations to the students, and thus these explicit expectations can set in motion a process that can lead to improved student performance.

Feedback is the most effective scaffold to improve student work, and particularly when it is targeted at a specific assessment task, given regularly during students' performance of the task or immediately after the completion of the task. ${ }^{32}$ Feedback is effective only when it contains concrete information on how the highest level of performance can be achieved rather than simply evaluating the current level of work. Huba and Freed suggest that rather than 'emphasizing grades in assessment, the focus should be on descriptive feedback for improvement. Feedback that focuses on self-assessment and self-improvement is a form of intrinsic motivation. ${ }^{33}$ If meaningful feedback is provided in a timely manner, students are motivated to make positive changes in their current and subsequent work. However, the longer the delay in feedback, the less effective the feedback will be on performance.

Providing timely feedback alone is not sufficient; students need to be adequately prepared to use the detailed feedback. Detailed feedback on the rubric is useful in analyzing where students' strengths and weaknesses lie and helps students identify the areas that need work so as to set their own plans for improvement. Feedback should never be provided as a means for a one-time quick fix, but rather be considered as a continuous

\footnotetext{
${ }^{31}$ Andrade and Du, "Student Perspectives on Rubric-Referenced Assessment"; Dawson, "Assessment Rubrics: Towards Clearer and More Replicable Design, Research and Practice"; and Sadler, "Transforming Holistic Assessment and Grading into a Vehicle for Complex Learning."

${ }^{32}$ Paul Black and Dylan Wiliam, "Assessment and Classroom Learning," Assessment in Education: Principles, Policy \& Practice 5, no. 1 (1998): 7-74.

${ }^{33}$ Huba and Freed, Learner-Centered Assessment on College Campuses, 59.
} 
process with repeated instances of feedback and opportunities to change students' self-perceptions and behavior. ${ }^{34}$

Maximizing improved student performance through the use of rubrics requires teachers to go beyond being merely prescriptive. Although rubrics set the expectations for a task, it is unwarranted to assume that all students will understand what is expected of them, or how they should approach the task. Torrance argues that students are more likely to succeed when assessment tasks have greater clarity on process, criteria and how the tasks are to be graded, coupled with more detailed assistance from teachers on how to achieve a particular grade or result. ${ }^{35}$ In that same vein, Rezaei and Lovorn found that without training regarding effective rubric use, reliability or validity will likely not improve. ${ }^{36} \mathrm{Stu}^{-}$ dents need help in understanding rubrics and must be taught how to actively use a rubric. ${ }^{37}$ Discussing with students the techniques that can help them understand how to use different grading tools and engaging them in activities that teach them the benefits of grading tools is necessary for students to use rubrics effectively. A further powerful approach is to cocreate the rubric with the students. Andrade describes the cocreation of a rubric in her own teaching practice. ${ }^{38}$ The cocreation process begins with discussing strong and weak examples of student work, and then asking the students to 'brainstorm criteria for their own work.' Andrade then uses the resulting list of criteria to draft a rubric, before eliciting comments from the students. ${ }^{39}$ As pointed out by Huba and Freed, this process helps build consensus about the meaning of the criteria to be used in the rubric. They further note that including 'students' ideas in the final rubric conveys respect for students as people and builds student ownership for learning. ${ }^{40}$

\footnotetext{
${ }^{34}$ Black and Wiliam, "Assessment and Classroom Learning."

35 Torrance, "Assessment as Learning?"

${ }^{36}$ Ali Reza Rezaei and Michael Lovorn, "Reliability and Validity of Rubrics for Assessment Through Writing," Assessing Writing 15, no. 1 (2010): 19-39.

${ }^{37}$ Reddy and Andrade, "A Review of Rubric Use in Higher Education."

${ }^{38}$ Andrade, "Teaching with Rubrics: The Good, the Bad, and the Ugly."

${ }^{39}$ Andrade, "Using Rubrics to Promote Thinking and Learning."

${ }^{40}$ Huba and Freed, Learner-Centered Assessment on College Campuses, 170.
} 


\section{How to Create the Elements of A High-Quality Rubric?}

Creating rubrics can be both time consuming and conceptually difficult depending on the type of rubric. ${ }^{41}$ However, the process for developing a rubric, no matter the type, follows a similar set of steps ${ }^{42}$ : (a) define the learning outcomes of the module; (b) describe the assessment tasks that cover these learning outcomes; and, (c) identify the criteria and standards of performance for these assessment tasks. In starting from the learning outcomes of a course, this process is similar to the backward design approach used in course development and recognizes the importance of alignment with the learning outcomes. ${ }^{43}$ It is the criteria and standards of performance that constitute the rubric, but formulating these is not a trivial task.

Figure 3.1 details the procedure for rubric development and how it fits into course design by building on the assessment process of Huba and Freed. ${ }^{44}$

In this rubric development procedure, the critical step is to identify the criteria and standards for the rubric. It is rarely necessary to build rubrics from scratch, instead referring to rubric samples can be a first step to developing a new rubric. There are many examples of rubrics that can be found on the web. One good collection is the set of rubrics developed under the VALUE (Valid Assessment of Learning in Undergraduate Education) project by the Association of American Colleges and Universities. ${ }^{45}$ However, such sample rubrics should never be used as is, even when being used for a similar assignment. The practice of 'adopt and

\footnotetext{
${ }^{41}$ Balch, Blanck, and Balch, "Rubrics-Sharing the Rules of the Game.

42 Craig A. Mertler, "Designing Scoring Rubrics for Your Classroom," Practical Assessment, Research and Evaluation 7, no. 25 (2001); Deborah Allen and Kimberly Tanner, "Rubrics: Tools for Making Learning Goals and Evaluation Criteria Explicit for Both Teachers and Learners," CBE Life Sciences Education 5, no. 3 (2006): 197-203; and Y. M. Reddy, "Effect of Rubrics on Enhancement of Student Learning," Journals of Education 7, no. 1 (2007): 3-17.

${ }^{43}$ Grant P. Wiggins and Jay McTighe, Understanding by Design (Alexandria: Association for Supervision and Curriculum Development, 2005); Biggs and Tang, Teaching for Quality Learning at University.

${ }^{44}$ Huba and Freed, Learner-Centered Assessment on College Campuses, 10.

45 Terrel L. Rhodes, ed., Assessing Outcomes and Improving Achievement: Tips and Tools for Using Rubrics (Washington: Association of American Colleges and Universities, 2010).
} 


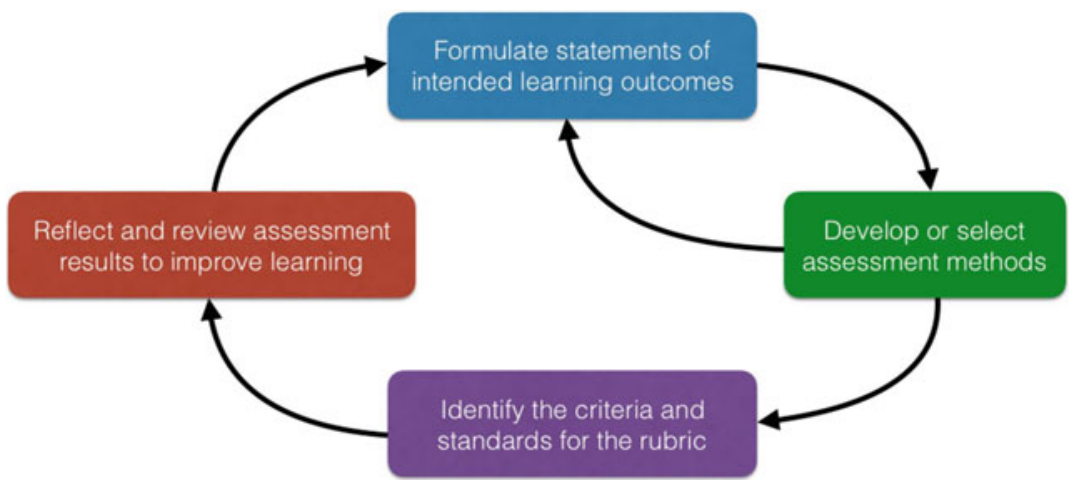

Fig. 3.1 Rubric development as part of course design (adapted from Huba and Freed, 2000)

adapt $^{46}$ can be a useful strategy when faced with the task of developing a rubric. In this approach, a complete working rubric is adopted and then adapted to suit the assessment context. The adaptation process begins by reflecting on the assessment task and the new context for which the rubric is being adapted. This context is twofold: first, the rubric needs to capture what is expected from the students; and second, how the teacher expects to grade the task. In the adaptation, the criteria and standards can be retained, but the performance level descriptions should be adapted to the new context. A rich source for these descriptions can be the feedback provided to students in previous assignments. Most times, teachers end up giving the same or similar feedback to students at various levels of performance, and these consistent evaluative judgments can then be easily translated into the intended proficient standards expected from students.

The rubric development process is never over but always evolving. ${ }^{47}$ Banerjee et al. recommend regular monitoring and modification of rubrics to ensure reliability, validity, and usability. ${ }^{48}$ Monitoring will include evaluating the degree to which the scale was functioning and in which

${ }^{46}$ Crusan, Assessment in the Second Language Writing Classroom, 72.

${ }^{47}$ Balch, Blanck, and Balch, "Rubrics-Sharing the Rules of the Game."

48 Jayanti Banerjee, Yan Xun, Mark Chapman, and Heather Elliott, "Keeping Up with the Times: Revising and Refreshing a Rating Scale," Assessing Writing 26 (2015): 5-19, https://doi.org/10.1016/j.asw.2015.07.001. 
parts. ${ }^{49}$ This requires sense-making sessions with peers and students as partners 'where they are presented with descriptive facts against each evaluation criteria and are involved in a process of determining how well criteria have been achieved. ${ }^{50}$ This approach can increase the transparency in evaluation and grading and can form the basis for rubric refinement. Modification of rubrics necessitates a systematic review and revision process. Studies suggest an approach that combines expert intuition, knowledge and experience needs to be employed in the review and revision process. ${ }^{51}$ This involves an understanding of success indicators for the assessment task based on evidence from literature, an empirical analysis of past student performance data, and the study of different task samples from the past assignment submissions.

\section{How to Use Rubrics Effectively?}

The use of rubrics is not without criticism; many have argued that rubrics can be too subjective, too vague or too detailed, or that they can restrict students' understanding of learning and their ability to selfregulate. ${ }^{52}$ Poorly designed rubrics can also 'misdirect student efforts and mis-measure learning. ${ }^{53}$ Students need to understand how to approach and react to different practices of using rubrics-based assessments. Teachers can overcome such challenges and support students through careful planning. In this section, we provide some examples of how to make use of rubrics effectively.

${ }^{49}$ Gerriet Janssen, Valerie Meier, and Jonathan Trace, "Building a Better Rubric: Mixed Methods Rubric Revision,” Assessing Writing 26 (2015): 51-66. https://doi.org/10. 1016/j.asw.2015.07.002.

${ }^{50}$ Pauline Dickinson and Jeffery Adams, "Values in Evaluation-The Use of Rubrics," Evaluation and Program Planning 65 (2017): 113-116.

${ }^{51}$ Banerjee, Yan, Chapman, and Elliott, "Keeping Up with the Times"; Janssen, Meier, and Trace, "Building a Better Rubric"; and Dickinson and Adams, "Values in EvaluationThe Use of Rubrics."

52 Torrance, "Assessment as Learning?"; Lene Nordrum, Katherine Evans, and Magnus Gustafsson, "Comparing Student Learning Experiences of In-text Commentary and Rubric-Articulated Feedback: Strategies for Formative Assessment," Assessment \& Evaluation in Higher Education 38, no. 8 (2013): 919-940; and Brookhart, "Appropriate Criteria: Key to Effective Rubrics."

53 Brookhart, "Appropriate Criteria: Key to Effective Rubrics.” 
Table 3.1 Single-point rubric as an instructional scaffold ${ }^{\mathrm{a}}$

\begin{tabular}{llll}
\hline $\begin{array}{l}\text { Assignment } \\
\text { criteria }\end{array}$ & $\begin{array}{l}\text { Concerns } \\
\text { Areas that need } \\
\text { work }\end{array}$ & $\begin{array}{l}\text { Criteria } \\
\text { Standards for } \\
\text { proficient student } \\
\text { performance }\end{array}$ & $\begin{array}{l}\text { Advanced } \\
\text { Evidence of } \\
\text { exceeding standards }\end{array}$ \\
\hline Criteria \#1 & $\begin{array}{l}\text { Description } \\
\text { reflecting } \\
\text { achievement of } \\
\text { mastery level of } \\
\text { performance for } \\
\text { criteria \#l } \\
\text { Description } \\
\text { reflecting } \\
\text { achievement of } \\
\text { mastery level of } \\
\text { performance for } \\
\text { criteria \#2 } \\
\text { Description } \\
\text { reflecting } \\
\text { achievement of } \\
\text { mastery level of } \\
\text { performance for } \\
\text { criteria \#3 }\end{array}$ \\
\hline
\end{tabular}

aAdapted from Fluckiger, "Single Point Rubric"; Balch, Blanck, and Balch, "Rubrics-Sharing the Rules of the Game"

A student-centered learning environment creates opportunities for students to showcase their creativity, push them beyond their comfort zone, and more importantly learn from their mistakes. For example, a wellcrafted single-point rubric, as shown in Table 3.1, can be one such instructional scaffold. It offers clarity of the assessment task along with clear guidance and support, which according to Hockings et al. are necessary to enhance independent learning. ${ }^{54}$ It not only makes the process and expectations of disciplinary knowledge and communication transparent to students, but also opens new possibilities for the teacher to create

${ }^{54}$ Christine Hockings, Liz Thomas, Jim Ottaway, and Rob Jones, "Independent Learning-What We Do When You're Not There," Teaching in Higher Education 23, no. 2 (2018): 145-161, https://doi.org/10.1080/13562517.2017.1332031. 
a significant learning experience that helps students develop higher-level extending and applying skills. ${ }^{55}$

Like holistic and analytic rubrics, a single-point rubric breaks down the assessment tasks into categories and outlines the standards for proficient student performance, but deliberately leaves open-ended the areas for success and shortcomings. Thus, a single-point rubric does not impose boundaries on student performance, instead offers flexibility in setting their own learning goals and promotes student creativity without sacrificing clarity. As Fluckiger notes, it 'allows time for goal setting and revision, provides a place for noting current status, and sets an expectation of initiative and innovation.' 56 It also emphasizes descriptive, personalized feedback specific to individual students and has the power to create a significant learning experience that challenges the focus on grades inherent in analytic rubrics. Thus, a single-point rubric acts as: (a) a process scaffold to support students in tackling complex assignments by breaking them down into smaller components; (b) a critical thinking scaffold to demand sophisticated thinking in students; and, (c) a disciplinary practice scaffold to induct students into the professional discourse and practice of their discipline. ${ }^{57}$

Initiating classroom discussion using single-point rubrics prior to the start of an assignment can prompt reflection and promote scholarly critical thinking. ${ }^{58}$ The intentionally blank open-ended spaces used to record areas of concern and excellence can stimulate discussion on the thought processes, analyses and judgments for each of the components and generate pre-assessment narratives. Reitmeier and Vrchota discuss the use of such exercises for deeper reflection not only to help students identify and achieve baseline knowledge, but also to be aware of how they meet

${ }^{55}$ L. Dee Fink, Creating Significant Learning Experiences: An Integrated Approach to Designing College Courses (San Francisco: Jossey-Bass, 2003).

${ }^{56}$ Fluckiger, "Single Point Rubric."

${ }^{57}$ Allyson Skene and Sarah Fedko, Instructional Scaffolding (University of Toronto Scarborough: Centre for Teaching and Learning, 2014).

${ }^{58}$ Jon F. Schamber and Sandra L. Mahoney, "Assessing and Improving the Quality of Group Critical Thinking Exhibited in the Final Projects of Collaborative Learning Groups," The Journal of General Education 55, no. 2 (2006): 103-137, http://dx.doi. org/10.1353/jge.2006.0025. 
the proficient standards and to provide evidence for how they have gone above and beyond proficient standards. ${ }^{59}$

Turning now to rubrics in general, Sadler argues that the listed criteria may not mean the same thing to all students and may not be specific enough to guide student thinking. ${ }^{60}$ Rubrics may not always be selfexplanatory, and so it is good practice to do a mock critique in a class using exemplars, taken for instance from previous years' work, that have gone through the same marking and feedback process. ${ }^{61}$ As a variation, Blommel and Abate suggest the use of published journal articles as exemplars for such critiques. ${ }^{62}$ Mock critiques help students understand the nature of the assessment task and signal the expected quality required to excel. Lipnevich et al. investigated the efficacy of providing detailed rubrics and written exemplars and found that such practice does indeed lead to substantial improvement in student performance. ${ }^{63}$ Nordrum, Evans, and Gustafsson extended this practice by providing commented exemplars and explanations for the grade the exemplar was assessed to merit. ${ }^{64}$ Mock critiques can further be used as tools for peer assessment and peer feedback. Getting students ready to be engaged in peer assessment is a two-stage process: The first stage involves familiarizing students with the rubric for reflection and critique of their own work and the second stage involves providing detailed feedback to peers. This approach recognizes the powerful learning that takes place when receiving and giving peer feedback, in particular for the development of evaluative judgment. Nicol et al. further suggest that the provider of feedback can benefit

${ }^{59}$ Cheryl A. Reitmeier and Denise A. Vrchota, "Self-Assessment of Oral Communication Presentations in Food Science and Nutrition," Journal of Food Science Education 8, no. 4 (2009): 88-92.

${ }^{60}$ D. Royce Sadler, "The Futility of Attempting to Codify Academic Achievement Standards," Higher Education 67 (2014): 273-288, https://doi.org/10.1007/s10734-0139649-1.

${ }^{61}$ Dawson, "Assessment Rubrics: Towards Clearer and More Replicable Design, Research and Practice."

${ }^{62}$ Matthew L. Blommel and Marie A. Abate, "A Rubric to Assess Critical Literature Evaluation Skills," American Journal of Pharmaceutical Education 71, no. 4 (2007): 63.

${ }^{63}$ Anastasiya A. Lipnevich, Leigh N. McCallen, Katherine P. Miles, and Jeffrey K. Smith, "Mind the Gap! Students' Use of Exemplars and Detailed Rubrics as Formative Assessment," Instructional Science 42 (2014): 539-559.

${ }^{64}$ Nordrum, Evans, and Gustafsson, "Comparing Student Learning Experiences of Intext Commentary and Rubric-Articulated Feedback." 
more than the receiver, as it is in the provision of feedback that evaluative judgment is exercised. ${ }^{65}$

By integrating rubrics into assignments, students can self-assess their own work using a rubric and attach their marked rubric along with the assignment for grading. Recurring use of rubrics in a course that offers multiple opportunities for students to use them in assignments is an effective method to improve student learning. Such use can shape the formation of criteria in which the work is graded and can support the process of designing and developing co-constructed analytic rubrics, which can be 'powerfully instructive.' 66

Thus, rubrics help in providing timely feedback that is detailed, diagnostic, easier-to-read, personalized, and specific to each student's work. Teachers can simply circle or check the appropriate descriptions that apply, while also adding in targeted comments only when needed. This makes the grading process both fairer and more efficient. In this way, rubrics are excellent tools that allow for easy tracking of student progress and improvement over time, promoting self-assessment and self-improvement.

\section{How Rubrics Can Impact Your Teaching Practice?}

Beyond making assessments fair, transparent and consistent, teachers who advocate the use of rubrics report that they make a significant impact in encouraging and enabling reflective practice, see for example the review by Jonsson and Svingby. ${ }^{67}$ Such advocates argue that rubrics provide insight into the effectiveness of their teaching practice. Huba and Freed suggest several ways in which rubrics can become excellent instructional illuminators' to enhance instructional quality ${ }^{68}$ :

${ }^{65}$ David Nicol, Avril Thomson, and Caroline Breslin, "Rethinking Feedback Practices in Higher Education: A Peer Review Perspective," Assessment \& Evaluation in Higher Education 39, no. l (2014): 102-122, https://doi.org/10.1080/02602938.2013.795518.

66 Andrade, "Using Rubrics to Promote Thinking and Learning."

${ }^{67}$ Jonsson and Svingby, "The Use of Scoring Rubrics: Reliability, Validity and Educational Consequences."

${ }^{68}$ Huba and Freed, Learner-Centered Assessment on College Campuses; Popham, "What's Wrong-And What's Right-With Rubrics." 
1. Foremost is the need to design rubrics that are clearly aligned with learning outcomes. This alignment helps teachers gain greater clarity on both content and outcomes as they are focused on what they what their students to learn rather than on what they intend to teach.

2. Rubrics steer teachers toward being learning- and learner-centric rather than being task-centric. Referencing overall rubric results in class can be an excellent way of addressing class problems by not singling out individual students. Rubrics showing student development over time can help teachers gain a clearer view of teaching, specifically blind spots, omissions, and strengths.

3. Revision of rubrics takes place as teachers gather information and capture areas of concern in students' understanding of criteria, students' quality of work, and as teachers reflect on the difficulty in assessing and scoring student work. These can be used as teaching moments to teach or talk about the issues that are important and how such issues can be corrected. Not only does such information help in revising rubrics, it also supports the reviewing of teaching strategies and learning activities, or may even lead to the revision of learning outcomes. Rubrics can thus lead to a cycle of continuous improvement.

4. Teachers can also share their own rubrics and rubrics-articulated feedback with colleagues to initiate dialogue about teaching that can lead to rubric cocreation and development through collaboration. Not only will it promote a careful yet faster review and revision process but may also lead to the development of department-wide and/or institution-wide rubrics that represent common practices of particular interpretations of the discipline. More importantly, the signaling to students is coherent with regard to the quality of work expected of them from their teachers for most of the courses and emphasize the discipline-specific qualities that they need to develop to become experts in that area.

5. Teachers tend to associate a set of rubrics to one assignment, but it is certainly possible to learn a great deal about one's teaching methods and student learning across multiple assignments, and across multiple courses. This cross-sectional analysis can be used to identify areas for improvement in one's teaching. This analysis can also be used as persuasive evidence of teaching improvement in annual review, and in application for promotion and tenure. 
Table 3.2 Teacher summary rubric for teaching improvement ${ }^{\mathrm{a}}$

\begin{tabular}{|c|c|c|c|c|}
\hline \multirow[t]{2}{*}{$\begin{array}{l}\text { Assignment } \\
\text { criteria }\end{array}$} & \multicolumn{2}{|c|}{$\begin{array}{l}\text { Summary of student performance } \\
\text { on various aspects/components }\end{array}$} & \multicolumn{2}{|c|}{$\begin{array}{l}\text { Summary of changes to mediate } \\
\text { teaching improvement }\end{array}$} \\
\hline & $\begin{array}{l}\text { Areas that are } \\
\text { of concern }\end{array}$ & $\begin{array}{l}\text { Areas that } \\
\text { exceeded } \\
\text { expectations }\end{array}$ & $\begin{array}{l}\text { Changes to } \\
\text { instruction }\end{array}$ & $\begin{array}{l}\text { Changes to } \\
\text { assignment }\end{array}$ \\
\hline
\end{tabular}

Criteria \#1

Criteria \#2

Criteria \#3

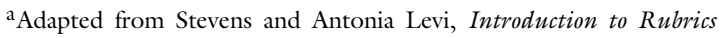

A strategy to support this process of reflection and revision for teaching improvement can involve the use of a teacher summary rubric (Table 3.2).

Teacher summary rubrics condense how students completed an assignment in terms of accomplishing specific learning goals and understanding their discipline. Summary rubrics can be completed while grading the assignment with an assessment rubric. The patterns that develop under each of the criteria can help teachers identify the strengths and weaknesses of the assignment. Improvements to the assignment can then be developed and overall teaching practice can be modified to support better student learning. This strategy is an efficient way to check the alignment between course objectives and student learning, and to gather meaningful feedback on the overall class performance.

\section{CONCLUding Remarks}

Rubrics support the process of both summative and formative assessments. They are excellent tools for grading and judgment evaluation when used as scoring rubrics but can also be effective tools to explicate the learning and teaching processes when used as instructional rubrics.

Scoring rubrics are primarily grading tools that are effective in providing objective and consistent assessment of student work. They provide teachers a mechanism to score reliably, make valid judgments, and rationalize the grades awarded. They clarify teacher expectations and inform students on how to meet them in an easy-to-follow visual format. They facilitate transparency in instruction by making objectives and criteria explicit to students that are consistent with teaching goals. The 
feedback that students receive through scoring rubrics can help them improve their performance on subsequent work. Such transparency and feedback increase student self-confidence, self-efficacy, self-awareness, and self-determination. ${ }^{69}$

Instructional rubrics embody the clear shift from teacher-centered, summative assessments to student-centered, formative assessments. They promote student achievement by allowing both students and teachers to use evaluative judgments and assessment results as means to further student learning. They help teachers provide productive, targeted feedback, and prompt students' active involvement in making sense and engaging with feedback for ongoing improvement. They prompt students to continuously self-evaluate their work against specific criteria through reflection and action on feedback. While teachers are the enablers of facilitating student feedback literacy, students are the architects of utilizing such feedback for reflection and action. ${ }^{70}$ Instructional rubrics, and in particular, single-point rubrics are excellent scaffolding tools that support such student engagement with feedback and favor the process of assessment as learning. Further, they demand students' cognitive thinking and develop students' disciplinary expertise and promote the use of assessment for new learning. Thus, holistically designed instructional rubrics scaffold the processes of self-assessment and self-regulated learning, and enable students to achieve specific outcomes of an assessment task and demonstrate what has been learned and achieved. ${ }^{71}$ Finally, rubrics also promote the process of peer assessment and peer feedback by improving their ability to judge and provide feedback to their own and their peers' work, thus changing students' perspectives on their own abilities and potential.

Rubrics allow teachers to: (a) summarize student performance; (b) tabulate student accomplishment of learning goals; (c) disaggregate student scores by specific criteria and skills; and, (d) identify patterns of

\footnotetext{
${ }^{69}$ Winkelmes, Boye, and Tapp, Transparent Design in Higher Education Teaching and Leadership.

${ }^{70}$ David Carless, "Feedback Loops and the Longer-Term: Towards Feedback Spirals," Assessment \& Evaluation in Higher Education 44, no. 5 (2019): 705-714, https://doi. org/10.1080/02602938.2018.1531108.

${ }^{71}$ David Boud and Rebecca Soler, "Sustainable Assessment Revisited," Assessment ê Evaluation in Higher Education 41, no. 3 (2016): 400-413, https://doi.org/10.1080/ 02602938.2015.1018133.
} 
strengths and weaknesses of students' work and of the assignments themselves. Thus, rubrics provide teachers with a greater understanding of their own teaching practice and encourage teachers to become reflective practitioners.

\section{BIBLIOGRAPHY}

Allen, Deborah, and Kimberly Tanner. "Rubrics: Tools for Making Learning Goals and Evaluation Criteria Explicit for Both Teachers and Learners." CBE Life Sciences Education 5, no. 3 (2006): 197-203.

Andrade, Heidi G. "Using Rubrics to Promote Thinking and Learning." Educational Leadership 57, no. 5 (2000): 13-18.

- "Teaching with Rubrics: The Good, the Bad, and the Ugly." College Teaching 53, no. 1 (2005): 27-30.

Andrade, Heidi G., and Ying Du. "Student Perspectives on Rubric-Referenced Assessment." Practical Assessment, Research \& Evaluation 10, no. 5 (2005): $1-11$.

Arter, Judith, and Jay McTighe. Scoring Rubrics in the Classroom: Using Performance Criteria for Assessing and Improving Student Performance. Thousand Oaks: Sage, 2001.

Balch, David, Robert Blanck, and David H. Balch. "Rubrics-Sharing the Rules of the Game." Journal of Instructional Research 5 (2016): 19-49.

Banerjee, Jayanti, Yan Xun, Mark Chapman, and Heather Elliott. "Keeping Up with the Times: Revising and Refreshing a Rating Scale." Assessing Writing 26 (2015): 5-19. https://doi.org/10.1016/j.asw.2015.07.001.

Biggs, John, and Catherine Tang. Teaching for Quality Learning at University. Maidenhead: Open University Press, 2007.

Black, Paul, and Dylan Wiliam. "Assessment and Classroom Learning." Assessment in Education: Principles, Policy o Practice 5, no. 1 (1998): 7-74.

Blommel, Matthew L., and Marie, A. Abate. "A Rubric to Assess Critical Literature Evaluation Skills." American Journal of Pharmacentical Education 71, no. 4 (2007): 63.

Bolton, Fred. C. "Rubrics and Adult Learners: Andragogy and Assessment." Assessment Update 18, no. 3 (2006): 5-6.

Boud, David, and Rebecca Soler. "Sustainable Assessment Revisited." Assessment \& Evaluation in Higher Education 41, no. 3 (2016): 400-413. https://doi. org/10.1080/02602938.2015.1018133.

Broad, Bob. What We Really Value: Beyond Rubrics in Teaching and Assessing Writing. Logan: Utah State University Press, 2003.

Brookhart, Susan M. How to Create and Use Rubrics for Formative Assessment and Grading. Alexandria: ASCD, 2013. 
- "Appropriate Criteria: Key to Effective Rubrics." Frontiers in Education 3, no. 22 (2018): 1-12. https://doi.org/10.3389/feduc.2018.00022.

Carless, David. "Feedback Loops and the Longer-Term: Towards Feedback Spirals." Assessment \& Evaluation in Higher Education 44, no. 5 (2019): 705714. https://doi.org/10.1080/02602938.2018.1531108.

Crusan, Deborah. Assessment in the Second Language Writing Classroom. Ann Arbor: University of Michigan Press, 2010.

_. "Dance, Ten; Looks, Three: Why Rubrics Matter." Assessing Writing 26 (2015): 1-4.

Dawson, Phillip. "Assessment Rubrics: Towards Clearer and More Replicable Design, Research and Practice." Assessment \& Evaluation in Higher Education 42, no. 3 (2017): 347-360. https://doi.org/10.1080/02602938.2015. 1111294.

Dickinson, Pauline, and Jeffery Adams. "Values in Evaluation-The Use of Rubrics." Evaluation and Program Planning 65 (2017): 113-116.

Efklides, Anastasia. "Interactions of Metacognition with Motivation and Affect in Self-Regulated Learning: The MASRL Model." Educational Psychologist 46, no. 1 (2011): 6-25.

Fink, L. Dee. Creating Significant Learning Experiences: An Integrated Approach to Designing College Courses. San Francisco: Jossey-Bass, 2003.

Fluckiger, Jarene. "Single Point Rubric: A Tool for Responsible Student SelfAssessment." Delta Kappa Gamma Bulletin 76, no. 4 (2010): 18-25.

Hockings, Christine, Liz Thomas, Jim Ottaway, and Rob Jones. "Independent Learning-What We Do When You're Not There." Teaching in Higher Education 23, no. 2 (2018): 145-161. https://doi.org/10.1080/13562517. 2017.1332031 .

Huba, Mary E., and Jann E. Freed. Learner-Centered Assessment on College Campuses: Shifting the Focus from Teaching to Learning. Needham Heights: Allyn and Bacon, 2000.

Janssen, Gerriet, Valerie Meier, and Jonathan Trace. "Building a Better Rubric: Mixed Methods Rubric Revision.” Assessing Writing 26 (2015): 51-66. https://doi.org/10.1016/j.asw.2015.07.002.

Jonsson, Anders. "Rubrics as a Way of Providing Transparency in Assessment." Assessment \& Evaluation in Higher Education 39, no. 7 (2014): 840-852.

Jonsson, Anders, and Gunilla Svingby. "The Use of Scoring Rubrics: Reliability, Validity and Educational Consequences." Educational Research Review 2, no. 2 (2007): 130-144.

Kohn, Alfie. "The Trouble with Rubrics." English Journal 95, no. 4 (2006): 12-16.

Lipnevich, Anastasiya A., Leigh N. McCallen, Katherine P. Miles, and Jeffrey K. Smith. "Mind the Gap! Students' Use of Exemplars and Detailed Rubrics as Formative Assessment." Instructional Science 42 (2014): 539-559. 
Mertler, Craig A. "Designing Scoring Rubrics for Your Classroom.” Practical Assessment, Research and Evaluation 7, no. 25 (2001).

Nicol, David, Avril Thomson, and Caroline Breslin. "Rethinking Feedback Practices in Higher Education: A Peer Review Perspective." Assessment \& Evaluation in Higher Education 39, no. 1 (2014): 102-122. https://doi.org/10. 1080/02602938.2013.795518.

Nordrum, Lene, Katherine Evans, and Magnus Gustafsson. "Comparing Student Learning Experiences of In-text Commentary and Rubric-Articulated Feedback: Strategies for Formative Assessment." Assessment \& Evaluation in Higher Education 38, no. 8 (2013): 919-940.

Panadero, Ernesto. "Instructional Help for Self-Assessment and Self-Regulation: Evaluation of the Efficacy of Self-Assessment Scripts vs. Rubrics." Unpublished PhD diss., Universidad Autónoma de Madrid, 2011.

Panadero, Ernesto, and Anders Jonsson. "The Use of Scoring Rubrics for Formative Assessment Purposes Revisited: A Review." Educational Research Review 9 (2013): 129-144.

Popham, W. James. "What's Wrong-And What's Right-With Rubrics." Educational Leadership 55, no. 2 (1997): 72-75.

Reddy, Y. M. "Effect of Rubrics on Enhancement of Student Learning." Journals of Education 7, no. 1 (2007): 3-17.

Reddy, Y. Malini, and Heidi G. Andrade. "A Review of Rubric Use in Higher Education." Assessment \& Evaluation in Higher Education 35, no. 4 (2010): 435-448. https://doi.org/10.1080/02602930902862859.

Reitmeier, Cheryl A., and Denise A. Vrchota. "Self-Assessment of Oral Communication Presentations in Food Science and Nutrition." Journal of Food Science Education 8, no. 4 (2009): 88-92.

Rezaei, Ali R., and Michael Lovorn. "Reliability and Validity of Rubrics for Assessment Through Writing." Assessing Writing 15, no. 1 (2010): 19-39.

Rhodes, Terrel L., ed. Assessing Outcomes and Improving Achievement: Tips and Tools for Using Rubrics. Washington: Association of American Colleges and Universities, 2010.

Sadler, D. Royce. "Transforming Holistic Assessment and Grading into a Vehicle for Complex Learning." In Assessment, Learning and Judgement in Higher Education, edited by Gordon Joughin, 1-19. Dordrecht: Springer, 2009.

-. "The Futility of Attempting to Codify Academic Achievement Standards." Higher Education 67 (2014): 273-288. https://doi.org/10.1007/ s10734-013-9649-1.

Schamber, Jon F., and Sandra L. Mahoney. "Assessing and Improving the Quality of Group Critical Thinking Exhibited in the Final Projects of Collaborative Learning Groups." The Journal of General Education 55, no. 2 (2006): 103137. http://dx.doi.org/10.1353/jge.2006.0025. 
Skene, Allyson, and Sarah Fedko. Instructional Scaffolding. University of Toronto Scarborough: Centre for Teaching and Learning, 2014.

Stevens, Dannelle D., and Antonia J. Levi. Introduction to Rubrics: An Assessment Tool to Save Grading Time, Convey Effective Feedback and Promote Student Learning. Sterling: Stylus, 2013.

Tierney, Robin, and Marielle Simon. "What's Still Wrong with Rubrics: Focusing on the Consistency of Performance Criteria Across Scale Levels." Practical Assessment, Research \& Evaluation 9, no. 2 (2004): 1-7.

Torrance, Harry. "Assessment as Learning? How the Use of Explicit Learning Objectives, Assessment Criteria and Feedback in Post-secondary Education and Training Can Come to Dominate Learning." Assessment in Education: Principles, Policy \& Practice 14 (2007): 281-294.

Wiggins, Grant P., and Jay McTighe. Understanding by Design. Alexandria: Association for Supervision and Curriculum Development, 2005.

Winkelmes, Mary-Anne, Allison Boye, and Suzanne Tapp, eds. Transparent Design in Higher Education Teaching and Leadership: A Guide to Implementing the Transparency Framework Institution-Wide to Improve Learning and Retention. Stirling: Stylus, 2019.

Zimmerman, Barry J. "Self-Regulated Learning and Academic Achievement: An Overview." Educational Psychologist 25, no. 1 (1990): 3-17.

Open Access This chapter is licensed under the terms of the Creative Commons Attribution 4.0 International License (http://creativecommons.org/licenses/ by $/ 4.0 /$ ), which permits use, sharing, adaptation, distribution and reproduction in any medium or format, as long as you give appropriate credit to the original author(s) and the source, provide a link to the Creative Commons license and indicate if changes were made.

The images or other third party material in this chapter are included in the chapter's Creative Commons license, unless indicated otherwise in a credit line to the material. If material is not included in the chapter's Creative Commons license and your intended use is not permitted by statutory regulation or exceeds the permitted use, you will need to obtain permission directly from the copyright holder.

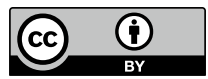




\title{
Educating Adult Learners: Bridging Learners' Characteristics and the Learning Sciences
}

\author{
Ho Yan Yin and Wei Ying Rebekah Lim
}

\section{INTRODUCTION}

Current understandings of adult learning are largely built on the basis of the life-stage characteristics of the learners, i.e., being adults, and therefore by implication, shaping certain teaching approaches such as selfdirected learning. The work of Kasworm, Rose, and Ross-Gordon ${ }^{1}$ and other leading scholars in the adult learning field have unpacked at length the characteristics of adult learners and, by association, their ways of learning. While such a perspective and work have been useful, we contend that

${ }^{\mathrm{l}}$ Carol E. Kasworm, Amy D. Rose, and Jovita M. Ross-Gordon, eds., Handbook of Adult and Continuing Education (New York: Sage, 2010).

H. Y. Yin $(\bowtie) \cdot$ W. Y. R. Lim

Teaching \& Learning Centre, Singapore University of Social Sciences, Singapore, Singapore

e-mail: yyho@suss.edu.sg

W. Y. R. Lim

e-mail: rebekahlimwy@suss.edu.sg

(C) The Author(s) 2020

C. S. Sanger and N. W. Gleason (eds.),

Diversity and Inclusion in Global Higher Education, https://doi.org/10.1007/978-981-15-1628-3_4 
it is no longer sufficient to fully engage adult learners in different learning situations on a lifelong and lifewide basis. In this chapter, drawing on survey data from a case university, we posit that it is equally important to view adult learning from the learning sciences point of view, so as to develop competent learners who are able to transcend across various contexts of work, learning, and society. We further contend that this broader view of adult learning, considering both the adult learner characteristics and the science of learning, is a more inclusive approach of education where a productive adult education can contribute toward the good of society.

We first begin by articulating our motivation to deepen our current understanding of adult learning. Next, we describe the common conceptions of the characteristics of adult learners and, by extension, their ways of learning and knowing. This is followed by the presentation of the survey results which suggested that the learning preference and the learning behavior of adult learners are not a simplistic reflection of their characteristics as adults; a critique we put forth in the discussion section. Finally, we conclude that the work from the learning sciences can enhance our pedagogical approach to adult learning, adding value from the evidences gleaned from learning research.

\section{Impetus to DeEpen Our Understanding of Adult LEARNING}

In recent years, given the increasing globalized and interconnected nature of societies, the work on lifelong learning has been studied in tandem with that of adult learning. Educating adults on a continuous and lifelong basis has been viewed as one important mechanism for sustaining a vibrant, healthy, and adaptable workforce. The import of recognizing adult learning and the contexts in which they navigate has increased over time, encapsulated in the UNESCO conceptualization of "Education for the 21 st Century" as learning to do, know, be, live together and change. ${ }^{2}$

Such a view is particularly appreciated in a small city-state such as Singapore with globalized economic ties. With human capital as one of her main resources, it is imperative that her workforce is not only knowing and adapting to changing economies, but doing so where health,

${ }^{2}$ Jacques Delors, Learning: The Treasure Within (Paris: UNESCO, 1996). 
well-being, and civic and social connectedness are well-considered. In response, the government-sponsored SkillsFuture program is a national movement "to provide citizens with opportunities to develop their fullest potential throughout life." ${ }^{3}$ Among many initiatives, there is an increasing emphasis for adult learners to return to formal education to deepen their skills for lateral or horizontal career movements for a global economy.

The impetus to deepen our understanding of adult learning stems from this background. The institutes of higher learning have been seeing more adult learners returning to school. While this is heartening, teaching conversely has become more complex. The range of prior experiences, knowledge, learning preferences, and behavior has become more diverse, and correspondingly, teachers would need to broaden their repertoire of skills in order to achieve learning goals. From literature, we had known that pedagogies such as experiential learning (learning by doing), self-directed learning, and andragogy are common approaches of engaging adults. ${ }^{4}$ These approaches are well-documented and have largely proven their efficacy. Moreover, these approaches resonate with characteristics of adult learners, which is a life-stage view of the learner profile.

\section{Defining the Adult Learner}

The transition from childhood to adulthood has been celebrated with rituals and milestones. These rituals and milestones that mark adulthood are different between societies and culture groups. Therefore, trying to come to a unifying understanding of what defines a person as an adult is not easy considering the disparity among the different societies and culture groups.

The same difficulty is faced by researchers and educators who try to set boundaries to demarcate adult learners entering institutions of higher learning from conventional fresh school leavers ("traditional age" students). While it is common to use the legal age to define adulthood, it is not as simple to use the same principle to define adult learners. Johnson, Taasoobshirazi, Clark, Howell, and Breen used an example to show why

\footnotetext{
3 “About SkillsFuture." SkillsFuture Singapore Agency. Accessed May 31, 2019, from https://www.skillsfuture.sg/AboutSkillsFuture.

${ }^{4}$ Sharan B. Merriam and Laura L. Bierema, Adult Learning: Linking Theory and Practice (San Francisco: Jossey-Bass, 2014).
} 
using age to define adult learners would be problematic. ${ }^{5}$ For example, a nineteen-year-old undergraduate could already be a parent, shouldering the responsibilities typical of an adult, while a twenty-four-year-old undergraduate may have never left school or has yet to shoulder any adult responsibilities simply because they have been studying all this time. If age were to be used to define adult learners, it would then exclude the nineteen-year-old even though their life reflects more adult responsibilities.

The age example is just one of several dilemmas involved in the attempt to define adult learners. While there is no formal consensus among educators and researchers about the definition of adult learners, it is generally agreed that adult learners have the following characteristics ${ }^{6}$ :

- Adult learners take on many roles in their lives. They may be a parent, a child, a partner, a spouse, an employee, or an employer all at the same time.

- Because of the multiple roles, by extension, adult learners have many responsibilities and commitments.

- Most adult learners enroll in part-time programs rather than fulltime programs.

However, it is interesting to observe a sort of reversal in trend in recent years. Conventional fresh school leavers in institutions of higher learning are taking on more responsibilities and commitments as many are either working part-time, volunteering, or undergoing internships while studying at the same time. ${ }^{7}$ Hence, these fresh school leavers may be juggling as many roles as adult learners, though some will argue that the responsibilities they face may not be as heavy as those faced by adult learners.

\footnotetext{
${ }^{5}$ Marcus Lee Johnson, Gita Taasoobshirazi, Lauren Clark, Leah Howell, and Mishele Breen, "Motivations of Traditional and Non-traditional College Students: From SelfDetermination and Attributions, to Expectancy and Values," The Journal of Continuing Higher Education 64 (2016): 3-15, https://doi.org/10.1080/07377363.2016.1132880.

${ }^{6}$ Ellen E. Fairchild, "Multiple Roles of Adult Learners," New Directions for Student Services 102 (2003): 11-16; Jovita M. Ross-Gordon, "Research on Adult Learners: Supporting the Needs of a Student Population that Is No Longer Non-traditional," Peer Review 13, no. 1 (2011): 26-29.

${ }^{7}$ Adam G. Panacci, "Adult Students in Higher Education: Classroom Experiences and Needs," College Quarterly 18, no. 3 (2015), accessed May 31, 2019, from https://files. eric.ed.gov/fulltext/EJ1087330.pdf.
} 
Nevertheless, it will be interesting and important to monitor this development to see whether there is a need to rethink if the notion of adult learners and its implications to pedagogy continue to hold in the years ahead.

\section{Educating Adult LeARners}

The education of adults is not a modern undertaking. Our ancient teachers had already undertaken this task-one could visualize the learning taking place with the educational exchanges Plato and Aristotle had with their adult students as they debated wide-ranging issues from ethics, education, philosophy to metaphysics. ${ }^{8}$ Today, the education of adults is a studied field, and andragogy is a forerunner in this field in terms of shaping how educators approach adult learning and teaching.

The word "Andragogy" is mostly associated with Malcolm Knowles' work even though Alexander Kapp, a German high school teacher, was the person known to have coined the term in $1833 . .^{9}$ Andragogy is the art and science of helping adults to learn. How a teacher approaches the teaching of adults is usually based on assumptions Knowles made about adult learners. The assumptions are ${ }^{10}$ :

1. Adult learners need to know the rationale of why they are learning something.

2. Unlike children whereby their self-concept is still developing, adult learners enter the classroom with a fully developed self-concept, which usually entails assuming full responsibilities for their own lives.

3. Adult learners are not blank slates and that they come with a wealth of experiences.

4. Adult learners' readiness to learn is often oriented to the roles and responsibilities they have.

${ }^{8}$ Selahattin Turan, "Plato's Concept of Education in 'Republic' and Aristotle's Concept of Education in 'Politics," Education and Science 36, no. 162 (2011): 31-38.

${ }^{9}$ John A. Henschke, "Considerations Regarding the Future of Andragogy," Adult Learning 22, no. 1 (2011): 34-37, https://doi.org/10.1177/104515951102200109.

${ }^{10}$ Malcolm S. Knowles, Elwood F. Holton III, and Richard A. Swanson, The Adult Learner: The Definitive Classic in Adult Education and Human Resource Development, 8 th ed (New York: Routledge, 2015). 
5. Adult learners are problem-centered and are motivated to learn when the learning is perceived to be helping them perform tasks and solve immediate problems.

6. Adult learners are intrinsically motivated to learn.

According to Knowles, drawing on the life-stage view in characterizing adult learners, adult learners are self-directing because of their developed sense of self, which is being responsible for their own lives and decisions. Hence, they know what they want to learn, which is shaped by their needs and experiences. Because learning needs are propelled by internal pressures, adult learners are intrinsically motivated. In short, Knowles' depiction of adult learners can be seen as those who have developed selfconcepts, are experience-rich, and are intrinsically motivated.

Knowles' andragogy is popular and influential because it provides applicable teaching principles for teachers of adult learners. ${ }^{11}$ For example, teachers should tap on adult learners' self-directedness in their pedagogical practices to enhance adult learners' experience. Spending some time to explain the underlying reasons for teaching certain concepts may activate the self-directing tendencies and spur them on to learn. Adult learners' rich experience should also be tapped to facilitate their learning through problem-based teaching approach, which is preferred by adult learners who need to see relevance in what they are learning. Essentially, Knowles' andragogy centers upon adult learners' characteristics and the teaching and learning processes are built on these characteristics.

\section{LEARNiNg BEHAVIORS OF AdULT LEARNERS IN INSTITUTIONS OF Higher LEARNING}

With more adult learners returning to school, the shift in student population means that some institutions of higher learning are becoming unconventional from the traditional model of university, whereby the student population comprises a mix of fresh school leavers and adult learners. The case university discussed in this chapter is one such example of an unconventional institution of higher learning in the Singapore educational landscape where there is a mix of adult learners and fresh school

${ }^{11}$ Tracy Carpenter-Aeby and Victor G. Aeby, "Application of Andragogy to Instruction in an MSW Practice Class," Journal of Instructional Psychology 40, no. 1-4 (2013): 3-13. 
leavers enrolled in the undergraduate programs. Classes for the part-time adult learners are usually arranged in the evenings or on weekends and a blended learning approach is also comprehensively incorporated into the curriculum design to imbue greater flexibility into the learning ecology to help adult learners manage their studies better along with their various commitments.

The work of Malcolm Knowles and other researchers of adult learners' characteristics present the notion that adult learners are unique from children, and even from fresh school leavers in conventional universities. Such characterization suggests that a different teaching approach is needed for adult learners with the rationale being that adult learners may be learning differently. ${ }^{12}$ As part of ongoing efforts to deepen understanding of adult learners, further propelled by the SkillsFuture movement where more adult learners are returning to formal learning, the case university spearheaded different initiatives to constantly evaluate the university's provision to ensure the adult learners are well supported. One such initiative is conducting a learning needs survey to collect information on the learning preferences and learning behaviors from the university's adult learners. We discussed the results from the learning needs survey in the following sections.

\section{Survey Process and Survey Content}

The learning preference and learning needs survey was based on a similar student learning needs survey developed by Khiat. ${ }^{13}$ Items in the current survey were updated where needed. An expert panel comprising faculty members and administrative executives also reviewed the items to ensure clarity and appropriateness of the survey.

The survey was hosted on an online survey platform. Students accessed the survey via a link sent together with the email invitation for survey participation. The entire survey was made up of 196 items and measured

12 Beverly Woodson Day, Stella Lovato, Candance Tull, and Jovita Ross-Gordon, "Faculty Perceptions of Adult Learners in College Classrooms," The Journal of Continuing Higher Education 59 (2011): 77-84, https://doi.org/10.1080/07377363.2011.568813

${ }^{13}$ Henry Khiat, "Academic Performance and the Practice of Self-Directed Learning: The Adult Student Perspective," Journal of Further and Higher Education 41, no. 1 (2017): 44-59, https://doi.org/10.1080/0309877x.2015.1062849. 
many different constructs such as expectation for a good instructor, experience of using technology for learning, perceived academic competency, and time management skills. Constructs related to perceived institutional support like availability of academic competency support, display of good teaching practices, display of good instructor qualities, and instructors' usage of technology for students' learning were also included in the survey.

Only results from items related to demographic information, learning preferences (i.e., self versus group study, learning styles, and learning modality), and learning behaviors (i.e., time of study, duration of self-study, duration of assignment preparation, and completeness of exam revision) will be reported here.

\section{Survey Respondents Information}

A total of 886 adult learners (male $=45.7 \%$ ) enrolled in the university's part-time programs responded to the survey invitation. The demographic information of the survey respondents is shown in Table 4.1.

With $78 \%$ of the respondents reporting to be holding a full-time job, the adult learners at the case university showed similar characteristics as adult learners described by most researchers-working full-time with multiple roles and responsibilities while studying part-time.

Table 4.1 Demographic information

\begin{tabular}{cccccc}
\hline \multicolumn{6}{c}{ Age (\%) } \\
\hline Below 25 & $25-30$ & $31-40$ & $41-50$ & $51-60$ & $61-70$ \\
\hline 25.4 & 40.6 & 19.1 & 10.2 & 3.7 & 1.2 \\
\hline \multicolumn{5}{c}{ Marital Status (\%) } \\
\hline Single & Married & Divorced & Separated & Widowed \\
\hline 70.5 & 27.2 & 1.7 & 0.1 \\
\hline Holds full-time job & Holds part-time job & Self-employed & Not working \\
\hline 78.0 & 7.3 & 3.7 & 10.9 \\
\hline
\end{tabular}




\section{Survey Results}

While exploratory factor analysis and confirmatory factor analysis were used to establish the properties of the survey and both descriptive and inferential statistics like ANOVA and correlation were used to analyze the survey responses, only frequencies of responses will be reported here for the understanding of the learning preferences and learning behaviors of the adult learners.

\section{Learning Preference \& Behavior}

The survey asked the adult learners to respond to questions with regard to their learning preferences and learning behaviors. When asked about a preference for studying by themselves or studying in a group (Survey Question: Which mode of learning do you most prefer? Self-study or group study), $78.7 \%$ of the adult learners preferred self-study compared to $21.3 \%$ who preferred to study in a group.

To find out about preferred learning style, the adult learners were asked to give a rating to eight different learning styles comprising of reading, listening, writing, observing, doing, talking, discussing, and asking (Survey Question: What is your preferred learning style? \{I being your most preferred to 8 being the least preferred $\}$ ). The adult learners rated reading, listening, and doing as their top three preferred learning styles. On the other hand, talking, asking, and discussing were their top three least preferred learning styles.

When asked to rate their preferred lesson delivery methods, $61.3 \%$ of adult learners rated face-to-face lessons as their most preferred lesson delivery method, while $30.2 \%$ and $8.5 \%$ rated blended learning and full online learning as their most preferred lesson delivery method, respectively (Survey Question: Rank the following types of lesson delivery according to your preference. \{Face-to-face sessions, Blended format, Online sessions\}) (see Fig. 4.1).

Besides preference, the adult learners were asked to report on their learning behaviors. Adult learners were asked about the time period when they were most likely to find time to study (Survey Question: At which of the following times do you most frequently self-study or do group study? \{Including preparing for tutor-marked assignment\} e.g., 12 midnight-2 a.m., 2.01 a.m. -4 a.m.). Responses collected showed that $65.2 \%$ of the adult learners found time to study between 8 p.m. and 12 a.m. while 
PREFERRED LESSON DELIVERY METHOD
Most Preferred $\quad$ Second Preferred $\quad$ Least Preferred

F2F SESSIONS

BLENDED

ONLINE SESSIONS
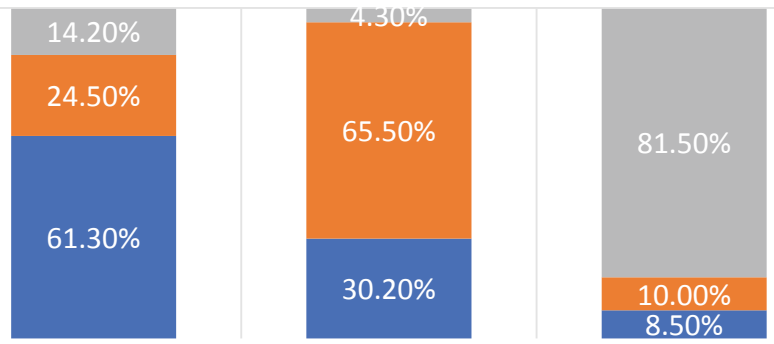

Fig. 4.1 Adult learners' rating of their preferred lesson delivery methods

$10.2 \%$ found time to study between $6 \mathrm{p} . \mathrm{m}$. and $8 \mathrm{p} . \mathrm{m}$. The rest of the adult learners reported studying between 12 a.m. and before 6 p.m. (less than $6 \%$ in any of the two-hour interval period between 12 a.m. and 6 p.m.) (see Fig. 4.2).

To find out how much time adult learners spent on self-revision, the following survey question was asked-Average number of hours spent in self-study per week (excluding preparing for tutor-marked assignment). Responses showed that $55.4 \%$ of adult learners reported spending up to five hours per week on self-study. The highest reported number of hours was 2-3 hours of self-study per week (28.2\%) (see Fig. 4.3).

\section{Assessment-Related Behavior}

To find out the average number of hours adult learners spent to complete an assignment (which may be an essay or a report), the following survey question was asked-How many hours do you take to finish a tutor-marked assignment? Responses collected showed that $59.7 \%$ of the adult learners reported spending 12 hours and more to complete an assignment. The highest reported number of hours was spending more than 21 hours to complete an assignment (30.1\%) (see Fig. 4.4).

As for exam preparation, adult learners were asked to report the average amount of examinable content they were able to complete revising for before the exam (Survey Question: On average, I complete of the 
Fig. 4.2 The time periods for when adult learners reported they most likely have time to Time of Study study

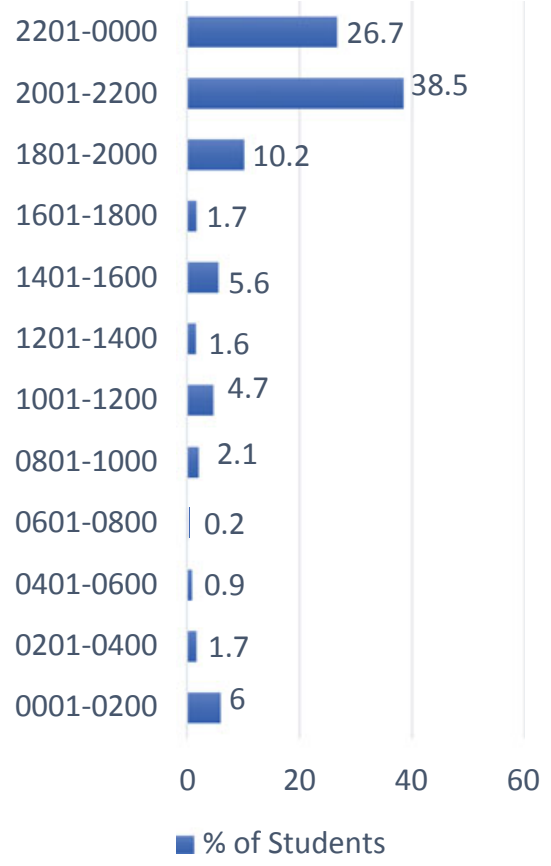

examinable content before taking the exam. \{0-25\%, 26-50\%, 51-75\%, 76$100 \%\}) .43 .8 \%$ of the adult learners reported being able to complete exam revision for $76-100 \%$ of examinable content. $46.2 \%$ reported being able to complete revision for $51-75 \%$ of examinable content. $7.8 \%$ reported being able to complete revision for $26-50 \%$ of the examinable content while $2.3 \%$ completed less than $25 \%$ of the examinable content before taking an exam.

To summarize the responses collected about the adult learners' learning preferences and learning behaviors, the adult learners seemed to prefer a more solitary form of learning where reading, listening, and doing are the preferred forms of activity. $61.3 \%$ preferred the face-to-face lesson format over blended $(30.2 \%)$ or online $(8.5 \%)$ lesson modes. $55.4 \%$ of adult learners reported spending up to five hours for self-studying, within which $28.2 \%$ reported spending $2-3$ hours. In terms of assessment-related 
Fig. 4.3 Average

number of hours (per week) spent by adult learners on self-studying (excluding time spent on assignment preparation)

\section{Average \# of Hours Spent on Self- \\ Study/Week}

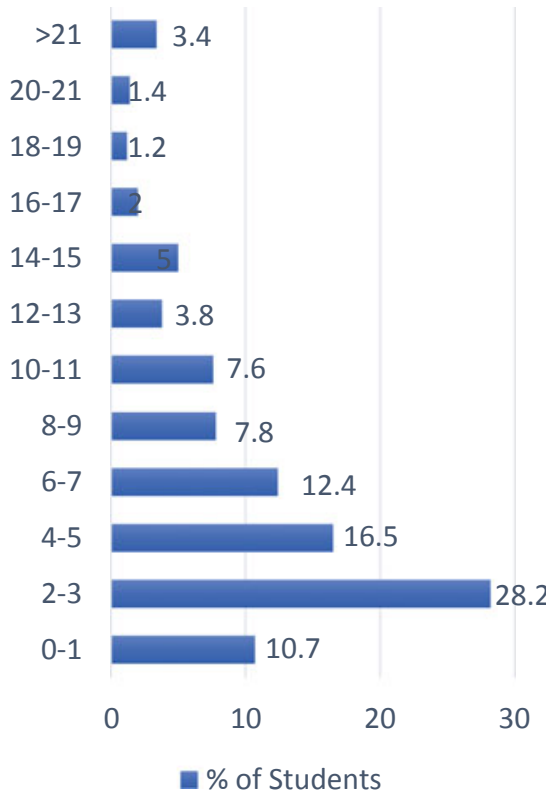

behavior, $43.8 \%$ reported completing at least $75 \%$ of exam revision, while $59.7 \%$ reported spending more than twelve hours completing their assignments.

\section{Discussion AND RECOMMENDATIONS}

Broadly, the learning behavior (e.g., 89.3\% of students reported studying at least 2 hours per week) and the assessment-related behavior (e.g., $59.7 \%$ reported spending at least 12 hours to complete an assignment) appear consistent with characteristics of adult learners as self-directed learners who would invest time and effort on learning. However, the survey results also raised the question if the amount of time and effort are adequate. For instance, one would wonder how do half of those surveyed who did not complete exam revision cope in the exams $(43.8 \%$ of 
Fig. 4.4 Average number of hours spent by adult learners to complete one assignment

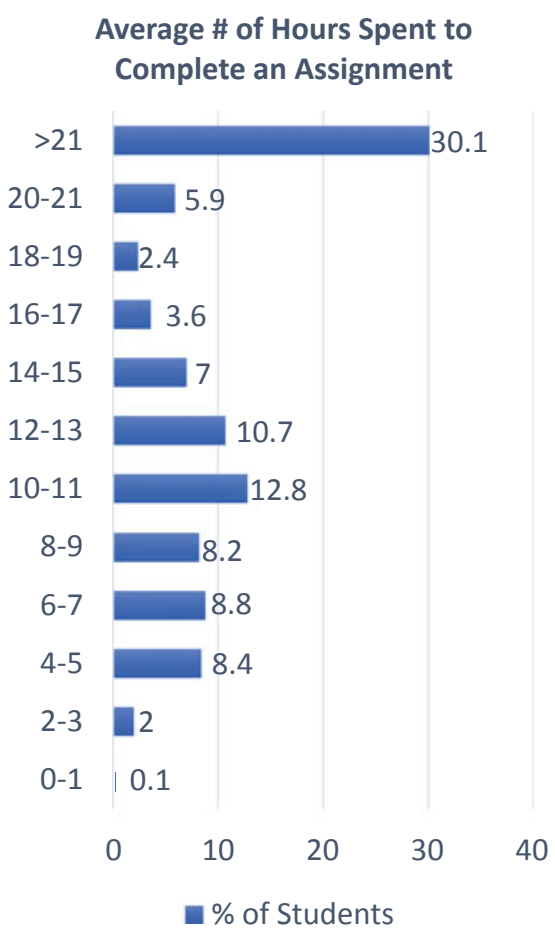

adult learners reported being able to complete at least $76 \%$ of exam revision)? Moreover, only $30.2 \%$ of adult learners preferred blended learning, a mode assumed to give adult learners the flexibility they need.

While the survey results will be clarified with a focus group which we will subsequently conduct, the current findings suggest that adult learners' learning preference and behavior are not a simplistic reflection of their life stage as adult learners. We contend that their learning preference and behavior indicate the complex multifaceted adult learners' behavior toward learning. The findings provided a basis to assess if current pedagogies of adult learning require a relook and if new practices are needed. After decades of research in the science of learning, the learning sciences field has developed evidence-based principles informing us how people learn. Combining our understanding of adult learners with strategies derived from the learning sciences could be the way forward for the field as we make good of the time and effort put in by adult learners. 
The following section discusses how we draw on the learning sciences to draw implications for adult learning pedagogies. First, the findings indicate adult learners do spend time on their studies (as evidenced by having just $10.7 \%$ of the surveyed adult learners report spending less than an hour per week on self-studying). Teachers of adult learners could capitalize on this and help students to optimize their studying efforts. One approach of active learning strategy is to have adult learners make overt their knowledge by organizing and representing them. Ambrose, Bridges, DiPietro, Lovett, and Norman explained that the organizations of knowledge could be different between novice and experts, where experts' organization of knowledge showed denser and more complex connections between constructs as compared to novices' knowledge organization. ${ }^{14}$ By encouraging adult learners to make overt their knowledge, they can then assess if there are any misconceptions in learning or lack of depth in learning. One such strategy of making knowledge overt is through visualization study techniques such as mind maps or concept maps. Teachers can further help adult learners by developing course material or resources that allow adult learners to make comparison between their represented knowledge and what they are supposed to achieve.

The strategy of making knowledge overt through organization and representation is also useful in view of adult learners' preferred learning style. The results of the survey showed that the most preferred learning style is reading. Coupled with a strong preference to self-studying $(78.7 \%)$, it suggests a somewhat passive and traditional learning style. Hence the encouragement for overt representation of knowledge by adult learners, together with good course resources for comparison, becomes more critical. It becomes an opportunity for adult learners to assess their learning progress.

When it comes to the mode of learning, most adult learners $(61.3 \%)$ preferred the face-to-face class format, rather than blended or online learning. Instead of didactic lectures, face-to-face sessions are to be well used for active learning. Knowles argued for teachers to utilize adult learners' prior knowledge as a teaching and learning resource to motivate and engage adult learners. However, Ambrose et al. cautioned that

${ }^{14}$ Susan A. Ambrose, Michael W. Bridges, Michele DiPietro, Marsha C. Lovett, and Marie K. Norman, How Learning Works: Seven Research-Based Principles for Smart Teaching (San Francisco: Jossey-Bass, 2010). 
students' prior knowledge can either help learning or hinder learning. ${ }^{15}$ To help learning, students' prior knowledge needs to be activated using good questioning technique. However, prior knowledge needs to be sufficient, appropriate, and accurate to have a positive impact on learning. Prior knowledge becomes a hindrance to learning if it is insufficient, inappropriate, or inaccurate. Ambrose et al. further gave the example of misconceptions as a type of inaccurate prior knowledge that is difficult to change and could have a forward acting impact on future learning, where new learning can be distorted or misinterpreted by misconceptions.

Therefore, in order to tap on adult learners' rich experience, the implication for teachers is to first activate this prior knowledge via posing good questions and good facilitation techniques to encourage discussion. This exercise is to help adult learners see the relevance and connection between new and prior knowledge. Teachers also need to assess the veracity and extent of prior knowledge the adult learners possess. This will shape how the prior knowledge is to be utilized for learning, and not assumed that the prior knowledge adult learners seemingly possess is enough to scaffold their new learning.

The learning style and lesson format preference displayed by adult learners of the case university suggested a preference for a more familiar way of teaching and learning, specifically ways that they have been taught, i.e., face-to-face lessons with the teacher and the learner passively receiving information via reading or listening. This could reflect the learner's past learning experiences' influencing their current learning experience. This also shows a desire for structure in learning, which seems to contradict with self-directedness and flexibility which would be more helpful in view of adult learners' busy lives. For example, online lessons will be more flexible for adult learners as it will reduce the need to come to campus for lessons and they can better manage their schedules. However, only $8.5 \%$ chose online learning as their preferred lesson mode. Knowles' andragogy views adult learners as self-directing but the propensity for selfdirectedness may not be uniform across adult learners.

To help adult learners see the affordances of blended and online learning, where there is greater flexibility and space to learn, teachers of adult

15 Ambrose et al., How Learning Works. 
learners could place greater emphasis on setting the appropriate course climate. Course climate refers to the intellectual, social, physical, and technological environments in which learners learn. Teachers could address the uncertainty around online and blended learning by making it safe. Safety can be introduced to the course climate via principles of respect and inclusion and by providing support. Teachers could scaffold adult learners through the process of learning online. Teachers can first introduce a starter list of e-resources that students have access to, and gradually withdraw the hand-holding and by making accessing digital content count in assessment and interaction. That way, adult learners will know and appreciate blended and online learning, and realise that learning is not always about having face-to-face lessons with the teachers.

One significant finding from the survey result is the amount of time adult learners spent on assignment preparation (i.e., 59.7\% spent at least 12 hours completing an assignment). This shows that adult learners are motivated to complete their assignments and teachers of adult learners can capitalize on this to further motivate adult learners. A takeaway for teachers, then, is to ensure that assignments are aligned with the learning outcomes. Not only will the adult learners be motivated to complete the assignments, but more importantly, they also achieve learning goals teachers set out for them as they work on the assignments. Using assessment to drive learning, coupled with targeted feedback, can be viewed as a goal-directed practice according to Ambrose et al. ${ }^{16}$

The notion of practice is to engage learners in the performance, and only in the observable in psychomotor, writing, or discourse are teachers able to provide targeted feedback. Feedback can take two forms-one to indicate progress and the other to indicate areas of improvement. It is common for teachers to focus on weakness when providing feedback. Such feedback is important as learners can then work on improving their performances. For example, the case university should encourage teachers to provide feedback to help adult learners in their weak areas especially if the course is a module with an end-of-course exam. This is because the survey results showed that adult learners put in much effort to revise for their exam (i.e., $43.8 \%$ completed at least $76 \%$ of exam revision). Therefore, the provision of targeted feedback that directs learners to the correct resource for improvement is an important practice. On the other hand,

${ }^{16}$ Ambrose et al., How Learning Works. 
feedback about progress is equally important and should not be excluded as it will serve as motivation for adult learners. It also reinforces confidence in adult learners in their abilities to learn. This is important, particularly for some adult learners who have been away from school for a very long time.

In addition, identifying the appropriate level of challenge in the assessment is important. Pitching has to be appropriate such that it is neither too daunting nor too easy. Besides, there could be opportunities for assessment to be accumulated such that performance can be built iteratively. From an assessment for learning point of view, assignments can be broken into smaller tasks, and iteratively build on one another. With good feedback, this is how learners gradually gain mastery.

On the whole, the education of adult learners can be made more effective by considering both the learner characteristics and the learning sciences. An understanding of the learning process and the incorporation of effective teaching and learning principles and strategies by teachers is equally important, in order to bring about the best learning experiences for adult learners.

\section{CONCLUSION}

In a way, the perception of adult learners may have been unfairly influenced by our perception of what being an adult means, which is being responsible for oneself and knowing what one wants and needs. Adult learners may know what they need to learn but it does not mean that they know how to go about learning it. The results from the survey suggested that the self-directed notions of adult learners may not be homogenous across the adult learner population. Therefore, it is important for teachers to consider both the learner characteristics and the learning process when designing pedagogies. As such, there is a need to continuously assess learning progress of adult learners through well-crafted assessment and to provide the correct level of scaffolding where needed. The same process of assessing students' learning needs and meeting them with pedagogically sound teaching practices should be similarly applied to adult learners as with learners of other ages. 


\section{BIBLIOGRAPHY}

Ambrose, Susan A., Michael W. Bridges, Michele DiPietro, Marsha C. Lovett, and Marie K. Norman. How Learning Works: Seven Research-Based Principles for Smart Teaching. San Francisco: Jossey-Bass, 2010.

Carpenter-Aeby, Tracy, and Victor G. Aeby. "Application of Andragogy to Instruction in an MSW Practice Class." Journal of Instructional Psychology 40, no. 1-4 (2013): 3-13.

Day, Beverly Woodson, Stella Lovato, Candance Tull, and Jovita Ross-Gordon. "Faculty Perceptions of Adult Learners in College Classrooms." The Journal of Continuing Higher Education 59 (2011): 77-84. https://doi.org/10.1080/ 07377363.2011 .568813 .

Delors, Jacques. Learning: The Treasure Within. Paris: UNESCO, 1996.

Fairchild, Ellen E. "Multiple Roles of Adult Learners." New Directions for Student Services 102 (2003): 11-16.

Henschke, John A. "Considerations Regarding the Future of Andragogy." Adult Learning 22, no. 1 (2011): 34-37. https://doi.org/10.1177/ 104515951102200109.

Johnson, Marcus Lee, Gita Taasoobshirazi, Lauren Clark, Leah Howell, and Mishele Breen. "Motivations of Traditional and Non-traditional College Students: From Self-Determination and Attributions, to Expectancy and Values." The Journal of Continuing Higher Education 64 (2016): 3-15. https://doi. org/10.1080/07377363.2016.1132880.

Kasworm, Carol E., Amy D. Rose, and Jovita M. Ross-Gordon, eds. Handbook of Adult and Continuing Education. New York: Sage, 2010.

Khiat, Henry. "Academic Performance and the Practice of Self-Directed Learning: The Adult Student Perspective." Journal of Further and Higher Education 41, no. l (2017): 44-59. https://doi.org/10.1080/0309877x.2015. 1062849.

Knowles, Malcolm S., Elwood F. Holton III, and Richard A. Swanson. The Adult Learner: The Definitive Classic in Adult Education and Human Resource Development. 8th ed. New York: Routledge, 2015.

Merriam, Sharan B., and Laura L. Bierema. Adult Learning: Linking Theory and Practice. San Francisco: Jossey-Bass, 2014.

Panacci, Adam G. "Adult Students in Higher Education: Classroom Experiences and Needs." College Quarterly 18, no. 3 (2015). Accessed May 31, 2019, from https://files.eric.ed.gov/fulltext/EJ1087330.pdf.

Ross-Gordon, Jovita M. "Research on Adult Learners: Supporting the Needs of a Student Population That Is No Longer Non-traditional." Peer Review 13, no. 1 (2011): 26-29.

SkillsFuture Singapore Agency. "About SkillsFuture." Accessed May 31, 2019, from https://www.skillsfuture.sg/AboutSkillsFuture.

Turan, Selahattin. "Plato's Concept of Education in 'Republic' and Aristotle's Concept of Education in 'Politics." Education and Science 36, no. 162 (2011): 31-38. 
Open Access This chapter is licensed under the terms of the Creative Commons Attribution 4.0 International License (http://creativecommons.org/licenses/ by $/ 4.0 /$ ), which permits use, sharing, adaptation, distribution and reproduction in any medium or format, as long as you give appropriate credit to the original author(s) and the source, provide a link to the Creative Commons license and indicate if changes were made.

The images or other third party material in this chapter are included in the chapter's Creative Commons license, unless indicated otherwise in a credit line to the material. If material is not included in the chapter's Creative Commons license and your intended use is not permitted by statutory regulation or exceeds the permitted use, you will need to obtain permission directly from the copyright holder.

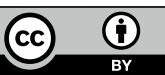




\title{
Culture and Learning: Confucian Heritage Learners, Social-Oriented Achievement, and Innovative Pedagogies
}

\author{
Shelen Ho
}

\section{INTRODUCTION}

An important topic of education today is "How do we prepare students for the Fourth industrial revolution (4IR)?" The 4IR is expected to generate exponential change and disruptions to industries around the world. The digital revolution is characterized by a fusion of technology and is fundamentally different from the past three revolutions in terms of velocity and scope. It is impacting every aspect of how people work and how people live, creating significant threats and opportunities. Knowledge and skills that we learned through formal education in the past are now becoming irrelevant. Employees are urged to be prepared to completely re-skill to succeed and thrive. Many believe that the answer to the challenges the world faces in this evolution is education.

Education authorities in many Asian nations have unveiled ambitious plans to revamp their education systems to embrace the 4IR. The message

S. Ho $(\bowtie)$

University of Reading, Reading, UK

(C) The Author(s) 2020

C. S. Sanger and N. W. Gleason (eds.),

Diversity and Inclusion in Global Higher Education, https://doi.org/10.1007/978-981-15-1628-3_5 
is clear that the education sector needs to adapt to change and rethink the way it delivers knowledge to remain relevant in the new industrial era. To address the challenges of the 4IR, there have been several education policy proposals. These initiatives have all encouraged teaching and learning for creativity, innovation and higher order thinking (HOT) skills ${ }^{1}$ rather than the traditional conceptual knowledge, procedural knowledge and remote memorization. Teachers are motivated to move toward studentcentered learning and constructivist learning in order to develop students as independent learners. Peer-oriented collaborative learning approaches to inculcate emotional and cultural intelligences are also desired key pedagogic strategies.

While acknowledging the pressing need to prepare the young generation with the skillsets for the 4IR, previous studies have raised appropriateness concerns about the practicality of applying these education theories across cultures. This is especially so for communities where students have been regarded as passive recipients of data. As Neuman and Bekerman argue, it would be difficult for the teacher to teach using a constructivist approach in such passive learning cultures. "Innovations which are intended to facilitate learning may be so disturbing for those affected by them - so threatening to their belief systems - that hostility is aroused and learning becomes impossible." 3

The purpose of this chapter is to highlight the gaps in education reform and use the broad lens of culture to illuminate how ethnocentrism influences the perceived possibilities and willingness to adopt educational innovations in the 4IR. The chapter begins with an overview of the 4IR and associated recent education reform efforts. The discussion then focuses on the key considerations of HOT skills and sociocultural intelligence to meet the challenges of the new industrial revolutionary age. The support for integrating HOT skills in the curriculum is provided in a case of strategic management modules. The chapter also discusses the need to consider cultural resources when applying education theories in

\footnotetext{
${ }^{1}$ Benjamin Bloom, ed., Taxonomy of Educational Objectives, Handbook I: Cognitive Domain (New York: David McKay, 1956).

${ }^{2}$ Yair Neuman and Zvi Bekerman, "Cultural Resources and the Gap Between Educational Theory and Practice," Teachers College Record 103, no. 3 (2000): 471-484.

${ }^{3}$ Hywel Coleman, ed., "Autonomy and Ideology in the English Language Classroom," in Society and the Language Classroom (Cambridge: Cambridge University Press, 1996), 11 .
} 
classrooms. In particular, the chapter discusses the application of popular pedagogic practices such as flipped instructional model and team-based learning (TBL), and how they can be used with students from Confucian Heritage Cultures (CHC). The case provided how traditional cultural values can contribute to pedagogic goal achievements and positively impact the intended learning outcomes, contrary to many previous studies on CHC learners.

\section{The Fourth Industrial Revolution and Education REFORM EFFORTS}

Klaus Schwab wrote in The Fourth Industrial Revolution, that we are standing on the brink of a technological revolution that will fundamentally alter the way we live, work, and relate to one another. The founder and Executive Chairman of the World Economic Forum described an era that will be characterized by a fusion of technologies that is blurring the lines between the physical, digital, and biological spheres. He called for governments and citizens to make sure these cutting-edge technologies are used to benefit humankind, as a complement to human creativity, empathy, and stewardship, to lift humanity into a new collective and moral consciousness based on a shared sense of destiny. ${ }^{4}$

It is increasingly clear that the rapid development of technology has changed everyone's economic, social, and cultural status quo. ${ }^{5}$ Schwab argues that this revolution is different in scale, scope, and complexity from any that have come before. ${ }^{6}$ Characterized by a range of new technologies that are fusing the physical, digital, and biological worlds, the developments are affecting all disciplines, economies, industries, and governments, and even challenging ideas about what it means to be human. The Organization for Economic Cooperation and Development's latest Employment outlook suggests that in the next fifteen to twenty years, $14 \%$ of existing jobs are at high risk of being fully automated, while

\footnotetext{
${ }^{4}$ Klaus Schwab, The Fourth Industrial Revolution (Geneva: World Economic Forum, 2016).

${ }^{5}$ Roger Chao Jr., "Educating for the Fourth Industrial Revolution," November 10, 2017, https://www.universityworldnews.com/post.php?story=20171107123728676.

${ }^{6}$ Schwab, The Fourth Industrial Revolution.
} 
another $32 \%$ are at risk of radical change. ${ }^{7}$ In another recent report on the future of jobs by the World Economic Forum, an estimated 75 million jobs may be displaced by a shift in the division of labor between humans and machines, while 133 million new roles may emerge globally by 2022.8

The blurring of technology into every part of our lives is becoming the norm. How do we educate for the 4IR? How do we prepare the next generation to be able to navigate this new world? Are our education systems and programs relevant to the 4IR? And if not, how do we reconstruct our education systems so that they are? ${ }^{9}$

In the last decade, STEM education has received tremendous attention in education reform efforts and in popular media. STEM is a curriculum based on the idea of educating students in four specific disciplines-science, technology, engineering, and mathematics - in an interdisciplinary and transdisciplinary way and often including a project or problem-based approach tied to authentic or real-world contexts. ${ }^{10}$ Much has been proclaimed about the need for more STEM programs in schools. The logic is simple: The wave of future economic prosperity lies in a workforce that is well-versed in rising job markets like science, technology, engineering, and math. Thus, there has been an increased investment in STEM initiatives in schools worldwide.

Yet there is a case to be made that our society's growing focus on STEM - while both laudable and necessary-has spawned an either/or mentality that undervalues the very subjects that might help us become the best stewards of technology. While STEM initiatives are a wonderful start into the exploration of the four areas of study, the critical process of creativity and innovation is missing. Students in STEM programs may

7 "The Future of Work Is Now. Are We Ready?," Organisation for Economic Co-operation and Development, accessed June 20, 2019, http://www.oecd.org/ employment/outlook/.

${ }^{8}$ World Economic Forum, The Future of Jobs Report 2018 (Geneva: World Economic Forum, 2018).

${ }^{9}$ Chao, "Educating for the Fourth Industrial Revolution."

${ }^{10}$ Melanie LaForce, Elizabeth Noble, Heather King, S. Holt, and Jeanne Century, The 8 Elements of Inclusive STEM High Schools (Chicago: University of Chicago, 2014); Erin E. Peters-Burton, Sharon Lynch, Tara Behrend, and Barbara Means, "Inclusive STEM High School Design: 10 Critical Components." Theory into Practice 53, no. 1 (2014): 64-71. 
have more experiential learning opportunities, but they are often limited to only science, technology, engineering, and math. Our economy requires much more than an understanding of these areas; it requires creation and ingenuity. In fact, inherent in problem- and project-based learning are opportunities for student growth in the twenty-first-century skills such as collaboration, critical thinking, creativity, accountability, persistence, and leadership. ${ }^{11}$ STEM alone does not foster these essential ingredients.

Recent years have seen intensive interest in the concept of STEAM. ${ }^{12}$ STEAM is a way to take the benefits of STEM and complete the package by integrating STEM principles in and through arts. In this sense, STEAM takes STEM to the next level ${ }^{13}$ : It allows students to connect their learning in the critical areas of science, technology, engineering, and math together with arts practices, elements, design principles, and standards to bring the whole pallet of learning to their disposal. STEAM is expected to remove limitations and replace them with wonder, critique, inquiry, and innovation. However, along with curricular innovations we need pedagogical approaches that teach students twenty-firstcentury thinking skills. What is needed is a broader and more inclusive view of STEAM that spans disciplines, with entry points across contexts, to equally engage both analytical and HOT skills in the curriculum.

As with any educational intervention, the fundamental questions to ask in this case are: Can we teach HOT skills? How do we teach HOT skills?

\section{Teaching Thinking Skills and Social Contextual INFLUENCES}

The idea that thinking can be taught is ancient. Beginning with the efforts of Plato and the introduction of Socratic dialog, we see attention to improving intelligence and promoting effective thinking as a recurring educational trend throughout the ages. Early in the twentieth century,

11 "What Is Project-Based Learning (PBL)?," Buck Institute, http://www.bie.org/ about/what_pbl; "Framework for Twenty-First Century Learning," BattelleforKids, http://www.p21.org/our-work/p21-framework.

${ }^{12}$ Anne Jolly, "STEM vs. STEAM: Do the Arts Belong?," November 18, 2014, http:// www.edweek.org/tm/articles/2014/11/18/ctq-jolly-stem-vs-steam.html.

${ }^{13}$ Susan Riley, STEAM in the Classroom Look-For List," February 1, 2018, https:// educationcloset.com/2018/02/01/steam-in-the-classroom/. 
Dewey again focused North American's attention to the importance of thinking as an educational aim. ${ }^{14}$ At the same time, Selz was advocating the idea of learnable intelligence in Europe. ${ }^{15}$ In the 1970s and 1980s, specific programs designed to teach thinking took shape, many of which continue in schools today. More recent studies also supported the importance of developing thinking skills in learning. ${ }^{16}$ Even in the early 1990s, Gauge posited "Many educators believe that specific knowledge will not be as important to tomorrow's workers and citizens as the ability to learn and make sense of new information." 17 Efforts to teach thinking have continued to proliferate in the new millennium, often becoming less programmatic in nature and more integrated within the fabric of schools.

Jarvis advocates that the role of a teacher is to facilitate learning situations so students can find things out for themselves. ${ }^{18}$ A popular quote by Peter Senge "Knowledge is constructed, not transferred" provides a vision of the modern education system. The belief is that students are not blank slates upon which knowledge is etched. They come to learning situations with already formulated knowledge, ideas, and understandings. This previous knowledge is the raw material for the new knowledge they will create. Through an active learning process, students can construct their understanding and consequently develop HOT skills. This aligns with the constructivism learning theory which has its historical roots in the work of Dewey, Bruner, Vygostsky, and Piaget. ${ }^{19}$

${ }^{14}$ John Dewey, How We Think: A Restatement of the Relation of Reflective Thinking to the Educative Process (Boston: D. C. Heath and Company, 1933).

15 O. SElz, "Attempt to Raise the Level of Intelligence," Zeitschrift fur Psychologie 134 (1935): 236-301.

${ }^{16}$ C. Norris and J. L. Poirot, Problem Solving and Critical Thinking for Computer Science Educators (Eugene: International Society for Technology in Education, 1990); Tom Morgan, "Using Technology to Enhance Learning: Changing the Chunks," Learning and Leading with Technology 23, no. 5 (1996): 49-51; Lynn A. Fortana, C. Dede, C. S. White, and W. M. Cates, Multimedia: A Gateway to Higher-Order Thinking Skills (Fairfax: George Mason University, 1993).

${ }^{17}$ As quoted in Christopher Fischer, Linda Bol, and Shana Pribesh, "An Investigation of Higher-Order Thinking Skills in Smaller Learning Community Social Studies Classrooms," American Secondary Education 39, no. 2 (2011): 5.

${ }^{18}$ Peter Jarvis, The Theory and Practice of Teaching, 2nd ed. (New York: Routledge, 2006).

${ }^{19}$ John Dewey, The Quest for Certainty (New York: Minton, 1929); Jerome S. Bruner, "The Act of Discovery," Harvard Educational Review 31, no. 1 (1961): 21-32; Lev 
A report by the World Economic Forum encourages educators to create spaces that enable people to think freely, to think divergent and creative thoughts. ${ }^{20}$ It further emphasizes that in a society where people fear having those thoughts, the likelihood of being able to enjoy progress is significantly diminished. This brings to the surface that thinking skills should be studied in a relevant social context to have an in-depth understanding of the rich picture surrounding the society's learning culture. Cross-cultural research that has examined thinking skills has found a few distinct patterns. In a study examining creativity and reasoning with college students in Hong Kong and the United States, Niu, Zhang, and Yang found that American students scored significantly higher than the Hong Kong Chinese students on a measure of creative production (writing titles for jokes). ${ }^{21}$ This difference is attributed to cultural factors that influence how individuals think and solve problems. Although no explanation for this difference was provided, Nisbett et al. argued that cultural differences represent unique systems of thought and cognition. ${ }^{22}$ Their study argues that differences in Ancient Chinese and Greek philosophies continue to exert influence today, leading East Asians to be more likely to pay attention to the "big picture," whereas Americans are more often focused on the details. This largely mirrors widely accepted sociocultural conceptions of individualism and collectivism as a social structure, ${ }^{23}$ but points to inherent differences in cognitive style and approach largely tied to the impact of culture on ways of thinking.

Vygotsky, Thought and Language (Cambridge: MIT Press, 1962); Jean Piaget, "The Psychogenesis of Knowledge and Its Epistemological Significance," in Language and Learning, edited by Massimo Piatelli-Palmarini (Cambridge: Harvard University Press, 1980), 23-34.

${ }^{20}$ World Economic Forum, "What Is the Fourth Industrial Revolution?," CN Crypto News, April 27, 2019, https://www.cncryptonews.com/what-is-the-fourth-industrialrevolution/.

${ }^{21}$ Niu Weihua, John Zhang, and Yang Yingrui, "Does Culture Always Matter: For Creativity, Yes, for Deductive Reasoning, No!," in Creativity and Reason in Cognitive Development, edited by James C. Kaufman and John Baer (New York: Cambridge University Press, 2006), 282-296.

${ }^{22}$ Richard E. Nisbett, Peng Kaiping, Incheol Choi, and Ara Norenzayan, "Culture and Systems of Thought: Holistic Versus Analytic Cognition," Psychological Review 108, no. 2 (2001): 291-310.

${ }^{23}$ S. Lau, "Collectivism's Individualism: Value Preference, Personal Control, and the Desire for Freedom Among Chinese in Mainland China, Hong Kong, and Singapore," Personality and Individual Differences 13, no. 3 (1992): 361-366. 
Thus far, the discussions have revealed two key considerations for innovations in education pedagogic strategies for the 4IR. First, the need for educators to integrate appropriate HOT skills in the curriculum. Second, the importance of social context considerations when delivering and cocreating knowledge with students. So, where do we proceed from here? At this point, the author wishes to share her own pedagogic practices in her classrooms in Malaysia where she taught strategic management modules to illustrate these two key considerations.

\section{A Case of Innovations in Pedagogic Strategies For Strategic Management Education}

In recent years, the issue of the employability skills of Malaysian university graduates has been the attention of academia, policymakers, employers, and community members. ${ }^{24}$ Literature shows that the issue of unemployment among Malaysian university graduates was associated with graduates' low employability skills. ${ }^{25}$ Various studies have associated the low employability rate of the Malaysian university graduates to the mismatch between what was taught at the universities and the skills needed for the twenty-first century. ${ }^{26}$

Intuitive thinking, critical analysis, and ability to work effectively in teams are the key attributes sought after by employers in today's competitive labor market when tasks are complex and decisions are nonprogrammable, requiring multilevel analysis and team inputs. Previous

\footnotetext{
${ }^{24}$ Ministry of Higher Education Malaysia, The National Graduate Employability Blueprint 2012-2017 (Serdang: Universiti Putra Malaysia Press, 2012).

${ }^{25}$ Idrus Hairuszila, M. H. Hazadiah, and Normah Abdullah, "Challenges in the Integration of Soft Skills in Teaching Technical Courses: Lecturer's Perspectives," Asian Journal of University Education 5, no. 2 (2009): 67-81; Morshidi Sirat, Chan Lean Heng, Munir Shuib, Shukran Abdul Rahman, Seri R. A. Kamil, and Jasvir K. N. Singh, "Employability of Graduates in Malaysia," in Employability of Graduates in Malaysia Graduate Employability in Asia, ed. UNESCO (Bangkok: UNESCO, 2012), 24-37.

${ }^{26}$ Sirat, Chan, Munir, Shukran, Seri, and Singh, "Employability of Graduates in Malaysia"; Norizan Abdul Razak, Hazita Azman, Mohd Salehuddin Abdul Aziz, Azizah Yaacob, and Wong Fook Fei, Kajian Pembentukan Ujian Kompetensi Bahasa Inggeris bagi Pelajar IPTA di Malaysia (A Study of Developing an English Language Competency Test for Malaysian IPTA Students) (Kuala Lumpur, Malaysia: Intensification of Research in Priority Areas [IRPA], 2007).
} 
studies have also found that HOT skills are one of the key competencies to be integrated into the new curriculum for the twenty-first century. ${ }^{27}$

\section{The Need for Intuitive Thinking Skills}

Spender has long advocated that the "strategic management education" industry is suffering from isomorphism and dominated by a strong industry recipe, having few differing perspectives, a step-by-step structure, and domestic orientation. ${ }^{28}$ De Wit and Meyer explained the urgent need to change the features of current strategic management teaching contents to multiple strategy perspectives, issue-based structures, and international orientation, to be relevant to the turbulent business world today. ${ }^{29}$

Not only is there a need to innovate industry-relevant curriculum content, delivering it to the students through an appropriate learning and teaching process is equally important to ensure students' achievement of intended learning objectives. Cicero (106-43 B.C.), a Roman orator and statesman once said, "Not only is there an art in knowing a thing, but also a certain art in teaching it." ${ }^{30}$ Strategic decision-making is central to organizational actions and long-term competitiveness. ${ }^{31}$ In management literature, strategic decision-making is regarded as a prevalently rational process: analytical, linear, and step-by-step. ${ }^{32}$ However, optimal strategic decision-making requires both rationality and intuition. ${ }^{33}$ David

${ }^{27}$ Sirat, Chan, Munir, Shukran, Seri, and Singh, "Employability of Graduates in Malaysia"; Norizan, Azman, Salehuddin, Azizah, and Wong, Kajian Pembentukan Ujian Kompetensi Bahasa Inggeris bagi Pelajar IPTA di Malaysia.

${ }^{28}$ J. C. Spender, Industry Recipe: An Enquiry into the Nature and Sources of Managerial Judgment (New York: Basil Blackwell, 1989).

${ }^{29}$ Bob de Wit and Ron Meyer, Strategy Synthesis: Managing Strategy Paradoxes to Create Competitive Advantage, 4th ed. (London: Cengage Learning EMEA, 2014).

${ }^{30}$ Cicero, The Treatises of M.T. Cicero, translated by C. D. Tonge (London: Bell and Dandy, 1870), 450.

${ }^{31}$ Giovanni Gavetti, Daniel Levinthal, and Willian Ocasio, "Neo-Carnegie: The Carnegie School's Past, Present, and Reconstructing for the Future," Organization Science 18, no. (2007): 523-536.

${ }^{32}$ Laure Cabantous and Jean-Pascal Gond, "Rational Decision Making as Performative Praxis: Explaining Rationality's Éternal Retour,” Organization Science 22, no. 3 (2011): 573-586.

${ }^{33}$ Said Elbanna, "Strategic Decision Making: Process Perspectives," International Journal of Management Reviews 8, no. 1 (2006): 1-20; Said Elbanna and J. Child, "Influences 
explained that although the strategic-management process is an objective, systematic approach for making major decisions in an organization, strategic management is not a pure science that lends itself to a neat, 1-2-3 approach. ${ }^{34} \mathrm{He}$ said intuition is essential and particularly useful for making decisions in situations of great uncertainty or little precedent. Intuition is commonly conceptualized as a decision-making mechanism that relies on rapid, nonconscious recognition of patterns and associations to derive affectively charged judgments. ${ }^{35}$ From years of industry experience in organization restructuring and strategic development, the author supports the literature's findings that intuition is essential to making effective strategic decisions. Albert Einstein acknowledged the importance of intuition when he said, "Imagination is more important than knowledge, because knowledge is limited, whereas imagination embraces the entire world." 36

If intuition is nonconscious thinking, how do we teach intuition? What would strategy education look like if educational orthodoxy was challenged and the teaching process was reinvented to integrate this HOT skill in curriculum delivery?

\section{Pedagogic Strategies: Team-Based Learning with Flipped Instructional Model}

As established earlier, strategic management topics are not pure science. Many strategic and marketing decisions are made in situations of great uncertainty. It requires intuition and ability to draw meaningful conclusions from critical analysis of data in a diverse team environment. Hence, in the author's design and planning of the modules, she focuses principally

on Strategic Decision Effectiveness: Development and Test of an Integrative Model," Strategic Management Journal 28 (2007): 431-453; Ann Langley, Henry Mintzberg, Patricia Pitcher, Elizabeth Posada, and Jan Saint-Macary, "Opening Up decision Making: The View from the Black Stool," Organization Science 6, no. 3 (1995): 260-279.

${ }^{34}$ Fred R. David, Strategic Management: Concepts and Cases, 15th ed. (London: Pearson, 2015).

${ }^{35}$ Erik Dane and Michael G. Pratt, "Exploring Intuition and Its Role in Managerial Decision Making," Academy of Management Journal 32, no. 1 (2007): 33-54.

${ }^{36}$ As quoted in Eugene Raudsepp, "Can You Trust Your Hunches?," Management Review 49, no. 4 (1960): 7. 
on developing HOT and effective team skills in students, so they are prepared for this reality at the workplace. A key pedagogical theory guiding the design is constructive alignment of the intended learning outcomes of developing these crucial capabilities for employability, with teaching strategies and assessment methods. ${ }^{37}$

The author finds the flipped instructional model ${ }^{38}$ and $\mathrm{TBL}^{39}$ a good fit to deliver the intended learning outcomes. Flipped learning requires a radical redefinition of the role of the teacher, the student, and the best use of time between them. It is a pedagogical approach in which direct instruction moves from the group learning space in class to the individual learning space outside class (Fig. 5.1).

The resulting group learning space is then transformed into a dynamic, interactive learning environment. In class, the teacher guides students as they apply concepts and engage creatively in the subject matter, to solve authentic, real-world problems and make collaborative decisions. ${ }^{40}$ Students construct their own understanding and knowledge of the world, through purposefully designed experiential class activities and then reflecting on those experiences. ${ }^{41}$ In constructivist teaching, the teacher plays the role of a facilitator and students as cocreators of knowledge in class.

${ }^{37}$ John Biggs and C. Tang. Teaching for Quality Learning at University, 4th ed. (Maidenhead: Open University Press, 2011).

38 Jon Bergmann and Aaron Sams, "Flipped Learning: Maximizing Face Time," $T+D$ 68, no. 2 (2014): 28-31; Kathleen Fulton, "Upside Down and Inside Out: Flip Your Classroom to Improve Student Learning," Learning and Leading with Technology 39, no. 8 (2012): 12-17; Amy Roehl, Shweta L. Reddy, and Gayla J. Shannon, "The Flipped Classroom: An Opportunity to Engage Millennial Students Through Active Learning Strategies," Journal of Family and Consumer Science 105, no. 2 (2013): 44-49.

${ }^{39}$ Dean Parmelee, Larry Michaelsen, Sandy Cook, and Patricia Hudes, "Team-Based Learning: A Practical Guide: AMEE Guide No. 65," Medical Teacher 34, no. 5 (2012): 275-287; Michael Mcinerney and L. Dee Fink, "Team-Based Learning Enhances LongTerm Retention and Critical Thinking in an Undergraduate Microbial Physiology Course," Journal of Microbiology and Biology Education 4 (2003): 3-12; Nadia Rania, Laura Migliorini, and Stefania Rebora, "Team-Based Learning and Life Skills: A Qualitative Study from Psychological Students' Point of View," Health Science Journal 10, no. 1/2 (2015): 1-7.

${ }^{40}$ Bergmann and Sams, "Flipped Learning: Maximizing Face Time."

${ }^{41}$ Carl Bereiter, "Constructivism, Socioculturalism, and Popper's World 3," Educational Researcher 23, no. 7 (1994): 21-23. 


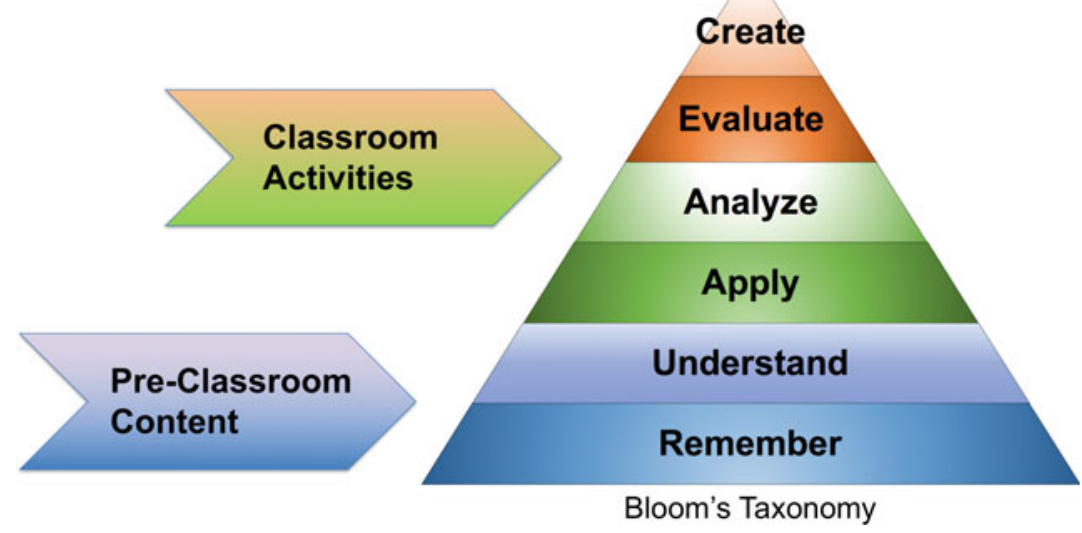

Fig. 5.1 Flipped learning

The teacher and students together, explore and address the students' preexisting conceptions and then build on them. ${ }^{42}$

To put a structure to her flipped classrooms, the author adopted the TBL instructional strategy. Team learning can offer significant benefits compared to learning individually. Many philosophies, such as Lean Six Sigma, are based around team problem solving, and some of the world's biggest corporations have adopted them. TBL is a form of collaborative learning using a special sequence of individual work, group work, and immediate feedback to create a motivational framework in which students increasingly hold each other accountable for coming to class prepared and contributing to discussion. ${ }^{43}$ The primary learning objective in TBL is to

${ }^{42}$ K. M. Oliver, "Methods for Developing Constructivism Learning on the Web," Educational Technology 40, no. 6 (2000): 5-16.

${ }^{43}$ Larry K. Michaelsen, Arletta Knight, and L. Dee Fink, Team-Based Learning: A Transformative Use of Small Groups in College Thinking (Sterling: Stylus Publishing, 2004); Larry K. Michaelsen and Michael Sweet, "The Essential Elements of Team-Based Learning," New Directions for Teaching and Learning 116, no. (2008): 7-27. 
go beyond simply covering content and focus on ensuring that students have the opportunity to practice using course concepts to solve problems while developing reasoning and HOT skills. It is designed to provide students with both conceptual and procedural knowledge. ${ }^{44}$ The methodology of TBL makes it an exemplary structure for a flipped classroom. ${ }^{45}$

Many previous studies have concluded that flipped classroom produces a wide variety of benefits for students, educational administrators, and faculty members who are engaged in the active learning process. ${ }^{46}$

${ }^{44}$ Michael Sweet and Larry Michaelsen, Team-Based Learning in the Social Sciences and Humanities: Group Work That Works to Generate Critical Thinking and Engagement (Sterling: Stylus Publishing, 2012).

45 Jennifer Moffett, “Twelve Tips for 'Flipping' the Classroom," Medical Teacher 37, no. 4 (2014): 331-336.

${ }^{46}$ Michaelsen and Sweet, "The Essential Elements of Team-Based Learning"; Shannon Flumerfelt and Greg Green, "Using Lean in the Flipped Classroom for at Risk Students," Educational Technology and Society 16, no. I (2013): 356-366; Fulton, "Upside Down and Inside Out"; Jacqueline McLaughlin, Mary Roth, Dylan Glatt, Nastaran Gharkholonarehe, Christopher Davidson, LaToya Griffin, Denise Esserman, and Russell Mumper, "The Flipped Classroom: A Course Redesign to Foster Learning and Engagement in a Health Professions School," Academic Medicine 89, no. 2 (2014): 236-243; Richard Pierce and Jeremy Fox, "Instructional Design and Assessment: Vodcasts and Active Learning Exercises in a 'Flipped Classroom' Model of a Renal Pharmacotherapy Module," American Journal of Pharmacentical Education 76, no. 10 (2012): 1-5; Cheryl Talley and Stephen Scherer, "The Enhanced Flipped Classroom: Increasing Academic Performance with Student-Recorded Lectures and Practice Testing in a 'Flipped' STEM Course," The Journal of Negro Education 82, no. 3 (2013): 339-347; Stephanie G. Wilson "The Flipped Class: A Method to Address the Challenges of an Undergraduate Statistics Course," Teaching of Psychology 40, no. 3 (2013): 193-199; Jeremy Strayer, "How Learning in an Inverted Classroom Influences Cooperation, Innovation, and Task Orientation," Learning Environments Research 15, no. 2 (2012): 171-193. 
TBL has also been widely applied across disciplines, including criminal justice, ${ }^{47}$ psychology ${ }^{48}$ sociology, ${ }^{49}$ literature and English, ${ }^{50}$ business, ${ }^{51}$ biology, ${ }^{52}$ nursing, ${ }^{53}$ and other medical fields. ${ }^{54}$ Additionally, TBL has been used not only in higher education, but also in middle and high schools. ${ }^{55}$

${ }^{47}$ Jane Tucker and Mary Brewster, "Evaluating the Effectiveness of Team-Based Learning in Undergraduate Courses," Journal of Criminal Justice Education 26, no. 4 (2015): $446-470$.

${ }^{48}$ Krisztina V. Jakobsen, Megan McIlreavy, and Sarah Marrs, “Team-Based Learning: The Importance of Attendance," Psychology Teaching and Learning 13, no. 1 (2014): 25-31.

${ }^{49}$ Erica Hunter and Bryan Robinson, "Connecting Students to the Social World: Using Team-Based Learning in the Sociology Classroom," in Team-Based Learning in the Social Sciences and Humanities, 81-97.

${ }^{50}$ Rozanne Harde and Sandy Bugeja, "Team-Based Learning in the First-Year English Classroom," in Team-Based Learning in the Social Sciences and Humanities, 143-158; Bill Robertson and Christine Reimers. "Team-Based Learning for Critical Reading and Thinking in the Literature and Great Books Courses," in Team-Based Learning in the Social Sciences and Humanities, 129-141.

${ }^{51}$ Larry K. Michaelsen, Warren E. Watson, and Robert H. Black, "A Realistic Test of Individual Versus Group Consensus Decision Making," Journal of Applied Psychology 74, no. 5 (1989): 834-839.

52 Jeffery Carmichael, “Team-Based Learning Enhances Performance in Introductory Biology," Journal of College Science Teaching 38, no. 4 (2009): 54-61.

${ }^{53}$ Michele C. Clark, Nguyen Hoang T., Chris Bray, and Ruth Levine, "Team-Based Learning in an Undergraduate Nursing Course," Journal of Nursing Education 47, no. 3 (2008): 111-117.

${ }^{54}$ Chung Eun-Kyung, Jung-Ae Rhee, Young-Hong Baik, and Oh-Sun A, "The Effect of Team-Based Learning in Medical Ethics Education," Medical Teacher 31, no. 11 (2009): 1013-1017; Daniel P. Hunt, Paul Haidet, John H. Coverdale, and Boyd Richards, "The Effect of Using Team Learning in an Evidence-Based Medicine Course for Medical Students," Teaching and Learning in Medicine 15, no. 2 (2003): 131-139; N. K. Zgheib, J. A. Simaan, and R. Sabra, "Using Team-Based Learning to Teach Pharmacology to Second Year Medical Students Improves Student Performance," Medical Teacher 32, no. 2 (2010): 130-135.

55 Scott Kubista-Hovis, “I don't Dare Teach with Inquiry-Based Teaching Methods When I Have State Testing Breathing Down My Neck," in Team-Based Learning in the Social Sciences and Humanities, 291-300; Jeanne Wanzek, Shawn Kent, Sharon Vaughn, Elizabeth Swanson, Greg Roberts, and Martha Haynes, "Implementing Team-Based Learning in Middle School Social Studies Classes," Journal of Educational Research 108, no. 4 (2014): 331-344; Shawn Kent, Jeanne Wanzek, Elizabeth Swanson, and Sharon Vaughn, "Team-Based Learning for Students with High-Incidence Disabilities in High School Social Studies Classrooms," Learning Disabilities Research and Practice 30, no. 


\section{Team-based Learning (TBL) in Flipped Classroom}

\section{Topic: Industry Analysis (2 Face-to-Face Sessions)}
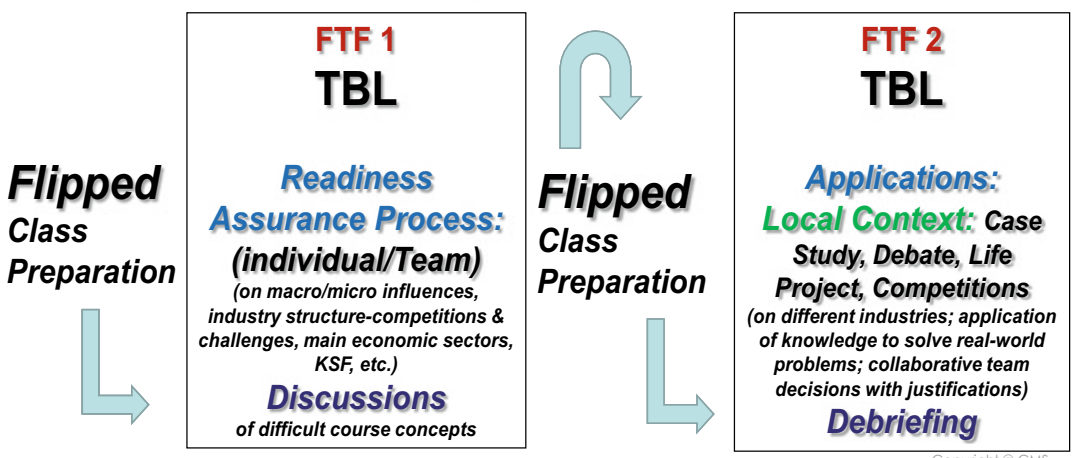

Fig. 5.2 Pedagogic strategies for strategic management in classrooms

Figure 5.2 shows an example of the author's pedagogic strategy in her flipped classrooms with the learning outcomes of students cocreating knowledge while developing HOT skills and effective teamwork behaviors. It addresses the first consideration for innovations in education pedagogic strategies for the 4IR. This is the easy part of the challenge. As the popular idiom goes, "The proof of the pudding is in the eating." The second consideration is the real test of success: understanding of the sociocultural context in the implementation of the pedagogic strategies. The practice of an innovative pedagogy requires deep deliberation of the students' sociocultural settings and learning cultures to ensure that the optimal result can be achieved from the new pedagogy. ${ }^{56}$ Does flipped classroom and TBL make sense to the students? Is there a cultural fit?

1 (2015): 3-14; Jeanne Wanzek, Sharon Vaughn, Shawn Kent, Elizabeth Swanson, Greg Roberts, Martha Haynes, Anna-Maria Fall et al., "The Effects of Team-Based Learning on Social Studies Knowledge Acquisition in High School," Journal of Research on Educational Effectiveness 7, no. 2 (2014): 183-204.

${ }^{56}$ Fariza Puteh-Behak, Darmi Ramiaida, and Mohamed Yuslina, "Implementation of a Western-Based Multiliteracies Pedagogy in Malaysia: A Socio-Cultural Perspective," Journal of Language Studies 15, no. 1 (2015): 1-24. 


\section{The Significance of Culture in Learning}

Sociocultural theory suggests that all human activities are socially, culturally, and historically constructed. ${ }^{57}$ Jaramillo asserted that Vygotsky defined society as an entity that consists of "rules and norms of the society that adults and more competent peers teach their younger initiates." 58 The cultural background of a society is a significant factor that influences human activities and shapes the society members' interpretations of the world around them, including the different conceptions about learning. This point was stressed by Hong when he defined culture as "networks of knowledge, consisting of learned routines of thinking, feeling and interacting with other people, as well as a corpus of substantive assertions and ideas about aspects of the world." 59

To understand students' learning process in a particular cultural context, it is important to consider the ways students make meaning and make sense of the world around them. Eldridge and Cranston, in their investigation of transnational education management between Australia and Thailand, asserted that the study of the sociocultural attributes of the local setting was important to determine the correct strategies for academic and operational management of a transnational higher education program. ${ }^{60}$ Novera confirmed that cultural issues were important in his investigation of the adjustment process of Indonesian students studying

${ }^{57}$ James A. Jaramillo, "Vygotsky's Sociocultural Theory and Contributions to the Development of Constructivist Curricula," Education 117, no. 1 (1996): 133-140; James P. Lantolf, ed., "Introducing Sociocultural Theory," in Sociocultural Theory and Second Language Learning (Oxford: Oxford University Press, 2000), 1-26; Mamour C. Turuk, "The Relevance and Implications of Vygotsky's Sociocultural Theory in the Second Language Classroom," ARECLS 5 (2008): 244-262.

58 Jaramillo, "Vygotsky's Sociocultural Theory and Contributions to the Development of Constructivist Curricula," 136.

${ }^{59}$ Hong Ying-yi, "A Dynamic Constructivist Approach to Culture: Moving from Describing Culture to Explaining Culture," in Understanding Culture: Theory, Research, and Application, edited by Robert S. Wyer, Chi-Yue Chiu, and Hong Ying-yi (New York: Taylor \& Francis, 2009), 4.

${ }^{60}$ Kaye Eldridge and Neil Cranston, "Managing Transnational Education: Does National Culture Really Matter," Journal of Higher Education Policy and Management 31, no. 1 (2009): 67-79. 
in Australian universities. ${ }^{61} \mathrm{He}$ interviewed 25 Indonesian postgraduate students who were studying in universities in Victoria, Australia and his study highlighted that the cultural differences between Indonesians and Australians had impacted the adjustment process of the Indonesian students.

There were also many studies that have been conducted on the area of misconceptions of Asian students' learning styles due to a lack of understanding of the local sociocultural factors that influenced learning. ${ }^{62}$ The findings confirmed that studying the sociocultural patterns of a particular society is significant in understanding the distinctive ways of learning. Ignoring students' sociocultural influences toward learning might result in inaccurate interpretation of their learning experiences. Rosenberg, Westling, and McLeskey, stated that cultural tendencies impact the way students participate in learning. ${ }^{63}$ They asserted that lack of knowledge about the culture of the students might lead to misunderstanding of the students' responses or behavior in the process of learning. They gave an example of American students' assertiveness in the classroom as this might be perceived as inappropriate by some Eastern educators. Similarly, many Asian students' quietness in the classroom might be perceived as passiveness by some Western educators.

In summary, as much as it is important for students to have a suitable pedagogical approach in achieving the goal of producing employable graduates for the 4IR, it is also important to investigate the sociocultural factors that influenced the students' learning. However, sociocultural studies is a very broad area of research and the author does not intend to deliver information that is too shallow to be useful. To provide

${ }^{61}$ Isvet A. Novera, "Indonesian Postgraduate Students Studying in Australia: An Examination of Their Academic, Social and Cultural Experiences," International Education Journal 5, no. 4 (2004): 475-487.

${ }^{62}$ Chia Mun Onn, "Major Differences Between Eastern and Western Philosophies as the Basis for Adult Education-The Singapore Experience," 2011, http://www.eaea.org/ index.php?k=12117; Gan Zhengdong, "Asian Learners’ Re-examined: An Empirical Study of Language Learning Attitudes, Strategies, and Motivation Among Mainland Chinese and Hong Kong Students," Journal of Multilingual and Multicultural Development 30, no. 1 (2009): 41-58; Shi Lijing, "The Successors to Confucianism or a New Generation? A Questionnaire Study on Chinese Students' Culture of Learning English," Language, Learning and Culture 19, no. 1 (2006): 122-147.

${ }^{63}$ Michael S. Rosenberg, David L. Westling, and James McLeskey, Special Education for Today's Teachers: An Introduction (Upper Saddle River: Prentice Hall, 2008). 
depth, the current discussion will focus on the pedagogy of flipped classroom and TBL in a Malaysian learning context with Confucian Heritage Culture (CHC).

\section{The Context: Confucian Heritage Culture (CHC)}

Asia is a geographically expansive and populous region of incredible social and cultural variation. The regions' ethnic and religious diversity is particularly striking to the outside observer. It is not uncommon for countries in the region to have dozens, if not hundreds, of local vernaculars. China has 56 recognized ethnic groups and many more undistinguished ethnic minority communities. Papua New Guinea alone contains 850 distinct language groups, $15 \%$ of the world's total. On top of this linguistic heterogeneity, all the world's major religions have found a home in the region, sometimes brought by traders, missionaries, or colonial settlers. Local rulers have variously adopted Islam, Buddhism, Hinduism, and Christianity as a state religion, although religious diversity remains the norm within the population at large. This ethnic and religious diversity continues to develop and become more complex, as long-standing cleavages are supplemented with ongoing migration within and between countries.

As with many Asian nations, Malaysia is a multiethnic, multicultural, and multilingual society, and the many ethnic groups in the country maintain separate cultural identities. ${ }^{64}$ The society of Malaysia has in fact been described as "Asia in miniature." 65 The original culture of the area stemmed from its indigenous tribes, along with the Malays who moved there in ancient times. Substantial influence exists from the Chinese and Indian cultures, dating back to when trade with those countries began in the area. Persian, Arab, and British culture have also exerted influence.

Some people are confused with the words "ethnicity" and "culture," and these words are often used interchangeably especially in the Western world. However, there are major differences between the two, evident in a multiethnic and multicultural environment as in Malaysia. Ethnicity of a

${ }^{64}$ Joel S. Kahn, Southeast Asian Identities: Culture and the Politics of Representation in Indonesia, Malaysian, Singapore and Thailand (Singapore: Institute of Southeast Asian Studies, 1998).

${ }^{65}$ Barbara W. Andaya and Leonard Y. Andaya, A History of Malaysia (London: Macmillan, 1982), xiii. 
person is related more with the racial affinities while culture is a shared set of beliefs, morals, values that are reflective of way of life. Hence, different ethnic groups could share common beliefs and values, for instance, the Confucian Heritage Culture (CHC).

$\mathrm{CHC}$ is described by education research communities as a group of Asian nation-states with their motherland and overseas population who share Confucian values, which consistently reflect in social behavior and practices, including academic outcomes and learning approaches. ${ }^{66}$ More than $85 \%$ of the student population from different ethnic groups in the author's classrooms are from the CHC background. Students completed a short questionnaire on $\mathrm{CHC}$ values at the beginning of each term. The author, from a native minority tribe, also shares $\mathrm{CHC}$ values. This presents a good scenario of an almost absolute CHC environment to explore the pedagogic practice of flipped classroom and TBL in the context.

\section{Perception: Confucian Heritage Culture (CHC)}

Asian students are often described as shy and unwilling to ask questions or speak up in class, exhibiting compliance and obedience. They are perceived to be surface learners, often relying upon rote learning, reciting the

\footnotetext{
${ }^{66}$ John Biggs, “Academic Development in Confucian Heritage Culture” (Paper, International Symposium on Child Development, Hong Kong, 1996); John Biggs, "Learning from the Confucian Heritage: So Size Doesn't Matter?," International Journal of Educational Research 29 (1998): 723-738; John Biggs, "Western Misperceptions of the Confucian-Heritage Learning Culture," in The Chinese learner: Cultural, Psychological, and Contextual Influences, edited by David Watkins and John Biggs (Hong Kong: CERC and ACER, 1996), 45-67; Sally Chan, "The Chinese Learner-A Question of Style," Education and Training 41, no. 6/7 (1999): 294-304; Lee Wing On, "The Cultural Context for Chinese Learners: Conceptions of Learning in the Confucian Tradition," in The Chinese Learner, 25-41; Roger G. Tweed and Darrin R. Lehman, "Learning Considered Within a Cultural Context: Confucian and Socratic Approaches," American Psychologist 57, no. 2 (2002): 89-99; Wang Junju, "Understanding the Chinese Learners from a Perspective of Confucianism," in Researching Cultures of Learning, edited by Martin Cortazzi and Jin Lixian (London: Palgrave Macmillan, 2013), 61-79; David A. Watkins and John Biggs, eds., Teaching the Chinese Learner: Psychological and Pedagogical Perspectives (Hong Kong: CERC and ACER, 2001); Nguyen Phuong-Mai, Cees Terlouw, and Albert Pilot, "Cooperative Learning vs Confucian Heritage Culture's Collectivism: Confrontation to Reveal Some Cultural Conflicts and Mismatch," Asia Europe Journal 3, no. 3 (2005): 403-419.
} 
thought of exemplary scholars and concerned only with absorbing knowledge rather than understanding it. This passive learning style is often attributed to Confucian core values and ethics, attached to the $\mathrm{CHC} .{ }^{67}$ Due to their Confucian inheritance, $\mathrm{CHC}$ learners also value collective harmony, refrain from expressing opinions that assert their own individuality in thought but that might clash with group norms, and habitually defer to authority rather than disagree with elders or teachers. ${ }^{68}$ Thus, "good students do not challenge their teachers; but faithfully copy and reproduce them," and in a culture where such exemplary persons' wisdom has the cachet of common sense, academic citations are even not considered necessary. 69 "Students who have been brought up in a $\mathrm{CHC}$ have learnt to value diligent study, social harmony, reverence for teachers' authority and avoidance of conflict in a face-to-face classroom environment...therefore, probing and open student-student and teacherstudent interactions are not the norm for them." 70 This is considered in contrast with the Western student learning style, which is described as assertive, independent, self-confident, and willing to ask questions and explore ways of thinking and acting. Individualism is seen as problematic

${ }^{67}$ Nola Purdie, John Hattie, and Graham Douglas, "Student Conceptions of Learning and Their Use of Self-Regulated Learning Strategies: A Cross-Cultural Comparison," Journal of Educational Psychology 88, no. 1 (1996): 87-100; M. Cortazzi and L. Jin, "Large Classes in China: Good Teachers and Interaction," in Teaching the Chinese Learner: Psychological and Pedagogical Perspectives, 115-134; Lee, "The Cultural Context for Chinese Learners"; Wang, "Understanding the Chinese Learners from a Perspective of Confucianism"; David Wu, "Parental Control: Psycho-Cultural Interpretations of Chinese Patterns of Socialization," in Growing Up the Chinese Way: Chinese Child and Adolescent Development, edited by Lau Sing (Hong Kong: The Chinese University of Hong Kong Press, 1996), 128; Michael Bond, Beyond the Chinese Face: Insight from Psychology (Hong Kong: Oxford University Press, 1992); Yang Kuo-Shu, "Sinicization of Psychological Research in Chinese Society: Directions and Issues (in Chinese)," in The Sinicization of Social and Behavioral Science Research in Chinese Societies, edited by Yang Kuo-Shu and Ch'ung-i Wen (Taipei: Institute of Ethnology, 1982), 153-187; Ganakumaran Subramaniam, "Confronting Asian Concerns in Engaging Learners to Online Education," International Education Studies 1, no. 4 (2008): 10-18.

${ }^{68}$ Jane Turner, Language in the Academy (Bristol: Multilingual Matters, 2011).

${ }^{69}$ Colin Sowden, "Plagiarism and the Culture of Multilingual Students in Higher Education Abroad," ELT Journal 59, no. 3 (2005): 227.

${ }^{70}$ Jean Chiu Yi-Ching, "Facilitating Asian Students' Critical Thinking in Online Discussions," British Journal of Educational Technology 40, no. 1 (2009): 43. 
for CHC learners. ${ }^{71}$ The other habitually ingrained values include filial piety, humaneness, ritual propriety, justice, and respect for education.

The notion that many Asian societies are Confucian, and that they share active Confucian heritages that permeate ethical, ritual, and educational life is common among education theorists. ${ }^{72}$ The Confucian concept of relational self emphasizes people's interdependency and deep commitment to social harmony and hierarchy, while excluding a serious engagement in the social ideal of equality. ${ }^{73}$ Students from many Asian countries are from birth immersed in this Confucian heritage, which has conditioned their expectations regarding academic discourse and academic standards. Asian students are criticized for not thinking deeply and not being critical enough in learning, likely leading to low-quality outcomes. ${ }^{74}$

The general perception of these theorists is that Asian students with $\mathrm{CHC}$ background would face challenges in adapting to more deductive reasoning, critical thinking, and open exchanges of ideas, which characterize many pedagogic practices common in many North American and European classrooms. The question to ask next is whether this perception is accurate. To assess whether $\mathrm{CHC}$ learners are in fact likely to struggle with more active learning pedagogies, the author has studied the implementation of flipped classrooms and TBL for the learning outcomes of HOT skills and effective teamwork behaviors among students from $\mathrm{CHC}$ background in the author's strategic management classrooms.

${ }^{71}$ Ulla Connor, Contrastive Rhetoric: Cross-Cultural Aspects of Second Language Writing (Cambridge: Cambridge University Press, 1996); Purdie, Hattie, and Douglas, "Student Conceptions of Learning and Their Use of Self-Regulated Learning Strategies."

${ }^{72}$ Insup Taylor and Martin Taylor, Writing and Literacy in Chinese, Korean and Japanese (Amsterdam: John Benjamins, 2014); Jae Park, "Metamorphosis of Confucian Heritage Culture and the Possibility of an Asian Education Research Methodology," Comparative Education 47, no. 3 (2011): 381-393; Turner, Language in the Academy; Joan Carson, "Cultural Backgrounds: What Should We Know About Multilingual Students?," TESOL Quarterly 32, no. 4 (1998): 735-740.

${ }^{73}$ Yuan Lijun, "Confucian and Feminist Notions of Relational Self and Reciprocity: A Comparative Study," Journal of East-West Thought, accessed June 25, 2019, https://www. cpp.edu/ jet/Documents/JET/Jet17/Yuanl-9.pdf.

${ }^{74}$ Shaun O'Dwyer, "Deflating the 'Confucian Heritage Culture' Thesis in Intercultural and Academic English Education," Language, Culture and Curriculum 30, no. 2 (2017): 198-211; Connor, Contrastive Rhetoric; Amanda Maxwell, Guy Curtis, and Lucia Vardanega, "Does Culture Influence Understanding and Perceived Seriousness of Plagiarism?," International Journal for Educational Integrity 4, no. 2 (2008): 25-40. 


\section{MAKing It WORK With CONFUCIAN Heritage Culture (CHC)}

The author disagrees with the general perception that $\mathrm{CHC}$ is a hindrance to the adoption of active, critical thinking-oriented pedagogic practices in $\mathrm{CHC}$ classrooms. The author posits that there has perhaps been unreflective, shallow, and superficial orientalist stereotyping of Asian students from the $\mathrm{CHC}$ traditions. While it is true that many of the traditional cultural beliefs could have influenced students' authority orientations and classroom behaviors, Confucianism is also much more than this. There is a need to have a more in-depth understanding of Confucian heritage of Asian students in the present-day state of civil society in Asian countries, in order to reduce the chances of misunderstandings and of ethnocentrism. $^{75}$

For instance, Confucian philosophy demands reflection, persistence and stoic response to pain. ${ }^{76}$ This is evident in the perseverance and resilience of many Asian businesses in difficult times. In Confucian ethics, respect for seniors and "face consciousness" to maintain harmony, provides an explanation for why students in class seldom asked questions of what teachers taught, leading to the perception of unquestioning acceptance of teachers' knowledge. ${ }^{77}$ However, not asking questions does not necessarily mean students are not paying attention or mentally active. Likewise, Cortazzi and Jin argue that students could be mentally active by

${ }^{75}$ Carson, "Cultural Backgrounds: What Should We Know About Multilingual Students?"; Gayle L. Nelson, "Comments on Ruth Spack's 'The Rhetorical Construction of Multilingual Students': Categorizing, Classifying, Labeling: A Fundamental Cognitive Process," TESOL Quarterly 32, no. 4 (1998): 727-732; O'Dwyer, "Deflating the "Confucian Heritage Culture' Thesis in Intercultural and Academic English Education."

${ }^{76}$ Clara C. Park, "Learning Style Preferences of Asian American (Chinese, Filipino, Korean, and Vietnamese) Students in Secondary Schools," Equity and Excellence in Education 30, no. 2 (1997): 68-77.

${ }^{77}$ David Murphy, “Offshore Education: A Hong Kong Perspective," Australian Universities Review 30, no. 2 (1987): 43-44; Chan, "The Chinese Learner-A Question of Style"; Chiu, "Facilitating Asian Students' Critical Thinking in Online Discussions"; Sowden, "Plagiarism and the Culture of Multilingual Students in Higher Education Abroad"; S. Chen, Learning Strategies in a Multicultural Environment (Beijing: Beijing Language and Culture University Press, 2007); Helena W. S. Hing, "Characteristics of Chinese Students' Learning Styles," International Association of Computer Science and Information Technology 62, no. 8 (2013): 36-39. 
cooperating with teachers and actively listening to teachers. ${ }^{78}$ The author shares the view of Cortazzi and Jin and disagrees that Asian students are passive learners. ${ }^{79}$ Rather, they are reflective learners demonstrated by them asking thoughtful questions after sound reflection. In fact, the Chinese word “xue wen" 學問, meaning knowledge, stresses the importance of questioning and enquiring-demonstrating a deep approach to learning.

To further illustrate the need to have a deeper understanding of the sociocultural context as the second key consideration in the adoption of innovations in education pedagogic strategies for the 4IR, the author will elaborate on two specific areas that CHC traditions have positive influences on the practice of flipped and TBL in her classrooms in delivering the expected learning outcome.

\section{CHC Inclination for Intuitive Thinking}

In the previous section, we have discussed how both intuitive and rational decision-making are valuable for strategic decision-making. We also discussed how education reforms to STEM education are designed to prepare students well in analytical thinking and making rational decisions. The initial perceived challenge is with intuitive thinking.

As mentioned earlier, people in all cultures are likely to possess both intuitive and rational reasoning systems, but cultural variation may exist in their relative accessibility to the extent that different values are placed on these reasoning systems. Many theorists have documented cultural differences in the intellectual outlooks of Asian and Western societies. ${ }^{80} \mathrm{An}$ analytic mode of thought has been held to be more prevalent in Western cultural groups. This mode is characterized by decoupling of the object

${ }^{78} \mathrm{M}$. Cortazzi and L. Jin "Cultures of Learning: Language Classrooms in China," in Society and the Language Classroom, 169-206.

${ }^{79}$ Cortazzi and Jin, "Large Classes in China: Good Teachers and Interaction."

${ }^{80}$ Fung Yu-Lan, A History of Chinese Philosophy, translated by Derek Bodde (Princeton: Princeton University Press, 1952); Geoffery Lloyd, "Science in Antiquity: The Greek and Chinese Cases and Their Relevance to the Problems of Culture and Cognition," in Modes of Thought: Explorations in Culture and Cognition, edited by David R. Olson and Nancy Torrance (Cambridge: Cambridge University Press, 1996), 15-33; Liu Shu-Hsien, "The Use of Analogy and Symbolism in Traditional Chinese Philosophy," Journal of Chinese Philosophy 1, no. 3-4 (1974): 313-338; Hajime Nakamura, The Ways of Thinking of Eastern Peoples (New York: Greenwood Press, 1988). 
from its context, assigning the object to categories based on necessary and sufficient features, and a preference for using rules, including the rules of formal logic, to explain and predict the object's behavior. In contrast, a holistic mode of thought has been held to be more prevalent in Asian cultural groups. This mode is characterized by attention to the context or field as a whole, a concern with relationships among objects and between the field and the object, and a preference for intuitive approaches, as well as dialectical reasoning, which seeks the middle-way between conflicting propositions. $^{81}$

Recent evidence indicates that some of these differences in analytic versus holistic outlooks find their counterparts in several thought processes of contemporary North Americans and East Asians. ${ }^{82}$ For instance, East Asians see social behavior as the outcome of person-context interactions, in contrast to the characteristic American view of social behavior as the unfolding of dispositions. As a result, East Asians are less prone to the fundamental attribution error, ${ }^{83}$ or the tendency to over attribute behavior to dispositions despite obvious situational constraints. ${ }^{84}$ East Asians are more field dependent than Americans, ${ }^{85}$ being more influenced by the position of the surrounding frame when judging the position of the rod in the rod-and-frame task. ${ }^{86}$ East Asians have a more holistic sense of causality: They draw on a wider range of factors to explain events.

${ }^{81}$ Ara Norenzayan, Edward. E. Smith, Beom Jun Kim, and Richard E. Nisbett, "Cultural Preferences for Formal Versus Intuitive Reasoning," Cognitive Science 26, no. (2002): 653-684.

${ }^{82}$ Nisbett, Peng, Choi, and Norenzayan, "Culture and Systems of Thought: Holistic Versus Analytic Cognition"; Norenzayan, Smith, Kim, and Nisbett, "Cultural Preferences for Formal Versus Intuitive Reasoning"; Ara Norenzayan and Ricard E. Nisbett, "Culture and Causal Cognition," Current Directions in Psychological Science 9, no. 4 (2000): 132135 .

${ }^{83}$ Lee Ross, "The Intuitive Psychologist and His Shortcomings," in Advances in Experimental Social Psychology, edited by Leonard Berkowitz (New York: Academic Press, 1977), 173-220.

${ }^{84}$ Incheol Choi, Richard E. Nisbett, and Ara Norenzayan, "Causal Attribution Across Cultures: Variation and Universality," Psychological Bulletin 125, no. 1 (1999): 47-63.

${ }^{85}$ Herman A. Witkin and John W. Berry, "Psychological Differentiation in CrossCultural Perspective," Journal of Cross-Cultural Psychology 6, no. 1 (1975): 4-87.

${ }^{86} \mathrm{Ji}$ Li-Jun, Peng Keyin, and Richard Nisbett, "Culture, Control, and Perception of Relationships in the Environment," Journal of Personality and Social Psychology 78, no. 5 (2000): 943-955. 
As a result, East Asians experience less surprise at unexpected events and show more hindsight bias, ${ }^{87}$ the tendency to view events as having been inevitable in retrospect. ${ }^{88}$ East Asians also tend to prefer dialectical resolutions to apparent contradictions, so that the contradiction is tolerated, or a compromised solution is sought. Americans are more likely to respond to contradiction by polarizing their opinions-deciding that one proposition is true and the other false. ${ }^{89}$

The East Asian cultural sphere are the countries in East Asia that were historically influenced by the Chinese culture and share a Confucian ethical philosophy. The above evidence suggests that East Asian students from the $\mathrm{CHC}$ tradition are potentially more intuitive. Confucian heritage tradition appears to have a positive impact on associative thinking capability and being naturally comfortable with gray areas. Hence, the author posits that the challenge is not about cultural support for intuitive thinking. The challenge is about how teachers can support these students with intuitive inclination by heritage, to think intuitively.

\section{The Concept of Social-Oriented Achievement Motivation (SOAM)}

Taking a social-cognitive perspective of motivation, McClelland and Maehr and Nicholls were among the pioneers who asserted that culture shapes achievement motivation. ${ }^{90}$ They maintain that every culture cultivates values or beliefs concerning qualities that are important, worth pursuing, and socially desirable. These culture-bound beliefs in turn guide the selection of achievement goals and the means of their pursuit adopted by individuals in the culture.

${ }^{87}$ Baruch Fischhoff, "Hindsight's Foresight: The Effect of Outcome Knowledge on Judgment Under Uncertainty," Journal of Experimental Psychology: Human Perception and Performance 1, no. 3 (1975): 288-299.

${ }^{88}$ Incheol Choi and Richard E. Nisbett, "The Cultural Psychology of Surprise: Holistic Theories and Recognition of Contradiction," Journal of Personality and Social Psychology 79, no. 6 (2000): 890-905.

${ }^{89}$ Peng Kaiping and Richard E. Nisbett, "Culture, Dialectics, and Reasoning About Contradiction," American Psychologist 54 (1999): 741-754.

${ }^{90}$ David McClelland, The Achieving Society (Princeton: Von Nostrand, 1961); M. L. Maehr and J. Nicholls, "Culture and Achievement Motivation: A Second Look," in Studies in Cross-Cultural Psychology, edited by Neil Warren (New York: Academic Press, 1980), 221-267. 
Originating from research in the Western tradition, ${ }^{91}$ achievement goal theory postulates that students' purposes for engaging in academic tasks serve as a motivating force that leads to achievement behaviors. The theory conceptualizes four types of goals: (1) mastery-approach goal, which emphasizes learning new knowledge and improving one's skills; (2) mastery-avoidance goal, which emphasizes the avoidance of losing skills and competence; (3) performance-approach goal, which emphasizes demonstrating one's superiority in comparison to others; and (4) performance-avoidance goal, which emphasizes the avoidance of showing one's incompetence relative to others. According to Spence, these motivational constructs mirror Western individualist values well. ${ }^{92}$ Observing that people in the Eastern collectivist societies are driven by achievement motivations inherently different from those theorized in the West, Yu and Yang propose the concepts of individual-oriented and social-oriented achievement motivations (SOAM). ${ }^{93}$ Individual-oriented achievement motivation (IOAM) describes the tendency to pursue internally determined goals in one's own way, whereas SOAM refers to the tendency to achieve externally determined goals in a socially desirable way. Since there are value differences underlying the two, Yu and Yang believe that IOAM is more salient among people in individualist societies, whereas SOAM predominates among those in the collectivist tradition. Other researchers have made similar observations in achievement motivation with Eastern collectivistic societies and Western individualistic societies. ${ }^{94}$ While contending that there are underlying differences between the concepts of

${ }^{91}$ Andrew J. Elliot, "A Conceptual History of the Achievement Goal Construct," in Handbook of Competence and Motivation, edited by Andrew J. Elliot and Carol S. Dweck (New York: The Guilford Press, 2005), 52-72.

92 Janet T. Spence, “Achievement American Style: The Rewards and Costs of Individualism," American Psychologist 40, no. 12 (1985): 1285-1295.

${ }^{93} \mathrm{Yu}$ An-Bang and Yang Kuo-Shu, "The Nature of Achievement Motivation in Collectivist Societies," in Individualism and Collectivism: Theory, Method, and Applications, edited by Uichol Kim, Harry C. Triandis, Cigdem Kagitcibasi, Sang-Chin Choi, and Gene Yoon (Thousand Oaks: Sage, 1994), 239-250.

${ }^{94}$ Yang Kuo-Shu and Yu An-Bang, "Social-Oriented and Individual-Oriented Achievement Motives: Conceptualization and Measurement" (Paper, Symposium on Chinese Personality and Social Psychology for the XXIVth International Congress of Psychology, Sydney, 1988); Yu An-Bang and Yang Kuo-Shu, "Social-Oriented and Individual-Oriented Achievement Motivation: A Conceptual and Empirical Analysis (in Chinese)," Bulletin of the Institute of Ethnology, Academia Sinica 64 (1987): 51-98; Yu and Yang, "The Nature of Achievement Motivation in Collectivist Societies"; Yu An-Bang, "Ultimate 
individual-oriented and SOAM, the author argues that the two can coexist and function interactively in motivating students' achievement behaviors, with CHC.

Confucianism is the cornerstone of traditional Chinese culture. Confucian traditions emphasize group orientation, interpersonal harmony, acceptance of authority, and the importance of education and academic attainments. Chang, Wong, and Teo posit that the critical question concerning achievement motivation in the collective context seem to be whether in cultures where the collective is emphasized, the individuals have the same kind of intrinsic motives to achieve? ${ }^{95}$ To accept the possibility that individuals in the collective context might be low on the motivation to achieve, one might have to accept the assumptions that (1) the motivation to achieve and the motivation to affiliate are necessarily at odds with each other and (2) that individual achievement and the collective goals are at each other's expenses. In their studies, Chang, Wong, and Teo contend that these assumptions are not always true in the Chinese cultural context. They argue that in the Chinese context, individual achievement in terms of mastery in academic settings serves both the taskoriented motivations as well as the social-oriented motivations. In the academic settings, individual Chinese might approach achievement via both the individually oriented and the socially oriented goal conceptualizations and behavioral scripts.

In recent years, economic reforms have accelerated the process of modernization, openness, and globalization in the region. In responding to these rapid changes, educational systems in many Asian societies began to emphasize values oriented to individuality, independent thinking, and creativity. ${ }^{96}$ There is a trend that individualist-oriented values are now more increasingly adopted by Asians, especially the youth. In the $\mathrm{CHC}$

Life Concerns, Self, and Chinese Achievement Motivation," in The Handbook of Chinese Psychology, edited by Michael H. Bond (Hong Kong: Oxford University Press, 1996), 227-246. Farideh Salili, "Accepting Personal Responsibility for Learning," in The Chinese Learner, 86-105; Vivienne Tao and Hong Ying-Yi, "When Academic Achievement Is an Obligation-Perspectives from Social-Oriented Achievement Motivation," Journal of Cross-Cultural Psychology 45, no. 1 (2014): 110-136.

95 Chang Weining C., Wong Wing-Keung, and Grace Teo, "The Socially Oriented and Individually Oriented Achievement Motivation of Singaporean Chinese Students," Journal of Psychology in Chinese Societies 1, no. 2 (2000): 39-63.

${ }^{96}$ John Hawkins, N. Zhou, and J. Lee, "China: Balancing the Collective and the Individual," in Value Education for Dynamic Societies: Individualism or Collectivism, edited 
traditions, social recognition and task-mastery are intertwined. ${ }^{97}$ Confucian ethics place high value on both individual competence as well as social harmony. ${ }^{98}$ In many Western cultures, an individual's success is often defined as performance excellence in achievement goals chosen based on the individual's own aspiration. Contrary to this individually oriented notion, achievement to the $\mathrm{CHC}$ learners serves a dual function: realization of the individual's aspiration and gaining societal approval. ${ }^{99}$ Children's achievement is regarded as the most important objective in parents' expectations. ${ }^{100}$ To meet this dual demand, the CHC learners often choose to excel in achievement goals, normatively defined by the society. In other words, for an individual, achievement is defined as individual reaching success within the collective context. ${ }^{101}$ An individual's achievement is not achievement in isolation but achievement in collective. Academic achievement is hence a social endeavor to bring pride to the family and glorify the ancestry (光宗耀祖).

On the other hand, Confucius maintained that in an ideal society, power prestige and fortune can be attained through individual mastery of skills and knowledge. The age-old civil servants' examination in China further institutionalized this belief and the actual practice of the path to success. Task-related motives can thus be seen as intimately related to satisfaction of socially related needs. These positive correlations suggest that

by William K. Cummings, Maria T. Tatto, and John Hawkins (Hong Kong: Comparative Educational Research Center, 2001), 191-206.

${ }^{97}$ Rebecca P. Ang and Chang Weining C., "Impact of Domain-Specific Locus of Control on Need for Achievement and Affiliation," The Journal of Social Psychology 139, no. 4 (1999): 527-530; Wm Theodore de Bary, Learning for One's Self: Essays on the Individual in Neo-Confucian Thought (New York: Columbia University Press, 1991).

${ }^{98}$ Chang Weining C. and Wong Wing-Keung, "Rational Traditionalism: Chinese Values in Singapore," in Values and Development: A Multi-Disciplinary Approach with Some Comparative Studies, edited by Hank Lim and Ranjit Singh (Singapore: Center for Advanced Studies, 1998), 295-308.

${ }^{99}$ Yang and Yu, "Social-Oriented and Individual-Oriented Achievement Motives."

${ }^{100}$ Yang Kuo-Shu, "Chinese Personality and Its Change," in The Psychology of the Chinese People, edited by Michael H. Bond (Hong Kong: Oxford University Press, 1986), 106-170.

${ }^{101}$ Tu Weiming, Confucian Thought: Selfhood as Creative Transformation (Albany: State University of New York Press, 1985); Yang and Yu, "Social-Oriented and IndividualOriented Achievement Motives"; Yu An-Bang, "Socializational Factors of Individual's Achievement Motivation in Family," Bulletin of the Institute of Ethnology 71 (1991): 87-132. 
within the $\mathrm{CHC}$ community, an individual's striving toward achievement is not seen as incompatible with that individual's striving toward social approval. With this dual emphasis on both the individual as well as the collective, a happy medium for the CHC students would be provided by achievement goals that could integrate both individual-oriented achievement as well as social-oriented communion needs. ${ }^{102}$ Spence postulated that different societies find different collective solutions to manage these two senses of motivation to achieve and the motivation for affiliation. ${ }^{103}$

The author contends that teachers play an important role in inspiring and supporting individual student's motivation to achieve success, in both the socially oriented and individual-oriented achievement goals. With CHC students where the communion sense of self prevails, there is a need for teachers innovating pedagogic strategies to understand the culture-achievement relations and how the motivation to achieve regulates the selection of goals and goal-directed behaviors of individual students. For instance, the author posits that TBL is culturally appropriate for CHC learners. In a collective-oriented culture, students find comfort and security by engaging in discussions in small groups rather than asking questions or voicing one's opinion openly in a larger class. ${ }^{104}$ The teacher can have more engaging conversations with small groups applying scaffolding strategies to cocreate knowledge. In addition, teacher-student relationships are highly valued and viewed on long-term bases. ${ }^{105}$ Biggs believed that Asian students were more active in one-to-one interactions with teachers and engaging in peer discussion outside instead of within class itself. ${ }^{106}$ Group-society norms of relationships extend beyond classroom.

102 Chang, Wong, and Teo, "The Socially Oriented and Individually Oriented Achievement Motivation of Singaporean Chinese Students."

103 Spence, "Achievement American Style: The Rewards and Costs of Individualism."

${ }^{104}$ Cortazzi and Jin, "Cultures of Learning: Language Classrooms in China"; William Littlewood, "Students' Attitudes to Classroom English Learning: A Cross-Cultural Study," Language Teaching Research 5, no. 1 (2001): 3-28.

105 Cheng Xiaotang, “Asian Students' Reticence Revisited," System 28, no. 3 (2000): 435-446; Wang, "Understanding the Chinese Learners from a Perspective of Confucianism."

106 Biggs, "Academic Development in Confucian Heritage culture." 
The author believes this trust and respect for teachers are two important components for teachers to create a supportive and nurturing learning environment for students, especially with new innovative pedagogic practices, to develop HOT skills. Asking students to embrace new and possibly uncomfortable modes of learning, such as flipped classroom and TBL, will work best when students trust in their teacher's expertise and knowledge. Among CHC learners, there is a cultural expectation that teachers are knowledgeable and trustworthy intellectual guides. This trust can be harnessed to compassionately encourage students to embrace more active learning approaches and develop critical thinking skills.

\section{ConcLusion}

This chapter has highlighted the gaps in education reform for the 4IR to include HOT skills and sociocultural understanding. It is hard to imagine any educator who is not aware of the importance of teaching HOT skills to prepare the young generation to live in the twenty-first century. The premise that research literature supports the teaching and learning of HOT skills is no longer an issue for contention. ${ }^{107}$ HOT skills should be an integral part of teaching and learning especially at the higher education level. Thinking skills should be part of the curriculum if students are to solve problems individually, cooperatively, and creatively.

The challenge lies with how best to teach these HOT skills. This chapter discusses strategies to fuse and integrate innovative pedagogic practice of flipped instructional model and TBL that would foster HOT skills among students from $\mathrm{CHC}$ contexts. The author also argues that the collaborative learning embedded in TBL is culturally appropriate for the collectivist community.

Seo and Koro-Ljungberg believe that without understanding the role of cultural identity and heritage embedded in a particular cultural framework, higher education cannot achieve one of its most important goals: to provide quality education for all. ${ }^{108}$ While the author agrees with the

${ }^{107}$ Yee Mei Hong, Widad Binti Othman, Jailani Bin Md Yunos, Tee Tze Kiong, Razali Bin Hassan, and Mimi Mohaffzya Binti Mohamad, "The Level of Marzano Higher Order Thinking Skills Among Technical Education Students," International Journal of Social Science and Humanity 1, no. 2 (2011): 121-125.

${ }^{108}$ Seo Seonjin and Mirka Koro-Ljungberg, "A Hermeneutical Study of Older Korean Students' Experiences in American Higher Education: From Confucianism to Western 
importance of culturally responsive teaching for today's educators, the author argues that the understanding of traditional values should not be superficial; it should be critically evaluative. Students who come from a $\mathrm{CHC}$ have been described negatively in the literature for their supposedly passive learning style. The author challenges this criticism and advocates that there has been insufficient depth of understanding of the cultural values beneath the surface of social life to uncover the assumptions of this community. Most times, a narrow aspect of a culture is captured and shared, compounding misunderstandings.

The author discusses Confucian heritage cultural inclination toward intuition and how CHC students' achievement motivations could be strategically harnessed to support innovative pedagogic practices. The author argues that Confucian heritage has limited explanatory value in characterizing the observed learning habits of Asian students. It is out of touch with the realities of today's diverse Asian societies. There is Confucian heritage, but its historical diversity and philosophical sophistication have often been poorly comprehended and its contemporary influence in education has been exaggerated. There are other, more plausible explanations for the observed Asian learning habits, which teachers and researchers should also explore. More attention should be given to situation-specific factors of teaching methodologies, learning environment, learning habits rather than cultural factors. Perhaps, we need different attitudes about the world, to view cultures as unique and special, and to consider how cultural differences can be leveraged to enhance student learning.

\section{BIBLIOGRAPHY}

Andaya, Barbara W., and Leonard Y. Andaya. A History of Malaysia. London: Macmillan, 1982.

Ang, Rebecca P., and Chang Weining C. "Impact of Domain-Specific Locus of Control on Need for Achievement and Affiliation." The Journal of Social Psychology 139, no. 4 (1999): 527-530.

BattelleforKids. "Framework for Twenty-First Century Learning." http://www. p21.org/our-work/p21-framework.

Educational Values," Journal of Studies in International Education 9, no. 2 (2005): 164187. 
Bereiter, Carl. “Constructivism, Socioculturalism, and Popper's World 3." Educational Researcher 23, no. 7 (1994): 21-23.

Bergmann, Jon, and Aaron Sams. "Flipped Learning: Maximizing Face Time." $T+D$ 68, no. 2 (2014): 28-31.

Biggs, John. “Academic Development in Confucian Heritage Culture." Paper presented at the International Symposium on Child Development, Hong Kong, 1996.

—. "Learning from the Confucian Heritage: So Size Doesn't Matter?" International Journal of Educational Research 29 (1998): 723-738.

- "Western Misperceptions of the Confucian-Heritage Learning Culture." In The Chinese Learner: Cultural, Psychological, and Contextual Influences, edited by David Watkins and John Biggs, 45-67. Hong Kong: CERC and ACER, 1996.

Biggs, John, and C. Tang. Teaching for Quality Learning at University. 4th ed. Maidenhead: Open University Press, 2011.

Bloom, Benjamin S., ed. Taxonomy of Educational Objectives, Handbook I: Cognitive Domain. New York: David McKay, 1956.

Bond, Michael. Beyond the Chinese Face: Insight from Psychology. Hong Kong: Oxford University Press, 1992.

Bruner, Jerome S. “The Act of Discovery." Harvard Educational Review 31, no. 1 (1961): 21-32.

Buck Institute. "What Is Project-Based Learning (PBL)?” http://www.bie.org/ about/what_pbl.

Cabantous, Laure, and Jean-Pascal Gond. "Rational Decision Making as Performative Praxis: Explaining Rationality's Éternal Retour." Organization Science 22 , no. 3 (2011): 573-586.

Carmichael, Jeffery. "Team-Based Learning Enhances Performance in Introductory Biology." Journal of College Science Teaching 38, no. 4 (2009): 54-61.

Carson, Joan. "Cultural Backgrounds: What Should We Know About Multilingual Students?” TESOL Quarterly 32, no. 4 (1998): 735-740.

Chan, Sally. "The Chinese Learner-A Question of Style." Education and Training 41, no. 6/7 (1999): 294-304.

Chang, Weining C., and Wong Wing-Keung. "Rational Traditionalism: Chinese Values in Singapore." In Values and Development: A Multi Disciplinary Approach with Some Comparative Studies, edited by Hank Lim and Ranjit Singh, 295-308. Singapore: Center for Advanced Studies, 1998.

Chang, Weining C., Wong Wing-Keung, and Grace Teo. "The Socially Oriented and Individually Oriented Achievement Motivation of Singaporean Chinese Students." Journal of Psychology in Chinese Societies 1, no. 2 (2000): 39-63.

Chao, Roger, Jr. "Educating for the Fourth Industrial Revolution." November 10, 2017. https://www.universityworldnews.com/post.php?story= 20171107123728676. 
Chen, S. Learning Strategies in a Multicultural Environment. Beijing: Beijing Language and Culture University Press, 2007.

Cheng, Xiaotang. "Asian Students' Reticence Revisited." System 28, no. 3 (2000): 435-446.

Chia, Mun Onn. "Major Differences Between Eastern and Western Philosophies as the Basis for Adult Education-The Singapore Experience." 2011. http:// www.eaea.org/index.php?k=12117.

Chiu, Jean Yi-Ching, "Facilitating Asian Students' Critical Thinking in Online Discussions." British Journal of Educational Technology 40, no. 1 (2009): 4257.

Choi, Incheol, and Richard E. Nisbett. "The Cultural Psychology of Surprise: Holistic Theories and Recognition of Contradiction." Journal of Personality and Social Psychology 79, no. 6 (2000): 890-905.

Choi, Incheol, Richard E. Nisbett, and Ara Norenzayan. "Causal Attribution Across Cultures: Variation and Universality." Psychological Bulletin 125, no. 1 (1999): 47-63.

Chung, Eun-Kyung, Jung-Ae Rhee, Young-Hong Baik, and Oh-Sun A. "The Effect of Team-Based Learning in Medical Ethics Education." Medical Teacher 31, no. 11 (2009): 1013-1017.

Cicero. The Treatises of M.T. Cicero. Translated by C. D. Tonge. London: Bell and Dandy, 1870.

Clark, Michele C., Nguyen Hoang T., Chris Bray, and Ruth Levine. "TeamBased Learning in an Undergraduate Nursing Course." Journal of Nursing Education 47, no. 3 (2008): 111-117.

Coleman, Hywel, ed. "Autonomy and Ideology in the English Language Classroom." In Society and the Language Classroom, 1-16. Cambridge: Cambridge University Press, 1996.

Connor, Ulla. Contrastive Rhetoric: Cross-Cultural Aspects of Second Language Writing. Cambridge: Cambridge University Press, 1996.

Cortazzi, M., and L. Jin "Cultures of Learning: Language Classrooms in China." In Society and the Language Classroom, edited by Hywel Coleman, 169-206. Cambridge: Cambridge University Press, 2016.

- "Large Classes in China: Good Teachers and Interaction." In Teaching the Chinese Learner: Psychological and Pedagogical Perspectives, edited by David A. Watkins and John Biggs, 115-134. Hong Kong: CERC and ACER, 2001. Dane, Erik, and Michael G. Pratt. "Exploring Intuition and Its Role in Managerial Decision Making." Academy of Management Journal 32, no. 1 (2007): 33-54.

David, Fred R. Strategic Management: Concepts and Cases. 15th ed. London: Pearson, 2015.

de Bary, Wm. Theodore. Learning for One's Self: Essays on the Individual in Neo-Confucian Thought. New York: Columbia University Press, 1991. 
de Wit, Bob, and Ron Meyer. Strategy Synthesis: Managing Strategy Paradoxes to Create Competitive Advantage. 4th ed. London: Cengage Learning EMEA, 2014.

Dewey, John. How We Think: A Restatement of the Relation of Reflective Thinking to the Educative Process. Boston: D. C. Heath and Company, 1933.

- The Quest for Certainty. New York: Minton, 1929.

Elbanna, Said. "Strategic Decision Making: Process Perspectives." International Journal of Management Reviews 8, no. 1 (2006): 1-20.

Elbanna, Said, and J. Child. "Influences on Strategic Decision Effectiveness: Development and Test of an Integrative Model." Strategic Management Journal 28 (2007): 431-453.

Eldridge, Kaye, and Neil Cranston. "Managing Transnational Education: Does National Culture Really Matter." Journal of Higher Education Policy and Management 31, no. l (2009): 67-79.

Elliot, Andrew J. "A Conceptual History of the Achievement Goal Construct." In Handbook of Competence and Motivation, edited by Andrew J. Elliot and Carol S. Dweck, 52-72. New York: The Guilford Press, 2005.

Fariza, Puteh-Behak, Darmi Ramiaida, and Mohamed Yuslina. "Implementation of a Western-Based Multiliteracies Pedagogy in Malaysia: A Socio-Cultural Perspective." Journal of Language Studies 15, no. 1 (2015): 1-24.

Fischer, Christopher, Linda Bol, and Shana Pribesh. "An Investigation of HigherOrder Thinking Skills in Smaller Learning Community Social Studies Classrooms." American Secondary Education 39, no. 2 (2011): 5-26.

Fischhoff, Baruch. "Hindsight's Foresight: The Effect of Outcome Knowledge on Judgment Under Uncertainty." Journal of Experimental Psychology: Human Perception and Performance 1, no. 3 (1975): 288-299.

Flumerfelt, Shannon, and Greg Green. "Using Lean in the Flipped Classroom for at Risk Students." Educational Technology and Society 16, no. 1 (2013): 356-366.

Fortana, Lynn A., C. Dede, C. S. White, and W. M. Cates. Multimedia: A Gateway to Higher-Order Thinking Skills. Fairfax: George Mason University, 1993.

Fulton, Kathleen. "Upside Down and Inside Out: Flip Your Classroom to Improve Student Learning." Learning and Leading with Technology 39, no. 8 (2012): 12-17.

Fung, Yu-Lan. A History of Chinese Philosophy. Translated by Derek Bodde. Princeton: Princeton University Press, 1952.

Gan, Zhengdong. "Asian Learners' Re-examined: An Empirical Study of Language Learning Attitudes, Strategies, and Motivation Among Mainland Chinese and Hong Kong Students." Journal of Multilingual and Multicultural Development 30, no. 1 (2009): 41-58. 
Gavetti, Giovanni, Daniel Levinthal, and Willian Ocasio. "Neo-Carnegie: The Carnegie School's Past, Present, and Reconstructing for the Future." Organization Science 18, no. (2007): 523-536.

Hairuszila, Idrus, M. H. Hazadiah, and Normah Abdullah. "Challenges in the Integration of Soft Skills in Teaching Technical Courses: Lecturer's Perspectives." Asian Journal of University Education 5, no. 2 (2009): 67-81.

Harde, Rozanne, and Sandy Bugeja. "Team-Based Learning in the First-Year English Classroom." In Team-Based Learning in the Social Sciences and Humanities: Group Work That Works to Generate Critical Thinking and Engagement, edited by Michael Sweet and Larry K. Michaelsen, 143-158. Sterling: Stylus Publishing, 2012.

Hawkins, John, N. Zhou, and J. Lee. "China: Balancing the Collective and the Individual." In Value Education for Dynamic Societies: Individualism or Collectivism, edited by William K. Cummings, Maria T. Tatto, and John Hawkins 191-206. Hong Kong: Comparative Educational Research Center, 2001.

Hing, Helena W. S. "Characteristics of Chinese Students' Learning Styles." International Association of Computer Science and Information Technology 62, no. 8 (2013): 36-39.

Hong, Ying-yi. "A Dynamic Constructivist Approach to Culture: Moving from Describing Culture to Explaining Culture." In Understanding Culture: Theory, Research, and Application, edited by Robert S. Wyer, Chi-Yue Chiu, and Ying-yi Hong. New York: Taylor \& Francis, 2009.

Hunt, Daniel P., Paul Haidet, John H. Coverdale, and Boyd Richards. "The Effect of Using Team Learning in an Evidence-Based Medicine Course for Medical Students." Teaching and Learning in Medicine 15, no. 2 (2003): 131-139.

Hunter, Erica, and Bryan Robinson. "Connecting Students to the Social World: Using Team-Based Learning in the Sociology Classroom." In Team-Based Learning in the Social Sciences and Humanities: Group Work That Works to Generate Critical Thinking and Engagement, edited by Michael Sweet and Larry K. Michaelsen, 81-97. Sterling: Stylus Publishing, 2012.

Jakobsen, Krisztina V., Megan McIlreavy, and Sarah Marrs. "Team-Based Learning: The Importance of Attendance." Psychology Teaching and Learning 13, no. 1 (2014): 25-31.

Jaramillo, James A. "Vygotsky's Sociocultural Theory and Contributions to the Development of Constructivist Curricula." Education 117, no. 1 (1996): 133-140.

Jarvis, Peter. The Theory and Practice of Teaching. 2nd ed. New York: Routledge, 2006.

Ji, Li-Jun, Peng Keyin, and Richard Nisbett. "Culture, Control, and Perception of Relationships in the Environment." Journal of Personality and Social Psychology 78, no. 5 (2000): 943-955. 
Jolly, Anne. "STEM vs. STEAM: Do the Arts Belong?" November 18, 2014. http://www.edweek.org/tm/articles/2014/11/18/ctq-jolly-stem-vssteam.html.

Kahn, Joel S. Southeast Asian Identities: Culture and the Politics of Representation in Indonesia, Malaysian, Singapore and Thailand. Singapore: Institute of Southeast Asian Studies, 1998.

Kent, Shawn, Jeanne Wanzek, Elizabeth Swanson, and Sharon Vaughn. "TeamBased Learning for Students with High-Incidence Disabilities in High School Social Studies Classrooms." Learning Disabilities Research and Practice 30, no. 1 (2015): 3-14.

Kubista-Hovis, Scott. "I Don't Dare Teach with Inquiry-Based Teaching Methods When I Have State Testing Breathing Down My Neck." In Team-Based Learning in the Social Sciences and Humanities: Group Work That Works to Generate Critical Thinking and Engagement, edited by Michael Sweet and Larry K. Michaelson, 291-300. Sterling: Stylus Publishing, 2012.

LaForce, Melanie, Elizabeth Noble, Heather King, S. Holt, and Jeanne Century. The 8 Elements of Inclusive STEM High Schools. Chicago: University of Chicago, 2014.

Langley, Ann, Henry Mintzberg, Patricia Pitcher, Elizabeth Posada, and Jan Saint-Macary. "Opening Up Decision Making: The View from the Black Stool." Organization Science 6, no. 3 (1995): 260-279.

Lantolf, James P., ed. "Introducing Sociocultural Theory." In Sociocultural Theory and Second Language Learning, 1-26. Oxford: Oxford University Press, 2000.

Lau, S. "Collectivism's Individualism: Value Preference, Personal Control, and the Desire for Freedom Among Chinese in Mainland China, Hong Kong, and Singapore." Personality and Individual Differences 13, no. 3 (1992): 361-366.

Lee, Wing On. "The Cultural Context for Chinese Learners: Conceptions of Learning in the Confucian Tradition." In The Chinese Learner: Cultural, Psychological, and Contextual Influences, edited by David Watkins and John Biggs, 25-41. Hong Kong: CERC and ACER, 1996.

Littlewood, William. "Students' Attitudes to Classroom English Learning: A Cross-Cultural Study." Language Teaching Research 5, no. 1 (2001): 3-28.

Liu, Shu-Hsien. "The Use of Analogy and Symbolism in Traditional Chinese Philosophy." Journal of Chinese Philosophy 1, no. 3-4 (1974): 313-338.

Lloyd, Geoffery. "Science in Antiquity: The Greek and Chinese Cases and Their Relevance to the Problems of Culture and Cognition." In Modes of Thought: Explorations in Culture and Cognition, edited by David R. Olson and Nancy Torrance, 15-33. Cambridge: Cambridge University Press, 1996. 
Maehr, M. L., and J. Nicholls. "Culture and Achievement Motivation: A Second Look." In Studies in Cross-Cultural Psychology, edited by Neil Warren, 221267. New York: Academic Press, 1980.

Maxwell, Amanda, Guy Curtis, and Lucia Vardanega. "Does Culture Influence Understanding and Perceived Seriousness of Plagiarism?" International Journal for Educational Integrity 4, no. 2 (2008): 25-40.

McClelland, David. The Achieving Society. Princeton: Von Nostrand, 1961.

Mcinerney, Michael, and L. Dee Fink. "Team-Based Learning Enhances LongTerm Retention and Critical Thinking in an Undergraduate Microbial Physiology Course." Journal of Microbiology and Biology Education 4 (2003): 3-12.

McLaughlin, Jacqueline, Mary Roth, Dylan Glatt, Nastaran Gharkholonarehe, Christopher Davidson, LaToya Griffin, Denise Esserman, and Russell Mumper. "The Flipped Classroom: A Course Redesign to Foster Learning and Engagement in a Health Professions School." Academic Medicine 89, no. 2 (2014): 236-243.

Michaelsen, Larry K., Arletta Knight, and L. Dee Fink. Team-Based Learning: A Transformative Use of Small Groups in College Thinking. Sterling: Stylus Publishing, 2004.

Michaelsen, Larry K., and Michael Sweet. "The Essential Elements of TeamBased Learning." New Directions for Teaching and Learning 116, no. (2008): $7-27$.

Michaelsen, Larry K., Warren E. Watson, and Robert H. Black. "A Realistic Test of Individual Versus Group Consensus Decision Making." Journal of Applied Psychology 74, no. 5 (1989): 834-839.

Ministry of Higher Education Malaysia. The National Graduate Employability Blueprint 2012-2017. Serdang: Universiti Putra Malaysia Press, 2012.

Moffett, Jennifer. "Twelve Tips for 'Flipping' the Classroom." Medical Teacher 37 , no. 4 (2014): 331-336.

Morgan, Tom. "Using Technology to Enhance Learning: Changing the Chunks." Learning and Leading with Technology 23, no. 5 (1996): 49-51.

Morshidi, Sirat, Chan Lean Heng, Munir Shuib, Shukran Abdul Rahman, Seri R. A. Kamil, and Jasvir K. N. Singh. "Employability of Graduates in Malaysia." In Employability of Graduates in Malaysia Graduate Employability in Asia, edited by UNESCO, 24-37. Bangkok: UNESCO, 2012.

Murphy, David. “Offshore Education: A Hong Kong Perspective." Australian Universities Review 30, no. 2 (1987): 43-44.

Nakamura, Hajime. The Ways of Thinking of Eastern Peoples. New York: Greenwood Press, 1988.

Nelson, Gayle L. "Comments on Ruth Spack's 'The Rhetorical Construction of Multilingual Students': Categorizing, Classifying, Labeling: A Fundamental Cognitive Process.” TESOL Quarterly 32, no. 4 (1998): 727-732. 
Neuman, Yair, and Zvi Bekerman. "Cultural Resources and the Gap Between Educational Theory and Practice." Teachers College Record 103, no. 3 (2000): 471-484.

Nguyen, Phuong-Mai, Cees Terlouw, and Albert Pilot. "Cooperative Learning vs Confucian Heritage Culture's Collectivism: Confrontation to Reveal Some Cultural Conflicts and Mismatch.” Asia Europe Journal 3, no. 3 (2005): 403419.

Nisbett, Richard E., Peng Kaiping, Incheol Choi, and Ara Norenzayan. "Culture and Systems of Thought: Holistic Versus Analytic Cognition." Psychological Review 108, no. 2 (2001): 291-310.

Niu, Weihua, John Zhang, and Yang Yingrui. "Does Culture Always Matter: For Creativity, Yes, for Deductive Reasoning, No!" In Creativity and Reason in Cognitive Development, edited by James C. Kaufman and John Baer, 282-296. New York: Cambridge University Press, 2006.

Norenzayan, Ara, and Ricard E. Nisbett. "Culture and Causal Cognition." Current Directions in Psychological Science 9, no. 4 (2000): 132-135.

Norenzayan, Ara, Edward E. Smith, Beom Jun Kim, and Richard E. Nisbett. "Cultural Preferences for Formal Versus Intuitive Reasoning." Cognitive Science 26, no. (2002): 653-684.

Norizan, Abdul Razak, Hazita Azman, Mohd Salehuddin Abdul Aziz, Azizah Yaacob, and Wong Fook Fei. Kajian Pembentukan Ujian Kompetensi Bahasa Inggeris bagi Pelajar IPTA di Malaysia (A Study of Developing an English Language Competency Test for Malaysian IPTA Students). Kuala Lumpur, Malaysia: Intensification of Research in Priority Areas (IRPA), 2007.

Norris, C., and J. L. Poirot. Problem Solving and Critical Thinking for Computer Science Educators. Eugene: International Society for Technology in Education, 1990.

Novera, Isvet A. "Indonesian Postgraduate Students Studying in Australia: An Examination of Their Academic, Social and Cultural Experiences." International Education Journal 5, no. 4 (2004): 475-487.

O'Dwyer, Shaun. "Deflating the 'Confucian Heritage Culture' Thesis in Intercultural and Academic English Education." Language, Culture and Curriculum 30, no. 2 (2017): 198-211.

Oliver, K. M. "Methods for Developing Constructivism Learning on the Web." Educational Technology 40, no. 6 (2000): 5-16.

Organisation for Economic Co-operation and Development. "The Future of Work Is Now. Are We Ready?” Accessed June 20, 2019, from http://www. oecd.org/employment/outlook/.

Park, Clara C. "Learning Style Preferences of Asian American (Chinese, Filipino, Korean, and Vietnamese) Students in Secondary Schools." Equity and Excellence in Education 30, no. 2 (1997): 68-77. 
Park, Jae. "Metamorphosis of Confucian Heritage Culture and the Possibility of an Asian Education Research Methodology." Comparative Education 47, no. 3 (2011): 381-393.

Parmelee, Dean, Larry Michaelsen, Sandy Cook, and Patricia Hudes. "TeamBased Learning: A Practical Guide: AMEE Guide No. 65." Medical Teacher 34, no. 5 (2012): 275-287.

Peng, Kaiping, and Richard E. Nisbett. "Culture, Dialectics, and Reasoning About Contradiction." American Psychologist 54 (1999): 741-754.

Peters-Burton, Erin E., Sharon Lynch, Tara Behrend, and Barbara Means. "Inclusive STEM High School Design: 10 Critical Components." Theory into Practice 53, no. 1 (2014): 64-71.

Piaget, Jean. "The Psychogenesis of Knowledge and Its Epistemological Significance." In Language and Learning, edited by Massimo Piatelli-Palmarini, 23-34. Cambridge: Harvard University Press, 1980.

Pierce, Richard, and Jeremy Fox. "Instructional Design and Assessment: Vodcasts and Active Learning Exercises in a 'Flipped Classroom' Model of a Renal Pharmacotherapy Module." American Journal of Pharmacentical Education 76, no. 10 (2012): 1-5.

Purdie, Nola, John Hattie, and Graham Douglas. "Student Conceptions of Learning and Their Use of Self-Regulated Learning Strategies: A CrossCultural Comparison." Journal of Educational Psychology 88, no. 1 (1996): 87-100.

Rania, Nadia, Laura Migliorini, and Stefania Rebora. "Team-Based Learning and Life Skills: A Qualitative Study from Psychological Students' Point of View." Health Science Journal 10, no. 1/2 (2015): 1-7.

Raudsepp, Eugene. “Can You Trust Your Hunches?” Management Review 49, no. 4 (1960): 7 .

Riley, Susan. "STEAM in the Classroom Look-For List." February 1, 2018. https://educationcloset.com/2018/02/01/steam-in-the-classroom/.

Robertson, Bill, and Christine Reimers. "Team-Based Learning for Critical Reading and Thinking in the Literature and Great Books Courses." In Team-Based Learning in the Social Sciences and Humanities: Group Work That Works to Generate Critical Thinking and Engagement, edited by Michael Sweet and Larry K. Michaelsen, 129-141. Sterling: Stylus Publishing, 2012.

Roehl, Amy, Shweta L. Reddy, and Gayla J. Shannon. “The Flipped Classroom: An Opportunity to Engage Millennial Students Through Active Learning Strategies." Journal of Family and Consumer Science 105, no. 2 (2013): 4449.

Rosenberg, Michael S., David L. Westling, and James McLeskey. Special Education for Today's Teachers: An Introduction. Upper Saddle River: Prentice Hall, 2008 . 
Ross, Lee. "The Intuitive Psychologist and His Shortcomings." In Advances in Experimental Social Psychology, edited by Leonard Berkowitz, 173-220. New York: Academic Press, 1977.

Salili, Farideh. "Accepting Personal Responsibility for Learning." In The Chinese Learner: Cultural, Psychological and Contextual Influences, edited by David A. Watkins and John B. Biggs, 86-105. Hong Kong: CERC and ACER, 1996.

Schwab, Klaus. The Fourth Industrial Revolution. Geneva: World Economic Forum, 2016.

Selz, O. "Attempt to Raise the Level of Intelligence." Zeitschrift fur Psychologie 134 (1935): 236-301.

Seo, Seonjin, and Mirka Koro-Ljungberg. "A Hermeneutical Study of Older Korean Students' Experiences in American Higher Education: From Confucianism to Western Educational Values." Journal of Studies in International Education 9, no. 2 (2005): 164-187.

Shi, Lijing. "The Successors to Confucianism or a New Generation? A Questionnaire Study on Chinese Students' Culture of Learning English." Language, Learning and Culture 19, no. 1 (2006): 122-147.

Sowden, Colin. "Plagiarism and the Culture of Multilingual Students in Higher Education Abroad." ELT Journal 59, no. 3 (2005): 226-233.

Spence, Janet T. "Achievement American Style: The Rewards and Costs of Individualism." American Psychologist 40, no. 12 (1985): 1285-1295.

Spender, J. C. Industry Recipe: An Enquiry into the Nature and Sources of Managerial Judgment. New York: Basil Blackwell, 1989.

Sternberg, Robert J., and Wendy M. Williams. Educational Psychology. Boston: Allyn \& Bacon, 2002.

Strayer, Jeremy. "How Learning in an Inverted Classroom Influences Cooperation, Innovation, and Task Orientation." Learning Environments Research 15, no. 2 (2012): 171-193.

Subramaniam, Ganakumaran. "Confronting Asian Concerns in Engaging Learners to Online Education." International Education Studies 1, no. 4 (2008): 10-18.

Sweet, Michael, and Larry Michaelsen. Team-Based Learning in the Social Sciences and Humanities: Group Work That Works to Generate Critical Thinking and Engagement. Sterling: Stylus Publishing, 2012.

Talley, Cheryl, and Stephen Scherer. "The Enhanced Flipped Classroom: Increasing Academic Performance with Student-Recorded Lectures and Practice Testing in a 'Flipped' STEM Course." The Journal of Negro Education 82, no. 3 (2013): 339-347.

Tao, Vivienne, and Hong Ying-Yi. "When Academic Achievement Is an Obligation-Perspectives from Social-Oriented Achievement Motivation." Journal of Cross-Cultural Psychology 45, no. 1 (2014): 110-136. 
Taylor, Insup, and Martin Taylor. Writing and Literacy in Chinese, Korean and Japanese. Amsterdam: John Benjamins, 2014.

Tu, Weiming. Confucian Thought: Selfhood as Creative Transformation. Albany: State University of New York Press, 1985.

Tucker, Jane, and Mary Brewster. "Evaluating the Effectiveness of Team-Based Learning in Undergraduate Courses." Journal of Criminal Justice Education 26, no. 4 (2015): 446-470.

Turner, Jane. Language in the Academy. Bristol: Multilingual Matters, 2011.

Turuk, Mamour C. "The Relevance and Implications of Vygotsky's Sociocultural Theory in the Second Language Classroom." ARECLS 5 (2008): 244-262.

Tweed, Roger G., and Darrin R. Lehman. "Learning Considered Within a Cultural Context: Confucian and Socratic Approaches." American Psychologist 57, no. 2 (2002): 89-99.

Vestberg, Hans. "Why We Need Both Science and Humanities for a Fourth Industrial Revolution Education." September 21, 2018. https://www. weforum.org/agenda/2018/09/why-we-need-both-science-and-humanitiesfor-a-fourth-industrial-revolution-education/.

Vygotsky, Lev. Thought and Language. Cambridge: MIT Press, 1962.

Wang, Junju. "Understanding the Chinese Learners from a Perspective of Confucianism." In Researching Cultures of Learning, edited by Martin Cortazzi and Jin Lixian, 61-79. London: Palgrave Macmillan, 2013.

Wanzek, Jeanne, Sharon Vaughn, Shawn Kent, Elizabeth Swanson, Greg Roberts, Martha Haynes, Anna-Maria Fall, Stephanie Stillman-Spisak, and Michael Solis. "The Effects of Team-Based Learning on Social Studies Knowledge Acquisition in High School." Journal of Research on Educational Effectiveness 7, no. 2 (2014): 183-204.

Wanzek, Jeanne, Shawn Kent, Sharon Vaughn, Elizabeth Swanson, Greg Roberts, and Martha Haynes. "Implementing Team-Based Learning in Middle School Social Studies Classes." Journal of Educational Research 108, no. 4 (2014): 331-344.

Watkins, David. A., and John Biggs. Teaching the Chinese Learner: Psychological and Pedagogical Perspectives. Hong Kong and Melbourne: CERC and ACER, 2001.

Wilson, Stephanie G. "The Flipped Class: A Method to Address the Challenges of an Undergraduate Statistics Course." Teaching of Psychology 40, no. 3 (2013): 193-199.

Witkin, Herman A., and John W. Berry. "Psychological Differentiation in CrossCultural Perspective." Journal of Cross-Cultural Psychology 6, no. 1 (1975): 4-87.

World Economic Forum. The Future of Jobs Report 2018. Geneva: World Economic Forum, 2018. 
. "What Is the Fourth Industrial Revolution?" CN Crypto News, April 27, 2019. https://www.cncryptonews.com/what-is-the-fourth-industrialrevolution/.

Wu, David. "Parental Control: Psycho-Cultural Interpretations of Chinese Patterns of Socialization." In Growing Up the Chinese Way: Chinese Child and Adolescent Development, edited by Lau Sing, 1-28. Hong Kong: The Chinese University of Hong Kong Press, 1996.

Yang, Kuo-Shu. "Chinese Personality and Its Change." In The Psychology of the Chinese People, edited by Michael H. Bond, 106-170. Hong Kong: Oxford University Press, 1986.

Yang, Kuo-Shu, and Yu An-Bang. "Social-Oriented and Individual-Oriented Achievement Motives: Conceptualization and Measurement." Paper presented at the Symposium on Chinese Personality and Social Psychology for the XXIVth International Congress of Psychology, Sydney, 1988.

- "Sinicization of Psychological Research in Chinese Society: Directions and Issues (in Chinese)." In The Sinicization of Social and Behavioral Science Research in Chinese Societies, edited by Yang Kuo-Shu and Ch'ung-i Wen, 153-187. Taipei: Institute of Ethnology, 1982.

Yee, Mei Hong, Widad Binti Othman, Jailani Bin Md Yunos, Tee Tze Kiong, Razali Bin Hassan, and Mimi Mohaffzya Binti Mohamad. "The Level of Marzano Higher Order Thinking Skills Among Technical Education Students." International Journal of Social Science and Humanity 1, no. 2 (2011): $121-125$.

Yu, An-Bang. "Socializational Factors of Individual's Achievement Motivation in Family." Bulletin of the Institute of Ethnology 71 (1991): 87-132.

- "Ultimate Life Concerns, Self, and Chinese Achievement Motivation." In The Handbook of Chinese Psychology, edited by Michael H. Bond, 227-246. Hong Kong: Oxford University Press, 1996.

Yu, An-Bang, and Yang Kuo-Shu. "Social-Oriented and Individual-Oriented Achievement Motivation: A Conceptual and Empirical Analysis (in Chinese)." Bulletin of the Institute of Ethnology, Academia Sinica 64 (1987): 51-98.

-. "The Nature of Achievement Motivation in Collectivist Societies." In Individualism and Collectivism: Theory, Method, and Applications, edited by Uichol Kim, Harry C. Triandis, Cigdem Kagitcibasi, Sang-Chin Choi, and Gene Yoon, 239-250. Thousand Oaks: Sage, 1994.

Yuan, Lijun. "Confucian and Feminist Notions of Relational Self and Reciprocity: A Comparative Study.” Journal of East-West Thought. Accessed June 25, 2019, from https://www.cpp.edu/ jet/Documents/JET/Jet17/Yuanl-9.pdf.

Zgheib, N. K., J. A. Simaan, and R. Sabra. "Using Team-Based Learning to Teach Pharmacology to Second Year Medical Students Improves Student Performance." Medical Teacher 32, no. 2 (2010): 130-135. 
Open Access This chapter is licensed under the terms of the Creative Commons Attribution 4.0 International License (http://creativecommons.org/licenses/ by $/ 4.0 /$ ), which permits use, sharing, adaptation, distribution and reproduction in any medium or format, as long as you give appropriate credit to the original author(s) and the source, provide a link to the Creative Commons license and indicate if changes were made.

The images or other third party material in this chapter are included in the chapter's Creative Commons license, unless indicated otherwise in a credit line to the material. If material is not included in the chapter's Creative Commons license and your intended use is not permitted by statutory regulation or exceeds the permitted use, you will need to obtain permission directly from the copyright holder.

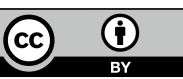


Liberal Arts Curricula in Asia Through the Diversity and Inclusion Lens 


\title{
Diversifying the Liberal Arts Curriculum in an Asian Context
}

\author{
Charles Bailyn
}

\section{INTRODUCTION}

The liberal arts approach to undergraduate education has three basic components. It assumes that learning in breadth across the curriculum is still important at the undergraduate level, and that specialization in a discipline or profession is only part of what should be accomplished in the classroom. It also encompasses learning outside the classroom, in a residential setting - it is commonly claimed that what students learn outside the classroom, by living with one another and through organizing student activities, is as important as what happens within the classroom. And the pedagogical approach favors independent thinking, in the form of individual and group projects, writing assignments and discussion, rather than,

\author{
C. Bailyn (凶) \\ Department of Astronomy, Yale University, New Haven, CT, USA \\ e-mail: charles.bailyn@yale.edu \\ (C) The Author(s) 2020 \\ C. S. Sanger and N. W. Gleason (eds.), \\ Diversity and Inclusion in Global Higher Education, \\ https://doi.org/10.1007/978-981-15-1628-3_6
}


or in addition to, high stakes examinations. ${ }^{1}$ As this philosophy of teaching spreads across the globe, the residential aspects and the pedagogical aspects have roughly similar issues to what have been faced in American colleges and universities, where this ethos has been in place for over a century. But the implementation of a liberal arts curriculum, in particular the trade-offs and challenges associated with the breadth curriculum, can look very different in Asia and other parts of the world.

The depth component of the curriculum typically consists of a major in a discipline or well-defined interdisciplinary area, comprising approximately half the course work for the degree, often culminating in some kind of large senior project. There is little disagreement on what a major looks like-the program of a typical Physics major or Economics major looks much the same from institution to institution. Approaches to curricular breadth, by contrast, vary widely from one liberal arts institution to another. In many cases they take the form of distribution requirements, in which students are asked to take a certain number of courses from particular categories (science, humanities, writing, arts, etc.) without regard to the specific content of the particular courses. The precise definition of the categories, and the number of courses required in each, is subject to revision and change in this model, and the rules vary across different institutions.

The principal argument in favor of the distribution system is that it generates faculty and student satisfaction with the classes. When faculty are allowed free rein over what they teach and how they teach it, they teach to their passions and generally do it very well-significantly better than if they are obliged to teach to a set curriculum. When the students can choose from a range of classes that satisfy a particular distribution

${ }^{1}$ The history of the liberal arts approach in the United States is sketched in Andrew Delbanco, College: What It Was, and Should Be (Princeton: Princeton University Press, 2012), which also provides a critique of the current situation. A thoughtful defense of the liberal arts is offered by the current President of Wesleyan University Michael S. Roth, Beyond the University: Why Liberal Education Matters (New Haven: Yale University Press, 2014). There have also been many fierce critiques of higher education in the United States today. Two of the most influential are Allan Bloom, The Closing of the American Mind (New York: Simon \& Schuster, 1987); William Deresiewicz, Excellent Sheep: The Miseducation of the American Elite and the Way to a Meaningful Life (New York: Free Press, 2014). Interestingly, neither of these critiques attacks the concept of a liberal arts education as such-both argue, in different ways, that the approach itself is good, but has been perverted and betrayed by current educational practices. 
requirement, they pick the instructors and the subject matter they prefer and are generally happy with their choices.

But there are some serious disadvantages to the distribution system. Most notably, there is no way to generate a coherent curriculum. The courses taken by students outside their major are items selected from a smorgasbord of offerings and do not generally build on or relate to each other. Students also often pick courses they are already comfortable with, whether the comfort zone pertains to subject matter, to instructional style, or (as is often the case) the identity of their fellow students. Within the social sciences, for example, one tends to end up with courses in gender studies taken almost exclusively by students who are already committed feminists, and investment strategy courses selected largely by (predominantly male) future financiers, where the liberal arts ethos might suggest that the opposite would be preferable. Thus, the distribution system often segregates students rather than bringing them together, and narrows and reinforces rather than broadens their intellectual horizons.

But distribution systems are not the only choice for the "breadth" part of a liberal arts education. There is also a tradition of a "core" curriculum-a series of classes which all students take together. This tradition lives on in some American institutions, notably at Columbia and Chicago universities, where all undergraduates take the "core." In the Directed Studies program at Yale, which is an option selected by about $10 \%$ of the students, students also pursue a core curriculum.

The advantages of a core curriculum, as practiced at these institutions and others, are many. First, it generates a shared experience among the students. This is particularly valuable when the students come from a wide range of backgrounds, as the tendency to fall into silos-linguistic, disciplinary, ethnic, or cultural-is mitigated when everyone is reading the same books at the same time, thus providing something to talk about across boundaries. At residential liberal arts institutions with distribution systems, students are generally not in the same classes as each other, so there is surprisingly little conversation between students about academics, and thus the valuable shared living experience does not extend to intellectual matters. In a core curriculum, students can be assigned to small classes or discussion sections in an intentional way, mixing cultures, previous background, academic interests and so on, so that they realize the full benefit of a diverse population in the classroom. This results in students finding themselves both in situations where they are more knowledgeable than their classmates and in situations where they are relatively ignorant or 
poorly prepared. If handled correctly (a significant pedagogical challenge that requires thought and sensitivity from the faculty), this can be used to instill both humility and confidence. Another advantage of a mandated common curriculum is that faculty advising can go deeper than simply a discussion of what courses the student should elect. This is sometimes disconcerting to the faculty: I recall one colleague asking plaintively what he was supposed to talk to the students about if they already knew what courses they would take.

The fact that students are all taking the same courses provides an appealing format, which many institutions use. All students attend weekly lectures - these supplement the readings that all students are doing, providing a shared experience for the students. It also provides an avenue through which the faculty showcase their expertise and enthusiasm. Each faculty member gives one or two lectures per semester, which can be more carefully prepared than if they were giving a whole semester of lectures, and the students get an early opportunity to sample the style and expertise of a large swathe of the faculty. But the bulk of the teaching is done in small seminars, which typically meet several times per week, each taught by a single member of the teaching team. It is in the seminars that the primary teaching and learning is done, through a discussion led by the faculty member. Since the faculty members cannot be domain experts for most of the readings, they can present themselves as guides and mentors, rather than as authorities, throughout the semester. In this way the liberal arts focus on independent creative thought is not just requested of the students, but is modeled by the faculty.

The teaching teams are themselves an important positive consequence of this type of course design. Through their colleagues, faculty members become acquainted with areas of scholarship somewhat distant from their own, which can be particularly useful when those areas are culturally relevant to groups of students within the institution. The teaching teams also function as pedagogical workshops, in which the faculty can exchange ideas and techniques about teaching in a more organic way than through events sponsored by teaching and learning centers or otherwise initiated by the administration. The teams can also serve as personal support groups for the faculty, particularly for new and young members of the team, and as incubators for new ideas for the institution as a whole.

Despite these advantages, there is a profound complexity to core curricula, which is why they have largely (although not entirely) been abandoned in American undergraduate liberal arts programs. That is the basic 
question of what should be in the core. The stakes could hardly be higher: every student at the institution will experience whatever is part of the core; many students will not encounter anything that is not in the core and outside their major. As the intellectual and cultural worlds of modern university have become increasingly diversified, faculty views on what every student should know and do have fragmented. This question has also become enmeshed in larger issues of diversity and inclusion within higher education and throughout society.

An interesting example of the disputes over core curricula in the United States is the recent controversy at Reed College in Oregon USA over their "Humanities 110" course..$^{2}$ This is a year-long course, taken by all first-year students, which serves as the centerpiece of their breadth curriculum. For many years, Humanities 110 featured an in-depth study of the ancient Mediterranean world, considered to provide the underpinnings of modern culture. Recently, students' groups and some faculty have mounted increasingly vehement protests against this curriculum, accusing it of a racist overemphasis on the foundations and achievements of white European civilization. Students held silent protests during lectures, causing considerable consternation among sympathetic faculty giving the lectures, and more radical groups insisted on being given time during the lectures to present their views, which the faculty and administration rejected. The argument that the concept of "white" was an anachronism in relation to the ancient Middle East was not persuasive, and a planned re-examination of the curriculum was moved forward. In the end, the first semester continued to be focused on the ancient Middle-East and on Athens, but the second semester was divided into two modules, one on the evolution of Tenochtitlan/Mexico City from Aztec

\footnotetext{
${ }^{2}$ This controversy was covered extensively in the press. See Colleen Flaherty, "Diversifying a Humanities Course," April 12, 2018, https://www.insidehighered.com/news/ 2018/04/12/responding-student-criticism-its-foundational-humanities-course-too-whitereed; Vimal Patel, "Students Said a Keystone Course Was Racist: Here's What Professors Did About It," April 11, 2018, https://www.chronicle.com/article/Students-Said-aKeystone/243095 for reports from higher education journals. For a relatively polite version of the more caustic view typical of conservative news media, see Katherine Timpf, "Campus Activists: Humanities 110 Course Should Not Include White Authors," May 8, 2018, https://www.nationalreview.com/2018/05/campus-activists-humanities-110course-should-not-include-white-authors/.
} 
to Spanish to modern Mexican civilization, and the other on the aesthetics and politics of the Harlem renaissance in the early twentieth century. ${ }^{3}$ This has not satisfied the student activists, who are now campaigning for the addition of a unit on African civilizations, for the emphasis on Athens in the first part of the course to be replaced by a focus on Jerusalem or Cairo, and for the module on New York City to be broadened to include Motown and other influences. ${ }^{4}$

It is a fascinating dispute, from curricular, cultural, and behavioral standpoints. But it contains a giant hole: where is Asia? Over half the world's population seems to be completely missing from the conversation. Africa vs "the west." Cairo vs Athens. Detroit vs New York. But no mention whatsoever of anything from Mumbai to Tokyo to Jakarta. It is of a piece with American demographic categories, which are typically divided into "white," "black," "Hispanic," and "Asian." Of these categories, "white" is considered the dominant culture, while "black" and "Hispanic" are "underrepresented minorities" for which fierce arguments are being made for increased representation, in the curriculum, in the student body, and in the ranks of the faculty. But "Asian" is a category of ambivalent valence which is generally not included either in efforts to support "traditional values" or in efforts to increase diversity. 5

${ }^{3}$ For the current and past reading lists and syllabi of the course, see Reed College, "Humanities 110," https://www.reed.edu/humanities/huml10/.

${ }^{4}$ For a statement of activist student reaction to the new curriculum can, see Reedies Against Racism, January 31, 2018, https://www.facebook.com/ reediesagainstr4cism/posts/this-morning-nigel-nicholson-dean-of-faculty-and-libbydrumm-chair-of-humanities/1619940544751479/.

5 There is currently a legal case being pursued against Harvard University on behalf of Asian-American students who the suit claims have been discriminated against in the admissions process. See Katie Reilly, "As the Harvard Admissions Case Nears a Decision, Hear from 2 Asian-American Students on Opposite Sides," TIME, March 12, 2019, https://time.com/5546463/harvard-admissions-trial-asian-american-students/; Eric Hoover, "At One Final Hearing, Harvard and Students for Fair Admissions Squared Off: Here's What Happened," February 12, 2019, https://www.chronicle.com/article/ At-One-Final-Hearing-Harvard/245695. But it is interesting that the originator of the suit, Edward Blum, was previously prominent in suits arguing against affirmative action for black and Hispanic students, as discussed Matthew J Johnson, "How the Latest Front Attacking Affirmative Action Might Backfire Against the Harvard Case", Slate, April 26, 2019, https://slate.com/news-and-politics/2019/04/affirmative-action-harvard-caseedward-blum-university-of-california.html. I am among those who believe that this suit is a stalking-horse for anti-affirmative action arguments, rather than a good faith effort on behalf of the Asian-American students. 
In the United States, neither the "traditional" core curricula, nor the proposed revised versions feature Asian literature, history, art, philosophy, or politics in any significant way. The Reed controversy perfectly demonstrates the situation. The curriculum has gone from a full year on the foundations of western civilization, to half a year on those foundations, and a quarter each focused on the African-American experience in New York, and on the development of Hispanic culture in Mexico. And the ongoing controversy is on whether Africa is sufficiently represented. Asia is simply not part of the conversation at all, either of the traditionalists or the reformers.

So, I would argue that the concept of "diversity" as it is discussed and disputed in American universities, is itself in drastic need of diversification. It is hard to accept a definition of "diversity" that excludes over half of the world's population, or flattens an extraordinary range of cultures and experiences into the single category of "Asian," and then either puts that category to the side or uses it as a proxy in battles between "traditional values" (represented by white European and American cultures) and "diversity and inclusion" (focused on black and Hispanic cultures). In what follows, I will recount one particular effort to include Asia in a core curriculum, and draw some lessons for others who might wish to make the attempt.

\section{The Yale-NUS College Common Curriculum}

Yale-NUS College is a liberal arts college located in Singapore, developed jointly by Yale and by the National University of Singapore (NUS). The institution was formally founded in 2011, began operations in 2013, graduated its first class of students in 2017 , and is now in a steady state of operations, with a student body of 1000 (50\% Singaporean, 50\% from the rest of the world) and a faculty of over 100, most on long-term or tenured contracts. The institution offers 14 majors across the full range of liberal arts and sciences, and a number of joint and double degree programs with schools within NUS and Yale. The faculty are an autonomous group, selected especially for Yale-NUS (although tenured faculty also hold tenure through NUS) augmented by frequent visitors from the two founding institutions.

It was decided early on that Yale-NUS would have a "common" curriculum that all students would take, rather than a distribution system similar to those of its parent institutions. In this way, it was hoped that a 
coherent curriculum, encompassing "Asia and the world" could be implemented, and the culturally diverse student body and faculty could be brought together. During an "incubation" year prior to the arrival of the first cohort of students, three dozen faculty members and administrators worked together to devise this curriculum. In the course of this work, a founding document was produced ${ }^{6}$ describing and explaining the choices that were made. Here I will discuss only the parts of the Yale-NUS common curriculum that pertain to the humanities, and are thus parallel to the "core" curricula in the United States, but it should be noted that the common curriculum also covered the social and natural sciences, an interesting curricular experience in itself.

I had the honor to serve as the inaugural Dean of Faculty of Yale-NUS College, which meant that I led the faculty hiring process, and was one of the leaders of the development of the curriculum. These two activities were interestingly entwined-we devised an outline of the common curriculum, which prompted us to hire faculty covering the areas in which we expected to need expertise; those new colleagues refined and advanced the curriculum, prompting more hiring, and so on. Throughout, we concentrated on hiring faculty who were excited to develop and teach this new curriculum. Our hiring process featured workshops involving candidates for positions across the disciplines, who were asked to discuss curricular matters with each other and current members of the faculty, and were evaluated on their enthusiasm and effectiveness in this situation. By hiring with the explicit understanding that the common curriculum would be at the center of activity for all faculty, we managed to avoid some (but not all) of the difficulties of creating a new common curriculum posed by the increasing diversity of faculty background and expertise.

I am in an unusual and somewhat awkward position in discussing the development and execution of the humanities part of the common curriculum. My scholarly expertise lies far from the humanities: I am an astrophysicist. My personal background is firmly rooted in the west-I had never even visited any part of Asia prior to the age of 40 . Thus, I have neither personal nor professional expertise in many of the crucial issues, and indeed for most of my life I have myself embodied

\footnotetext{
${ }^{6}$ The report, entitled Yale-NUS College: a new community of learning, contains a detailed discussion of the goals and philosophy of the new curriculum. See Bryan Garsten, Rajeev Patke, Charles Bailyn, Jane M. Jacobs, Kang Hway Chuan, and Bryan Penprase, rale-NUS College: A New Community of Learning (New Haven: Yale University, 2013).
} 
the American neglect of Asia that I discussed above. So, I approach these questions not from any position of expert knowledge or understanding, but from the perspective of a well-meaning but admittedly naïve administrator trying to organize the best learning experience for a globally diverse student body.

The overall structure of the Yale-NUS common curriculum involved a four-semester sequence of courses, in which the fraction of the students' coursework occupied by the common curriculum, as opposed to electives and courses in their majors, gradually diminished. In the first semester, all the courses were common; in the second semester three courses were common and one was elective; in the third semester there were two common courses, and in the fourth semester one course-the major was selected during the fourth semester. ${ }^{7}$ The humanities portion of the common curriculum consisted of two courses in the first year, one entitled "Literature and the Humanities" (abbreviated LitHum) and one entitled "Philosophy and Political Thought" (abbreviated PPT). Together, these courses comprise half of every student's course of study in their first year. Both were structured with one lecture in common each week, and two weekly seminar meetings with 15-18 students in each seminar. Given the student population, which started with 150 students per year and evolved to 250 in steady state, there were between 10 and $14 \mathrm{sec}-$ tions in each course. Some instructors (but not all) taught two sections, which resulted in teaching teams of between 6 and 10 different instructors. The basic learning goal of both first-semester humanities courses was to present students with a global curriculum in the humanities that lived up to the vision statement of the new College which references "in Asia,

\footnotetext{
7 There were also two courses in the "common" curriculum that were to be taken in the third and fourth year, chosen among a list of options (and in this way more like a distribution requirement). The system has since been modified to eliminate the common curriculum course in the fourth semester and one of the courses in the last two years. This was done in part because the sequencing for the majors proved to be too cramped, and in part because of difficulties associated with some of the common courses themselves. However, the humanities courses discussed here have been retained, although their content continues to evolve. The current version of the Yale-NUS common curriculum can be found here. Yale-NUS College, "Common Curriculum," https://www. yale-nus.edu.sg/curriculum/common-curriculum/.
} 
for the world." 8 Thus, the outlook would be global, with a particular focus on Asia.

The concept of "Asia" is of course problematic in itself. In cultural terms, there isn't really any such thing. One can perhaps identify a coherent culture and history associated with China, or Japan, or India, or the Islamic middle east, or various other regions and polities. But by lumping all of these together into "Asia," one broadens the category so much that it becomes hard to identify any unifying characteristics or cultural coherence at all. At first glance, one might as well go all the way, and talk about "the world" without specifying "Asia" as a particular focus. But Yale-NUS is situated in Singapore, which serves as an entrepot for a large fraction of the geographical region generally denoted as "Asia." Chinese, Malay, and Tamil cultures and languages are all regarded as native and are bound together inside a historically British city. So, the attempt to formulate a curriculum that really did represent Asia in some broad sense was necessary in a way that might not be true of an institution located in China, or India, or Japan, or the Gulf States. We could not fall back on a particular culture as a center of our curriculum, or even, as the new Reed curriculum does, as a center with strongly centrifugal elements attached to it. We needed to face up to the challenges of a curriculum without any specific cultural center at all.

As we considered how such a curriculum might work, a key first move was to escape from the idea of a "canon"-a group of works thought to be the best and most important works that could be studied. This idea of a canon is the basis of the traditional western core curricula, as well as offshoots like Norton anthologies and libraries of great works, and so on. But when one is exploring a range of different cultures, with none more central to the endeavor than the others, the concept of a canon is profoundly problematic, as it results in an inescapable valuation of particular works and the cultures they emerge from as superior to others, which is precisely what needs to be avoided. So, it's important to view the works selected as representative of their cultures, rather than being in any sense "the best." With this approach, one could choose works based on the enthusiasm of the faculty members who comprised the teaching

\footnotetext{
${ }^{8}$ The vision statement of the new college took a form similar to a haiku: "A community of learning / Founded by two great Universities / in Asia, for the world." This vision was strongly reinforced throughout the early days of the college, to the extent that the first student rock band adopted the name "Community of Learning."
} 
team, and in so doing harness the passions and teaching excellence that are the best features of the distribution system.

The same principle applied to the different cultures under study. As the students and faculty at Reed College have discovered, there is simply no way to incorporate every culture that merits inclusion into a one-year syllabus. Deciding what texts to read based on who "merits" inclusion is a recipe for divisive cross-cultural antagonism. We briefly contemplated subcourses focused on China, India, the West and so on, but this was clearly unworkable, simply in terms of available time. And even if it were feasible, the goal cannot be to include everything-the world is simply too big, and if nothing is left out, then everything will be addressed so superficially as to be worthless. ${ }^{9}$ Rather, an appropriate goal might be to encompass a broad enough range so that every student (and perhaps every faculty member) is faced during the course with something that is profoundly strange to them.

These considerations argue strongly against a curriculum that is fixed from year-to-year. The exclusion of particular texts, and even of whole cultures, can't be justified as a permanent feature of the curriculum. A multi-cultural setting in the modern world must have some commitment to inclusivity - students, faculty, and outside sponsors and observers will insist upon it. The small number of texts that can be read in a single common curriculum course cannot fully manifest such inclusivity. But a rotating series of works over many years can come much closer. Of course, a given student only takes the course once. So considerable effort has to be taken to convey that the reasons that particular works and cultures are studied in a given year are not a reflection of a valuation of the intrinsic worth of the texts and cultures selected. This can be a hard message to get across since students expect to be shown "the best." So, it needs to

${ }^{9}$ An interesting example of this problem is presented by the "World History" advanced placement course available in many US high schools. This course became so diffuse that the decision was recently made to eliminate the ancient world, and start the curriculum in the Renaissance. This brought immediate objections that the choice of the late fifteenth century as a starting point was profoundly Eurocentric, so the start date was moved back to the twelfth century (see CollegeBoard, "AP World History," https://apcentral. collegeboard.org/courses/ap-world-history/course/updates-2019-20 for a description of the new version). This new version, entitled "World History: Modern" will be introduced in the 2019-2020 academic year, so it remains to be seen how it will work out. But any restriction on time or place will be more appropriate for some cultures than for others, so in a sense "world history" is impossible, as it must contain either contain everything, or some aspects of "the world" will be favored over others. 
be continually reinforced by the faculty and the administration, both in discussions on a particular set of readings in a given semester, and across time.

An advantage of choosing from a wide range of works that cycle through the curriculum is that one can choose a selection of works associated with key issues in the culture and in the lives of the students. In the case of the Yale-NUS common curriculum, the PPT course started with Confucian thought, and the LitHum course started with the Ramayana. These choices had the advantage that they highlighted two different Asian traditions at the start of the courses. But there were other advantages, associated with the specific content of these works. One of the key aspects of Confucian thought is the question of what an "educated gentleman" ought to know, and how such a person ought to behave. This is a question of immediate import for students embarking on a liberal arts education within a society that has traditionally valued more instrumental forms of education. The ideas can be directly connected to what the students are experiencing as first-year college students, and are thus less abstract than, for example, the issues of reality and illusion associated with Plato's Cave. The Ramayana is an interesting place to start the discussion of epic, since, unlike Homer, it remains an oral tradition in many parts of the world, and thus the transition from an oral to a written culture can be explored directly.

But changing the curriculum year-to-year presents a problem from the faculty perspective in terms of time commitment and preparation. Preparing to teach a whole new set of texts each year would be a monumental effort, and would likely result in weaker teaching overall. So much of the course should persist from one year to the next. It is also the case that faculty members will likely rotate in and out of the teaching teams, to accommodate departures and arrivals, study leaves, the need for a full slate of advanced courses in the majors, and so on. Since the need for continuity and change applies both to the faculty and to the curriculum, it seems wise to associate them. That is, new faculty in the teaching team will bring with them new works to read and discuss, replacing those associated with faculty who are no longer part of the teaching team. This also ensures that faculty are able to present the works and issues that most concern them in the lectures.

Two examples of works that featured in the first version of LitHum, but subsequently rotated out, were the sixteenth-century-Chinese novel "Journey to the West," and a selection of Persian ghazals. Journey to the 
West seemed like a natural choice-it features stories that are still widely known in local cultures, serves as a foundation of the modern novel, and uses the term "west" to mean India, a welcome change of perspective for those like myself whose life and thought are centered in Europe and the Americas. We paired this with Cervantes' "Don Quixote," which plays a comparable role in the development of the European novel, and is often featured in western core curricula. But the combination of these two works proved to be too much reading for the time available, and without the pairing, Journey to the West seemed less crucial, and other works were substituted. The ghazals relied on the scholarly expertise of a particular faculty member, and when she left the institution, the use of these particular works proved to be hard to maintain. Thus, shifts in the reading list can come about for reasons of course coherence, and specifics of the faculty teaching team, as well as from deeper considerations of relevance to the educational mission.

One general anxiety was whether there would be anything to connect the different works from different cultures. Within a single cultureChina, India, the West-different works speak to each other because the later authors had in fact read the earlier authors. Thus, Virgil reads Homer, and Dante reads Virgil, and Milton reads Dante, and so on down to the beginning of the twentieth century when things start to get complicated. No such chain of influences exists when one switches cultures-at least not until the European imperialists imposed western culture on the rest of the world, an interaction which presents problems of its own. So we considered various ploys to try to make sure the texts studied were not isolated from each other-we considered organizing by themes ("justice" and "family" for example) as we were doing with the common curriculum course in the social sciences; we considered sequences within one culture: mini-courses on China, on Islam, on the West, and so forth.

We needn't have worried. The faculty and the students brought their own sensibilities to bear on the works, and made the connections themselves. What connected the works was that they were being read in this particular place, by these particular people, together. The common curriculum not only used joint study of specific works to bind together the community of learning - it used the community to unify the works.

Two examples can stand-in for a whole host of connections that cropped up as these courses were being taught. First was a moment during the LitHum course, during the study of the ancient Greek classic, 
Homer's Odyssey. The lecturer was discussing Odysseus's universal characteristics - he has attributes of male and female; god and mortal; Greek and barbarian. The lecturer then pointed out the relevance of the work of the fourth-century-Chinese Philosopher Mengzi on questions of taxonomy and the "rectification of names" in the Confucian tradition. Since everyone in the lecture hall had been reading Mengzi in Philosophy and Political Thought, the other first-semester humanities course, a connection was forged, not just between two traditions, but between all the students and faculty present for the lecture. Mengzi and Homer had, of course, no direct link between them-but the connection is real, even though it was created in a twenty-first-century classroom.

Another example came in another LitHum lecture on Greek literature, this time about the great female heroes Antigone and Medea. The first forty minutes of the lecture could have been lifted directly from a Directed Studies lecture at Yale, focused purely on a close reading of aspects of the works themselves. But then at the end, the lecturer moved to the early twentieth century and described the circumstances of one of the first translations of the ancient Greek dramatist Euripides into Chinese. The translator (a woman) had apparently also written a forward, in which she noted the emasculation of China by the Japanese occupation, and urged Chinese men to adopt the same kind of heroism as the female protagonists of the plays. A better example of the applicability of enduring literary themes to situations unanticipated by the authors would be hard to come by.

As noted, one consequence of the greater range of the material is strain on the faculty, who must all become familiar with texts far outside their fields of expertise, and that in some cases they may not even have heard of before. This is particularly difficult for the junior faculty who have less teaching experience, and who are often already troubled by issues of authority in the classroom. At Yale-NUS, we were fortunate to have an "incubation year" in which planning for the curriculum and for the institution took place for a year before the students arrived. This was essential for the development and delivery of the common curriculum. For example, the faculty recruited expert colleagues who created a six-week reading 
course on Chinese philosophy, an area of the curriculum that was particularly unknown to many of our philosophy faculty, who had generally been trained in American departments focusing on analytic philosophy. ${ }^{10}$

One difficulty we encountered was the incorporation of specific skills into common courses that were conceived of as focused on content areas-on texts and analysis. Where in the common curriculum did one learn a foreign language? Practice writing and speaking skills? Learn statistics? In LitHum and PPT, the key question was writing-while communication is an essential skill in all disciplines, the textual basis of study in the humanities necessitates a focus on reading and writing, so these skills are often associated with study in the humanities. This connection may be too narrow. There are many kinds of communication crucial to the modern age that are remote from the traditional academic essay. For example, YouTube videos and PowerPoint presentations are key forms of communication across the globe today, and there is much that can be taught and learned about effective use of these modes. Nevertheless, argumentative writing remains a crucial skill, and at Yale-NUS, the place we sought to teach this skill was in the humanities courses.

Embedding writing within LitHum and PPT presented some difficulties. First, the level of preparation and enthusiasm among the teaching team for skills-based teaching varied significantly. Given the preparation necessary to teach the texts as such, additional preparation for the pedagogical challenge of teaching writing was difficult to fit in. We standardized the number and length of the required essays, but in the first iterations of the course, there was great diversity in the level of focus on the craft of writing. We considered courses or submodules on writing as such, and also outsourced some of the specific work of counseling students to the Writer's Center. But the results were uneven, and it has taken considerable effort to build effective writing instruction into the common

${ }^{10}$ Philosophy presents particular problems for an Asian-oriented curriculum in terms of training for faculty members. Two prominent American scholars of Chinese philosophy (both of whom have been part of the Yale-NUS faculty) wrote in the New York Times that the absence of non-western philosophy in American and European departments was so severe that the departments should be renamed "European Philosophy." This prompted comments, including some who argued strongly that Asian philosophy should indeed not be included within "Philosophy," but rather in "Religious Studies" or "Asian Studies." This in turn prompted one of the authors to expand the arguments in favor of greater inclusion of Asian philosophy into a full length book. 
curriculum. This effort continues today-Yale-NUS has recently restructured aspects of the Writer's Center and its relationship with the common curriculum, so this piece of the curriculum remains a work in progress. It should be noted that the relationship between skills and content is a perennial problem in breadth curricula-whether it is better to have specialized skills courses, or to embed the skills across the curriculum is a subject of considerable dispute. And the problem extends beyond writing within the humanities - the crucial skill of effective visual and oral presentation of technical material has similar issues.

The question of writing leads to issues relating to the other arts. The first semester of both LitHum and PPT focuses largely on literary and philosophical texts, as is common in "Great Books" curricula, regardless of the cultural orientation. But the second half of the courses, with their focus on more recent times, provided opportunities to study visual and performing arts alongside written texts. The study of forms other than written texts provided both opportunities and challenges. Clearly, a focus on breadth education is enhanced by the study of music, theater, and art, which are the focus of a considerable amount of student extracurricular activity-indeed, some distribution systems have an explicit "arts" requirement distinct from other humanities. It is also the case that adding units on the arts enabled faculty in those areas to participate in the common curriculum on equal terms with their colleagues in literature and philosophy. Given our commitment that every faculty member should have the opportunity and obligation to participate in the common curriculum, and the use of the common curriculum as a showcase to students for the range of faculty interests, this was a plus. But adding units on the arts exacerbated other issues with the common curriculum. In particular, units focused on material not in textual form made it even harder for the faculty to master the range of material they were required to teach, and it made it harder to embed writing as such into the curriculum. The optimum way to include visual and performing arts in a core curriculum is thus not clear, but it is a question that must be addressed.

\section{CONCLUSION}

In all of the above, there is a constant theme. Devising and revising such a curriculum is a constant and ongoing effort. It is not the case that one can invent a core curriculum, and then declare the job done and focus solely on delivering the course to the students. This approach-that a 
well-designed course is timeless and deserves reconsideration no more than once a generation, if at all-contributed strongly to the downfall of the "western civ" core courses. Without opportunities to review and renew the courses, the deepest concerns of the community of faculty and students, and of society more generally, diverged further and further from what was being taught. Since there was no way to adjust on the fly, this divergence eventually resulted in painful high-stakes overhauls that generated conflict well beyond the specific discussions about the pedagogical and curricular issues directly involved. It would have been much better if these courses could have moved slowly, year-by-year, with the times. Such an evolution is difficult when the curriculum is presumed to be canonical-but in the absence of the assumption of a canon, it is not just possible, but necessary.

But curriculum reviews are time-consuming efforts. They take hours of discussion and negotiation and considerable organizational effort. If the curriculum is to be reviewed and renewed, on a regular, perhaps a continuing basis, the required effort must be built into the expectations for and of the faculty. In this model "teaching" is more than delivering courses to students. It is also a matter of reconsidering the courses, revising them, and putting in the hard work needed to master new texts and works, as well as new pedagogical approaches to skills and content. For this process to be successful, the institution must support it by providing the faculty with the time necessary to fully engage with curriculum development. The faculty must support it by being willing to reconsider cherished texts and pedagogical techniques and master new approaches and material on an ongoing basis. Only with these commitments can we ask our students to open their minds and hearts to an education that explores the true breadth of the world they inhabit.

\section{BIBLIOGRAPHY}

Bloom, Allan. The Closing of the American Mind. New York: Simon \& Schuster, 1987.

CollegeBoard. "AP World History." https://apcentral.collegeboard.org/ courses/ap-world-history/course/updates-2019-20.

Delbanco, Andrew. College: What It Was, and Should Be. Princeton: Princeton University Press, 2012.

Deresiewicz, William. Excellent Sheep: The Miseducation of the American Elite and the Way to a Meaningful Life. New York: Free Press, 2014. 
Flaherty, Colleen. "Diversifying a Humanities Course." April 12, 2018. https:// www.insidehighered.com/news/2018/04/12/responding-student-criticismits-foundational-humanities-course-too-white-reed.

Garsten, Bryan, Rajeev Patke, Charles Bailyn, Jane M. Jacobs, Kang Hway Chuan, and Bryan Penprase. Yale-NUS College: A New Community of Learning. New Haven: Yale University, 2013.

Hoover, Eric. "At One Final Hearing, Harvard and Students for Fair Admissions Squared Off: Here's What Happened." February 12, 2019. https://www. chronicle.com/article/At-One-Final-Hearing-Harvard/245695.

Johnson, Matthew J. "How the Latest Front Attacking Affirmative Action Might Backfire Against the Harvard Case", Slate, April 26, 2019. https://slate. $\mathrm{com} /$ news-and-politics /2019/04/affirmative-action-harvard-case-edwardblum-university-of-california.html.

Patel, Vimal. "Students Said a Keystone Course Was Racist: Here's What Professors Did About It." April 11, 2018. https://www.chronicle.com/article/ Students-Said-a-Keystone/243095.

Reed College. "Humanities 110." https://www.reed.edu/humanities/ hum $110 /$.

Reedies Against Racism. January 31, 2018. https://www.facebook.com/ reediesagainstr4cism/posts/this-morning-nigel-nicholson-dean-of-facultyand-libby-drumm-chair-of-humanities/1619940544751479/.

Reilly, Katie. "As the Harvard Admissions Case Nears a Decision, Hear from 2 Asian-American Students on Opposite Sides." TIME, March 12, 2019. https://time.com/5546463/harvard-admissions-trial-asian-americanstudents/.

Roth, Michael S. Beyond the University: Why Liberal Education Matters. New Haven: Yale University Press, 2014.

Timpf, Katherine. "Campus Activists: Humanities 110 Course Should Not Include White Authors.” May 8, 2018. https://www.nationalreview.com/ 2018/05/campus-activists-humanities-110-course-should-not-include-whiteauthors/.

Yale-NUS College. "Common Curriculum." https://www.yale-nus.edu.sg/ curriculum/common-curriculum/. 
Open Access This chapter is licensed under the terms of the Creative Commons Attribution 4.0 International License (http://creativecommons.org/licenses/ by $/ 4.0 /$ ), which permits use, sharing, adaptation, distribution and reproduction in any medium or format, as long as you give appropriate credit to the original author(s) and the source, provide a link to the Creative Commons license and indicate if changes were made.

The images or other third party material in this chapter are included in the chapter's Creative Commons license, unless indicated otherwise in a credit line to the material. If material is not included in the chapter's Creative Commons license and your intended use is not permitted by statutory regulation or exceeds the permitted use, you will need to obtain permission directly from the copyright holder.

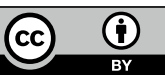




\title{
Service-Learning as a Means to Understand Socio-Economic Privilege, Inequality, and Social Mobility
}

\author{
Mikiko Nishimura and Hitomi Yokote
}

\section{Introduction: The Challenge of Civic Engagement to Address Social Inequality in Liberal Arts EDUCATION IN AsIA}

Liberal arts education has rapidly spread in Asia over the past 20 years. According to Godwin, 44\% of the total of 161 programs outside the United States were created after 2000 and approximately 13\% (69) of

${ }^{1}$ K. A. Godwin, "The Global Emergence of Liberal Education: A Comparative and Exploratory Study" (PhD diss., Boston College, 2013), https://dlib.bc. edu/islandora/object/bc-ir:104384; K. A. Godwin, "The Worldwide Emergence of Liberal Education," International Higher Education 79 (2015): 2-4.

\footnotetext{
M. Nishimura $(\bowtie) \cdot H$. Yokote

International Christian University, Tokyo, Japan

e-mail: nmikiko@icu.ac.jp

H. Yokote

e-mail: yokohitomi@icu.ac.jp

(C) The Author(s) 2020

C. S. Sanger and N. W. Gleason (eds.),

Diversity and Inclusion in Global Higher Education, https://doi.org/10.1007/978-981-15-1628-3_7
} 
liberal arts programs in the world are found in Asia where India, Japan, and Hong Kong share half of them. ${ }^{1}$ The main reasons for this trend are three-fold. First, there has been a widespread notion that the highly specialized academic fields have limitations to tackle complexities of the global issues for which the interdisciplinary approach of liberal arts education was considered as a better alternative. Second, the twenty-firstcentury skills and competencies for innovation advocated in the international sphere ${ }^{2}$ were in line with fundamental principles of liberal arts education that emphasize critical thinking, moral and civil character, and use of knowledge to improve the world. ${ }^{3}$ Third, the "international" liberal arts education has become one "business model" in East Asia to attract international students and to meet the global market needs. ${ }^{4}$

While civic engagement with social equity and justice has been one of the core values of liberal arts education in North America, what is distinctive about the rapid expansion of liberal arts education programs in Asia is its heavy emphasis on pragmatic motivation initially to catch up with the West and more recently to become a global leader. Large-visioned ideals, moral purpose as members of a civil society, criticism against moral emptiness of modern sciences featured by the US liberal arts traditions are largely absent or at best only implicitly embedded. ${ }^{5}$ Yang claims that the East Asian societies have had a strong catch-up mind-set with the West

${ }^{2}$ K. Ananiadou and M. Claro, "2lst Century Skills and Competencies for New Millennium Learners in OECD Countries" (OECD Education Working Papers No. 41, 2009); OECD, The Future of Education and Skills: Education 2030 (Paris: OECD, 2018).

${ }^{3}$ R. Chopp, "Remaking, Renewing, Reimagining the Liberal Arts College Takes Advantage of Change," in Remaking College: Innovation and the Liberal Arts, edited by R. Chopp, S. Frost, and D. H. Weiss (Baltimore: Johns Hopkins University Press, 2014), 13-24.

${ }^{4}$ A. Yonezawa and M. Nishimura, "Revisiting Key Values, Roles, and Challenges of Liberal Arts Education in East Asia," in Liberal Arts Education and Colleges in East Asia: Possibilities and Challenges in the Global Age, edited by I. June, M. Nishimura, and T. Sasao (Singapore: Springer, 2016), 125-136.

5 J. Buchler, "Reconstruction in the Liberal Arts," in A History of Columbia College on Morningside, edited by D. C. Miner (New York: Columbia University Press, 1954); R. M. Hutchins, The Higher Learning in America (New Haven: Yale University Press, 1968); H. C. King, "What the College Stands for," Association of American Colleges Bulletin III, no. 1 (1917): 24; A. Meiklejohn, The Liberal College (Boston: Marshall Jones, 1920); W. Summerscales, Affirmation and Dissent (New York: Teachers College Press, 1970). 
that has led them to focus on Western practicality, rather than consider moral underpinnings of educational systems. ${ }^{6}$

Furthermore, the neoliberal outlook and focus on "practicality" in higher education in Asia has been intensified by the recent trend of internationalization of higher education literatures with a strong focus on numerical trends of student mobility, diversity and flexibility of programs, the university ranking, and quality assurance. ${ }^{7}$ Internationalization efforts in higher education institutions tend to aim at preparing students for the global economy where the focus is on developing "global competencies" that would enable students to become internationally mobile and readily employable in a variety of cultural contexts. ${ }^{8}$ Fostering citizenship, social equality, inclusive society, and common good seem to be a lost agenda in higher education in many Asian contexts.

At the same time, social inequality in Asia is expanding ever more rapidly than before and in any other region. While the East Asia and Pacific region have the lowest income inequality of the world, the Gini coefficient rose from 32.7 to 38.1 between 1990 and 2014 with the largest magnitude of rise in the world during this period. ${ }^{9}$ Empirical evidence shows that while equal distribution of educational opportunity generally contributed to reducing income inequality, higher per capita income, greater openness to international trade, and faster technological progress made both income and education distribution unequal. ${ }^{10}$

${ }^{6}$ R. Yang, "The East-West Axis? Liberal Arts Education in East Asian Universities," in Liberal Arts Education and Colleges in East Asia: Possibilities and Challenges in the Global Age, edited by I. June, M. Nishimura, and T. Sasao (Singapore: Springer, 2016), 27-38.

${ }^{7}$ S. J. Chen, "Shifting Patterns of Student Mobility in Asia," Higher Education Policy 25, no. 2 (2012): 207-224; K. H. Mok and K. M. Yu, Internationalization of Higher Education in East Asia: Trends of Student Mobility and Impact on Education Governance (New York: Routledge, 2014); M. Shah and D. T. N. Quyen, eds. The Rise of Quality Assurance in Asian Higher Education (Cambridge: Chandos Publishing, 2017).

${ }^{8}$ F. Atkas, K. Pitts, J. C. Richards, and I. Silova, "Institutionalizing Global Citizenship: A Critical Analysis of Higher Education Programs and Curricula," Journal of Studies in International Education 21, no. 1 (2017): 65-80.

${ }^{9}$ P. Andersson, "Inequality in Asia and the Pacific" (Presentation, Interregional Expert Group Meeting on Placing Equality at the Center of Agenda 2030, Santiago, June 2018), https://www.cepal.org/sites/default/files/presentations/s1_3._pandersson.escap_.pdf.

${ }^{10} \mathrm{~J}$. Lee and H. Lee, "Human Capital and Income Inequality" (ADBI Working Paper Series No. 810, Asian Development Bank Institute, Tokyo, 2018). 
Fast income growth and rapid progress of globalization and technological change seem to have accelerated income inequality in Asia over the past two and half decades.

Given this trend, how does liberal arts education address social inequality and inclusion at local and global levels in Asia? In this chapter, we attempt to discuss service-learning programs to examine the challenges and potential of liberal arts education in Asia to enhance civic engagement and greater awareness of socio-economic diversity in the international/intercultural dimension. In the next section, we discuss the linkage between service-learning and civic engagement, and the controversy over higher education's role in reproducing social inequality. Section "ICU's International Service-Learning and Its Impact on Students" presents the case of international service-learning programs at International Christian University (ICU) in Japan to examine the program's learning outcomes and challenges. Finally, section "Discussion: Missing Link Between Moral Awareness and Civic Engagement" will critically reflect on the potential and future direction of service-learning programs in liberal arts education to address social inequality in Asian contexts.

\section{Service-Learning Program: Peril or Promise?}

There has been a prolonged debate in Sociology of Education over whether education in a meritocratic society generates chances for upward social mobility or reproduces social inequality. ${ }^{11}$ Given the high tuition in small-sized private liberal arts colleges in the United States, investing in liberal arts higher education is often regarded as a luxury, out of touch, elitist, ineffective, and well past in use. ${ }^{12}$ Previous studies also looked into positive comprehensive outcomes of liberal arts education in self-efficacy, leadership skills, civic engagement, and global connections. ${ }^{13}$

${ }^{11}$ A. R. Sadovnik, ed. Sociology of Education: A Critical Reader, 2nd ed. (New York: Routledge, 2010).

${ }^{12}$ J. Logan and J. Curry, "A Liberal Arts Education: Global Trends and Challenges," Christian Higher Education 14, nos. 1/2 (2014): 66-79; C. Rowen, "So Much More Than Salary: Outcomes Research in Liberal Arts," New Direction for Institutional Research 169 (2016): 51-60.

${ }^{13}$ E. T. Pascarella, G. C. Wolniak, T. A. D. Seifert, T. M. Cruce, and C. F. Blaich, "Liberal Arts Colleges and Liberal Arts Education," ASHE Higher Education Report 31, no. 3 (2005): 1-146; Rowen, "So Much More Than Salary." 
Service-learning is a pedagogy designed to transform the role of higher education from an elitist reproduction of privileges and social inequality to one of redressing social inequality through civic and community engagement at local and global levels. Service-learning is typically defined in the United States as "a credit-bearing, educational experience in which students participate in an organized service activity that meets identified community needs and reflect on the service activity in such a way as to gain further understanding of course content, a broader appreciation of the discipline, and an enhanced sense of civic responsibility." 14 In Asia, however, there exist many service-learning programs including but not limited to non-credit bearing programs, short-term summer international programs, and a graduation requirement without bearing a credit. In this context, service-learning is simply defined as "intentionally structured activities that engage students in social services to solve problems encountered by community members." 15

There are numerous service-learning practices in higher education in North America over the past four decades or more and their outcomes have been documented in abundant peer-reviewed journal articles and books. Service-learning is expected for students to gain insight about their personal strengths and identity, to learn about the realities of inequality, and to increase their empathy and sense of social responsibility and social justice. ${ }^{16}$ Service-learning has been found to be associated with a host of positive outcomes, including greater sensitivity and empathy, increased commitments to social justice, improved cultural competence or multicultural skills, and stereotype reduction. ${ }^{17}$

The learning outcomes of service-learning have also been reported to vary depending on the program type and student demographics.

${ }^{14}$ R. G. Bringle and J. A Hatcher, "A Service-Learning Curriculum for Faculty," Michigan Journal of Community Service Learning 2, no. 1 (1995): 112.

${ }^{15}$ K. Chan, E. Ng, and C. C. Chan, "Empowering Students Through Service-Leaning in a Community Psychology Course: A Case in Hong Kong," Journal of Higher Education Outreach and Engagement 20, no. 4 (2016): 25-35.

${ }^{16}$ K. R. Brewster, "Transformative and Transformed: Examining the Critical Potential of Service-Learning Positional Identities," Equity o Excellence in Education 51, nos. 3-4 (2018): 347-361.

${ }^{17}$ J. Conner and J. Erickson, "When Does Service-Learning Work? Contact Theory and Service-Learning Courses in Higher Education," Michigan Journal of Community Service Learning 23, no. 2 (2017): 53-65. 
For example, Brown et al. found that the service-learners in autonomyoriented placements that aimed at assisting the recipient with a partial solution had more positive attitudes toward social equality than did a control group and those in dependency-oriented programs that provided a full solution to recipients' needs. ${ }^{18}$ Another study by Conner and Erickson shows that service-learning with more attention to quality and engaged contact with communities had a more positive impact on reducing students' overall color-blindness and improving their awareness of blatant racial issues. ${ }^{19}$ They also point out that the impact was different by race and gender whereby non-white and male students improved their awareness significantly more than their counterparts.

Service-learning is more of the recent trend in Asia where Christian universities were the main driving force to adopt service-learning programs in the late 1990s to the 2000s. The Service-Learning Asia Network (SLAN) was established in 2002 and has held an annual meeting every year since. In Asia, service-learning has been reported to impact students' interpersonal, interactional, and behavioral changes. ${ }^{20}$ Yang et al. indicated that service-learning impacts students' conceptions of self as leaders who promote and uphold long-term benefits for community members and their peers. ${ }^{21}$ They further argue that international service-learning has the potential for supporting students' self-exploration by giving them opportunities to incorporate moral, cultural, and leadership values into their conceptions of self.

Nevertheless, since the late 2000 s, critical perspectives on servicelearning have grown to argue against the benefits of traditional "charitymode" service-learning. These critiques insist that it does not create

${ }^{18}$ M. A. Brown, J. D. Wymer, and C. S. Cooper, "The Counter-Normative Effects of Service-Learning: Fostering Attitudes Toward Social Equality Through Contact and Autonomy," Michigan Journal of Community Service Learning 23, no. 1 (2016): 37-44.

${ }^{19}$ Conner and Erickson, "When Does Service-Learning Work?".

${ }^{20}$ Chan, $\mathrm{Ng}$, and Chan, "Empowering Students Through Service-Leaning in a Community Psychology Course."

${ }^{21}$ M. Yang, L. Y. Y. Luk, B. J. Webster, A. W. Chau, and C. H. K. Ma, "The Role of International Service-Learning in Facilitating Undergraduate Students' Self-Exploration," Journal of Studies in International Education 20, no. 5 (2016): 416-436. 
structural change in society and is distanced from social justice. ${ }^{22}$ Clifford notes that traditional service-learning is skewed toward professional skill development and perceived as a mere "product" for career advancement. ${ }^{23}$ Such service-learning programs generate depoliticized participation, simply create the mere dreaming of justice, and reproduce cognitive deficits of students that ignore the structures of power, privilege, and oppression that made them lucky enough to get to do service. ${ }^{24}$ Critical perspectives argue that service-learning could potentially be considered exploitative, failing to provide students with a critical appreciation of the issues of power and inequality embedded in working with deprived or marginalized communities, thus reinforcing their prejudices, stereotypes, and deficit-based views cultivated by the societal context of neoliberalism. ${ }^{25}$

Critical perspectives suggest an alternative form of service-learning, often called "critical service-learning" whereby students should be supported and challenged to reflect on their own unconscious biases and stereotypical behaviors by critical reflection and reciprocity for social

${ }^{22}$ J. Clifford, "Talking About Service-Learning: Product or Process? Reciprocity or Solidarity?" Journal of Higher Education Outreach and Engagement 21, no. 4 (2017): 1-13; A. Furco, "Foreword," in Problematizing Service-Learning: Critical Reflections for Development and Action, edited by T. Stewart and N. Webster (Charlotte, NC: Information Age, 2011), ix-xi; T. Mitchell, "Traditional vs. Critical Service-Learning: Engaging the Literature to Differentiate Two Models," Michigan Journal of Community Service Learning 14, no. 2 (2008), 50-65.

23 Clifford, "Talking About Service-Learning."

${ }^{24} \mathrm{H}$. Burth, "The Contribution of Service-Learning Programs to the Promotion of Engagement and Political Participation: A Critical Evaluation," Citizenship, Social and Economics Education 15, no. I (2016): 58-66; D. Butin, "Dreaming of Justice: Critical Service-Learning and the Need to Wake Up," Theory into Practice 54, no. 1 (2015): $5-10$.

${ }^{25}$ M. Asghar and N. Rowe, "Reciprocity and Critical Reflection as the Key to Social Justice in Service Learning: A Case Study," Innovations in Education and Teaching International 54, no. 2 (2017): 117-125; M. Latta, T. M. Kruger, L. Payne, L. Weaver, and J. L. VanSickle, "Approaching Critical Service-Learning: A Model for Reflection on Positionality and Possibility," Journal of Higher Education Outreach and Engagement 22, no. 2 (2018): 31-55; Mitchell, "Traditional vs. Critical Service-Learning." 
change. ${ }^{26}$ Mitchell identifies "social change orientation, working to redistribute power, and developing authentic relationships" 27 as common elements to distinguish critical service-learning from traditional servicelearning. Learning outcomes are to acknowledge the unequal global power dynamics, reflect on students' own place in the global world, and ultimately address social injustice. ${ }^{28} \mathrm{~A}$ broader analysis of power within service-learning is key to understanding how hierarchy hinders the acknowledgment or problematization of inequality in critical servicelearning. ${ }^{29}$

It is also important to note that social inequality is not perpetuated solely by the side of the students who do the service from mostly the North or the more privileged, but also reinforced by the community members who receive service. There is danger in dependency-oriented service based on a savior mentality which reflects a negative view of the service recipient as dependent and incapable. ${ }^{30}$ However, Grain et al. indicate that the framing white international students as givers-of-knowledge and the catalysts of positive change was prevalent in local communities in Africa despite international service-learning programming that prepares students through decolonizing frameworks and critical self-reflection in Canada. ${ }^{31}$ The white supremacy imposed by colonialism and the postcolonial vestiges of white privilege continue to reveal in diverse ways in the process of service-learning, regardless of how much one attempts to decolonize its intent.

To overcome this dichotomous tension of colonizer/colonized or service-giver/service-taker, a concept of solidarity has been suggested.

${ }^{26}$ Asghar and Rowe, "Reciprocity and Critical Reflection as the Key to Social Justice in Service Learning"; F. Atkas, K. Pitts, J. C. Richards, and I. Silova, "Institutionalizing Global Citizenship: A Critical Analysis of Higher Education Programs and Curricula," Journal of Studies in International Education 21, no. 1 (2017): 65-80.

${ }^{27}$ Mitchell, "Traditional vs. Critical Service-Learning," 62.

${ }^{28}$ Atkas, Pitts, Richards, and Silova, "Institutionalizing Global Citizenship."

${ }^{29}$ T. D. Mitchell, D. M. Monahue, and C. Young-Law, "Service Learning as a Pedagogy of Whiteness," Equity and Excellence in Education 45, no. 4 (2012): 612-629.

${ }^{30}$ Brown, Wymer, and Cooper, "The Counter-Normative Effects of Service-Learning."

${ }^{31}$ K. Grain, T. Katumba, D. Kirumira, R. Nakasiita, S. Nakayenga, E. Nankya, V. Nteza, and M. Sssegawa, "Co-constructing Knowledge in Uganda: Host Community Conceptions of Relationships in International Service-Learning," Journal of Experiential Education 42, no. 1 (2019): 22-36. 
Tapia defines solidarity as actions that are developed in conjunction with the community and not for it. ${ }^{32}$ Solidarity is a way to resist colonial logics because it requires the configuration of new ways of being, interacting, and learning, which together emphasize the collective, the reciprocal, and mutual, rather than individualistic notions of the self. ${ }^{33}$ Santiago-Ortiz notes that "service" implies a hierarchical relationship from the outset and that "solidarity" opens the door for epistemic disobedience that transgresses colonialist understandings of knowledge and relationships. ${ }^{34}$ The concept of solidarity suggests that one should tackle social inequality and social justice beyond the hierarchical analysis of social groups and build a more horizontal and solidary community-university partnership.

Although we still lack sufficient and compelling evidence to suggest the types and depth of lessons learnt from service-learning programs in Asia as reference to the rich knowledge accumulation in North and South America, the next section will examine students' learning outcomes of international service-learning in and out of Japan and in particular in the context of International Christian University, lessons of which could be extended to other universities in Asia.

\section{ICU's INTERNATIONAL SERVICE-LEARNING AND ITS IMPACT ON STUDENTS}

International Christian University (ICU) is the leading liberal arts college in Japan with approximately 2800 students and 152 full-time faculty members with the distinctive feature of $40 \%$ of faculty coming from overseas and $30 \%$ being female professors. Its founding philosophy was supranational and derived from deep reflection on World War II. ${ }^{35}$ Democratic

${ }^{32}$ M. N. Tapia, “Academic Excellence and Community Engagement: Reflections on the Latin American Experience," in Higher Education and Civic Engagement: Comparative Perspectives, edited by L. Mcllrath, A. Lyons, and R. Munck (New York: Palgrave Macmillan, 2012), 193.

${ }^{33}$ Clifford, "Talking About Service-Learning"; A. Santiago-Ortiz, "From Critical to Decolonizing Service-Learning: Limits and Possibilities of Social Justice-Based Approaches to Community Service-Learning," Michigan Journal of Community Service Learning 25, no. 1 (2019): 43-54.

${ }^{34}$ Santiago-Ortiz, "From Critical to Decolonizing Service-Learning."

${ }^{35}$ M. Nishimura, "Liberal Arts for a New Japan: The Case of the International Christian University," in Liberal Arts Education and Colleges in East Asia: Possibilities and Challenges 
Table 7.1 ICU's service-learning program development phase

\begin{tabular}{|c|c|}
\hline Phase & Development \\
\hline $\begin{array}{l}\text { 1. Primary phase (1996-1998): } \\
\text { International exploration }\end{array}$ & $\begin{array}{l}\text { Introduced the practicum course } \\
\text { entitled "international internship" }\end{array}$ \\
\hline $\begin{array}{l}\text { 2. Second phase (1999-2005): } \\
\text { College-wide expansion and } \\
\text { institutionalization }\end{array}$ & $\begin{array}{l}\text { Expanded a service-learning } \\
\text { college-wide course, established the } \\
\text { Service-Learning Center in 2002, } \\
\text { initiated the Service-Learning Asia } \\
\text { Network (SLAN), and published the } \\
\text { monograph series on service-learning }\end{array}$ \\
\hline $\begin{array}{l}\text { 3. Third phase (2006-2008): } \\
\text { International partnership development }\end{array}$ & $\begin{array}{l}\text { Developed the cohort international } \\
\text { service-learning model programs in Asia } \\
\text { and Africa }\end{array}$ \\
\hline $\begin{array}{l}\text { 4. Fourth phase (2009-2015): } \\
\text { Standardization and routinization }\end{array}$ & $\begin{array}{l}\text { Standardized and routinized the cohort } \\
\text { international service-learning model } \\
\text { programs }\end{array}$ \\
\hline $\begin{array}{l}\text { 5. Fifth phase (2016-present): } \\
\text { Enbancing reciprocity in partnership }\end{array}$ & $\begin{array}{l}\text { Developed an inbound service-learning } \\
\text { program called Japan Summer } \\
\text { Service-Learning (JSSL) in } 2016 \text { to } \\
\text { enhance reciprocity in partnership }\end{array}$ \\
\hline
\end{tabular}

ideals have formulated ICU's unique organizational culture reflected in the respect for individuals, their freedom to develop, their rights in society, and students' rights to open participation and interaction in all classroom activities. ICU also enjoys an international and intercultural outlook of the student population with $10 \%$ being international students and $25 \%$ being returnees from abroad (i.e. Japanese students who spent their childhood overseas).

ICU is the pioneer of introducing a Service-Learning Program in Japan. The service-learning course was introduced in 1999 for the first time in Japan. As shown in Table 7.1, ICU followed five phases of development. It established the Service-Learning Center in 2002 and initiated the Service-Learning Asia Network (SLAN) with 8 universities and 1 non-profit organization in Asia including representation from China, Hong Kong, India, Indonesia, the Philippines, South Korea, and Thailand. International service-learning is a form of experiential education

in the Global Age, edited by I. June, M. Nishimura, and T. Sasao (Singapore: Springer, 2016), 51-62. 
that integrates community-led service activities, academic instruction, and intentional reflection in an international or cross-cultural setting. ${ }^{36}$

In this section, we illustrate two recent studies carried out by the coordinators at the Service-Learning Center of ICU to examine the characteristics of learning outcomes in light of the existing literatures and their challenges.

\section{Japan Summer Service-Learning (JSSL) in Pursuit of Stakeholders' Reciprocity}

After working with SLAN partners for two decades, ICU, together with the Center for Community Engagement of Middlebury College, one of our US partner institutions, developed an inbound service-learning program called the Japan Summer Service-Learning (JSSL) in 2016 to enhance reciprocity in partnership and to overcome the linear development model and savior complex mentality. JSSL is a four-week, community connected, cohort program in the summer tailored for incoming students from the SLAN partner universities, Middlebury College, and ICU. The participating students deepen their understanding of Japanese society through serving together in the local communities both in the urban and rural areas. In 2018, a total of 14 students participated: 6 students from SLAN partner universities (2 students each from Silliman University, the Philippines, Union Christian College, India, Assumption University, Thailand), 4 from Middlebury College, and 4 from ICU.

To explore and examine how the JSSL program has functioned to improve reciprocity, we applied the SOFAR model. ${ }^{37}$ Reciprocity does not take place just between the two entities such as the partner university and ICU, but it can take place in various forms, such as between the students and the beneficiary, community organizations, between the practitioners of institutions and the staff of receiving organizations. The SOFAR model delineated the structure of relationships in sub-sets and it is useful to articulate mutual relationships between the five stakeholders. It is a structural framework for relationships among the five constituencies, namely Students, Organizations in the community, Faculty,

\footnotetext{
${ }^{36}$ Robbin D. Crabtree, "Theoretical Foundations for International Service-Learning," Michigan Journal of Community Service Learning 15, no. 1 (Fall 2008): 18-36.

${ }^{37}$ R. C. Bringle, P. Clayton, and M. Price, "Partnerships in Service Learning and Civic Engagement," Partnerships 1, no. 1 (2009): 1-20.
} 
Administrators on campus, Residents in the community. ${ }^{38}$ It demonstrates a total of ten dyadic relationships between the five constituencies.

With the SOFAR model, we examined (1) how the JSSL program has contributed to building reciprocity among the stakeholders, and (2) what type of evaluation the program needs for further development to ensure reciprocity. We used qualitative data which reflects the voices of the participants and partner institutions. These data include ( 1 ) evaluations from student participants of JSSL, (2) semi-structured interviews with the JSSL coordinator, and (3) written reports submitted by ICU students after JSSL for 3 credits. By applying JSSL into the SOFAR model, we found three types of relationships with students as below to be more prominent in the JSSL program.

Students and Administrators (Dyad Numbered as 1)

Although the role of administrators is to coordinate the program, the relationship between students and administrators tends to become more than "communication with each other" 39 as the program proceeds. For example, one of the participants commented:

I received so much hospitality from people around us, including SLC (Service-Learning Center) staffs....Those experiences brought me to a completely different world from what I had seen a month ago, made us able to have a connection with community people, and made me open minded.

Multicultural interaction enriches communication and generates multiple perspectives. The interaction between Asian students and Middlebury staffs also enables students to learn reflections from a different perspective in their rich experiences.

\section{Community Organizations and Students (Dyad Numbered as 9)}

During summer, JSSL participants have service activities in both Mitaka city, Tokyo and Tenryu village, Nagano Prefecture. In Mitaka, students can design their activities for about three weeks. In the past programs,

\footnotetext{
${ }^{38}$ Bringle, Clayton, and Price, "Partnerships in Service Learning and Civic Engagement," 5 .

${ }^{39}$ Bringle, Clayton, and Price, "Partnerships in Service Learning and Civic Engagement," 4 .
} 
they engaged in community service activities at several institutions such as agricultural associations, nursing homes for the elderly, and elementary schools. Tenryu village is a rural and mountainous village where the elderly accounts for more than $60 \%$ of the population. The relationship with the local population was initiated by ICU students who did a community service-learning in the village in summer 2015. After their service activity, they thought a way to maintain their relationship and started the JSSL program together. This is an example of coordinating or joint planning with student and community organizations.

Furthermore, a few students' comments showed their appreciation to have inter-generational and various exchanges that are rare in daily life as follows:

- I was able to have a multi-generational exchange.

- I had such a good experience with JSSL program, for example, volunteering at facility for elderly people and elementary school in Mitaka and staying Tenryu village.

- Cooperating with not only JSSL members but also community people was the most meaningful.

\section{Students and Community Residents (Dyad Numbered as 6)}

For both ICU and visiting students, the interaction with the Tenryu village host community through home visits and homestays was one of the memorable activities of the participants. During their stay in the village, they learned to communicate with each other better despite their linguistic and cultural differences. They also had an opportunity to listen to the elder residents' narrative of the history of the village or story of World War II. These experiences indicate that they reached a deep level of communication with each other, although their interaction might remain at a transactional level. One student commented:

The most meaningful aspect of the programme, according to me, is the opportunity extended to us to experience the community rural life by interacting with the people belonging to several communities. This interaction helped understand several things including the fact that linguistic and cultural differences are not any barrier to human love and interaction. The love extended to us from those people helped me understand the importance of caring for others and the need to be more compassionate...the 
chance to interact with people freely proved to be the most meaningful aspect of the program unto me.

As such, we could identify the multilevel stakeholder relationships and their reciprocity. It was confirmed that JSSL contains good relationship with three dyads. It became apparent that ICU fosters students' learning and well-being and maintains relationships well with community organizations for the sake of running the program smoothly.

For the rest of seven dyads, however, there were not much data available to confirm. Anecdotal evidence suggests that there exists a good relationship between faculty and administrators (dyad numbered 10) and community organizers and community residents (dyad numbered 3) as it would have been impossible to carry out the successful JSSL program without such relationships. Nevertheless, much has to be done to improve reciprocity with community organizers and faculty.

Two distinctive observations stood out beyond the existing framework. First, as JSSL had internationally mixed groups with various cultural backgrounds, students appreciated the opportunity to learn from different perspectives of the service activities. The multicultural reciprocal learning among the student groups generated in JSSL added a new reciprocity to the service-learning program framework. For instance, one student deepened their insight on localism by associating with community residents and other students from overseas:

Advancement of globalization made our world borderless, which made our intercultural exchange possible with abundant merits through such networks. However, its downside is the lost concept of localization.... Coexisting with nature, respect for culture and tradition, spirit of mutual support are missing yet critical elements for us. Linking with people, community, and local network may reduce inequality and co-create equal and peaceful society in the future.

Others simply appreciate the new discovery of what was otherwise taken for granted:

By looking at the reaction when foreign students face Japanese culture which was new to them I was made to think of it (such as "why" and "how come"). This cannot be experienced without participating in the JSSL program. 
For me, it (the most meaningful aspect of JSSL) was definitely working in a multi-cultural environment. It was incredibly beneficial for me to have this experience. I feel like I have much more confidence with working -very closely- with people from all around the world. I learned how to communicate with strangers, how to be a better listener, and I learned how to think beyond my own perspective.

Second, students repeatedly mentioned their learning experiences about themselves through interactions with other students and local community residents, and being in a different environment. Revisiting a concept of self is not highlighted in the SOFAR model, but is reported in other service-learning programs in Asia. ${ }^{40}$ One student reflected on his/her own being:

My overall experience with service learning was a life-changing experience. It gave me a new perspective not just in service-learning but with the different perspective in life. It gave me the appreciation of living life in an orderly manner and being conscious with other people just by observing the Japanese people's lifestyle. It gave me the chance of gaining selfindependence by just living away from our home. I have also learned the importance of being active in helping and not to be apathetic in activities in the community... and the importance of living a much simpler life. I will never forget all of these moments that I had.

Another student shifted his/her initial expectation from exploring a new country to exploring oneself:

My experiences at the JSSL had been the most valuable experience to me as an individual as well as a societal being. My initial thoughts about the program was that I could explore a foreign country for the first time, learn about its culture and get to know a whole lot of people from various walk of life. But looking back now at the end of the program, I feel that this was more than just exploring a new country; it was exploring myself and opening myself to a whole lot of new perspectives.

${ }^{40}$ Yang et al., "The Role of International Service-Learning in Facilitating Undergraduate Students' Self-Exploration.” 
While JSSL has enhanced reciprocity, engagement, connection to the local community, and inclusivity and participation at the multicultural levels, reciprocity with and engagement of community organizers and faculty seem to be overlooked at least from the students' learning process and reflection. Furthermore, critical perspective on and structural analysis of social inequality and problems are missing from their reflection.

\section{Learning Outcome of International Service-Learning}

Kuronuma made research on the characteristics of ICU's service-learning using the Eyler and Giles Indicator model. ${ }^{41}$ The aim of the research was to compare the program characteristics and outcomes of service-learning between the US and Japanese universities and to extract distinctive outcome indicators of ICU's international service-learning programs.

Qualitative text analysis was made on 60 students' papers from the first three phases of ICU's development of international service-learning outlined in Table 7.1 (i.e. between 1996 and 2008). Those reports were broken down into 205 written description data for coding.

From the results of qualitative text analysis of students' papers, there appeared some distinctive learning outcomes of ICU that are different from Eylers and Giles' indicator. They include students' career choices and deep consideration of what the service is. In the primary phase (19961998), the influence of service-learning on students' career choice was more apparent than in other phases because the course was offered as an "internship" closely linked with career development. Deep consideration of meaning of service was more evident in the second and third phases. In the second phase, service-learning became the university-wide curriculum that included introduction to service-learning, preparation, and reflection courses. In the second and third phases, service-learning courses focused on the definition and moral reasoning of service and learning processes. As a matter of fact, it was between these two phases when ICU published the first three volumes of the monograph entitled The Service-Learning Studies Series to explore an academic and institutional identity of servicelearning. In these series, there was much discussion of the connection

${ }^{41}$ A. Kuronuma, "Learning Outcomes of International Service-Learning in the Japanese Context: The Case of International Christian University" (Paper, 7th Asia-Pacific Regional Conference on Service Learning, Singapore, June 2019); J. Eyler and D. E. Giles Jr., Where's the Learning in Service-Learning? (San Francisco: Jossey-Bass, 1999). 
between service-learning and Christian philosophy, experiential learning pedagogies, and whole-personal development. ${ }^{42}$

In contrast, the element that was commonly found in service-learning practices in the United States but not in ICU was citizenship. While citizenship is a major and critical outcome of service-learning in American higher education, it was less prominent in ICU. ICU's approach to service-learning focused on students' whole-personal development with Christian philosophy and there was comparatively less discussion or inquiry of social justice, social change, or democracy. Again, critical perspectives of service-learning that emerged in the international sphere in the late 2000s did not appear in any curricular intent, students' reports, or faculty-led monographs.

Overall findings show that ICU's service-learning in the first three phases focused on the content and operation of service activities, their quality improvement as pedagogy, and diversification of programs to create more opportunities for students to serve others. Such characteristics influenced the outcome to nurture "personal development," "perspective transformation," "interpersonal development," "avoiding stereotyping," "tolerance," and so on. While ICU distinctively shows the characteristics of deep conceptions of the meaning of doing service for others, "others" for or with whom we serve was vaguely defined. Positionality of students remained unquestioned and the programs did not clearly address social inequality or social justice issues.

\section{Discussion: Missing Link Between Moral Awareness and Civic Engagement}

The outcomes of ICU's service-learning in the previous section reveal that students learned much about their self-conceptions, obtained intercultural communication skills and competencies, and achieved personal development. Some received the intellectual stimulation to investigate underlying social issues, while others were able to revisit their own culture and social problems from a comparative lens in interacting with international students or communities in different countries.

42 International Christian University (ICU), Introduction to Service-Learning (Tokyo: ICU, 2004); ICU, Why Do People Do Service? (Tokyo: ICU, 2005); ICU, Invitation to Service-Learning (Tokyo: ICU, 2008). 
Nevertheless, critical perspectives were missing from the programs. The design of the programs almost entirely focused on students' learning of the self and society. The roles of community and faculty in promoting social and intellectual inquiry with students were negligent. Such design did not allow students to convey their thinking beyond personal experience to refer to the structural problems and strategic communication beyond cultural exchange. Reciprocity is depoliticized whereby everything that students see and feel are presented in such a way that students are supposed to receive them in the form of learning rather than question, reinterpret, challenge, and cocreate them with the community. Students perceive social problems, especially in a rural village or in a foreign country, as a "social problem" detached from them or where students did not perceive themselves as part of the change agent. This stance echoes with demonstrating their desire to help "the disadvantaged" in ways that do not require them to acknowledge or address structural inequality. ${ }^{43}$

Furthermore, the way volunteer opportunities are organized in Japan is worth noting in thinking about civic engagement with a critical lens. Local government organizations, community organizations, and nonprofit organizations usually post an advertisement for volunteer opportunities on their homepage, in public papers, and through universities. Students simply "apply" for the volunteer posts that match their interests. Community in this sense is the opportunity-giver and students are opportunity-taker, while students are service-giver and communities are service-taker. In this highly institutionalized and organized context of reciprocity, the concept of a joint change maker or solidarity is hard to grow. In the "General Education on Service-Learning" course at ICU, where students were required to do service for 18 hours in 9 weeks, one student asked how a part-time job and service were different apart from the presence/absence of monetary rewards. This question addresses students' passive perception of “opportunity-taker" to volunteer without questioning their status quo or pursuing any social change. This is the very concern critics have raised about institutionalized volunteer and learning opportunity. ${ }^{44}$

${ }^{43}$ Mitchell, Monahue, and Young-Law, "Service Learning as a Pedagogy of Whiteness."

${ }^{44}$ T. Stanton, "Half Full or Half Empty...Who Knows?: Reflections on Forty-Five Years in Service Learning's Trenches," in Where's the Wisdom in Service-Learning? edited by R. Shumer (Charlotte, NC: Information Age Publishing, 2019), 81-92. 
There is another contextual lens that we can offer here with regards to positionality of students. In East Asia, individuals are expected to adopt Confucian values and social norms, such as respecting authoritative persons' decisions, conforming to the majority's views, and giving priority to collective over personal interests. ${ }^{45}$ In Japan, people often use the term "gakusei" (student as a learning person) and "shakaijin" (a member of the society who contributes to the society mostly by participating in the labor market) to draw a line to maintain the status quo. Such a social norm suggests that a student is someone who has not yet entered a "society" to make a tangible contribution, thus substantially reinforces a notion of students' immaturity and limited control over what they can do. The comment we received from students in the General Education Course presents the case in point:

As a volunteer, I was told to guide the participants to respective seats at the event. A disabled person in the wheelchair came and needed an extra space. I found the need to create the space for it but felt that I should not just do it without permission from the event organizer. I was not sure how much I, as a student volunteer, can suggest a change of the planned operation or do something beyond what I was told to do.

In the hierarchical society by age, gender, social status, etc., students' spontaneity and self-efficacy as citizens are hard to grow. The literature on global citizenship education in East Asia also suggests that students tend to do well in exams to reproduce their knowledge on global citizenship, but that it is harder to translate that knowledge into behavioral change. ${ }^{46}$ Service-learning tends to encourage students to revisit their conception of self, but whether this revision will transform their behavior is potentially a critical challenge.

Faculty and staff who design service-learning may also need transformation if we are to seek more intellectual rigor and incorporation of social change and solidarity ideals into service-learning beyond

${ }^{45}$ M. Yang, B. Webster, and M. Prosser, "Travelling a Thousand Miles: Hong Kong Chinese Students' Study Abroad Experience," International Journal of Intercultural Relation 35, no. 1 (2011): 69-78.

${ }^{46}$ H. R. Sim, "Global Citizenship Education in South Korea Through Civil Society Organizations: Its Status and Limitations," Asian Journal of Education 17 (2016): 107129. 
dichotomous reciprocity of service-provider/service-taker or opportunitygiver/opportunity-taker. In an aging society with a declining universitygoing population and at the universalization stage of higher education, ${ }^{47}$ Japanese universities (and parents) are more and more over-protective for students and deal with them as a consumer and recipient of higher education services, which reinforces students' sense of immaturity and helplessness. Such a vicious circle should be overcome by generating more students' autonomy and responsibilities in service-learning so that they can obtain the sense of self as one who can transform a society. As Jacoby suggests, we may need a brave space for students on campus in addition to a safe space to empower and enhance their civic engagement. ${ }^{48}$

In order for learning outcomes of service-learning to sustain and to lead to behavioral change, its design should focus more on student inquiry of social issues (Why do we do service?) and their positionality and awareness of the social structure that affects their status quo as well as those oppressed/disadvantaged (What is the problem surrounding us and how can we approach it?). International service-learning challenges one's epistemology or deeply embedded beliefs and knowledge about the world around us. ${ }^{49}$ Such epistemological challenges should include our revision of the socially constructed self-concept as "student" in the Asian context.

With the tendency of focusing on Western practicality and growing competition in higher education in Asia, educators at the university level need to stop and contemplate their role in nurturing civically engaged students and scholars. Especially in hierarchical societies within Asia, it may be a long way to go to transform our mind-set from someone who receives/gives service and skillsets to someone who jointly works for a co-created purpose. The United Nation's Sustainable Development Goals (SDGs) (2015-2030) suggest that the concept of modern development should be revisited with the perspectives of global sustainability and social inclusion. Equity, inclusion, and quality of education are of primary importance outlined in SDG 4. Departing from an elusive quest of

${ }^{47}$ M. Trow, Problems in the Transition from Elite to Mass Higher Education (Berkeley: Carnegie Commission on Higher Education, 1973).

48 B. Jacoby, "The New Student Activism: Supporting Students as Agents of Social Change," Journal of College and Character 18, no. 1 (2017): 1-8.

${ }^{49}$ A. M. Oberhauser and R. Daniels, "Unpacking Global Service-Learning in Developing Contexts: A Case Study from Rural Tanzania," Journal of Higher Education Outreach and Engagement 21, no. 4 (2017): 139-170. 
catch-up mind-set with the West, we need to wrestle with the question of how higher education institutions can envision inclusive and equitable quality education for all and situate our role in enhancing social equality and inclusion as an earnest challenge of the twenty-first century.

\section{BIBLIOGRAPHY}

Ananiadou, K., and M. Claro. "21st Century Skills and Competencies for New Millennium Learners in OECD Countries." OECD Education Working Papers No. 41, 2009.

Andersson, P. "Inequality in Asia and the Pacific." Presentation at the Interregional Expert Group Meeting on Placing Equality at the Center of Agenda 2030, Santiago, June 2018. https://www.cepal.org/sites/default/ files/presentations/sl_3._pandersson.escap_.pdf.

Asghar, M., and N. Rowe. "Reciprocity and Critical Reflection as the Key to Social Justice in Service Learning: A Case Study." Innovations in Education and Teaching International 54, no. 2 (2017): 117-125.

Atkas, F., K. Pitts, J. C. Richards, and I. Silova. "Institutionalizing Global Citizenship: A Critical Analysis of Higher Education Programs and Curricula." Journal of Studies in International Education 21, no. 1 (2017): 65-80.

Brewster, K. R. "Transformative and Transformed: Examining the Critical Potential of Service-Learning Positional Identities." Equity \& Excellence in Education 51, nos. 3-4 (2018): 347-361.

Bringle, R. G., P. Clayton, and M. Price. "Partnerships in Service Learning and Civic Engagement." Partnerships 1, no. 1 (2009): 1-20.

Bringle, R. G., and J. A Hatcher. "A Service-Learning Curriculum for Faculty." Michigan Journal of Community Service Learning 2, no. I (1995): 112-122.

Brown, M. A., J. D. Wymer, and C. S. Cooper. "The Counter-Normative Effects of Service-Learning: Fostering Attitudes Toward Social Equality Through Contact and Autonomy." Michigan Journal of Community Service Learning 23, no. 1 (2016): 37-44.

Buchler, J. "Reconstruction in the Liberal Arts." In A history of Columbia College on Morningside, edited by D. C. Miner. New York: Columbia University Press, 1954.

Burth, H. "The Contribution of Service-Learning Programs to the Promotion of Engagement and Political Participation: A Critical Evaluation." Citizenship, Social and Economics Education 15, no. 1 (2016): 58-66.

Butin, D. "Dreaming of Justice: Critical Service-Learning and the Need to Wake Up." Theory into Practice 54, no. l (2015): 5-10.

Chan, K., E. Ng, and C. C. Chan. "Empowering Students Through ServiceLeaning in a Community Psychology Course: A Case in Hong Kong." Journal of Higher Education Outreach and Engagement 20, no. 4 (2016): 25-35. 
Chen, S. J. "Shifting Patterns of Student Mobility in Asia." Higher Education Policy 25, no. 2 (2012): 207-224.

Chopp, R. "Remaking, Renewing, Reimagining the Liberal Arts College Takes Advantage of Change." In Remaking College: Innovation and the Liberal Arts, edited by R. Chopp, S. Frost, and D. H. Weiss, 13-24. Baltimore: Johns Hopkins University Press, 2014.

Clifford, J. "Talking About Service-Learning: Product or Process? Reciprocity or Solidarity?" Journal of Higher Education Outreach and Engagement 21, no. 4 (2017): 1-13.

Conner, J., and J. Erickson. "When Does Service-Learning Work? Contact Theory and Service-Learning Courses in Higher Education." Michigan Journal of Community Service Learning 23, no. 2 (2017): 53-65.

Eyler, J., and D. E. Giles Jr. Where's the Learning in Service-Learning? San Francisco: Jossey-Bass, 1999.

Furco, A. "Foreword." In Problematizing Service-Learning: Critical Reflections for Development and Action, edited by T. Stewart and N. Webster, ix-xi. Charlotte: Information Age, 2011.

Godwin, K. A. "The Global Emergence of Liberal Education: A Comparative and Exploratory Study." PhD diss., Boston College, 2013. https://dlib.bc. edu/islandora/object/bc-ir:104384.

—. "The Worldwide Emergence of Liberal Education." International Higher Education 79 (2015): 2-4.

Grain, K., T. Katumba, D. Kirumira, R. Nakasiita, S. Nakayenga, E. Nankya, V. Nteza, and M. Sssegawa. "Co-constructing Knowledge in Uganda: Host Community Conceptions of Relationships in International Service-Learning." Journal of Experiential Education 42, no. 1 (2019): 22-36.

Hutchins, R. M. The Higher Learning in America. New Haven: Yale University Press, 1968.

International Christian University. Introduction to Service-Learning. Tokyo: International Christian University, 2004.

- Invitation to Service-Learning. Tokyo: International Christian University, 2008.

- Why Do People Do Service? Tokyo: International Christian University, 2005.

Jacoby, B. "The New Student Activism: Supporting Students as Agents of Social Change." Journal of College and Character 18, no. 1 (2017): 1-8.

King, H. C. "What the College Stands for." Association of American Colleges Bulletin III, no. 1 (1917): 24.

Kuronuma, A. "Learning Outcomes of International Service-Learning in the Japanese Context: The Case of International Christian University." Paper presented at the 7th Asia-Pacific Regional Conference on Service Learning, Singapore, June 2019. 
Latta, M., T. M. Kruger, L. Payne, L. Weaver, and J. L. VanSickle. "Approaching Critical Service-Learning: A Model for Reflection on Positionality and Possibility." Journal of Higher Education Outreach and Engagement 22, no. 2 (2018): 31-55.

Lee, J., and H. Lee. "Human Capital and Income Inequality." ADBI Working Paper Series No. 810, Asian Development Bank Institute, Tokyo, 2018.

Logan, J., and J. Curry. "A Liberal Arts Education: Global Trends and Challenges." Christian Higher Education 14, nos. 1/2 (2014): 66-79.

Meiklejohn, A. The Liberal College. Boston: Marshall Jones, 1920.

Mitchell, T. D. "Traditional vs. Critical Service-Learning: Engaging the Literature to Differentiate Two Models." Michigan Journal of Community Service Learning 14, no. 2 (2008): 50-65.

Mitchell, T. D., D. M. Monahue, and C. Young-Law. "Service Learning as a Pedagogy of Whiteness." Equity \& Excellence in Education 45, no. 4 (2012): 612-629.

Mok, K. H., and K. M. Yu. Internationalization of Higher Education in East Asia: Trends of Student Mobility and Impact on Education Governance. New York: Routledge, 2014.

Nishimura, M. "Liberal Arts for a New Japan: The Case of the International Christian University." In Liberal Arts Education and Colleges in East Asia: Possibilities and Challenges in the Global Age, edited by I. June, M. Nishimura, and T. Sasao, 51-62. Singapore: Springer, 2016.

Oberhauser, A. M., and R. Daniels. "Unpacking Global Service-Learning in Developing Contexts: A Case Study from Rural Tanzania." Journal of Higher Education Outreach and Engagement 21, no. 4 (2017): 139-170.

OECD. The Future of Education and Skills: Education 2030. Paris: OECD, 2018.

Pascarella, E. T., G. C. Wolniak, T. A. D. Seifert, T. M. Cruce, and C. F. Blaich. "Liberal Arts Colleges and Liberal Arts Education." ASHE Higher Education Report 31, no. 3 (2005): 1-146.

Rowen, C. "So Much More Than Salary: Outcomes Research in Liberal Arts." New Direction for Institutional Research 169 (2016): 51-60.

Sadovnik, A. R., ed. Sociology of Education: A Critical Reader. 2nd ed. New York: Routledge, 2010.

Santiago-Ortiz, A. "From Critical to Decolonizing Service-Learning: Limits and Possibilities of Social Justice-Based Approaches to Community ServiceLearning." Michigan Journal of Community Service Learning 25, no. 1 (2019): $43-54$.

Shah, M., and D. T. N. Quyen, eds. The Rise of Quality Assurance in Asian Higher Education. Cambridge: Chandos Publishing, 2017.

Sim, H. R. "Global Citizenship Education in South Korea Through Civil Society Organizations: Its Status and Limitations." Asian Journal of Education 17 (2016): 107-129. 
Stanton, T. "Half Full or Half Empty...Who Knows?: Reflections on Forty-Five Years in Service Learning's Trenches." In Where's the Wisdom in ServiceLearning? edited by R. Shumer, 81-92. Charlotte, NC: Information Age Publishing, 2019.

Summerscales, W. Affirmation and Dissent. New York: Teachers College Press, 1970.

Tapia, M. N. “Academic Excellence and Community Engagement: Reflections on the Latin American Experience." In Higher Education and Civic Engagement: Comparative Perspectives, edited by L. Mcllrath, A. Lyons, and R. Munck, 187-203. New York: Palgrave Macmillan, 2012.

Trow, M. Problems in the Transition from Elite to Mass Higher Education. Berkeley: Carnegie Commission on Higher Education, 1973.

Yang, M., B. Webster, and M. Prosser. "Travelling a Thousand Miles: Hong Kong Chinese Students' Study Abroad Experience.” International Journal of Intercultural Relation 35, no. 1 (2011): 69-78.

Yang, M., L. Y. Y. Luk, B. J. Webster, A. W. Chau, and C. H. K. Ma. "The Role of International Service-Learning in Facilitating Undergraduate Students' SelfExploration." Journal of Studies in International Education 20, no. 5 (2016): 416-436.

Yang, R. "The East-West Axis? Liberal Arts Education in East Asian Universities." In Liberal Arts Education and Colleges in East Asia: Possibilities and Challenges in the Global Age, edited by I. June, M. Nishimura, and T. Sasao, 27-38. Singapore: Springer, 2016.

Yonezawa, A., and M. Nishimura. "Revisiting Key Values, Roles, and Challenges of Liberal Arts Education in East Asia." In Liberal Arts Education and Colleges in East Asia: Possibilities and Challenges in the Global Age, edited by I. June, M. Nishimura, and T. Sasao, 125-136. Singapore: Springer, 2016. 
Open Access This chapter is licensed under the terms of the Creative Commons Attribution 4.0 International License (http://creativecommons.org/licenses/ by $/ 4.0 /$ ), which permits use, sharing, adaptation, distribution and reproduction in any medium or format, as long as you give appropriate credit to the original author(s) and the source, provide a link to the Creative Commons license and indicate if changes were made.

The images or other third party material in this chapter are included in the chapter's Creative Commons license, unless indicated otherwise in a credit line to the material. If material is not included in the chapter's Creative Commons license and your intended use is not permitted by statutory regulation or exceeds the permitted use, you will need to obtain permission directly from the copyright holder.

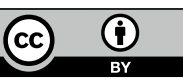




\title{
Building a Center for Writing and Communication: Inclusion, Diversity and Writing in the Indian Context
}

\author{
Kanika Singh
}

\section{Ashoka University and Its Centre for Writing AND COMMUNICATION}

Ashoka University is a private university established in 2014 in the north Indian state of Haryana on the outskirts of Delhi. Ashoka's study programs draw upon a liberal arts model of education where students are introduced to a variety of disciplines and ways of knowing the world. The undergraduate program offers students the flexibility to choose a combination of courses. For instance, one may major in History and do a minor in Visual Studies, or Media Studies, or opt for interdisciplinary majors like Economics and History. Moreover, the students are not expected to be passive receivers of knowledge. Ashoka's pedagogy emphasizes on making the university a space for critical thinking and the teacher-student interaction involves pedagogical tools that focus on student participation in

K. Singh $(\bowtie)$

Ashoka University, Haryana, India

e-mail: kanika.singh@ashoka.edu.in

(C) The Author(s) 2020

C. S. Sanger and N. W. Gleason (eds.),

Diversity and Inclusion in Global Higher Education, https://doi.org/10.1007/978-981-15-1628-3_8 
unpacking knowledge and creating it anew. Rather than producing rotememorized content, the students are encouraged to be critical thinkers where they learn to appreciate, examine, discuss, critique and innovate on what they learn about the world.

Theoretically, this approach is not a recent one, ${ }^{1}$ nevertheless, it is surprising how little it is practiced in schools and in institutions of higher education in India. Perhaps only a handful of schools, colleges and universities can boast of an active engagement with pedagogy where the students have the opportunity to be participants in the teaching-learning process. In most institutions, the case is overwhelmingly of the student being a passive receiver of knowledge with little idea of how the material present in the school textbook is relevant to the world. ${ }^{2}$ Even those of us who had the benefit of a good quality education have not encountered this in our school experience. A friend and fellow-academic whose research focuses on multilingual education remembers her own classes of science and mathematics at school. She was a good student, interested in these subjects and she recalls having enjoyed solving mathematical equations or problems based on conductors and resistances in a circuit diagram. However, she observes, 'While I enjoyed solving these problems on paper, I can't recognize the same concept when it appears in the real world. I got a great kick when I solved mathematical puzzles, but how do matrices shape the world we live it? How do they help me understand the real world?'3

Ashoka's pedagogical vision thus makes a departure from many existing institutions of higher education in India. Moreover, this approach is supported by good infrastructure and resources available to the students and the teachers, a good teacher-student ratio and close mentorship and learning support available to students. The Centre for Writing and Communication (CWC) at Ashoka is instrumental in providing close mentorship and learning support to students.

${ }^{1}$ Paulo Freire, Pedagogy of the Oppressed, translated by Myra Bergman Ramos (Great Britain: Penguin, 1972); bell hooks, Teaching to Transgress: Education as the Practise of Freedom (New York: Routledge, 1994).

2 This is because of a variety of factors including lack of resources, poor teacher-student ratio, ill-equipped and overworked teachers and several institutional and social factors.

${ }^{3}$ Shivani Nag, conversation with author, May 16, 2019. 
The CWC was established in 2014 as the university welcomed its first undergraduate class. It was envisaged as an integral part of Ashoka's curriculum and pedagogy. Initially, CWC's responsibility was to provide writing support to the Introduction to Critical Thinking (ICT) courses. The ICT is a writing course (taught in English) taken by all undergraduates at Ashoka in the very first semester of their undergraduate program, where close reading and critical analysis of content and learning to respond to it is introduced to students through writing exercises. The classroom teaching of the ICT was supported by one-on-one sessions conducted by the CWC where the students can brainstorm ideas, discuss their drafts and improve their writing samples. CWC played an important role in the pedagogical practices of developing critical thinking skills in students, principally through writing pedagogy.

In the last couple of years, Ashoka has seen rapid expansion in the number of students and the number and the levels of courses. While traditional programs like Economics, Mathematics, History, English and Political Science have expanded, several new programs have been introduced including Media Studies, Visual Studies, Environment Studies, Biology and Physics. The undergraduate cohort makes up the bulk of the student strength, and now postgraduate and graduate students are also part of the university. As a private university near Delhi with very high fees and the lack of caste-based reservation policy, ${ }^{4}$ Ashoka's student body overwhelmingly constitutes students from an elite, English-speaking background. Ashoka through its financial aid program has admitted a number of students from economically weaker sections, and from non-metropolitan areas within India. So, it is not only the numbers that have increased but also there is a student body with differing learning needs as a result of growing interdisciplinarity, different levels of courses, varying levels of fluency in English among students, and varied educational and social background of the students.

As the university has grown, the CWC too has had an opportunity to reconsider the role it can play in the university. As the head of the CWC, my responsibilities include both formulating an intellectual vision for the CWC and devising a working model to achieve it. For the purposes of this volume, I focus on the intellectual task before the CWC.

\footnotetext{
${ }^{4}$ As is mandatory in a government or public university.
} 
This paper shares some of the questions we have grappled with, the possibilities we have considered, and the initiatives taken since the year 2017 as an attempt to creatively engage with the issues of critical thinking, knowledge creation, pedagogy and inclusion within Ashoka and in India. Our work has been grounded in the following eight fundamental issues of inclusive writing support.

1. The interdisciplinary nature of the curriculum meant that the CWC should be willing and equipped to engage with a wide variety of disciplinary perspectives and study material, and not only text-based material, but also oral, visual, ethnographic, numerical, experimentbased and performative.

2. In the Indian context, displaying fluency in English is a marker of modernity and class. ${ }^{5}$ At Ashoka, English is the sole language of instruction, and indeed, of both formal and informal communication. In such a situation, how can pedagogy be made inclusive? On the one hand, equipping students with English language skills is helpful in enabling them to engage with the world. On the other hand, doing so without considering the languages they are comfortable in is an active form of exclusion.

3. While recognizing that providing English language support was necessary in Ashoka, how could we overcome the limitations of English language teaching in India?

4. Further, it is even more crucial to develop an English language support program that helps students not only learn the language but equips them be able to transfer knowledge from their contexts into academic writing in English.

5 . While writing is the primary medium of knowledge production and teaching-learning practices in the university spaces, given the diversity of the Indian context (as a multilingual society, with thriving oral, performative, visual and textual traditions), it was important to consider if writing was the only way of 'critical thinking.' And should

${ }^{5}$ Vaidehi Ramanathan, The English-Vernacular Divide: Postcolonial Language Politics and Practice (New Delhi: Orient Longman, 2005); Shalini Advani, Schooling the National Imagination: Education, English, and the Indian Modern (New Delhi: Oxford University Press, 2009). 
reading, writing, speaking in English be the only way to 'do' critical thinking? What are the ways in which Indian languages can be included in higher education pedagogy, without excluding English?

6. As tutors and instructors, an important factor to consider was the use of technology by the students for accessing and processing information. Traditional methods of reading, writing, accessing information-books, magazines, newspapers, all in printed form and even writing by hand-are rapidly become outdated. At least in Ashoka, for the majority of students, the primary method of accessing information and communicating is through digital platforms. My students take notes on their mobile devices and laptop screens, if at all, and they are extremely reluctant to visit the library to hunt for reading material; they would much rather scourge the internet for a digital copy of the readings. So they are not only reading different things, they are reading differently. There are a number of studies that show us that accessing content only digitally is a severely limiting way of knowing the world, and it also changes the way we understand the world. ${ }^{6}$ In this scenario, how do we read, write and communicate critically? How can we ensure that the teacher-learner interaction is effective? And what are its implications for inclusive education?

7. With the growing numbers, the CWC had to reconsider the one-onone sessions as the primary mode of engagement with the students. It was important to find alternative ways of interacting with the students and the teachers, within and outside the classroom and the curriculum.

8. And finally, how could the CWC contribute to make pedagogy at Ashoka inclusive?

\section{Building a Center for Writing ANd Communication}

The first step was recognizing that the Centre with its mandate of 'writing' and 'communication' is in the unique position of engaging with all the stakeholders in the university. This is because every activity in the

\footnotetext{
${ }^{6}$ For instance, Maryanne Wolf argues that humans' dependence on digital technology alters the functioning of the brain, affecting our capacity to think critically and reflect and even to empathize. See Wolf, Reader, Come Home: The Reading Brain in a Digital World (New York: HarperCollins, 2018).
} 
human world, particularly knowledge production and higher education, is some form of 'writing' or 'communication,' and therefore, can be critically seen through the lens of 'writing' and 'communication.' Such an approach helped us recognize the CWC as a dynamic space where the skills as well as the politics of writing and communication, the questions of pedagogy, language, curriculum and inclusion could be debated and experimented with. It is with this vision that the CWC has worked since the year 2017.

The most crucial aspect of creating such a Center is the composition of its team. We made a conscious effort to create a team where its members came from diverse backgrounds-disciplinary, linguistic and with the experience of writing in different contexts (academic, journalistic, popular, fiction and non-fiction). We particularly value educators with experience in creating learning materials for different kinds of audiences. Some of our team members have experience working with school children and neo-literates, creating learning material in distance mode, and as language teachers for English and other Indian languages. And, they have varying levels of educational qualifications: some have a Ph.D., others have a postgraduate degree. The CWC team includes anthropologists working on humor, music and food, a lawyer researching on manual scavengers, students of English literature and composition, a scholar and writer of children's books, artists, journalists, translators, and a historian researching with textual, visual, ethnographic material. These scholars and professionals have worked with different kinds of writing and communication practices which when put together in a university setting, introduces a range of ways of thinking about the world-a factor, that is in keeping with Ashoka's model of a liberal arts education. The diversity of expertise in the team, I believe, is instrumental to the CWC's vision. It is only when a group of scholars and professionals with their diverse experience, work closely with each other through the year to discuss reading, writing, communication and pedagogy, can we truly begin thinking about critical thinking and inclusivity.

\section{CWC ANd Introduction to Critical Thinking}

CWC's close association with the Introduction to Critical Thinking course (ICT) continues to be one of its main areas of activity. And now, this association is no longer limited to one-on-one student consultation sessions but incorporates workshops and programs by the CWC, within 
the ICT syllabus. These workshops are designed in discussion with the instructors and keeping in mind the needs of the syllabus and the class. They address the most fundamental aspects of critical thinking required for writing and communication. Some of the workshops which were designed and conducted by the CWC for ICT classes include How to write using multiple sources; Writing around numbers; Planning a historiographical essay; What is an argument; How to write conclusions; Plagiarism and citation. These workshops are particularly designed to be a combination of lecture, discussion, and in-class exercises in reading and writing, which can be individual or done in small groups and peer review. The workshops are supplemented by one-on-one sessions. As they are part of the ICT syllabus, all undergraduates participate in these sessions which constitute the building blocks of their academic work in Ashoka.

This was the first time that these workshops were being conducted by the CWC for the ICT sections using a mixed-method approach. The feedback was tremendously encouraging. Here's an excerpt from the feedback given on a Plagiarism and Citation workshop by an ICT instructor ${ }^{7}$ :

X's approach to the overall MLA format is very calming - X shows, without overstating it, that there is a clear logic to why any kind of formatting is useful! I liked that $Y$ kept prompting the students to complete the citations that $\mathrm{X}$ would begin to explain on the white board. And I loved their hand out, with the cover and inside page of different books, with different numbers of authors, editors, translators, publishers, and then broke those down into citations. I learned stuff, too! Of course, citations can be boring to hear about, but almost every student was taking notes - even the ones hiding behind laptop screens! They must be so relieved to have someone tell them how on earth these citations work, when to use brackets, how to properly cite, and so on. ${ }^{8}$

While such a pedagogical model is useful in providing learning support to large numbers of students and at the very beginning of their academic careers, we also recognize that just one writing course over a semester is not quite enough training in reading, writing and critical thinking. This is true both for students who have fluency in English and those who lack it. At the same time, it must be recognized that all the courses in

${ }^{7}$ The two tutors who conducted the workshop are referred to as $\mathrm{X}$ and $\mathrm{Y}$.

${ }^{8}$ Aditi Sriram, email to author, September 27, 2017. 
the university may not be writing-based or may not have in-built writing mechanisms. What could be the ways in which CWC could continue to provide reading, writing, learning support to the students and faculty? There were two major initiatives taken by the CWC to address this need:

1. Creation of a year-long support system for learning the English language

2. Introduction of extra-curricular, creative programs that address reading, writing, critical thinking skills and are fun!

\section{CWC's English Language Support Program}

At Ashoka, the language of instruction is English, and even informal communication is overwhelmingly English. All instructors are fluent in English and readings/study material is exclusively in English. This poses serious problems for those students at Ashoka who may not be fluent in English.?

Within this section too, there was a great diversity in backgrounds and levels of proficiency in English language. There could be several reasons for their lack of fluency in English: they could be first-generation learners, or they may have had limited exposure to English in their school education, and that too is likely to have been poorly taught. ${ }^{10}$ In our initial interaction with the students, we were able to identify some common problems. The students often tended to reproduce their assigned readings (which were in English) verbatim and lacked individual expression, both in spoken and written exercises. They found the texts difficult to comprehend and hesitated speaking or participating in class preferring to remain silent. There was also reluctance in writing assignments-they frequently avoided writing them, eventually submitting poor quality, plagiarized content to the instructor, much after the deadline, thereby affecting their overall academic performance. Additionally, some of them were more interested and indeed more comfortable in disciplines where fluency

\footnotetext{
${ }^{9}$ At present, this number is rather small, but it continues to grow. There were five out of 935 undergraduate students in 2017-2018, and sixteen out of 1163 undergraduate students in 2018-2019, who were offered year-round, close mentoring for English language support.

${ }^{10}$ See Advani, Schooling the National Imagination, 149-169, on limitations of English language teaching in Indian schools.
} 
and expression in English mattered less, such as mathematics, physics and computer science.

We were conscious that for successful knowledge acquisition, our emphasis cannot merely be on grammatically correct English or correcting the accent. Rather, it must be on enabling the student to use the language both in everyday communication and to critically think and communicate in an academic setting. English language programs in Indian schools typically offer a text-based approach where the success of instruction is evaluated by the students' ability to correctly present the content from the reading or the book. ${ }^{11}$ As shown by Advani, '...the assumption [in English teaching is] that the text is an artefact which has to be learnt. Knowing English becomes a matter of knowing the content of the chapter, not of learning to communicate in English. ${ }^{12}$ Moreover, language teaching is commonly advanced through content, which focuses on teaching morals and building character. Advani gives examples of how the texts are full of dialogues that are unrealistic and improbable in a real life situation. ${ }^{13}$ As she points out, 'If students and teachers are shaped into believing that the English syllabus is essentially fact-based, that the important aspects are contained in memorization and rote learning, and also that the important lessons are moral ones, the acquisition of language seems secondary. ...there is little possibility of creating communicative competence here; students may pick up specific structures but they will find it difficult to apply them in other situations or learn appropriate structure.' $^{14}$

CWC's English language teaching consciously moves away from such an approach. Our emphasis is to enable the students to transition from rote learning or mechanically reproducing the texts to critical thinking. The English language support is designed in a manner that enables students to acquire and improve on skills which they can apply to other courses, and indeed, outside the university, as well. A year-long English language support program has been set up, led by two Senior Writing Tutors at the CWC: Anurima Chanda and Anderson Glashan. We begin with a short two-week bridge program before the academic semester

\footnotetext{
${ }^{11}$ Advani, Schooling the National Imagination, 152, 156.

12 Advani, Schooling the National Imagination, 156.

${ }^{13}$ Advani, Schooling the National Imagination, 153.

${ }^{14}$ Advani, Schooling the National Imagination, 164.
} 
starts. During the academic year, two credited-courses are offered by the CWC: English Communication in the Monsoon semester and Intermediate English Communication in the Spring semester. These involve classroom teaching and one-on-one sessions. Regular follow up and contact is maintained over the holiday period by the CWC tutors. In addition, the students are encouraged to schedule individual weekly sessions to support other course-related work.

Through the year, the students are frequently made to work in pairs and in small groups. Initially, our strategy for the English communication classes was to give students multiple assignments (for the purposes of assessment) which however did not prove to be very successful. We have now switched to a single assignment, allowing students to spend more time on it and to break it up into parts, working on each element separately. Further, the learning material used in class was sourced from different disciplines and themes so that the students' varied interests could be accommodated. For grammar and vocabulary, the CWC tutors were involved in designing worksheets that the students attempted and received feedback on through individual appointments every week. Both the courses incorporate exercises addressing different components of language learning which a student is expected to use in their academic life: listening, speaking, reading and writing. Some of the most popular and successful activities included the game of Taboo, working together on jigsaw puzzles and passing secrets (a game also sometimes referred to as Telephone). Taboo is a game involving word association where each player tries to explain the word on their card without using the word itself or any of the five words listed on the card. The game of jigsaw puzzles involved dividing the class into groups. One member of a team is required to arrange the jigsaw pieces by following instructions (in English) from the other team members. Passing secrets (or Telephone) is useful as a listening and speaking exercise where it became easy for students to identify changes and errors in grammar and content. Another activity required the students to write dialogues for a real-life situation (such as reporting a theft or ordering food) and enacting it in class. These exercises are designed to encourage fluency in the use of the language in everyday informal and formal communication as opposed to highly improbable dialogues typically included in English textbooks. ${ }^{15}$ Many of these activities

${ }^{15}$ Advani, Schooling the National Imagination, 153. 
have involved conscious awareness of pedagogical methods and theories along with elements of trial and error. An anecdote shared with me by my colleague, Anurima Chanda, illustrates this well. She used a translation exercise which especially resonated both with her and the students. The students were asked to translate a song from their mother tongue into English. Her observation was that the students enjoyed the activity and were even trying to sing the English version. Later, while doing research for writing a book on Dr. B. R. Ambedkar, ${ }^{16}$ for children, Chanda discovered, to her surprise and pleasure, that Ambedkar's father had used the same strategy to teach his son English! ${ }^{17}$

Equipping students to transfer their language learning to critical thinking applicable to other aspects of their academic work is an important element of English language support program offered by the CWC. This aspect of learning at Ashoka has to be addressed simultaneously as the students were already doing other reading-heavy courses in different disciplines at Ashoka. In the first instance, we tried to identify and use existing and open access learning material, such as videos on the internet which explain and illustrate concepts like 'capitalism,' 'materialism' in a simple, story-form. However, we soon realized their limitations: the students had difficulty following the accent and the examples and analogies offered as these were very specific to the cultural background of the makers of the videos (most of the videos were made in the USA).

An alternative approach used by the CWC has been more successful in this objective. It combines exercises for English language with critical learning. Again, the students are made to work in pairs. The first step in the exercise requires each student to collect biographical information about their partners. This is to encourage formulation of questions, careful listening, understanding and taking notes. In the second step, each student verbally presents a biographical note on their partners. This is an exercise in selecting information, creating a narrative and then speaking. In the third and final step, the students are required to write a paper connecting information from their partner's bio-note, to the larger world. For instance, one of the students drew upon a Tibetan student's life and

${ }^{16}$ B. R. Ambedkar (1891-1956) was a social reformer, politician and a lawyer. He was the Chairman of the committee which drafted the Constitution of independent India. He was a strong critic of the caste system and in modern India, he is particularly recognized as a champion of Dalit struggles.

${ }^{17}$ Anurima Chanda, email to author, May 21, 2019. 
particular aspects of it were used to comment upon the life in exile and government policies in India, Tibet and China. Another approach that has been successful in enabling this transition has been the extra-curricular creative programs designed by the CWC team which I discuss the following section.

The pedagogy of the English language support is designed in a way that discourages rote learning and verbatim reproduction of the content by the students. Rather, they are encouraged to discuss their ideas, express their opinions, debate and work with peers. So, this is not merely a class in correcting English grammar and pronunciation; it has significant contributions in the way students who initially lacked proficiency in English are able to engage with what appears to them as a difficult, alien and often hostile academic environment.

There are many possibilities for improvement in this teaching program. We are especially interested in exploring greater use of multilingual strategies in English language teaching. At the same time, the existing support system has made a significant difference in the work and confidence levels of the participating students. A first-year undergraduate student, who started learning English only two years before joining Ashoka, had this to say about their English Communication class:

In terms of the class timing and mode of learning, English communication was by far, the most reliable class this semester for me. I have learned a quite interesting things from the class over a period of 3 months, that I am going to remember for the next four years. ... X and $\mathrm{Y}$ have been the mentors of this class. ... The class was not just about assignments, but it also consisted of fun activities. I still remember the class where we were divided into groups and $\mathrm{X}$ made us compete against each other in three rounds. The class included of games and activities such as puzzle, finding the error in the picture and giving our opinion on one of the topics. There were classes where we were even taught the basics of reading and writing. Throughout this class, I have learned this one thing that we should never think about what others would think while we raise up and ask questions. The tips and tricks, as well as the way in which we have started analyzing our paper is the one thing that $\mathrm{Y}$ has helped us with. There was a class, where we were taught on how to maintain the continuity between paragraphs. In one of the classes we were divided into teams and given topics to debate on, that was one of the classes that made us quite comfortable while expressing our opinion. It also worked as a great 
exercise to improve our communication skills in terms of raising questions and giving sleek answers. ${ }^{18}$

Yet another student pointed out that this class helped her tackle the courses she was taking in her first year at Ashoka. A faculty member who teaches writing courses at Ashoka shared her feedback on one of the students (identified as A) who had spent a year working closely with the CWC:

I'd just like to share with you [CWC tutors] the introduction that A wrote for his final paper in my class. I assumed he had taken your help with it, because of how well it's written, but he told me he did this completely by himself. He read it out loud in front of the class and listened to feedback from his classmates on how to improve his paragraph (which you can see in the comments). It was one of the stronger introductions we reviewed in class today, along with a clear thesis statement, and I was very happy. Thanks to both of you [CWC tutors] for working with him over the past 2 semesters, and building him up to be someone who can write such a great opening paragraph! ${ }^{19}$

\section{Creative Programs}

To further promote its pedagogical vision, CWC introduced extracurricular, creative programs open to all members of the university and the public. These events innovatively draw upon and analyze a diverse range of activities and media which are part of our daily lives: news, email, music, internet, media, board games, photographs, food and jokes, to name a few. These programs are designed and executed by CWC team members and invited experts. In the last two years the CWC team organized more than twenty such events. In this section, I write about some of the most popular ones and how they engage with some of the questions raised initially in this paper.

A workshop on writing recipes was designed by Mohini Mehta, an anthropologist working on food cultures, and a Writing Tutor at the CWC. Through this two-hour workshop, Mehta was able to demonstrate recipe-writing as a literary form and skill and simultaneously a highly

\footnotetext{
18 Anonymous student feedback to course instructors.

${ }^{19}$ Aditi Sriram, email to CWC, April 17, 2018.
} 
political act. The participants included Ashoka's undergraduate students some of whom were members of the university's Baking Society, a staff member who was interested in the theme and a graduate student researching food histories. The participants worked in pairs to write recipes on a dish of their choice and in any format and literary style. The language used was English but the use of vernacular terms was encouraged. The writing exercise was followed by a discussion on the craft of writing and the politics of writing about food. One of the participants chose to write a recipe for sandwiches giving precise quantities and the exact process illustrated with a diagram. In contrast, another participant wrote a personal narrative about making $k h i c h d i,{ }^{20}$ when and why they felt the urge to make it, the memories it invoked, how they went about procuring the utensils and the ingredients, and finally how it was savored. In another narrativestyle recipe written in this workshop, the participant used a number of vernacular words to refer to particular spices and their flavors and the emotions they generate. Mehta then used these writing samples to provoke a discussion about the language of writing about food, the genderroles assumed by the participants, the stereotypes they carried, and the slangs and insults couched in one's writing especially when writing about food. She also used the discussion as an entry point into feminist and subaltern theories which consider memory and personal accounts are valid narratives. The discussion examined the celebration of food as heritage, social groups whose food was represented as cuisine, and if food could be associated with painful memories. Mehta used popular cookbooks, ${ }^{21}$ films (Marathi film, Gulabjam), and works of Dalit writers to highlight these issues.

Organizing an activity like this has many pedagogical benefits. First, and perhaps most importantly, it is fun! It interests people, makes them curious and willing to experiment and explore. Second, our creative programs are open to everyone and follow a participatory format (rather than being lecture-based). Having a teacher, a student and a staff member participate in the same activity breaks down many power relations that operate in the classroom. Barriers like English language proficiency which affect confidence and hinder participation can be reduced to a great

${ }^{20}$ Khichdi is an easy-to-cook plain dish of rice and lentils cooked together; considered a poor man's fare; often eaten while fasting, or in convalescence.

${ }^{21}$ S. Meenakshi Ammal, The Best of Samaithu Par: The Classical Guide to Tamil Cuisine (Virginia: Viking, 2001). 
extent. Third, all our creative programs follow a similar model where the resource person leading the workshop can weave a topic or activity with critical thinking, the craft of writing and communication and its politics and draw connections between multiple sources. Mehta too was successful in doing this using sources like media, film, literature and personal experience. The fourth and a very significant element of these programs is that they facilitate transfer of learning outside the classroom and outside the curriculum. While they are pitched as standalone activities, they simultaneously provide a link to the interdisciplinary academic work the students do at Ashoka. In fact, students often write back to the CWC sharing how an event they attended was useful for a course they were doing at Ashoka or their life outside the university.

Another workshop which was successful in achieving this was the one on writing feghoots-short, pun-inspired stories. The workshop was led by Karandeep Mehra, Writing Tutor at CWC, and a sociologist whose research examines humor. Mehra explains the model of these stories and the format of the workshop, 'It starts from a basic facet of language -punning. One considers the possibility that one word may have more than one meaning, or may sound like another but have different meanings, or be spelt like another word but again have different meanings. A feghootwriting workshop takes the alternate meanings and uses of a pun, finds a way to connect them by crafting them into a story such that it can end the story with the original pun. ${ }^{, 22}$ In the workshop Mehra encouraged students to identify puns, their alternative meanings, and demonstrated how this play with language can be used by advertisers, politicians and critics. A few sample feghoots were discussed and the final exercise involved students choosing a pun and weaving a feghoot around it. The success of the workshop can be gaged from the fact that days after the event some the participants continued writing to Mehra with examples of puns they identified elsewhere. Mehra plans to further explore the use of multilingual puns in CWC's work-finding similar sounds across languages, for instance, 'I laughed yesterday' in Hindi is 'Michael Hussey' (main kal hasi)!

While much of our pedagogical work in the university involves grappling with textual sources, we also explored how intangible sources like

${ }^{22}$ Karandeep Mehra, email to author, May 23, 2019. 
music could be critically analyzed and what lessons could such an exercise offer for our academic work. CWC invited Varun Kishore, a Delhibased composer and producer to create a program around active listening in music. Using a score of instrumental music, Kishore presented an analysis of the different component of this single score, introduced the participants to listening exercises identifying and isolating arrangement, rhythm and instrumentation, and concluded with a discussion of 'sampling' in music and its implications for plagiarism and citation in academic writing. Sharanya Dutta, a Writing Tutor who participated in the event remarked that the comparison of sampling with citation worked well in driving home the point about good practices in academic integrity; how existing ideas may be used by people across the world while acknowledging the source. Dutta also found the listening bias exercise effective in demonstrating that non-verbal clues can be utilized to convey context. ${ }^{23}$

In the year 2018, CWC introduced Writing Geographies, a series which explores the questions of form and politics of writing about a place and by authors located in a place. The main inspiration to initiate this series was to engage with the vast linguistic diversity of India and it is one of the initial attempts by CWC to explore the questions of language and its implications for the ideals of critical thinking and inclusive pedagogy. In the first year of its existence, we highlighted three regions within India, and the languages, writing and expression, including fiction, non-fiction, oral, visual and textual, that emerge from that region. The format of the series was flexible, some events were designed as performances, others were dialogues and discussion. Scholars, professionals, activists whose work was informed by their respective geography and language were invited to discuss their work at Ashoka.

The first in the series was a critical examination of the term 'Northeast,' officially used to identify the seven states in the eastern-most part India, and the hierarchy and power relations embedded in its usage. These questions were explored through the writings of the political scientist, Sanjib Baruah who discussed the issues of writing about the Northeast with the journalist Sangeeta Baroorah Pisharoty. Another event in the series was a conversation with a team of women reporting from the region of Bundelkhand in central India. Their initiative is called Khabar Lahariya, a

${ }^{23}$ Sharanya Dutta, email to author, May 28, 2019. 
media platform run and managed by women of Bundelkhand. They primarily use digital media, report on local issues and in local dialects of Hindi. The representatives of the Khabar Labariya team, Kavita Devi (Digital Head) and Pooja Pande (Partnerships Head) interacted with Awadhesh Tripathi (Assistant Professor of Hindi, Ambedkar University Delhi) on issues of gender, caste, class and language and the local context informing their practice of journalism. In another event, CWC invited Shalim M. Hussain, a graduate student at Jamia Millia Islamia to perform a form of protest poetry referred to as Miya poetry, being created by Muslims in the state of Assam. Miya is a derogatory slang for the Bengali-origin Muslim community in the state of Assam in northeast India. In the session, Hussain presented Miya poetry to demonstrate how an expletive has been reappropriated by the Muslim community to protest its exclusion and explored questions of the language of protest, the act of translation from local dialects to English and its relevance for the affected community.

\section{CONCLUSION}

The examples shared above convey the guiding principles and tangible implementation of CWC's work in fostering a fundamentally inclusive writing support program appropriate to an Indian liberal arts context. These programs make the teaching practices in Ashoka more democratic and actively contribute to developing a critical engagement with the world. Within the university, the CWC has carved a unique space for itself by designing learning support and offering programs within the curriculum, while simultaneously going beyond the syllabus. As a result, the CWC has emerged as a platform where all members of Ashoka and even the wider academic community in India participate, debate, and critically engage with texts, languages, materialities, pedagogy and inclusion.

Going forward, the CWC and indeed, similar writing centers that have recently been established in other universities in India, have tremendous scope for contributing to the landscape of higher education in India and Asia. The CWC intends to develop its work to create an open access knowledge bank that shares the teaching material created by its tutors and instructors. This resource can be further developed by educators to cater to their specific contexts, and even for teacher training. The next step would be making it available in at least a few major Indian languages, besides English. There are many studies that highlight the benefits of 
multilingual education at school level in the Indian context, and its relationship to development and inclusion. ${ }^{24}$ It would be useful to explore its benefits in higher education. The writing center as an institution (in Ashoka and elsewhere) has the potential to emerge as a pioneering space to research and experiment with multilinguism, interdisciplinarity, pedagogy and inclusion in higher education.

Acknowledgement I am grateful to Shivani Nag of Ambedkar University Delhi for discussing this theme with me and offering valuable suggestions for this paper. I would like to thank all my colleagues at the CWC who have contributed to the team's work. I would especially like to acknowledge the colleagues whose work I have discussed here: Anurima Chanda, Anderson Glashan, Mohini Mehta, Karandeep Mehra, Sharanya Dutta, Jyotirmoy Talukar, Mayuri Patankar, Varun Kishore and Aditi Sriram.

\section{BIBLIOGRAPHY}

Advani, Shalini. Schooling the National Imagination: Education, English, and the Indian Modern. New Delhi: Oxford University Press, 2009.

Coleman, Hywel, ed. Multilingualism's and Development: Selected Proceedings on the 11th Language and Development Conference, New Delhi, India, 2015. New Delhi: British Council, 2017.

Freire, Paulo. Pedagogy of the Oppressed. Translated by Myra Bergman Ramos. Great Britain: Penguin, 1972.

hooks, bell. Teaching to Transgress: Education as the Practise of Freedom. New York and London: Routledge, 1994.

Ramanathan, Vaidehi. The English-Vernacular Divide: Postcolonial Language Politics and Practice. New Delhi: Orient Longman, 2005.

Skutnabb-Kangar, Tove, Robert Phillipson, Ajik K. Mohanty, and Minati Panda, eds. Social Justice Through Multilingual Education. Bristol: Multilingual Matters, 2009.

Wolf, Maryanne. Reader, Come Home: The Reading Brain in a Digital World. New York: HarperCollins, 2018.

${ }^{24}$ Tove Skutnabb-Kangar, Robert Phillipson, Ajik K. Mohanty, and Minati Panda, eds., Social Justice Through Multilingual Education (Bristol: Multilingual Matters, 2009); Hywel Coleman, ed., Multilingualism's and Development: Selected Proceedings on the 11th Language and Development Conference, New Delhi, India, 2015 (New Delhi: British Council, 2017). 
Open Access This chapter is licensed under the terms of the Creative Commons Attribution 4.0 International License (http://creativecommons.org/licenses/ by $/ 4.0 /$ ), which permits use, sharing, adaptation, distribution and reproduction in any medium or format, as long as you give appropriate credit to the original author(s) and the source, provide a link to the Creative Commons license and indicate if changes were made.

The images or other third party material in this chapter are included in the chapter's Creative Commons license, unless indicated otherwise in a credit line to the material. If material is not included in the chapter's Creative Commons license and your intended use is not permitted by statutory regulation or exceeds the permitted use, you will need to obtain permission directly from the copyright holder.

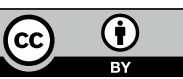


Supporting Historically Marginalized Populations 


\section{Gender and Sexual Diversity in Asian Universities}

Khoo Hoon Eng and Daryl W. J. Yang

\section{INTRODUCTION}

In January 2016, Indonesia's Technology, Research and Higher Education Minister Muhammad Nasir called for lesbian, gay, bisexual, transgender, and questioning (LGBTQ) students to be banned from university campuses in the country. ${ }^{1} \mathrm{He}$ was responding to reports that an informal group known as the Support Group and Resource Center on Sexuality Studies (SGRC) at the University of Indonesia (UI) had been allowed to provide counselling for LGBTQ students and advocate for the LGBTQ

1 "LGBT Not Welcome at University: Minister," The Jakarta Post, January 25, 2016, https://www.thejakartapost.com/news/2016/01/25/lgbt-not-welcomeuniversity-minister.html.

K. H. Eng · D. W. J. Yang $(\bowtie)$

Yale-NUS College, Singapore, Singapore

e-mail: darylyang@u.yale-nus.edu.sg

K. H. Eng

e-mail: hooneng.khoo@yale-nus.edu.sg

(C) The Author(s) 2020

C. S. Sanger and N. W. Gleason (eds.),

Diversity and Inclusion in Global Higher Education, https://doi.org/10.1007/978-981-15-1628-3_9 
community. In response, the university's Rector clarified that SGRC was not an official group recognized by the university.

Elsewhere, in Japan, a male graduate student from the law faculty at Hitotsubashi University committed suicide after his sexual orientation was made public against his will in August 2015. ${ }^{2}$ A year after his death, two students from the same university started a student group to foster a safe space for LGBTQ students on campus; the group was officially recognized by the university in May $2017 .^{3}$

These two examples from Indonesia and Japan demonstrate firstly, the serious challenges that continue to face LGBTQ university students across Asia and secondly, the different institutional approaches toward LGBTQ diversity and inclusion in the region that largely ranges from hostility to ambivalence. Often, affirming institutions are either found in societies that have never criminalized same-sex sexual acts, such as Taiwan, Thailand, and the Philippines, or have some Anglo-American affiliation as in the case of New York University's satellite campuses in Shanghai and Abu Dhabi or Yale-NUS College, the product of a collaboration between Yale University and the National University of Singapore. In rare instances, universities in more hostile environments, such as the Jakarta Theological Seminary in the capital city of Indonesia, have sought to adopt an affirming approach toward LGBTQ diversity despite public and political opposition. ${ }^{4}$

It is unsurprising that most Asian universities are not affirming of LGBTQ diversity. A significant proportion of countries that still criminalize consensual same-sex sexual acts are located in Asia and most Asian countries still have yet to introduce any legislative or policy measure to

\footnotetext{
${ }^{2}$ Nagayasu Shibun, "Sexual Minorities in Japan: The Myth of Tolerance," Nippon.com, October 21, 2016, https://www.nippon.com/en/currents/d00253/.

3 "2 Students form Social Group for Sexual Minorities at Hitotsubashi Univ. After Suicide," The Mainichi, February 28, 2019, https://mainichi.jp/english/articles/ 20190228/p2a/00m/0na/004000c.

${ }^{4}$ Eduard Merigo, "In Indonesia, LGBT Communities Viewed as Moral ThreatCondemned by Religion, and Increasingly, by Law," South China Morning Post, April 7, 2019, https://www.scmp.com/magazines/post-magazine/long-reads/article/ 3004634/indonesia-lgbt-community-viewed-moral-threat.
} 
protect LGBTQ persons from discrimination or violence. ${ }^{5}$ This is exacerbated by the stigma and prejudice against LGBTQ individuals that permeate some Asian societies because gender and sexual diversity are viewed negatively for historical, religious, and political reasons. This contributes to an unwelcoming and sometimes hostile environment that LGBTQ students find themselves contending with in their universities.

While existing literature on LGBTQ diversity and inclusion in higher education has identified the key challenges facing LGBTQ students, it has largely failed to engage with the specific experiences of Asian universities. We attempt to address this lacuna in the scholarship. This is important for three reasons. Firstly, as higher education expands in Asia, there needs to be a greater focus not only on the quality of education but also the experiences of students. Without a safe and affirming environment for all students, effective learning cannot take place. Secondly, LGBTQ issues are often viewed as undesirable foreign, specifically Western, practices in many Asian societies that are at odds with "Asian values." This poses a challenge to educators and university administrators navigating this complex socio-political landscape. Thirdly, LGBTQ students in Asia may experience their gender and sexual identities differently from their peers in Anglo-American settings as a result of how social institutions such as family and adulthood are culturally conceived.

Before we proceed and as others in this volume have emphasized, it is both difficult and disingenuous to speak about Asia as if it were a coherent conceptual or geographical category. The sheer diversity in history, culture, geography and politics not merely across the entire region but even between two neighboring countries makes it nearly impossible to generate any useful generalization about the whole continent. In particular, the socio-legal landscape relating to LGBTQ issues is especially diverse; while Taiwan has achieved marriage equality and India and Bhutan have repealed laws that criminalize same-sex intimacy, more than twenty other Asian countries still criminalize it. ${ }^{6}$ Nevertheless, in exploring Asian perspectives on the issues facing LGBTQ students in higher

${ }^{5}$ Lucas Ramon Mendos, State-Sponsored Homophobia Report 2019 (Geneva: ILGA, 2019).

6 “Taiwan Legalises Same-Sex Marriage in First for Asia," The Straits Times, May 18, 2019; "India's Top Court Lifts Ban on Gay Sex in Landmark Ruling," The Straits Times, September 6, 2018; and "Bhutan LGBT Community Celebrates After Homosexuality Is Decriminalised," The Straits Times, June 8, 2019. 
education, we believe that there are some common issues and themes that affect the regions which are worth examining. More fundamentally, we hope that this chapter demonstrates to educators that context is critical in approaching something as politically controversial and culturally sensitive as LGBTQ issues in the university setting.

As we will briefly outline later in this chapter, in countries where extensive research has been conducted, the challenges that LGBTQ students face are well-documented in terms of the relative invisibility of sexual and gender diversity on campus and the lack of targeted support resources. ${ }^{7}$ This chapter builds on existing scholarship by examining how these challenges manifest themselves in Asian universities where particular cultural and historical factors may exacerbate negative and potentially hostile attitudes toward LGBTQ identities and expressions. Unlike universities in North America and Europe, which are often already committed to LGBTQ inclusion in principle, most universities in Asia can either be described as hostile or ambivalent toward LGBTQ students. The strategies that may work in the former contexts may therefore either be impossible or extremely unfeasible in Asia. In this chapter, we use various case studies to develop a theoretical framework for understanding how universities in Asia, especially in countries with restrictive laws and unaccepting cultural attitudes, can become more affirming institutions for LGBTQ students as a result of factors such as student activism and globalization.

We develop this framework to categorize the different types of Asian universities in terms of their institutional approaches toward LGBTQ inclusion. We identify three types of approaches: affirmation, ambivalence, and hostility. This framework allows educators and administrators to better strategize their advocacy for LGBTQ inclusion as well as the implementation of culturally appropriate programs that best support LGBTQ students in their campuses. We focus especially on institutional approaches toward LGBTQ inclusion because the institution itself is often the key

${ }^{7}$ See, for instance, Sue Rankin, Genevieve Weber, Warren Blumenfeld, and Somjen Frazer, 2010 State of Higher Education for Lesbian, Gay, Bisexual \& Transgender People (Charlotte: Campus Pride, 2010); Susan B. Marine and D. Chase J. Catalano, "Engaging Transgender Students on College and University Campuses," in Student Engagement in Higher Education: Theoretical Perspectives and Practical Approaches for Diverse Populations, edited by Stephen J. Quaye and Shaun R. Harper (New York: Routledge, 2014), 135148; and Dafina-Lazarus Stewart and Mary F. Howard-Hamilton, "Engaging Lesbian, Gay, and Bisexual Students on College Campuses," in Student Engagement in Higher Education, 121-134. 
obstacle to fostering a more diverse university community in the Asian context as a result of social and political factors. Consequently, while individual educators may attempt to incorporate inclusive strategies in their pedagogy, they may face significant challenges in doing so. It is therefore crucial for those concerned with the well-being and learning of LGBTQ students to focus not only on specific teaching or student engagement strategies but also consider how they can effectively advocate for LGBTQ inclusion at an institutional level. In addition, while we focus largely on LGBTQ students, the institutional approach of a university also affects the experiences of LGBTQ staff and faculty in terms of whether they may face violence or discrimination or come out as LGBTQ on campus; a case involving the suicide of a librarian working at the Myanmar Imperial University illustrates the real impact that a hostile university environment can have on LGBTQ staff as well. ${ }^{8}$

The rest of this chapter proceeds as follows. Section "Challenges Facing LGBTQ Students in Asia" provides a brief context on the challenges facing LGBTQ students in Asia both within the university setting and more broadly in Asian societies. Section "Three Types of Institutional Approaches Toward LGBTQ Inclusion in Asia" outlines three types of institutional approaches toward LGBTQ students that can be found in Asia: hostility, ambivalence, and affirmation. Section "Engendering Affirmation Toward LGBTQ Students in Asian Universities" considers the factors that influence how universities can move from hostility to affirmation and the role that students, faculty, and administrators can play in engendering this institutional shift. Section "Pedagogical Strategies for Educators Working with LGBTQ Students or LGBTQ-Related Issues in the Classroom" discusses some strategies that educators may adopt in their pedagogy or curriculum design to better engage with LGBTQ students and LGBTQ-related subjects in the classroom. We conclude in Section "Conclusion and Future Directions" with a brief discussion on the broader impact that LGBTQ inclusion in higher education can have on Asian societies.

8 "Gay Myanmar Man Posts Facebook Bullying Note Before Taking Life," New Straits Times, June 25, 2019, https://www.nst.com.my/world/2019/06/499097/gaymyanmar-man-posts-facebook-bullying-note-taking-life. 


\section{Challenges Facing LGBTQ Students in Asia}

The challenges that LGBTQ students face in Asia are not dissimilar to those that LGBTQ students face elsewhere. According to Schueler, Hoffman, and Peterson, the four main challenges that LGBTQ students face are invisibility, conflicting social identities, homophobia, and a dominant heteronormative culture. ${ }^{9}$ These issues are not unique to the university environment but particularly affect LGBTQ students' identity formation, personal development, and academic engagement as young adults.

\section{Invisibility and the Silence of Sex}

Invisibility is defined as the absence of positive and visible role models for LGBTQ students among faculty, staff, and administrators as well as a lack of support resources that cater to these students. In Asian societies, this is worsened by strong cultural taboos surrounding sex and intimacy where it is considered unprofessional and unacceptable for faculty, staff, and administrators to discuss or share their personal lives, whether heterosexual or otherwise. ${ }^{10}$ Institutionally, because there are also often little to no support resources relating to sexual or reproductive health generally, it may be even harder to advocate for support resources targeted specifically at LGBTQ students. This is troubling because a survey conducted among over 3000 university students in five Southeast Asian countries highlighted the need to prioritize LGBTQ students who were disproportionately affected by mental health issues. ${ }^{11}$

\footnotetext{
${ }^{9}$ Schueler, Hoffman, and Peterson, "Fostering Safe, Engaging Campuses for Lesbian, Gay, Bisexual, Transgender, and Questioning Students," in Student Engagement in Higher Education: Theoretical Perspectives and Practical Approaches for Diverse Populations, edited by Shaun R. Harper and Stephen J. Quaye (New York: Routledge, 2010), 61-80.

${ }^{10}$ Marwaan Macan-Markar, "Asian Cultural Taboos Hide Links Between Sex and HIV/AIDS," Malaysiakini, July 11, 2002, https://www.malaysiakini.com/opinions/ 21679. See also Zhang Liying, Li Xiaoming, and Iqbal H. Shah, "Where Do Chinese Adolescents Obtain Knowledge of Sex? Implications for Sex Education in China," Health Education 107, no. 4 (2007): 351; Shantha Sankaranarayan, Eknath Naik, P. S. N. Reddy, G. Gurunani, Karuna Ganesh, Kailas Gandewar, K. P. Singh, and S. H. Vermund, "Impact of School-Based HIV and AIDS Education for Adolescents in Bombay, India," Southeast Asian Journal of Tropical Medicine and Public Health 27, no. 4 (1996): 692.

${ }^{11}$ Karl Peltzer and Supa Pengpid, "Minority Stress Among Lesbian, Gay, Bisexual, and Transgender (LGBT) University Students in ASEAN Countries: Associations with Poor Mental Health and Addictive Behaviour," Gender and Behaviour 14, no. 3 (2016): 7806.
} 


\section{Recognizing Different Dimensions of LGBTQ Students' Identities}

Just as students of color or faith in the West may struggle with conflicting identity dimensions, LGBTQ students in Asia similarly struggle with the cultural and religious rejection of their sexual or gender identities. This "double oppression"-in terms of being from a minority ethnic or religious group and being LGBTQ - however may transform into a "triple oppression" in the Asian context, where LGBTQ identities are often derided as a foreign, Western invention. LGBTQ students thus have to grapple not only with cultural and religious tensions but also historical and political ones, where their identities are perceived to be a neo-imperial import that are at odds with traditional "Asian values" and the postcolonial struggle. ${ }^{12}$ Because of these factors, it is unsurprising that homophobia and heteronormativity are particularly thorny issues in many Asian societies. This is especially the case in many Muslim-majority countries, where there are rising trends of Islamic fundamentalism and Islamization. This has led to the troubling trend of criminalization of or enhanced punishments for same-sex intimacy in Malaysia, Indonesia, and Brunei. ${ }^{13}$ Even when there is no explicit threat of violence or discrimination such as in parts of East Asia, parental and social expectations of conformity continue to marginalize LGBTQ students who face prejudice and rejection for being different.

\section{Understanding Different Needs of LGB and TNB Students}

At this point, it is important to note that though they are often combined, the challenges facing transgender and non-binary (TNB) students are often very different from those that lesbian, gay, and bisexual (LGB) students face. This is especially salient in some Asian societies, where attitudes toward non-normative gender identities and expressions may sometimes be more affirming than attitudes toward non-normative sexual orientations and practices. An example is Pakistan, where consensual samesex sexual conduct may attract the death penalty under shariah law but where the historical and cultural role of hijras, who are recognized as

\footnotetext{
${ }^{12}$ For a deeper discussion of the "Asian values" debate in the context of LGBTQ rights, see Po-Han Lee, "LGBT Rights Versus Asian Values: De/Re-constructing the Universality of Human Rights," The International Journal of Human Rights 20, no. 7 (2016): 978.

${ }^{13}$ Mendos, State-Sponsored Homophobia Report 2019, 127.
} 
belonging to a third gender, has led to growing social acceptance and legal protection. ${ }^{14}$ Conversely, in Japan, while many parts of the country have legalized same-sex marriage, ${ }^{15}$ transgender people continue to be forcibly sterilized as part of the policy requirements to correct their legal gender. ${ }^{16}$ It is therefore important to recognize that though they are often spoken of in the same breath, the experiences and needs of LGB students are often significantly different from those of TNB students.

\section{Appropriate Language and Terminology in Context}

Furthermore, within each identity category, there is significant diversity as well. As Stewart and Howard-Hamilton observed, "LGB people are not a monolithic group and the impact of other systems of oppression has prompted the development of communities within communities."17 This has led to different identificatory labels that vary across diverse groups. Though terms like lesbian and gay are globally recognizable, they may not be the most appropriate or familiar terms in certain contexts. ${ }^{18}$ The hijra comes to mind; though it is often (mis)translated as transgender or intersex, the cultural meanings attached to hijra cannot be represented by those other terms. In some cases, similar vocabulary may be utilized but with their own specific meanings and connotations; for instance, Boellstorff described how LGBTQ Indonesians referred to themselves as lesbi, gay or waria, terms which may appear similar to but are distinct from the Western conceptions of lesbian, gay, and transgender identity. ${ }^{19}$ It is therefore crucial that educators familiarize themselves with the relevant

${ }^{14}$ Mendos, State-Sponsored Homophobia Report 2019, 136.

${ }^{15}$ Mendos, State-Sponsored Homophobia Report 2019, 286.

${ }^{16}$ Graeme Reid, Kanae Doi, and Michael Bochenekh, 'A Really High Hurdle': Japan's Abusive Transgender Legal Recognition Process (New York: Human Rights Watch, 2019).

${ }^{17}$ Stewart and Hamilton, "Engaging Lesbian, Gay, and Bisexual Students on College Campuses," 122.

${ }^{18}$ See, for instance, William Leap and Tom Boellstorff, eds., Speaking in Queer Tongues: Globalization and Gay Language (Champaign: University of Illinois Press, 2004).

${ }^{19}$ Tom Boellstorff, "Gay and Lesbi Subjectivities, National Belonging and the New Indonesia," in Women in Indonesia: Gender, Equity and Development, edited by Kathryn Robinson and Sharon Bessell (Singapore: Institute of Southeast Asian Studies, 2002), 92-99. 
language that LGBTQ students may use in their particular communities to better relate to and engage with them.

\section{Diverse Cultural Conceptions of Gender and Sexuality}

It is also important to note that while LGBTQ identities may have become the dominant paradigm by which same-sex desire and practices are understood, this may not be the case in some Asian societies. For instance, because of social, cultural, and religious factors, an Arab man who engages in same-sex sexual activity in his youth may not identify as being gay and may go on to marry a woman and have children. This should not be misapprehended as internalized homophobia or suppression of one's homosexual desires. As Massad emphasizes, traditional Arab sexualities are not founded on the hetero-homo binary that prevails in contemporary imaginations. ${ }^{20}$ Educators should therefore be careful of relying on preconceived or non-native understandings of gender and sexuality that may not resonate with their students.

Given the potential violence and discrimination that LGBTQ students may face in many Asian universities, it is crucial for educators to carefully navigate classroom dynamics to support these students without potentially putting them at risk. Furthermore, educators who teach LGBTQ-related subjects need to contend with the different cultural contexts in Asia where some students may be less comfortable or familiar with these concepts. These issues will be discussed further in Section "Pedagogical Strategies for Educators Working with LGBTQ Students or LGBTQ-Related Issues in the Classroom".

\section{Three Types of Institutional Approaches Toward LGBTQ INCLUSION IN ASIA}

Having discussed the challenges that LGBTQ students in Asia face, this section turns toward the institution of the Asian university. While it is perhaps generally accepted in European or North American universities that LGBTQ inclusion is desirable and beneficial, this is not the case in most Asian universities. We describe three types of institutional approaches toward LGBTQ inclusion. Firstly, the archetypal European or

${ }^{20}$ Joseph A. Massad, Desiring Arabs (Chicago: University of Chicago Press, 2008). 
North American university may be described as an affirming institution that values LGBTQ inclusion. Secondly, most Asian universities may be best characterized as ambivalent toward LGBTQ students in that administrators and their policies do not acknowledge the existence of such diversity and ignore or condone any discrimination that LGBTQ students may face on campus. Finally, at the other end of the spectrum are hostile universities that not only condones discrimination against LGBTQ students but also actively perpetuates violence and discrimination through its faculty, administrators, and policies. Such universities are generally found in societies where harsh laws criminalizing same-sex intimacy exist and attitudes toward LGBTQ persons are extremely negative.

This framework is useful in several ways. Importantly, it situates the three university archetypes along a linear axis, where a hostile university may gradually shift from first being ambivalent to finally being affirming toward LGBTQ students. This institutional shift does not occur in a vacuum; since universities are embedded in the societies that they are located; they are acutely influenced by the prevailing socio-legal landscape. The next section discusses the factors that may engender this institutional shift.

Different strategies may be effective based on the institutional context that educators and administrators are operating in. For instance, an educator operating within a hostile institutional environment may adopt a less overt and resource-intensive strategy to engage with LGBTQ students: organizing a networking event for these students may not be feasible but a small, informal support group meeting might be. This framework thus allows educators and administrators to reflect on and better strategize how they may best support and advocate for LGBTQ students.

This framework thus allows for greater conceptual clarity when discussing Asian universities. The climate at a university in Beijing, China may be very different from one in Dhaka, Bangladesh. By distinguishing between different stages that Asian universities may be at, this framework provides theoretical nuance to the study of LGBTQ inclusion in Asia. Notwithstanding, the descriptions that follow and the table outlining each institutional approach appended at the end of this section are neither exhaustive nor definitive and would benefit from further clarification and development in future scholarship. 


\section{The Affirming University}

The terminal and desired institutional approach toward LGBTQ students, the affirming university is one that recognizes and, as its name suggests, affirms the gender and sexual diversity in the university community. This affirmation manifests itself in both university policy and programming as well as the wider campus culture. In some cases, such affirmation may be mandated by law through the actual implementation on the ground often falls short. For instance, in Taiwan, the Gender Equity Education Act requires schools to "provide a gender-fair learning environment, respect and give due consideration to students, faculty, and staff with different gender, gender temperaments, gender identity, and sexual orientation." 21 It also prohibits schools from discriminating against prospective and current students on the basis of their "gender, gender temperaments, gender identity or sexual orientation." 22 However, a recent study reported gaps in realizing these legal obligations due to various cultural and administrative challenges. ${ }^{23}$

Primarily, an affirming university would have an anti-discrimination policy in place that LGBTQ students-and other students from marginalized communities - can turn to should they experience bullying or discrimination from other students, faculty or administrators. This means that the policy is not only on the books but also actively enforced to protect LGBTQ students from any and all forms of discrimination. Furthermore, the university's housing, healthcare and other policies are LGBTQinclusive and the corresponding departments actively ensure that LGBTQ students feel comfortable seeking support from them. Policies also do not differentiate students based on their sexual orientation; for instance, if housing is available to students who are coupled, it would be available to both heterosexual and same-sex couples. Gender-neutral housing is available to students and they may change their gender markers without having to have amended their legal gender. Policy language is also written using inclusive language that does not perpetuate the gender binary or heteronormativity.

${ }^{21}$ The Republic of China (Taiwan), Article 12, Gender Equity Education Act, 2004.

22 Articles 13 and 14, Gender Equity Education Act.

${ }^{23}$ Ada L. Sinacore, Shu-chu Cha, and Jennifer Ho, "Gender Equity Education Act in Taiwan: Influences on the School Community," International Journal for Educational and Vocational Guidance 19, no. 2 (2019): 293-312. 
Besides that, there are activities and events that are either about or targeted at LGBTQ students. This may include support group meetings, networking events and talks or lectures about LGBTQ-related issues. LGBTQ students are visible in the university community, either through the establishment of official student groups or campus committees focusing on LGBTQ inclusion, and there are openly LGBTQ or LGBTQaffirming faculty or administrators to whom students can turn for support and mentorship.

Together, such policies and programming foster an affirming campus environment. LGBTQ students generally feel comfortable about disclosing their gender or sexual identities if they so choose and can seek support from various channels. Educators are free to teach about LGBTQ-related issues in the classroom as well because students are comfortable and familiar with them.

Examples that approximate this archetype include Yale-NUS College in Singapore and New York University (NYU) Shanghai. Both these institutions have established policies like those discussed above that are like their affiliated American universities which are known for their strong affirmation of LGBTQ diversity. Bangkok University has also put in place affirming policies such as a trans-inclusive uniform policy and Thammasat University has included discussions on gender identity led by a transgender lecturer in a mandatory course for all incoming first-year students. ${ }^{24}$ Hong Kong University (HKU) introduced gender-neutral bathrooms in 2016 and runs a Sexual Diversity Network that aims to increase awareness of "the needs of people from varied sexual orientations" and advocate sexual diversity on campus. ${ }^{25}$

${ }^{24}$ Jonathan Head, "Bangkok University Transgender Students Get New Uniform Rules," BBC News, June 9, 2015, https://www.bbc.com/news/world-asia-33060185; "Thai University Introduces Mandatory Class on Transgender Issues," TEAK Trans Empowerment, October 10, 2017, https://teak.site/thai-university-introduces-mandatoryclass-on-transgender-issues/.

${ }^{25}$ Cannix Yau, "University of Hong Kong Accused of Trying to Brainwash Campus with Unisex, LGBT-Friendly Toilets," South China Morning Post, September 2, 2016, https://www.scmp.com/news/hong-kong/education-community/article/ 2013151/university-hong-kong-accused-trying-brainwash; "Diversity and Social Inclusion," CEDARS-CoPE, accessed June 4, 2019, https://wp.cedars.hku.hk/web/cope/? $\mathrm{p}=849$. 


\section{The Ambivalent University}

The ambivalent university is characterized by the absence of any effective policies or programming that affirm LGBTQ diversity on its campus. There is therefore little to no specialized services supporting LGBTQ students because the university does not explicitly recognize the existence of gender and sexual diversity. For instance, according to one article, in Hong Kong, counselling services that are provided in universities do not actively reach out to LGBTQ students and counsellors often lack experience and expertise in dealing with LGBTQ students. ${ }^{26}$

In some cases, administrators are willing to provide support to LGBTQ students on a discretionary basis though this is not usually made known publicly. For instance, according to research conducted by the InterUniversity LGBT Network in Singapore, the two main public universities that provide on-campus housing can offer transgender students housing in a mixed-gender arrangement if students make a special request on the basis of their gender identity. ${ }^{27}$ However, this may not be entirely appropriate as it places the burden on transgender students to disclose their identities to university administrators.

At an ambivalent university, though discrimination may be prohibited in the university's code of conduct, there is no clear process for aggrieved students to seek recourse. Most cases of discrimination thus often go unreported. Where a case is reported, perpetrators of discrimination are often let off with a slap on the wrist, signaling to LGBTQ students that their safety and wellbeing are not of utmost priority to the university.

For instance, in 2014, a Malay Studies professor at the National University of Singapore (NUS) published a Facebook post referring to lesbianism as "cancers" and "social diseases." 28 In response, the University Provost sent a circular to all members of the university, stating that the

${ }^{26}$ Stuart Heaver, "LGBT Students Face so Much Prejudice in Hong Kong They're Afraid to Reveal Their Sexuality," South China Morning Post, November 29, 2018, https://www.scmp.com/lifestyle/family-relationships/article/2175396/lgbtstudents-face-so-much-prejudice-hong-kong-theyre.

${ }^{27}$ Rachel Yeo, "Trans* In College: A Handbook for Transgender Students in Singapore's Universities," Inter-University LGBT Network, https://interunilgbt.wixsite.com/ interunilgbt/books-resources.

${ }^{28}$ Pearl Lee, "NUS Prof's Comments on Lesbians Spark Protests from Past and Present Students," The Straits Times, February 28, 2014, https://www.straitstimes.com/ singapore/nus-profs-comments-on-lesbians-spark-protests-from-past-and-present-students. 
university "embraces faculty, staff and students regardless of gender, ethnicity, religion, nationality, political beliefs or sexual orientation." $29 \mathrm{He}$ added that he had counselled the faculty member in question, who merely acknowledged that his posts reflected "poor judgment in the tone and choice of words"; there was no acknowledgement that his views were discriminatory nor were any measures taken to ensure LGBTQ students can feel safe should they decide to take this professor's classes in the future.

Additionally, while LGBTQ students may informally organize themselves to provide peer support or advocate for themselves, they are not funded by or recognized by the ambivalent university. An example is UP Babaylan which is the first Filipino student LGBT group at the University of the Philippines, Diliman campus in Quezon City, Philippines. Similarly, though students in various Taiwanese universities have established LGBTQ groups since the 1990s, with the first being NTU GayChat at the National Taiwan University (NTU) in 1993, student activists report facing significant challenges registering and operating their groups at institutions that are funded by or affiliated with religious groups such as the Fu Jen Catholic University. ${ }^{30}$

\section{The Hostile University}

At the other end of the spectrum are the hostile universities, which are openly antipathetic toward LGBTQ students. Students who are perceived to be LGBTQ experience bullying and discrimination, that are often sanctioned by the university. An example is the "Back to Fitrah" event at the Universiti Sains Malaysia (USM), a contest organized by the USM Muslim Students Association to assist students with "disorders in sexual orientation return to their natural instincts." 31 Similarly, at Indonesia's Andalas University in Padang, West Sumatra, students were required to

${ }^{29}$ June Yang, "NUS Professor Acknowledges 'Poor Judgment' in Posts on Sexuality," Today Singapore, March 5, 2014, https://www.todayonline.com/singapore/nus-professoracknowledges-poor-judgement-posts-sexuality.

${ }^{30}$ Eddy Chang, "Taipei Watcher: LGBT Clubs Should Be Allowed to Come Out of the Closet," Taipei Times, September 27, 2015, http://www.taipeitimes.com/News/feat/ archives $/ 2015 / 09 / 27 / 2003628678 / 1$.

31 "Forum Not to Change LGBTs but to Foster Goodwill, Says USM Student Body," The Sun Daily, April 5, 2018, https://www.thesundaily.my/archive/forum-not-changelgbts-foster-goodwill-says-usm-student-body-HUARCH537814. 
sign a form declaring that they were not openly LGBTQ. The university's chancellor defended such a policy on the basis that the institution had the right to discriminate because of religious teachings. ${ }^{32} \mathrm{He}$ added that if an enrolled student is found to be LGBTQ, the university would "rehabilitate" them before expelling them.

For transgender and gender non-conforming students, many universities also have strict uniform or hair policies. In both Thailand and the Philippines, university students are expected to dress and present themselves according to specific requirements. For instance, Human Rights Watch found that many transgender students in the Philippines were suspended or even expelled for "cross-dressing." 33 There have also been multiple reports of transgender students being denied the ability to dress according to their gender identity and forced to wear the uniform or graduation gown of the sex they are assigned at birth. ${ }^{34}$

Based on the Table 9.1 outlined below, we compare two universitiesthe National University of Singapore and Hong Kong University-to consider their institutional approaches toward LGBTQ inclusion.

\section{Case Study 1: Ambivalent University}

National University of Singapore

There is no anti-discrimination policy protecting LGBTQ students. The official university policy refers to "Singapore nondiscrimination laws and the relevant Singapore government policies," which do not explicitly address sexual orientation, gender identity or expression. ${ }^{35}$ Though the Student Code of Conduct states that "students should avoid... the purveying or dissemination of pejorative viewpoints along sectarian lines (including but not limited to issues on race, language, religion, gender, sexuality,

32 "Indonesian University Refuses to Accept LGBT Students, Citing Protection of Their 'Rights'," Coconuts Jakarta, May 3, 2017, https://coconuts.co/jakarta/lifestyle/ indonesian-university-refuses-accept-lgbt-students-citing-protection-rights /

${ }^{33}$ Human Rights Watch, 'Just Let Us Be': Discrimination Against LGBT Students in the Philippines (New York: Human Rights Watch, 2017).

34 "University denies trans Student's Right to Wear Female Uniform; Reflects Discrimination Faced by Thailand's LGBT Community," Prachatai, January 22, 2019, https://prachatai.com/english/node/7887; Melalin Mahvongtrakul, "Uniform Justice," Bangkok Post, February 6, 2017, https://www.bangkokpost.com/lifestyle/social-andlifestyle/1193641/uniform-justice/feed/. 


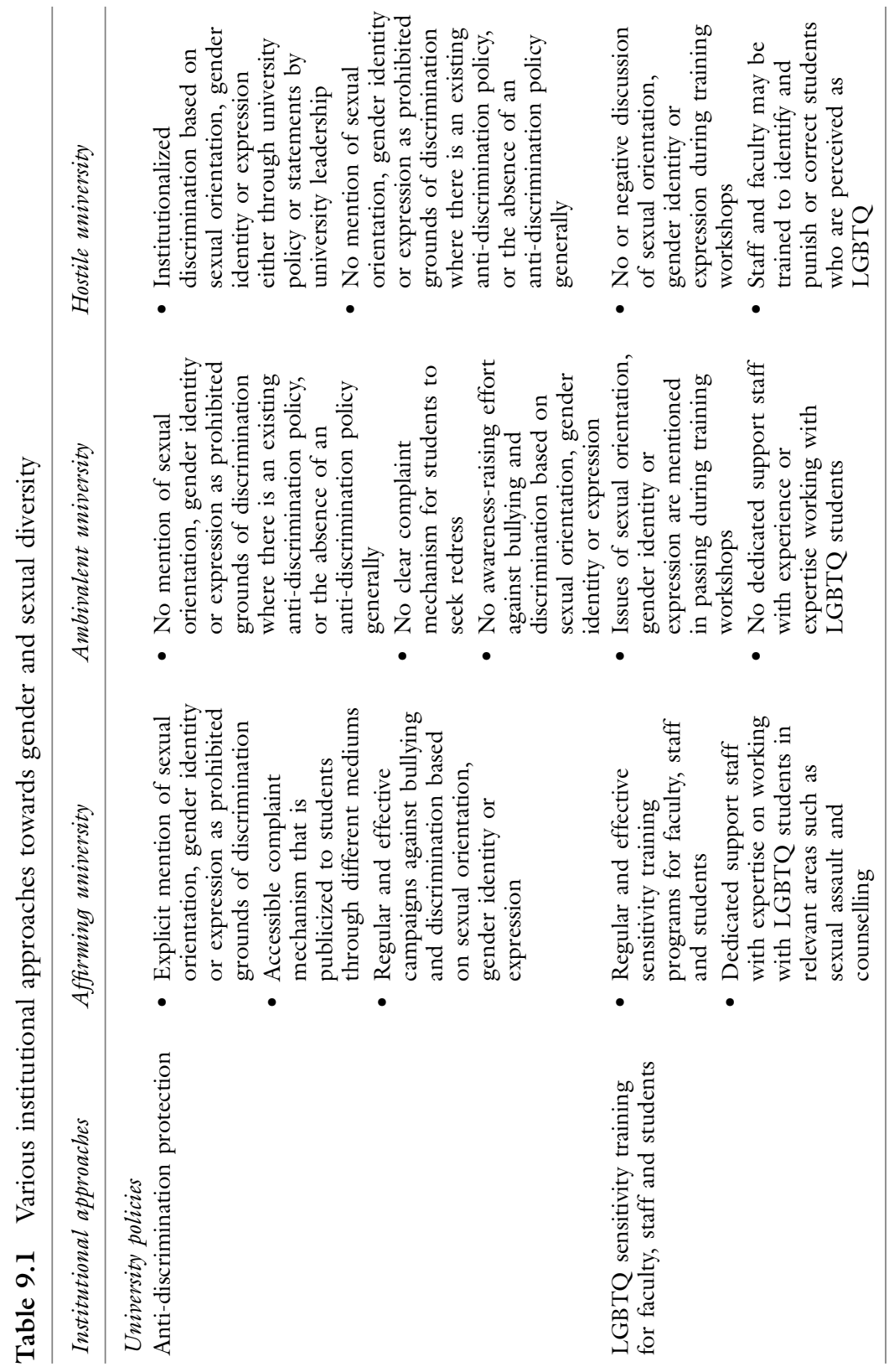




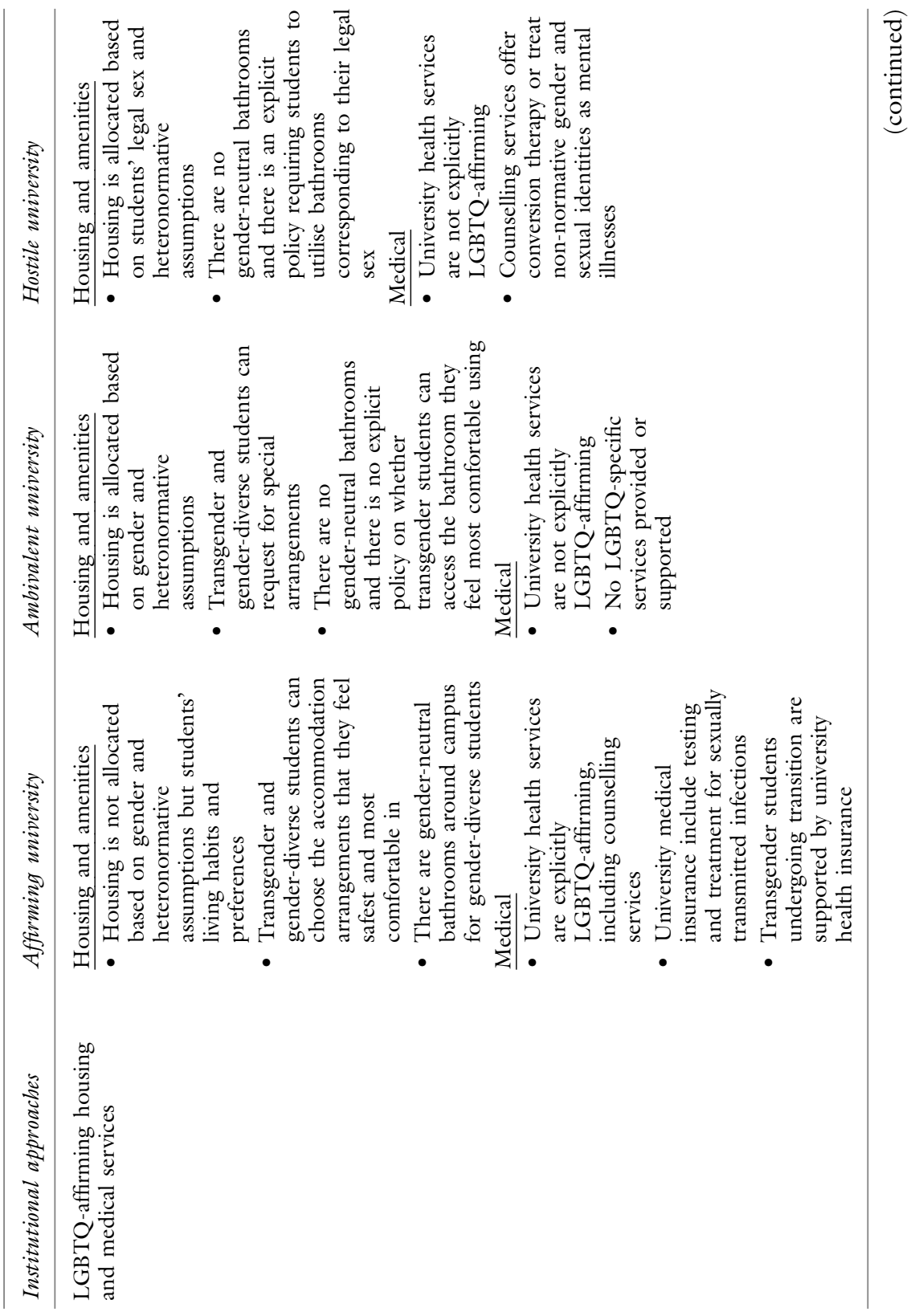




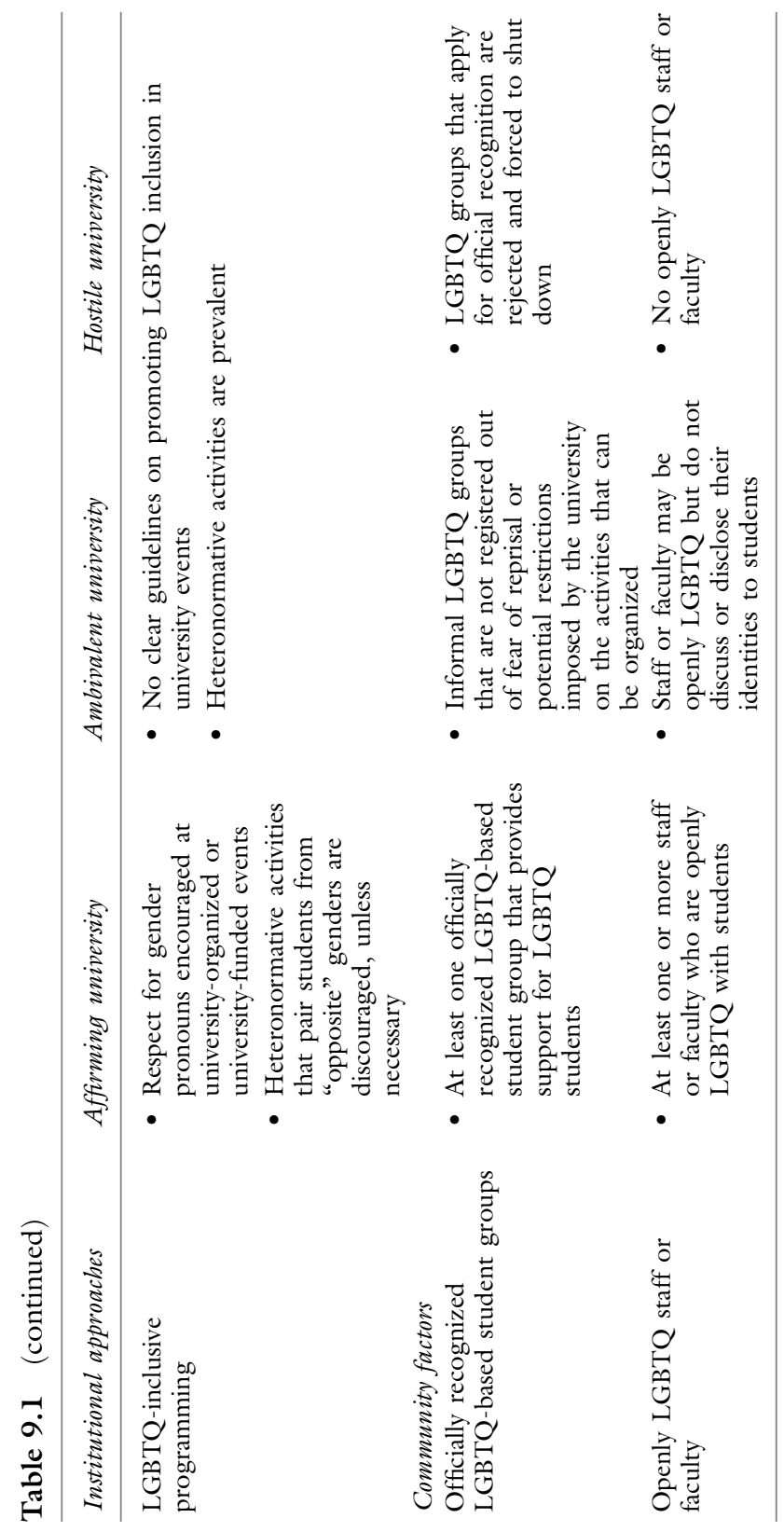


age, nationality)," it does not provide for any form of sanction against students who do so. 36

There are also no LGBTQ-specific training programs for staff or faculty. Though a university administrator has expressed a willingness to accommodate transgender students with respect to housing, it remains on a discretionary basis and there is no medical support for transgender students. ${ }^{37}$ There are no specific guidelines addressing LGBTQ inclusion for university events or programs.

There is no university-wide LGBTQ student group, though some groups have been set up in residential colleges. While there are some openly LGBTQ faculty or staff, they generally do not discuss or disclose their LGBTQ identities to students.

\section{Case Study 2: Affirming University}

Hong Kong University

The Equal Opportunity Unit of the university explicitly forbids sex discrimination and harassment on the grounds of sexual orientation. ${ }^{38}$ It also provides an online form and a set of formal procedures for the investigation of complaints. ${ }^{39}$

Though there does not appear to be LGBTQ-specific trainings, the Equal Opportunity Unit and the Centre of Development and Resources for Students (CEDARS) both provide some education resources on fostering an LGBTQ-inclusive campus environment. ${ }^{40}$ The Counselling and Person Enrichment Section (CoPE) of CEDARS also explicitly affirms LGBTQ students on its website and runs a Sexual Diversity Network, which focuses on increasing awareness on the needs of people from varied sexual orientations and promoting a sensitive counselling service and support network. ${ }^{41}$ The university has also introduced gender-neutral bathrooms. ${ }^{42}$

The university also recognizes the Queer Straight Alliance, which is a network of LGBTQ students, staff and allies across campuses in Hong

35 "Legal Information \& Notices," National University of Singapore, http://www.nus. edu.sg//legal-information-notices\#nondiscrimination.

36 "Code of Student Conduct," NUS Office of Student Affairs, http://www.nus.edu. $\mathrm{sg} / \mathrm{osa} /$ resources/code-of-student-conduct.

${ }^{37}$ Yeo, "Trans* In College." 
Kong. ${ }^{43}$ There is also at least one openly LGBTQ faculty, lecturer Brenda Alegre who joined the university to teach a course on gender and sexuality. 44

\section{Engendering Affirmation Toward LGBTQ Students IN ASIAN UNIVERSITIES}

The previous section demonstrates that many Asian universities remain either ambivalent or hostile toward LGBTQ students. Such approaches are unsurprising as they mirror the wider socio-legal environment that the universities are embedded in. In countries where same-sex intimacy remains criminalized, it is difficult for any university to adopt an affirming approach toward LGBTQ students without exposing itself to potential backlash for condoning or encouraging illegal activities. Even in societies without such laws, hostile socio-cultural attitudes similarly inhibit the ability of universities to address this issue. In some cases, administrators themselves may be prejudiced against LGBTQ students.

How then can educators support their institutions in adopting a more affirming approach toward LGBTQ students? We suggest that there are

\footnotetext{
38 "Policy Statement," Equal Opportunity Unit, http://www.eounit.hku.hk/en/aboutus/policy-statement.

39 "Online Form," Equal Opportunity Unit, http://www.eounit.hku.hk/en/ complaints-enquiries/online-form; "Procedures," Equal Opportunity Unit, http://www. eounit.hku.hk/en/complaints-enquiries/procedures.

40 "Student Orientation Guidelines," Equal Opportunity Unit, http://www.eounit.hku. hk/en/guidelines/student-orientation-guidelines; "How Can I Contribute in Promoting a LGBT-Friendly Environment on Campus?," CEDARS-CoPE, https://dmp.cedars.hku. hk/watch_video.php?v=RAXRKW1931YW.

${ }^{41}$ CEDARS-CoPE, "Diversity and Social Inclusion."

${ }^{42}$ Yau, "University of Hong Kong Accused of Trying to Brainwash Campus with Unisex, LGBT-Friendly Toilets."

43 CEDARS-CoPE, "Diversity and Social Inclusion."

${ }^{44}$ Kylie Knott, "Transgender Lecturer in Hong Kong on Her Fight to Be Accepted by a Conservative Society, and Her Fear of the Police," South China Morning Post, January 20, 2018.
} 
three main factors that can influence the institutional shift toward affirmation: an affirming socio-legal landscape, the globalization of higher education, and student activism.

\section{Affirming Socio-Legal Landscape}

As noted earlier, the wider socio-legal environment that universities operate in have a significant impact on the campus climate. Regardless of how much educators may try to foster an inclusive classroom environment, the lived realities of LGBTQ students outside of the classrooms will invariably affect the latter's learning and academic performance. It is therefore crucial for educators to consider how they can support LGBTQ students beyond the classroom.

An example is the active role of prominent academics in campaigning for the decriminalization of male same-sex intimacy in Singapore. Many professors and university administrators came out publicly as lead signatories to a petition calling for the repeal of Section 377A of the Penal Code, which punishes gay and bisexual men with up to two years' imprisonment for "acts of gross indecency." 45

Such public support for legal change however should be approached carefully. There are different ways by which educators can advocate for safer and more inclusive laws for their LGBTQ students. In some cases, if an educator is non-native and comes from the Global North, being overly vocal about these topics may reinforce the notion that LGBTQ issues are "Western" or "foreign." Instead, they should consider playing a more supportive role, by assisting or encouraging colleagues or university leaders who are native or from the region to speak up, which would be especially powerful in fostering attitudinal change within the community. Educators should thus strategically consider whether they are likely to be more effective in fostering a more LGBTQ inclusive campus by being on the frontline of advocacy or in working behind the scenes with other faculty, staff or students.

45 "Who We Are," Ready4Repeal, accessed June 6, 2019, from https://ready4repeal. com/who. 


\section{Globalization of Higher Education}

The international movement of people, institutions and ideas in the industry of higher education may encourage universities to adopt a more affirming approach toward LGBTQ students. Increasingly, more international universities are setting up satellite campuses in Asia and there is also an increasing number of collaborations with Asian universities to develop new academic programs or research centres. This presents an opportunity for academics and administrators to share affirming policies and approaches from their parents or previous institutions through these collaborations. Furthermore, it is in the interests of universities to become more LGBTQ-affirming to avoid the potential brain drain of talented students who are becoming increasingly mobile as well.

Nevertheless, the impact of the globalization of higher education may be limited due to the perception that such policies are "Western" and not applicable to the Asian context. It is therefore crucial that educators looking to propose the adoption of affirming policies do so in a strategic manner that will not invoke the specter of Western neo-imperialism. For instance, they should collaborate with local colleagues or students to increase the acceptability of such policies among the larger university community.

\section{Student Activism}

Finally, a major factor influencing the institutional shift toward affirmation comes from LGBTQ and allied students themselves who advocate for more affirming policies and programs. In several countries, students have set up groups to facilitate collective organizing and mutual support. This includes groups such as the Inter-University LGBT Network in Singapore, Action-Q in Hong Kong and UP Babaylan in The Philippines. There are however several risks and challenges that student activists may face in the course of their advocacy.

Clearly, many LGBTQ student groups have faced significant challenges in registering their groups with their university. This is usually the first step toward gaining recognition and resources, without which groups would struggle to recruit members and organize activities. Furthermore, there may be additional challenges in recruitment as students who are not open about their identities may fear the risk of being outed to other students, administrators or their families. As a result, groups find it doubly 
difficult to organize and strategize effectively as they lack the members to operate efficiently.

Moreover, the advocacy of LGBTQ student groups may provoke backlash from other student groups or the public. This may severely impede any progress on policy change and increase the risk of violence and discrimination against LGBTQ students. Thirdly, because of the risks that advocacy may pose, internal disagreements may arise among LGBTQ students in these groups as to whether they should focus on support and networking or advocacy. Some student organizers may prefer to focus on providing support to other LGBTQ students by creating a safe and affirming space that does not otherwise exist. However, conducting advocacy threatens the safety of that space due to the increased visibility and attention on the group and this may deter more vulnerable students from seeking support. Thus, the fracturing of these already-small communities may further hamper the effectiveness of any advocacy efforts.

Educators can offer their support and allyship to these student groups either formally or informally, depending on the context within which they are operating. This can include providing financial support or campus spaces to organize activities that students in unregistered groups may lack and organizing other faculty and administrators to support the students' advocacy efforts. For instance, in relation to the incident involving the NUS professor who had made homophobic comments about lesbian women, over eighty faculty from the same university published a forum letter in the national newspaper condemning his views. ${ }^{46}$ This public statement represented a powerful message to LGBTQ students that there were educators who were willing and ready to stand up to protect them from prejudice. At the same time, it also sent a signal to the university community at large that discriminatory behavior would not be tolerated by a sizeable proportion of educators.

${ }^{46}$ Khoo Hoon Eng, "Sending Wrong Signal on Tolerance," The Straits Times, March 6,2014 . 


\section{Pedagogical Strategies for Educators Working WITH LGBTQ STUDENTS OR LGBTQ-RELATED Issues IN THE ClassRoOM}

While institutional shifts may take years if not decades, educators may adopt strategies in the classroom to foster a more inclusive learning experience for LGBTQ students. This section outlines some of these strategies that both academic and student affairs educators may consider implementing in ambivalent or hostile institutions.

\section{Classroom Experience}

Rather than special strategies targeting LGBTQ students or LGBTQrelated issues in the classroom, common strategies that lead to being inclusive of a diverse student body can be adopted. ${ }^{47}$ Given that institutional support is likely absent, more experienced faculty should invest in the career development of other faculty by organizing workshops to share how common pedagogical principles of learning can be applied to create a LGBTQ-inclusive classroom to foster effective learning for all students. $^{48}$

One of the first steps for any faculty to take is to learn the language and terms used in LGBTQ discourse in the context in which they are working so that they can be sensitive to derogatory terms or slurs. This can ensure their classrooms are safe for LGBTQ students by guiding class discussions in a healthy manner. Another strategy is to outline the importance of respect for diversity at the beginning of the course and referencing specifically diversity based on sexual orientation and gender identity. This can set the tone for class participation in general and signal to LGBTQ students specifically that they are welcome in the class. In particularly hostile environments such as in countries with high rates of violence against

${ }^{47}$ Catherine S. Sanger, "Diversity \& Inclusion in Curriculum and Classroom," Yale-NUS College Centre for Teaching \& Learning, https://teaching.yale-nus.edu.sg/wpcontent/uploads/sites/25/2019/03/Diversity-and-Inclusion-Booklet_02.4.19-Online. pdf, 109.

${ }^{48}$ Michele DiPietro, "Applying the Seven Learning Principles to Creating LGBTInclusive Classrooms," Diversity \& Democracy 15, no. 1 (2012); "LGBTQ Inclusive Curriculum and Classroom Climate," Fordham University, accessed June 4, 2019, https://www.fordham.edu/info/25663/education_and_research_ethics_resources/ 6346/lgbtq_inclusive_curriculum_and_classroom_climate. 
LGBTQ persons, this signal can be conveyed implicitly by referring to sex or gender instead of sexual orientation and gender identity specifically.

\section{Inclusion of LGBTQ + Content in Curriculum}

In terms of curricular content, there should be purposeful inclusion of LGBTQ topics in various courses. By making these topics visible, LGBTQ students and others get the opportunity to engage intellectually across academic fields with topics related to their identities. Students who are part of minority groups (whether by ethnicity, social class, religion and/or sexual orientation) are motivated to learn when their identities are affirmed and included in the curriculum.

For example, an introductory course at Yale-NUS College that is taught to all first-year students invites them to consider the role of social forces in shaping their lives. Through a series of topics that include power, markets, family, social class, race, gender, religion and the state, students get a deeper understanding of how societies are organized and why. Such a course then easily introduces the concept of the diversity of sexual orientation. Another example of such a course at the National University of Singapore is titled "Sexuality in Comparative Perspective" where readings, films and discussions were utilized to cover the sociological nuances of LGBTQ topics. Other ways of engaging students included inviting guest speakers of diverse sexual orientations and gender identities to the class.

While courses from the social sciences and the humanities can easily incorporate issues of identity, social norms and oppressions that include LGBTQ communities, such courses in the curriculum need not be confined to these disciplines. For example, a useful guide to the development of LGBTQ-inclusive curriculum has suggestions for inserting LGBTQ content into subjects such as English Language, Arts, Literature, History, Social Studies, Science, and Mathematics. ${ }^{49}$

Even statistics courses can incorporate LGBTQ material, thus empowering students to learn statistics effectively at the same time as exploring the nuances and complexity of LGBT issues. ${ }^{50}$ At Carnegie Mellon University, Michele DiPietro used the theme of sexual orientation to teach the

${ }^{49}$ GLSEN, "Developing LGBT-Inclusive Classroom Resources," https://www.glsen. org/sites/default/files/LGBT\%20incl\%20curr\%20guide.pdf.

${ }^{50}$ DiPietro, "Diversity Content as a Gateway to Deeper Learning: The Statistics of Sexual Orientation," Diversity and Democracy 12, no. 3 (2009). 
concepts normally covered in an introductory statistics course. For example, the question of how many people are LGBT introduced the concepts of sampling and estimating proportions. Since many LGBT people will not self-identify in surveys, the question also raised the problem of bias and how one can identify, reduce, or estimate it. Similarly, the "nature versus nurture" question introduced hypothesis testing. Data from specific studies then introduced the correct use of various tests (T-test, ANOVA, Chi-Square).

\section{Visibility of LGBTQ Faculty and Allies}

Where LGBTQ faculty or staff are visible in the campus community, they may pose as positive role models to LGBTQ students who may otherwise have never encounter other LGBTQ people who are working adults. Furthermore, their visibility may have an educative effect on the campus community in general which can help to foster a more inclusive environment and reduce instances of discrimination or prejudice that LGBTQ students may face. An example is Aisha Mughal, who was the first openly transgender lecturer at Quaid-e-Azam University in Islamabad, Pakistan. ${ }^{51}$ The report noted that her employment signaled to the university community as well as society at large that "transgender [persons], with proper education and enlightenment, can prove to be contributing citizens of society, just like any other individual."

In addition, faculty who conduct research on LGBTQ communities can increase the visibility of LGBTQ issues in the campus community. For example, at NUS, a professor in the Faculty of Law has published two monographs on the gay movements in Singapore and Myanmar. ${ }^{52}$ By launching these two books with panel discussions chaired by the faculty's Dean, it was a signal to LGBTQ students that the faculty and senior administrators may be willing to create safe spaces for them in academia.

51 "Aisha Mughal First Transgender University Lecturer of Quaid-e-Azam University Islamabad Pakistan," Mehran Post, May 20, 2017, https://www.mehranpost.pk/aishamughal-first-transgender-university-lecturer/.

${ }^{52}$ Lynette J. Chua, Mobilizing Gay Singapore: Rights and Resistance in an Authoritarian State (Singapore: National University of Singapore Press, 2014); Lynette J. Chua, The Politics of Love in Myanmar: LGBT Mobilization and Human Rights as a Way of Life (Stanford: Stanford University Press, 2019). 


\section{Research and Career Resources for LGBTQ Students}

Educators can also foster a more inclusive environment for LGBTQ students by providing resources tailored to them. For instance, in collaboration with supportive administrators and student support staff, faculty can help to compile research and guides to graduate programs that include LGBTQ studies or employers that are LGBTQ-friendly to assist LGBTQ students in identifying suitable opportunities for further studies or employment.

LGBTQ students may also need additional support in career guidance. Educators can consider organizing workshops or consultations to help students prepare for issues that may arise as they seek employment. This can include strategies on how to respond to potentially intrusive interview questions that may force them to disclose their sexual orientation or gender identity, how gender non-conforming students should present themselves in a professional but authentic way as well as how to deal with potentially discriminatory or harassing comments or questions.

In sum, it should be clarified that these strategies are not exhaustive and should be adapted as necessary to the context of one's own institution and its social environment. Furthermore, educators may need to use discretion to avoid exposing any student, staff or faculty to hostile responses outside the classroom or campus. Mutual support is particularly crucial where the institutional environment may be hostile toward gender and sexual diversity and educators should seek out other like-minded colleagues to build solidarity and share their strategies and experiences.

\section{Conclusion ANd Future Directions}

This chapter has sought to explore how educators can foster more inclusive campuses for LGBTQ students at both the institutional and individual levels. We developed a theoretical framework to characterize three types of Asian universities in terms of their institutional approaches toward LGBTQ diversity. In hostile and ambivalent universities, both students and educators face various challenges in promoting LGBTQ inclusion and we have outlined a few strategies by which educators can advocate for safer campuses for LGBTQ students.

Further research should be conducted to better inform educators on how they can best support LGBTQ students in these different contexts. 
We will briefly discuss two issues that deserve attention in future scholarship.

Many hostile institutions are in deeply conservative societies in Asia. While the conflict between LGBTQ rights and religious freedom is playing out in the courts and legislatures across the Atlantic Ocean, this issue has not yet been studied adequately in Asia. Of relevance in the context of higher education is how educators should negotiate and manage differences between students of faith and LGBTQ students in the classroom and on campus generally. This is especially important when the power dynamics between the two groups of students may be significantly skewed in Asian universities compared to European or North American universities, due to differences in both the degree of secularism and the concept of secularity itself. ${ }^{53}$ At the same time, educators cannot appear biased to avoid alienating any particular student or group of students. This raises difficult but important questions that deserve further discussion in the literature. In addition, it may be worth exploring how communities of faith can support and advocate for LGBTQ inclusion; for instance, Catholic student groups in the Philippines have publicly supported a legislation to protect LGBTQ persons from discrimination. ${ }^{54}$

Furthermore, while we have discussed strategies generally, the experiences of transgender and gender-diverse students are likely to differ significantly from lesbian, gay and bisexual (LGB) students. This is especially because their marginalized identities may be more visible than LGB students. Those who choose to transition during university may also require additional support, especially since this is often a period when they live independently from their families. The challenges that these students may face in Asian universities should be examined to better inform educators on how they can best support them during their transition.

In conclusion, while openly hostile administrators in certain universities make it difficult to promote diversity and inclusion for LGBTQ students, it is possible to strategize to encourage ambivalent instructions to become more supportive. We hope that more faculty will be able to implement

${ }^{53}$ See, for instance, Kenneth Dean and Peter van der Veer, eds., The Secular in South, East, and Southeast Asia (London: Palgrave, 2019).

${ }^{54}$ Leonel Abasola, "Catholic Student Councils Back Philippine Gay Rights Bill," UCA News, August 13, 2018, https://www.ucanews.com/news/catholic-student-councils-backphilippine-gay-rights-bill/83043. 
some of the suggested strategies within their own institutions to make them safer and more inclusive spaces for their LGBTQ students.

\section{BIBLIOGRAPHY}

"2 Students form Social Group for Sexual Minorities at Hitotsubashi Univ. After Suicide." The Mainichi, February 28, 2019. https://mainichi.jp/english/ articles/20190228/p2a/00m/0na/004000c.

Abasola, Leonel. "Catholic Student Councils Back Philippine Gay Rights Bill." UCA News, August 13, 2018. https://www.ucanews.com/news/catholicstudent-councils-back-philippine-gay-rights-bill/83043.

Bangkok Times.

Boellstorff, Tom. "Gay and Lesbi Subjectivities, National Belonging and the New Indonesia." In Women in Indonesia: Gender, Equity and Development, edited by Kathryn Robinson and Sharon Bessell, 92-99. Singapore: Institute of Southeast Asian Studies, 2002.

CEDARS-CoPE. "How Can I Contribute in Promoting a LGBT-Friendly Environment on Campus?" Accessed June 4, 2019, from https://dmp.cedars.hku. hk/watch_video.php? $=$ RAXRKW1931YW.

_. "Diversity and Social Inclusion." Accessed June 4, 2019, from https:// wp.cedars.hku.hk/web/cope/?p=849.

Chua, Lynette J. Mobilizing Gay Singapore: Rights and Resistance in an Authoritarian State. Singapore: National University of Singapore Press, 2014.

- The Politics of Love in Myanmar: LGBT Mobilization and Human Rights as A Way of Life. Stanford: Stanford University Press, 2019.

Coconuts Jakarta. "Indonesian University Refuses to Accept LGBT Students, Citing Protection of Their 'Rights'." May 3, 2017. https://coconuts.co/ jakarta/lifestyle/indonesian-university-refuses-accept-lgbt-students-citingprotection-rights/.

Dean, Kenneth, and Peter van der Veer, eds. The Secular in South, East, and Southeast Asia. London: Palgrave, 2019.

DiPietro, Michele. "Applying the Seven Learning Principles to Creating LGBTInclusive Classrooms." Diversity \& Democracy 15, no. 1 (2012).

—. "Diversity Content as a Gateway to Deeper Learning: The Statistics of Sexual Orientation." Diversity and Democracy 12, no. 3 (2009).

Equal Opportunity Unit. "Policy Statement." http://www.eounit.hku.hk/en/ about-us/policy-statement.

—. "Student Orientation Guidelines." http://www.eounit.hku.hk/en/ guidelines/student-orientation-guidelines.

_. "Online Form." http://www.eounit.hku.hk/en/complaints-enquiries/ online-form. 
—. "Procedures." http://www.eounit.hku.hk/en/complaints-enquiries/ procedures.

Fordham University. "LGBTQ Inclusive Curriculum and Classroom Climate." Accessed June 4, 2019, from https://www.fordham.edu/info/25663/ education_and_research_ethics_resources/6346/lgbtq_inclusive_curriculum_ and_classroom_climate.

GLSEN. "Developing LGBT-Inclusive Classroom Resources.” https://www. glsen.org/sites/default/files/LGBT\%20incl\%20curr\%20guide.pdf.

Head, Jonathan. "Bangkok University Transgender Students Get New Uniform Rules." BBC News, June 9, 2015. https://www.bbc.com/news/world-asia33060185.

Human Rights Watch. 'Just Let Us Be': Discrimination Against LGBT Students in the Philippines. New York: Human Rights Watch, 2017.

Leap, William, and Tom Boellstorff, eds. Speaking in Queer Tongues: Globalization and Gay Language. Champaign: University of Illinois Press, 2004.

Lee, Po-Han. "LGBT Rights Versus Asian Values: De/Re-constructing the Universality of Human Rights." The International Journal of Human Rights 20, no. 7 (2016): 978.

\section{Malaysiakini.}

Massad, Joseph A. Desiring Arabs. Chicago: University of Chicago Press, 2008. Mehran Post.

Mendos, Lucas Ramon. State-Sponsored Homophobia Report 2019. Geneva: ILGA, 2019.

National University of Singapore. "Legal Information \& Notices." http://www. nus.edu.sg//legal-information-notices\#nondiscrimination.

New Straits Times.

NUS Office of Student Affairs. "Code of Student Conduct." http://www.nus. edu.sg/osa/resources/code-of-student-conduct.

Peltzer, Karl, and Supa Pengpid. "Minority Stress Among Lesbian, Gay, Bisexual, and Transgender (LGBT) University Students in ASEAN Countries: Associations with Poor Mental Health and Addictive Behaviour." Gender and Behaviour 14, no. 3 (2016): 7806.

Quaye, Stephen J., and Shaun R. Harper, eds. Student Engagement in Higher Education: Theoretical Perspectives and Practical Approaches for Diverse Populations. New York: Routledge, 2014.

Rankin, Sue, Genevieve Weber, Warren Blumenfeld, and Somjen Frazer. 2010 State of Higher Education for Lesbian, Gay, Bisexual \& Transgender People. Charlotte: Campus Pride, 2010.

Ready4Repeal. "Who We Are." Accessed June 6, 2019, from https:// ready4repeal.com/who. 
Reid, Graeme, Kanae Doi, and Michael Bochenekh. 'A Really High Hurdle': Japan's Abusive Transgender Legal Recognition Process. New York: Human Rights Watch, 2019.

Sanger, Catherine S. "Diversity \& Inclusion in Curriculum and Classroom." Yale-NUS College Centre for Teaching \& Learning. https://teaching.yale-nus. edu.sg/wp-content/uploads/sites/25/2019/03/Diversity-and-InclusionBooklet_02.4.19-Online.pdf, 109.

Sankaranarayan, Shantha, Eknath Naik, P. S. N. Reddy, G. Gurunani, Karuna Ganesh, Kailas Gandewar, K. P. Singh, and S. H. Vermund. "Impact of School-Based HIV and AIDS Education for Adolescents in Bombay, India." Southeast Asian Journal of Tropical Medicine and Public Health 27, no. 4 (1996): 692.

Shibun, Nagayasu. "Sexual Minorities in Japan: The Myth of Tolerance." Nippon.com, October 21, 2016. https://www.nippon.com/en/currents/ $\mathrm{d} 00253 /$.

Sinacore, Ada L., Shu-chu Cha, and Jennifer Ho. "Gender Equity Education Act in Taiwan: Influences on the School Community." International Journal for Educational and Vocational Guidance 19, no. 2 (2019): 293-312.

South China Morning Post.

Taipei Times.

"Thai University Introduces Mandatory Class on Transgender Issues." TEAK Trans Empowerment, October 10, 2017. https://teak.site/thai-universityintroduces-mandatory-class-on-transgender-issues/.

The Jakarta Post.

The Republic of China (Taiwan). Gender Equity Education Act. 2004.

The Straits Times.

The Sun Daily.

Today Singapore.

"University denies trans Student's Right to Wear Female Uniform; Reflects Discrimination Faced by Thailand's LGBT Community." Prachatai, January 22, 2019. https://prachatai.com/english/node/7887.

Yeo, Rachel. "Trans* In College: A Handbook for Transgender Students in Singapore's Universities." Inter-University LGBT Network. https://interunilgbt. wixsite.com/interunilgbt/books-resources.

Zhang, Liying, Li Xiaoming, and Iqbal H. Shah. "Where Do Chinese Adolescents Obtain Knowledge of Sex? Implications for Sex Education in China." Health Education 107, no. 4 (2007): 351. 
Open Access This chapter is licensed under the terms of the Creative Commons Attribution 4.0 International License (http://creativecommons.org/licenses/ by $/ 4.0 /$ ), which permits use, sharing, adaptation, distribution and reproduction in any medium or format, as long as you give appropriate credit to the original author(s) and the source, provide a link to the Creative Commons license and indicate if changes were made.

The images or other third party material in this chapter are included in the chapter's Creative Commons license, unless indicated otherwise in a credit line to the material. If material is not included in the chapter's Creative Commons license and your intended use is not permitted by statutory regulation or exceeds the permitted use, you will need to obtain permission directly from the copyright holder.

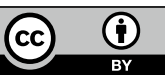




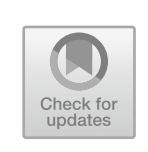

\title{
Higher Education for Women in Asia
}

\author{
Solveig Olson-Strom and Nirmala Rao
}

\section{INTRODUCTION}

The recent rapid growth in higher education around the world is undeniable. Worldwide enrolments have increased manifold in the past two or three decades, and a large part of this is due to women entering degree programs in multitudes. In terms of attendance rates, the gender gap in tertiary education has virtually disappeared in most places. In fact, women even outnumber men in higher education in many countries around the world, including developing and industrialized countries across all regions. In Asia especially, women's enrolment has accelerated in recent years as overall demand for higher education has accelerated. But do these encouraging numbers accurately reflect the bigger picture? By other measures, gender inequality in higher education remains a significant issue. Women continue to be overrepresented in certain fields and underrepresented in others (often those that are considered more prestigious or have higher earning potential). Their experiences at higher education institutions are vastly different from those of men in terms of campus climate and leadership opportunities. Employment outcomes also

S. Olson-Strom $(\bowtie) \cdot$ N. Rao

Asian University for Women, Chittagong, Bangladesh

e-mail: nirmala.rao@auw.edu.bd

(C) The Author(s) 2020

263

C. S. Sanger and N. W. Gleason (eds.),

Diversity and Inclusion in Global Higher Education, https://doi.org/10.1007/978-981-15-1628-3_10 
indicate persistent inequality. How do we interpret these seemingly contradictory developments? It is essential to understand the causes behind these trends in order to effectively tackle the ongoing challenges to gender equality in higher education.

Much of the literature surrounding gender and higher education has focused on North America (primarily the United States) and Western Europe. Yet Asia, though not homogeneous by any means, presents a starkly different context in many ways to the countries that have been at the center of the dialogue on gender equality and education. As the most populous region in the world, the higher education of women in Asia has the potential to transform the global landscape and influence the trajectory of our collective future. Though it is generally accepted that gender inequality in education hinders progress in a variety of ways, the focus tends to be on primary and secondary educational attainment. The policies targeting primary education and even secondary education for girls have been tremendously successful in Asia, with many countries achieving almost complete coverage at the primary level, and significant improvement in the rates of secondary school enrolment. Women's enrollment in secondary school has increased dramatically throughout the region, and, in many countries, the traditional gender gap in secondary school enrollment is gradually disappearing. In South Korea, Thailand, and Hong Kong, secondary-school enrollment is nearly the same for both sexes, while in the Philippines it remains slightly higher for women.

However, higher education plays a unique role in creating socially engaged, civically active, and innovative individuals. As the President of Asia Society once remarked:

Whenever there is a public discussion about education and about women in Asia, the focus is generally on the need for basic literacy: that women should be able to read, write and count. It is fundamental to their wellbeing. Studies have shown that these basic skills have been instrumental in greater economic empowerment, political participation and social engagement of women at even the lower level of societies. While the value of this basic education is undeniable and it is also badly needed, one might argue that... if women are to take more leadership roles in all sections and segments of the society, it goes without saying that women must be prepared to embrace the challenges of leadership in the 21 st century. Seen 
from this perspective, perhaps the right question is: Can we afford not to pay attention to higher education for women in Asia? ${ }^{1}$

Neoliberal arguments have emphasized the economic returns on investments in women's participation in higher education, while others stress that higher education is a human right and is essential for the creation of a moral and progressive society, as it enables an ongoing participation in a "life of the mind." The benefits at a social level are also apparent in improved productivity and greater participation in the cultural and political life of a community.

What are the unique opportunities available to women accessing higher education in Asia, the home to some of the world's biggest economies and most rapidly developing nations? What are the obstacles female students face in unlocking their own potential? How can policies, institutions, and individuals contribute toward a more equitable education system for all, regardless of gender, race, or class? In this chapter, we address these and other questions, using the Asian context as the frame for discussion. We begin by examining recent trends and ongoing challenges for women's higher education in Asia, and then focus on the role of single-sex institutions and the case of Asian University for Women. Finally, we identify opportunities for progress and offer recommendations moving forward.

\section{Trends and Challenges}

In a rapidly changing international economy, the strong commitment of developing countries to focus principally on primary education, sometimes at the cost of higher education, has been increasingly coming under scrutiny. Today's so-called global "knowledge revolution" represents a shift in international economic systems, whereby production processes are becoming increasingly technical and science-based, increasing the importance of higher education. Much of the analyses have missed many important social and economic effects of higher education that are critical to long-term economic growth and development. To the extent that the value of these benefits outweighs the costs, higher education represents a sound investment.

\footnotetext{
${ }^{1}$ Vishakha N. Desai, quoted in Asian University for Women Plan of Operation (Chittagong: AUW, 2005), 20. Accessed July 3, 2019, from http://asian-university.org/wpcontent/uploads/2018/08/AUW-Plan-of-Operations.pdf.
} 
Women today have greater access to higher education and degreegranting institutions today than at any other point in history. However, it is important to examine the reasons for this development as well as analyze the barriers that continue to keep higher education out of reach for many women. Furthermore, once women have crossed the threshold of higher education institutions, certain inequalities widen and gender norms are reinforced, even at single-sex universities. Finally, upon graduation, women are at a severe disadvantage when it comes to seeking employment. The trend of increasing privatization has the potential to address some of these issues, but only if effectively regulated.

\section{Growing Demand}

When praising the statistics showing women's increasing enrolment in higher education, many institutions and nations seem to be congratulating themselves on a job well done. While this trend is certainly to be celebrated, too rarely is the decision of women opting to pursue higher education emphasized. In this section, we address the question of why women are increasingly choosing to attend university. Gary Becker, William Hubbard, and Kevin Murphy create a model of the market for college graduates in order to analyze the costs and benefits of higher education. ${ }^{2}$ They conclude that while the benefits of attending college are no higher for women than for men, the differences in total cost can account for women overtaking men in college enrolments. Women have overall higher non-cognitive skills (such as self-motivation, self-discipline, and organization) than men, decreasing their total cost in continuing their education. Despite the fact that the authors claim to explain the global phenomenon of increased female representation in higher education, much of their evidence comes from data collected in the United States. Their evidence from other countries, when it comes to their key finding that women have higher non-cognitive abilities than men and thus a lower overall cost of entering higher education, stems from PISA test results, which do not include any South Asian countries. This kind of gap is all too common, and may lead to bias in supposedly unbiased data.

On the other hand, Mitra Shavarini approached this question by interviewing female students and faculty members in Iran about why they

\footnotetext{
${ }^{2}$ Becker, Hubbard, and Murphy, "Explaining the Worldwide Boom in Higher Education of Women," Journal of Human Capital 4, no. 3 (2010): 203-241.
} 
wanted to attend university and what they gained from it. ${ }^{3}$ She found four common themes: first, many viewed university as an escape from a controlling family environment or as a means to delay marriage. Second, students anticipated that a strong educational background could help them find a more suitable (higher class) husband. Third, women saw higher education as a means to raise their social status and sense of self-worth, and fourth, most believed a degree could offer them increased economic independence. These statements show that a shift in higher education toward increasing female enrolments is a result of women claiming agency over their education and their future. Instead of praising any particular institution or policy measure for the increase in women in higher education, it is important to recognize the women themselves who are putting in the work toward receiving their degrees. The reasons they give indicate that higher education offers them independence and a path toward success in a variety of ways. Though Becker, Hubbard, and Murphy also identified some similar factors in their description of the benefits of higher education for women, ${ }^{4}$ the idea of university as an escape from a restrictive family environment or an unwanted marriage is not addressed, potentially because of the American-centric focus of their study. In more conservative societies in Asia, this issue can be a more significant factor for women deciding whether to pursue higher education.

It is important to note here another difference from the American perspective. In Asia, education is often regarded as the primary path to economic success. ${ }^{5}$ Though there remain differences in how much families invest in sons as opposed to daughters, on all levels of the socioeconomic ladder, people are likely to see education for their children as the main way to improve their situation. This attitude is most evident in East Asia. On the other hand, in the United States, it can be argued that a focus on education is concentrated in families where the parents have strong educational backgrounds. The Coleman Report famously showed that family background is a greater determinant of educational outcomes than school

\footnotetext{
${ }^{3}$ Shavarini, "The Feminisation of Iranian Higher Education," International Review of Education 51, no. 4 (2005): 329-347.

${ }^{4}$ Becker, Hubbard, and Murphy, "Explaining the Worldwide Boom in Higher Education of Women."

${ }^{5}$ Melinda DP Bandalaria, "Open and Distance eLearning in Asia: Country Initiatives and Institutional Cooperation for the Transformation of Higher Education in the Region," Journal of Learning for Development 5, no. 2 (2018): 116-132.
} 
quality in the United States. However, later studies found that this effect is often the opposite in developing countries. ${ }^{6}$ Because families strongly prioritize education across the board in Asia, school quality can have a more significant impact than one's parents' educational attainment.

\section{Limitations to Women's Access}

A variety of barriers, from decisions on the familial level to national policies, continue to exist and reinforce one another to limit women's access to higher education. Though women's participation in higher education is increasing, a number of Asian nations have yet to fully close the gender gap. Furthermore, in many countries, the overall rates of enrolment in higher education are still so low that even if women were to attend university at the same rates as men, the vast majority of women would still be excluded. Finally, in many cases, women in higher education represent a narrow section of women in a country. Acknowledging that the progress toward gender equity in higher education favors some women and while excluding others is an important step toward creating more inclusive institutions and societies. When mentioning Asia in a United States-or Eurocentric discussion, many people point to religious and cultural conservatism as the reason for persistent gender inequalities in the region. While these are significant factors, they do not tell the whole story and often serve to reinforce false stereotypes about inherent sexism in a particular religion or culture. It is important to acknowledge how colonialism, particularly in South Asia, has shaped today's gender landscape in the region.

Women in Asia are not a homogenous group. Gender and class often interact to impede access to education. When there is a shortage of resources, women and girls often feel the negative impacts more strongly than men and boys. Many countries in Asia are lower-income, and thus offer less state support for higher education than their resource-rich counterparts. This increases the burden on families and students to pay for their education. In some countries, girls' education is seen as a less worthwhile investment than that of boys in part because they contribute more household labor from a younger age than boys. If they continue their

\footnotetext{
${ }^{6}$ Claudia Buchmann and Emily Hannum, "Education and Stratification in Developing Countries: A Review of Theories and Research," Annual Review of Sociology 27 (2001): 77-102.
} 
education, the family would not only need to spend money on school fees and related costs, but would also lose a significant source of labor. Many girls are expected to marry and focus on raising children rather than enter the workforce, so some families view their education, especially education beyond secondary school, as a sunk cost. However, this gender disparity in familial investment is much less pronounced in certain countries, particularly East Asian nations, Sri Lanka, the Philippines, and Thailand. ${ }^{7}$ Many parents see the education of their children as a path toward social mobility and have equal aspirations for their sons and daughters.

Another barrier on the familial level is an unwillingness to send girls and women far from home in order to further their education. This limitation can be found in both wealthy and poorer families, and is often caused by concerns for daughters' safety and security. If the only accessible institution of higher education is far from home, women are less likely to continue their education. Many families and communities also prefer gender-segregated education, which further limits the options female students have available to them. Moreover, women-only schools and universities often receive less funding and resources than their all-male or co-ed counterparts. This is one way in which the allocation of limited resources, the influence of traditional gender norms, and location interact to prevent women's attainment of higher education.

Women in Asia also face systemic and structural barriers to higher education. Certain national policies, even those intended to increase diversity, can end up limiting women's access. Rohini Sahni and Kalyan Shankar examine Indian policies in particular, and find that the structure of the quota system for public universities sometimes results in decreased enrolment opportunities for women. ${ }^{8}$ They also emphasize that educational development does not always amount to increased female inclusiveness, and note that within India, women's access to higher education varies widely based on location and caste. Certain regions have far more female students than others, and most women attending universities are from urban areas. Even though the overall gains in women's educational attainment since independence are encouraging, when examined more closely, it is unclear whether this growth can be sustained, mainly because of

\footnotetext{
${ }^{7}$ Swarna Jayaweera, "Gender and Access to Education in Asia," International Review of 33, no. 1 (1987): 455-466.

${ }^{8}$ Sahni and Shankar, "Girls' Higher Education in India on the Road to Inclusiveness: On Track but Heading Where?," Higher Education 63, no. 2 (2012): 237-256.
} 
these intersecting disparities. Adapting national and regional level policies to more clearly address the exclusion of certain groups of women and expanding the higher education system overall would be one move in the right direction, but would need to coincide with grassroots level reforms in order to be effective.

However, developing countries face their own barriers to reforms that might lead to greater gender equality. Buchmann and Hannum describe a few of the challenges faced by some governments in developing countries, such as a lack of resources, peripheral status in the world system, and uncertain legitimacy. ${ }^{9}$ These issues make creating and implementing policies difficult. For example, Pakistan has one of the widest gender gaps in Asia. ${ }^{10}$ The laws that are in place to empower women and shrink this gap are often ineffective because of entrenched patriarchal norms and the government's inability to enforce its laws. Many women are not even aware they have rights, yet they still find a way to pursue their education. The barriers they face come from all sectors of society and even sometimes their own families, and so it is imperative that reforms occur in all sectors as well. Government policies can be difficult to implement if the society rejects their intended purpose.

\section{Quality Concerns and Privatization}

A huge trend in higher education in Asia is increasing privatization, which in many cases also limits the educational opportunities available to women. Asia is now the largest provider of private higher education by enrolment, and is home to the largest distance learning institution in the world - the Indira Gandhi National Open University in India. Because of the increasing demand for higher education that public funds are unable to meet, the private sector has stepped in. However, private higher education in Asia has shifted toward a focus on industry and profits. Private institutions are often less concerned with facilitating diversity and inclusion than they are with recruiting students who will pay high tuition fees and gearing those students toward the corporate sector. There must be

\footnotetext{
${ }^{9}$ Buchmann and Hannum, "Education and Stratification in Developing Countries."

${ }^{10}$ Malik, Samina, and Kathy Courtney. "Higher Education and Women's Empowerment in Pakistan," Gender and Education 23, no. 1 (2011): 29-45.
} 
a balance in government policy that allows the private sector to flourish in order to meet the demand for higher education and regulates it enough to ensure certain standards of quality and equality are met. Even so, some argue that the private sector cannot meet enrolment demand as effectively as public institutions. Tilak notes that government spending is much more highly correlated with enrolment rates than private expenditure. ${ }^{11}$ When governments pull funding, the resulting gap is not always met with increases in spending by private entities. Tilak argues that investment by the state in higher education is indispensable and irreplaceable. Furthermore, the private sector's focus on certain subjects (generally engineering, information technology, and commerce) at the expense of others (often the arts, humanities, and social sciences) can limit the innovative and creative growth of a field and delay progress. Moreover, the subjects most commonly promoted by private institutions are those that women are often discouraged from pursuing, further limiting women's educational opportunities.

However, private institutions can also expand women's options by expanding the overall educational system. Certain private providers of higher education are aimed at particular minority groups or are singlesex. Leleh Jamshidi et al. argue that private entities can address "differentiated demand" - demand for a specific form or focus of higher education - more quickly than public institutions. ${ }^{12}$ Thus, increased demand for gender-segregated higher education could be met by private, singlesex institutions that allow women who may not otherwise have had any options to continue their education. But the authors also emphasize that coordination between the state and the private sector is essential for success. Private institutions are not necessarily a solution to gender disparities, but they can be a tool to advance women's educational attainment.

\section{Inequality in Experience}

Access to higher education is just one piece of the puzzle when it comes to women's overall experiences. Once they enter these institutions, whether

${ }^{11}$ Jandhyala B. G. Tilak, "Higher Education in South Asia: Crisis and Challenges," Social Scientist 43, nos. 1/2 (2015): 43-59.

${ }^{12}$ Laleh Jamshidi, Hamidreza Arasteh, Abdolrahim Naveh Ebrahim, Hassanreza Zeinabadi, and Palle Damkjer Rasmussen, "Developmental Patterns of Privatization in Higher Education: A Comparative Study," Higher Education 64, no. 6 (2012): 789-803. 
they are public, private, single-sex, or co-ed, women are faced with an entirely new set of challenges that reveal less encouraging statistics in terms of gender equality. As previously mentioned, women continue to be overrepresented in certain disciplines and underrepresented in others. Sometimes known as gender tracking, this can result from a variety of outside factors, ranging from societal constructs about which fields are seen as more "feminine" or "masculine" to outright hostility in male-dominated classrooms and labs. Meenakshi Gautum discusses this issue with a focus on India. ${ }^{13}$ She finds that fathers generally play a key role in decisions about which subject to pursue, especially in middle class and upper middle class families in urban areas. Students from lower class backgrounds were more likely to make this decision on their own, mainly because their families had little familiarity with the higher education system and which subjects might be considered more employable or prestigious. Gautum found that fathers influenced the decision-making process for both sons and daughters. However, the more prestigious subjects were generally the automatic choice for boys, while the subject choice for girls was more dependent on their perceived ability to work hard. Aside from family influence, there is often a chilly atmosphere for those women who do attempt to enter male-dominated fields in technology, engineering, and business. ${ }^{14}$ Overall, there are significant disparities across Asia and worldwide in terms of the disciplines men and women study, and this gender gap has yet to improve as much as the enrolment gap has. ${ }^{15}$

The everyday experience of attending an institution of higher education is also different for women and men. Universities, even those that are single sex, often contribute to reinforcing gender roles and norms. Certain textbooks and teaching materials erase the contributions women have made in various fields and society in general, and instructors (regardless of gender) often show bias toward male students. ${ }^{16}$ Female students are also more likely to be victims of sexual harassment and assault than

${ }^{13}$ Gautam, "Gender, Subject Choice and Higher Education in India: Exploring 'Choices' and 'Constraints' of Women Students," Contemporary Education Dialogue 12, no. 1 (2015): 31-58.

${ }^{14}$ Kristen A. Renn, "Roles of Women's Higher Education Institutions in International Contexts," Higher Education 64, no. 2 (2012): 177-191.

15 Patricia Licuanan, “The Challenge of Women's Higher Education in Asia," International Higher Education 37 (2015): 16-18.

${ }^{16}$ Malik and Courtney, "Higher Education and Women's Empowerment in Pakistan." 
their male peers. Furthermore, a lack of women in the administration and on the faculty of higher education institutions leads to a lack of institutional support, mentorship, and leadership opportunities for women. While some of these issues are mitigated at single-sex institutions, they are by no means eliminated. The education system often reinforces gender inequalities instead of diminishing or eliminating them. This issue is part of the reason gender inequality in employment outcomes persists so strongly despite the huge gains in gender parity in terms of enrolments.

\section{Inequality in Outcomes}

Female graduates face different employment opportunities than male degree holders and furthering their education can ironically even lower their chances of finding work. In some countries, such as India, women with more education are less likely to be employed than their less educated counterparts. ${ }^{17}$ Women in India who have completed higher education have a slight boost in employment rates over those with only a secondary level education, but their rates of employment are still lower than women with a primary school education or no education. This apparent paradox is the result of a variety of factors. Education offers benefits in the marriage market, and so higher levels of education might allow some women to marry into higher income families. The reinforcement of gender roles in society and the education system could be a part of why they choose not to work. Indeed, when accounting for other family income, the U-shaped effect that arises when mapping education level to labor force participation is less strong, but still present, so this explanation does not explain the entire picture. Another major reason is that there are simply no appropriate jobs for women with a moderate level of education. Women with the least education are generally participating in wage labor or working on family farms, and the expected negative correlation between these forms of labor and education level is present. However, there are simply too few salaried jobs available for the women that enter the job market with moderate to high qualifications.

Women who have completed higher education do not have the same opportunities and advantages available to them as men. In order for the development of a country to utilize the human capital of half of their

${ }^{17}$ Chatterjee, Esha, Sonalde Desai, and Reeve Vanneman, "Indian Paradox: Rising Education, Declining Women's Employment,” Demographic Research 38 (2018): 855-878. 
citizens, governments and societies must view female graduates as an irreplaceable resource. Discrimination in the job market and the workplace as well as societal expectations about what roles women should play have significant detrimental impacts on the progress of a country. When women attain degrees at similar rates to men but hold far fewer tenure track or higher level administrative positions in academia, a cycle of inequality is perpetuated. Arguably the biggest challenge with respect to higher education for women in Asia is no longer gender parity in terms of access but gender equality throughout the educational process and in the outcomes. If universities continue to mirror and propagate the gender stereotypes and biases present in society at large, there will be no progress on this front.

\section{Emergence of Single-Sex Institutions}

One distinctive feature of higher education in Asia is the rapid increase in women's only universities, especially considering their ongoing decline in the United States and many other western countries. Single-sex institutions theoretically provide solutions to many of the barriers discussed up to this point. They expand access for women whose families or circumstances would not allow them to attend a co-educational institution, and they can break down barriers to certain subject areas that are often hostile environments for women. Women's institutions often generally have an implicit or explicit focus on female empowerment, whether through a gender studies program or simply ongoing dialogue about women's issues and women's rights. They are able to provide an environment conducive to growing strong leaders, developing self-confidence and self-esteem, and preparing graduates to take on leadership roles as they enter the workforce. The results of these differences are tangible; numerous studies have shown women who attend single-sex institutions are higher achievers, and leave their mark in a wider range of fields including science, the arts, humanities, and business.

However, women's institutions also often face financial constraints as well as quality concerns. And despite being symbols of the advancement of women's status in society, they also often perpetuate traditional gender norms. ${ }^{18}$ Leadership and faculty positions at single-sex institutions are

${ }^{18}$ Renn, "Roles of Women's Higher Education Institutions in International Contexts." 
still mostly filled by men, and social stratification along the lines of race, ethnicity, and class can also be reproduced at women's universities. It is essential that these institutions prioritize inclusion and tolerance in order to fulfill the mission of women's empowerment many were founded on.

\section{Gender on the Agenda: The Case of Asian University for Women}

Against the well-rehearsed advantages of women's colleges and rooted in historic traditions for promoting empowerment and development of leadership skills among women, Asian University for Women (AUW) was established in 2008 in Chittagong, Bangladesh, with the intention to provide women drawn from diverse social, economic and language backgrounds with opportunities become critical thinkers and ethical leaders in their home communities. It was also based on the assumption that a single-sex institution, when done right, will not duplicate the assumptions and practices of the dominant culture that would exclude women from full participation in certain professions and certain aspects of societal life. Furthermore, a World Bank report that investigated barriers to women's higher education concluded that in countries like India, Pakistan, Nepal, Bangladesh, and many sub-Saharan African countries, the creation of single-sex institutions was both necessary and justified in addressing the disparity in women's higher education in these settings. The establishment of AUW was not only to provide quality education to women who might otherwise be unable to attend university due to cultural pressures, but also to provide a setting in which these young women can reflect on their individual and collective roles in their societies, and on how those roles can be recast for the benefit of all.

With more than 800 students enrolled on campus, AUW continually seeks to extend its outreach to recruit young women from the most underserved communities. AUW recruits talented and engaged students, regardless of their background or ability to pay tuition. In this way, AUW provides promising young women with the opportunities they deserve, and aims to establish a new talent pool of future leaders from all walks of life. Drawing from seventeen countries across Asia and the Middle East, AUW's recruitment efforts extend to local madrassas, hill tribes, ready-made garments factories, refugee communities, ethnic minorities in Afghanistan and Myanmar, daughters of microfinance borrowers and workers on the tea estates of Assam, Sri Lanka, and Sylhet. Systematic engagement with local schools, families, and NGOs helps AUW to 
access potential students and overcome any cultural and social barriers that young women from these underprivileged groups face.

Not all students arriving at AUW have received rigorous secondary schooling or English language training. Many have experienced poverty, displacement, and political instability and are in need of intensive remedial education. Pre-collegiate programs at AUW are founded upon the principle that circumstance is not an indicator of potential. AUW established Pathways for Promise in January 2016 as a tailored preparatory program with the ability to sufficiently equip any woman for undergraduate education. In Pathways, women who have not previously had access to high-quality English-language or mathematics training receive an additional year of pre-university preparation in advance of the oneyear Access Academy and then three-year Undergraduate Program. Access Academy is a flagship year of pre-collegiate courses at AUW with ten years' experience, focusing on English communication skills, critical thinking, problem-solving, and strategies for lifelong learning. The program is designed to help students overcome prior deficits in their educational background and prepare for success in AUW's Undergraduate Program.

In line with its mission, AUW's curriculum is interdisciplinary and cross-cultural in nature, and its faculty and staff engage students in applying theoretical knowledge to real-world problems. While its liberal learning curriculum draws in part upon a western liberal arts tradition, the curriculum is based on significant Asian content and the University's programs encourage students to apply the analytical tools they acquire to regional problems. Rather than separating education from professional training, the curriculum takes the best of the liberal arts tradition and integrates it with professional training for careers and leadership.

It was our founders' hope that a strong liberal education such as this would lay the foundation for a life of learning and thinking critically in a rapidly changing world. This is particularly important in today's knowledge-based economy, where technologies and production processes are constantly being modified and the ability for continuous learning and relearning is critical for remaining at the forefront of the business and scientific world. AUW students are high achievers and ready to take on leadership roles following the completion of their studies. Graduates are employed in a range of organizations including non-profit, research institutions, private companies, schools, non-governmental organizations, and 
government departments. Many go to graduate schools in top universities around the world and some even start their own ventures. Diversity is AUW's strength and priority, providing a varied and distinct community comprised of students, faculty and staff members from a wide range of economic, cultural, locational - rural/urban, ethnic, and religious backgrounds.

\section{Opportunities AND ReCOMMENDATIONS}

Clearly, efficient investment in women's higher education can bring huge returns, but these returns will not materialize if the gaps in women's experiences at university and outcomes post-graduation are not addressed. Graduate unemployment is sometimes used as a reason to limit public funding for higher education, but this issue is often more to do with a lack of robust quality standards rather than education not being a worthwhile investment. ${ }^{19}$ Education is unequivocally a public good and should be treated as such. The scarcity of high-level talent in developing countries coincides with a time of unprecedented demands for such capacity. Creating diverse and inclusive institutions of higher education will allow entire nations to reap the benefits of previously untapped potential, and should be a priority for all. This section will address specific reforms that can be made at the institutional, governmental, and individual levels to work toward this goal.

\section{Government Level Reforms}

As many governments of Asian countries are resource-poor, it is not feasible for them to subsidize higher education for everyone. The demand far outstrips the state's ability to supply. However, there are many steps and policies that could be taken to promote equality and inclusion. One essential point is creating policies to both support and regulate private institutions of higher education. The private sector can effectively complement public institutions in order to provide access to more students. To be sure, privatization has been accelerating in Asia regardless of government action. However, countries such as Malaysia and Indonesia have implemented policies that encourage the growth of privatization while

${ }^{19}$ Tilak, "Higher Education in South Asia." 
also ensuring certain academic standards are met. ${ }^{20}$ Quality assurance mechanisms can come in a variety of forms, and are possibly one of the most important roles a state can and should play in higher education. Again, returns on investments in higher education will not manifest if the educational institutions are lacking in quality. National-level policies can also successfully encourage diversity through affirmative action or quota systems. While these can be effective tools, they do not always have the intended effects. It is important to ensure, when formulating such policies, that they will not further disadvantage one underrepresented group in favor of another, but rather offer more opportunities to all underrepresented and vulnerable groups. Providing families, particularly those of a lower socioeconomic status, incentives to educate girls is also recommended. When costs of education are eliminated, children are much more likely to attend school, and for families who are less willing to spend money on their daughters than their sons, this kind of measure can make a huge difference in gender equity.

\section{Institutional Level Reforms}

Higher education institutions themselves have arguably the most influence over student access, experience, and outcome. Besides ensuring an academically rigorous and comprehensive curriculum, institutions should work to dismantle harmful systems of stratification that are too often reinforced within their halls. Active recruitment of female leadership and faculty members is an essential step toward creating a more equal experience for male and female students. This move will allow female students to find mentors that understand the challenges they face and can prioritize their distinctive needs. Representation is an essential aspect of fostering diversity. Cross-institutional collaboration can be an effective tool in this regard. Whether co-educational or single-sex, institutions of higher education can benefit from working together to solve system-wide problems.

In order to recruit from a broader pool of students, universities can work with each other (co-educational institutions in particular can learn from single-sex institutions) to develop concrete strategies for overcoming social and cultural barriers to women pursuing higher education. Reaching out to local organizations and secondary schools, emphasizing the

${ }^{20}$ Jamshidi et al., "Developmental Patterns of Privatization in Higher Education." 
safety and security of the campus environment, as well as the benefits of higher education to the family and community, is one method. Sending female representatives of the university to talk about their experiences can alleviate the concerns of those uncertain about attending a majority male institution. Providing scholarships aimed at recruiting female students will help overcome financial barriers for prospective students, put in place by families who are hesitant to spend money on a daughter's education. Institutions should also be wary of gender tracking, and promote women's participation in traditionally male-dominated fields. One component of this effort should be to ensure that teaching materials do not ignore the contributions made by women in their fields. The "hard sciences" cannot isolate themselves from social issues. All students, male and female, should be aware of the pervasiveness of gender discrimination and the all too common erasure of women's achievements. Encouraging faculty members to address these topics in their courses, whether in the humanities or the sciences, will go far in making female students feel heard and supported. Campus climate is another key factor of women's experiences in higher education. Strong policies and procedures for handling cases of sexual harassment and assault, open dialogue promoting women's empowerment and rights, and having various support systems and resources in place can enable women to thrive in a university setting. Comprehensive mental health support is a vital aspect of success in university, and robust processes for addressing student complaints are essential in building trust and community. Ensuring women have opportunities to develop their leadership skills is also vital. In co-ed institutions, leadership positions are overwhelmingly more male than the makeup of the student body. This issue goes hand in hand with ensuring female students have female mentors and leaders in the university administration that can guide them toward leadership opportunities. This helps them to build connections and skills that will improve their employment outcomes and allow them to use their education to help themselves, their families, and their communities.

Furthermore, diversity and access should be explicitly prioritized by everyone from student leaders to the administration. It needs to be clear that diversity and inclusion are core values of the institution and not simply a matter of numbers or quotas. Institutional leadership must vocally 
denounce intolerance and discrimination in all forms. Implementing trainings for faculty and staff focused on creating a university-wide community that prioritizes breaking down patriarchal norms and other harmful societal structures is another way to create an inclusive space. These trainings should help faculty and staff become more aware of classroom dynamics that allow male students to dominate as well as other challenges female students face so that they can more effectively support them. These changes cannot be put in place overnight, but if the leaders of a university prioritize female students and listen to their needs and concerns, they have already taken a significant step toward creating a more equal system of higher education and unlocking the potential of their female students.

\section{CONCLUSION}

Some have already dubbed the twenty-first century the Asian Century. However, this emerging region needs a generation of new innovators in order to truly address its long-standing social, political, and economic issues. Every member of society has a part to play in promoting progress and development through eliminating gender disparities. While it is important to recognize the interrelatedness of the challenges facing women's higher education in Asia, by the same token, widespread change can be achieved through relatively small shifts at the grassroots level. Everywhere in Asia there are examples of great tides of change. New roles are being demanded of countries, communities, and citizens. Women in Asia have been prominent at the highest levels - India, Pakistan, Bangladesh, Sri Lanka, Indonesia, Philippines, and now Myanmar all have had women as heads of state or government. Today, Asian women from all walks of life are gaining opportunities to succeed in these societies and to capture their rightful places as leaders, experts, and visionaries who can realize their full potential. Having been historically excluded from academia, women in Asia are claiming their space in higher education. They represent the future of development and innovation in the region. 


\section{BIBLIOGRAPHY}

Asian University for Women. Asian University for Women Plan of Operation. Chittagong: AUW, 2005. Accessed July 3, 2019, from http://asian-university. org/wp-content/uploads/2018/08/AUW-Plan-of-Operations.pdf.

Bandalaria, Melinda DP. "Open and Distance eLearning in Asia: Country Initiatives and Institutional Cooperation for the Transformation of Higher Education in the Region." Journal of Learning for Development 5, no. 2 (2018): 116-132.

Becker, Gary S., William H. J. Hubbard, and Kevin M. Murphy. "Explaining the Worldwide Boom in Higher Education of Women." Journal of Human Capital 4, no. 3 (2010): 203-241.

Buchmann, Claudia, and Emily Hannum. "Education and Stratification in Developing Countries: A Review of Theories and Research." Annual Review of Sociology 27 (2001): 77-102.

Chatterjee, Esha, Sonalde Desai, and Reeve Vanneman. "Indian Paradox: Rising Education, Declining Women's Employment.” Demographic Research 38 (2018): 855-878.

Gautam, Meenakshi. "Gender, Subject Choice and Higher Education in India: Exploring 'Choices' and 'Constraints' of Women Students." Contemporary Education Dialogue 12, no. 1 (2015): 31-58.

Jamshidi, Laleh, Hamidreza Arasteh, Abdolrahim Naveh Ebrahim, Hassanreza Zeinabadi, and Palle Damkjær Rasmussen. "Developmental Patterns of Privatization in Higher Education: A Comparative Study." Higher Education 64, no. 6 (2012): 789-803.

Jayaweera, Swarna. "Gender and Access to Education in Asia." International Review of Education 33, no. 1 (1987): 455-466.

Licuanan, Patricia. "The Challenge of Women's Higher Education in Asia." International Higher Education 37 (2015): 16-18.

Malik, Samina, and Kathy Courtney. "Higher Education and Women's Empowerment in Pakistan." Gender and Education 23, no. l (2011): 29-45.

Renn, Kristen A. "Roles of Women's Higher Education Institutions in International Contexts." Higher Education 64, no. 2 (2012): 177-191.

Sahni, Rohini, and V. Kalyan Shankar. "Girls' Higher Education in India on the Road to Inclusiveness: On Track but Heading Where?" Higher Education 63, no. 2 (2012): 237-256.

Shavarini, Mitra K. "The Feminisation of Iranian Higher Education." International Review of Education 51, no. 4 (2005): 329-347.

Tilak, Jandhyala B. G. "Higher Education in South Asia: Crisis and Challenges." Social Scientist 43, nos. 1/2 (2015): 43-59. 
Open Access This chapter is licensed under the terms of the Creative Commons Attribution 4.0 International License (http://creativecommons.org/licenses/ by $/ 4.0 /$ ), which permits use, sharing, adaptation, distribution and reproduction in any medium or format, as long as you give appropriate credit to the original author(s) and the source, provide a link to the Creative Commons license and indicate if changes were made.

The images or other third party material in this chapter are included in the chapter's Creative Commons license, unless indicated otherwise in a credit line to the material. If material is not included in the chapter's Creative Commons license and your intended use is not permitted by statutory regulation or exceeds the permitted use, you will need to obtain permission directly from the copyright holder.

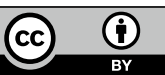


Leadership for Inclusion 


\title{
Conclusion: Strategic Leadership for Diversity and Inclusion in Higher Education
}

\author{
Nancy W. Gleason
}

\section{INTRODUCTION}

The interconnectedness of globalization, a growing middle class, and the expanding number of institutes of higher education is changing the diversity of higher education classrooms across Asia. Youth mobility is increasing along with the approaches to educational access across socioeconomic groups throughout the region. ${ }^{1}$ This increase in diversity of all kinds is excellent for teaching and learning. We know that diverse working groups are more productive, creative, and innovative. ${ }^{2}$ We know that

${ }^{1}$ Yang Peidong and Cheng Yi'en, "Educational Mobility and Transnationalization," in Higher Education in the Era of the Forth Industrial Revolution, edited by Nancy W. Gleason (Singapore: Palgrave, 2018), 39-63.

${ }^{2}$ Cedric Herring, "Does Diversity Pay?: Race, Gender, and the Business Case for Diversity," American Sociological Review 74, no. 2 (2009): 208-224.

N. W. Gleason $(\varangle)$

New York University Abu Dhabi, Abu Dhabi, United Arab Emirates

e-mail: NancyGleason@nyu.edu

(C) The Author(s) 2020

C. S. Sanger and N. W. Gleason (eds.),

Diversity and Inclusion in Global Higher Education, https://doi.org/10.1007/978-981-15-1628-3_11 
ideas generated by diverse groups are of higher quality ${ }^{3}$ and that the quality of critical analysis and decision-making is higher in groups exposed to "minority" viewpoints. 4

Higher education institutions need to shift to make room for more ideas and more types of people in the classroom in order to remain relevant and impactful. This requires that higher education change physical, curricular, and pedagogical approaches and allow for strategic leadership around diversity and inclusion. The goal is explicitly to harness diversity and inclusion efforts in order to deliver the competencies for lifelong learning and critical thinking. The exclusive transfer of content knowledge is no longer a sufficient form of higher education. Asking the learner to remember and understand the subject material is not enough; it is only the beginning. The challenge is that change in higher education is rare, slow, and costly. Strategic academic leadership is essential to the change process.

If institutions of higher education do not more thoughtfully integrate the diversity of ideas and learners entering their classrooms, then those institutions risk no longer properly preparing their graduates for success in a globally interconnected world. The workplace involves multimedia tools to engage with materials; the workplace demands creative and innovative problem solving; and the workplace requires cognitive adaptation to new projects and problems. To give these competencies to undergraduate students in Asia, we need to go beyond tests, we need to go beyond disciplinary courses, and we need to engage the students' prior knowledge in new ways. Much has been written on this already. Robert Aoun in Robot Proof explains that a good liberal education will develop numeracy, entrepreneurialism, and creativity in its graduates if they are to be properly prepared for the future of work. ${ }^{5}$ In Higher Education in the Era of the Fourth Industrial Revolution, I detail the ways in which automation

${ }^{3}$ Jack M. McLeod, Katie Daily, Zhongshi Guo, William P. Eveland, Jan Bayer, Seungchan Yang, and Hsu Wang, "Community Integration, Local Media Use, and Democratic Processes," Communication Research 23, no. 2 (1996): 179-209.

4 “Anthony L. Antonio, Mitchell J. Chang, Kenji Hakuta, David A. Kenny, Shana Levin, and Jeffery F. Milem, "Effects of Racial Diversity on Complex Thinking in College Students," Psychological Science 15, no. 8 (2004): 507-510.

${ }^{5}$ Aoun, Robot Proof (Cambridge: MIT Press, 2017). 
changes what students need to know, particularly within the South East Asian context. ${ }^{6}$

Traditional liberal arts education is being practiced in many parts of Asia with more frequency in the twenty-first century. An emphasis on critical thinking and problem-solving drives the curriculum in these settings and habits of mind that integrate mathematics with philosophy and the social and physical sciences are pursued by all students. This academic curriculum is typically buttressed with deliberate experiential learning and takes place within a residential setting. Graduates of these programs are distinct from those with technical or professional degrees. Majors can include history, anthropology, or creative writing for example. For the purposes of this chapter, this type of education is referred to as liberal international education because parts of the liberal arts approach are being adopted, with a few examples of it being practiced in full deliberate fashion, such as Yale-NUS College in Singapore or NYU Abu Dhabi in the United Arab Emirates.

As noted elsewhere in this edited volume, in Asia, learners' diversity extends well beyond nationality, religious affiliation, and ethnicity. As such, inclusive pedagogy in Asian liberal international higher education campuses takes on many different dimensions. There is diversity across physical, psychological and cogitative traits; diverse socio-economic backgrounds, diverse value systems, traditions and emerging identities, and diverse expectations around grading and assessment. The learners and the instructors come from different educational backgrounds-IB, A-Levels, PSLE, UK-System, Australian systems, home school, private school, public school, first-generation, polytechnics/Community Colleges, etc. In global universities with diverse student bodies, many students are studying in a language for the first time. Many of the students enrolled in these institutions are polylingual multimodal learners who acquire and share ideas differently from each other.

In hybrid universities, the international composition of the faculty also magnifies the importance of being thoughtful about diversity and inclusion in the curriculum and classroom. A large proportion of faculty in international education in Asia are not from the countries where they are working. Faculty may have very different ethnic and linguistic traits from their students. With different cultural backgrounds comes very different

\footnotetext{
${ }^{6}$ Nancy W. Gleason, ed., Higher Education in the Era of the Fourth Industrial Revolution (Singapore: Palgrave, 2018).
} 
attitudes and approaches to authority in the classroom, appropriate communication styles, and faculty responsibility for student mental health. For all these elements of diversity, there are corresponding policies and pedagogies of inclusion emerging as best practice in the Asian context. This curated volume, for the first time, sheds light on the unique circumstances and best practices of diversity and inclusion in the Asian liberal arts context.

Whether the goal is to launch a new diversity and inclusion effort or improve existing programs, how institutions of higher learning respond is context-specific because the meaning of diversity is different across cultural, political, regulatory, and socio-economic contexts. To date, much of what is written on diversity and inclusion in the higher education classroom pertains to the North American context in particular. While there is value in the research being done in North America, the application of this research to the variety of regulatory, political, and cultural contexts that exist from Japan to Indonesia, is challenging. Institutes of higher learning in Asia benefit from a distinctive dialogue within the literature about how best to address the growing diversity of learners and their specific needs. Theories of change can guide analysis and strategy development for modifications in higher education when appropriately applied to a specific organizational context. ${ }^{7}$

This chapter addresses how higher education leadership may apply theories of intentionally created changes to enact improvements around diversity and inclusion within the higher education context across Asia. The intention is to identify tangible and actionable steps that can be pursued by those with a mandate for strategic leadership to improve access to impactful learning for a diverse set of students, being taught to be a diverse set of classroom instructors. This analysis will apply theories of strategic change leadership to the specific challenges of integrating diversity and inclusion, by analyzing five possible action items and how to go about integrating them into higher education institutions.

${ }^{7}$ Adrianne Kezar, How Colleges Change: Understanding, Leading, and Enacting Change (New York: Routledge, 2014), 23. 


\section{Changing Landscape of Higher Education Across AsIa}

The massification of higher education in Asia is well documented. ${ }^{8}$ This is contributing to the growing diversity of the student body in higher education institutions across Eastern and Southern Asia. The increasing attention on diversity and inclusion is due in part to the fact that more students are attending tertiary education than ever before.

Table 11.1 details the significant increases in enrolments as a percentage of total population for several countries in Asia. South Korea maintains the highest enrolment rates, hovering around $100 \%$ for the past three decades, but Singapore also maintains a very high percentage of enrolments of tertiary-age youth with $86 \%$ of the population enrolling. China has seen the most significant growth with a $50 \%$ increase in enrolments from 1970 to 2017. Since the year 2000 India has increased enrolments from 9.552 to $28.54 \%$ (2017); Indonesia has increased from 14.88 to $36.77 \%$; Malaysia has increased from 25.63 to $44.17 \%$ enrolment; Thailand has increased from 34.7 to $49.287 \%$, and Vietnam has increased from 9.4 to $28.26 \%$ in enrolments for tertiary education. These percentage increases represent millions of new students enrolling in universities across Asia and the globe. Many of them are first-generation students, meaning their parents did not attend a formal tertiary institution. They bring fresh ideas, new understandings of success, and they are almost all technology natives. These shifts alone make the need to adapt our higher education system to be more inclusive of different ways of thinking and different ways of learning an imperative.

The Asian educational context is distinct, and the growing international liberal arts education is a relatively new aspect of this ecosystem.

${ }^{8}$ Alfred M. Wu and John N. Hawkins, Massification of Higher Education in Asia (New York: Springer, 2018); Mok Ka-ho and Jin Jiang, "Massification of Higher Education and Challenges for Graduate Employment and Social Mobility: East Asian Experiences and Sociological Reflections," International Journal of Educational Development 63 (2018): 44-51; Andreas Schleicher, "China Opens a New University Every Week," March 16, 2016, https://www.bbc.com/news/business-35776555; Joshua Mok Ka-ho, "Massive Expansion of Universities in Asia Raises Tough Questions on Social Mobility," March 8, 2016, http://theconversation.com/massive-expansion-of-universities-in-asia-raises-toughquestions-on-social-mobility-54680; UNESCO, Higher Education in Asia: Expanding Out, Expanding Up (Montreal: UNESCO, 2014), http://uis.unesco.org/sites/default/ files/documents/higher-education-in-asia-expanding-out-expanding-up-2014-en.pdf. 
Table 11.1 Tertiary enrolment statistics in selected Asian countries

\begin{tabular}{|c|c|c|c|c|c|c|}
\hline & \multicolumn{6}{|l|}{ Enrolment in \% } \\
\hline & 1970 & 1980 & 1990 & 2000 & 2010 & $2010 s$ \\
\hline World & 10.06 & 12.389 & 13.64 & 19.04 & 29.42 & 37.88 (2017) \\
\hline Population $^{\mathrm{a}}$ & 3684 & 4434 & 5281 & 6115 & 6923 & 7511 \\
\hline China & 0.13 & 1.14 & 3.01 & 7.62 & 24.05 & $51.01(2017)$ \\
\hline Population & 818 & 981 & 1051 & 1263 & 1338 & 1386 \\
\hline India & $4.95(1971)$ & 5.00 & 5.96 & 9.55 & 17.92 & $27.54(2017)$ \\
\hline Population & 555 & 698 & 873 & 1057 & 1234 & 1339 \\
\hline Indonesia & 2.85 & 3.35 & 8.38 & 14.88 & 23.04 & 36.28 (2017) \\
\hline Population & 114.79 & 147.4 & 181.4 & 211.5 & 241.8 & 264.6 \\
\hline Malaysia & N.A. & 3.991 & 7.18 & 25.63 & 37.32 & $44.12(2016)$ \\
\hline Population & 10.8 & 13.8 & 18.0 & 23.2 & 28.2 & 30.7 \\
\hline South Korea & $6.79(1971)$ & 12.44 & 36.51 & 76.68 & 102.76 & $93.78(2016)$ \\
\hline Population & 32.2 & 38.1 & 42.8 & 47.0 & 49.5 & 51.2 \\
\hline Thailand & $2.861(1971)$ & 10.369 & 15.865 & 34.787 & 50.365 & $49.29(2016)$ \\
\hline Population & 36.9 & 47.4 & 56.5 & 62.9 & 67.2 & 68.9 \\
\hline Vietnam & N.A. & 2.43 & 2.76 & 9.41 & 22.66 & $28.26(2016)$ \\
\hline Population & 43.4 & 54.3 & 67.99 & 79.9 & 89.97 & 93.6 \\
\hline \multicolumn{7}{|c|}{ Absolute Numbers } \\
\hline Singapore & $\begin{array}{l}7061 \\
6.842 \%\end{array}$ & 8634 & 22,005 & 36,121 & 55,295 & $\begin{array}{l}68,181(2017) \\
83.941 \% \\
(2016)\end{array}$ \\
\hline Population & 2.07 & 2.41 & 3.05 & 4.03 & 5.08 & 5.61 \\
\hline
\end{tabular}

UNESCO Institute for Statistics, cited in "School Enrolment, tertiary (\% gross)," World Bank, https://data.worldbank.org/indicator/se.ter.enrr; "Enrolment rate," OECD, https://data.oecd.org/ eduatt/enrolment-rate.htm; Ministry of Education Singapore, Education Statistics Digest 2018 (Singapore: Ministry of Education Singapore, 2018), https://www.moe.gov.sg/docs/default-source/ document/publications/education-statistics-digest/esd_2018.pdf

${ }^{a}$ Numbers displayed are in millions. Population for 2010 s is tagged to the latest year for tertiary enrolment

The liberal arts has expanded in Asia with a new wave of hybrid campuses and through innovations to existing programs. ${ }^{9}$ Where existing institutions have adapted, they have done so by are adding humanities to their STEM programs, and interdisciplinary approaches to the professional degrees. Cross-border collaboration between universities is increasingly common in higher education. Globalization has led to new changes

${ }^{9}$ Pericles Lewis, "Globalizing the Liberal Arts: Twenty-First Century Education," in Higher Education in the Era of the Fourth Industrial Revolution, 15-38. 
in internationalization of higher education in Asia. ${ }^{10}$ While many global hierarchies of knowledge, prestige, and reputation persist, students are still identifying ways to navigate in a trans-nationalized higher education landscape. ${ }^{11}$ This means the student body and the faculty members are more diverse themselves. For example, at Yale-NUS College in Singapore, where each cohort has just 250 students, the four-year institution has representation from over 60 countries. There is diversity in the curriculum as well. At NYU Abu Dhabi in the United Arab Emirates, the common core courses ask student broad questions that foster interdisciplinary understandings of critical issues such as climate change, peace, and global health.

\section{Strategic LeAdership FOR DIVERSITy AND INCLUSION}

In order to properly adapt higher education institutions to the new demands of more inclusive pedagogy, curriculum, and residential life, we need strategic academic leadership. Adrianna Kezar has developed a sixpart schematic for addressing theories of change which includes: Scientific management, evolutionary, social cognition, cultural, political, and institutional change. ${ }^{12}$ Which model of change best fits your context depends on the timeframe for change, and why the change is occurring among other things. Kezar provides a full schematic for the characteristics of these six approaches to change, as well as tactics, criticisms, and benefits for the various approaches. There are nine identified characteristics of the six schools that Kezar walks through.

Change in higher education is difficult. Strategic leadership within a higher education context, requires a given individual or committee to consider what mandate exists to support diversity and inclusion differently than has been done before within the institution. Much of the work already being done on campuses emanates from the student affairs or residential life offices of a given institution. These branches often provide awareness workshops and run cultural centers of various forms. Engaging with the efforts already underway can be a good place to start. But

\footnotetext{
${ }^{10}$ Futao Huang, "Internationalization of Higher Education in the Era of Globalization: What Have Been Its Implications in China and Japan?," Higher Education Management and Policy 19, no. 1 (2007): 47-61.

${ }^{11}$ Yang and Cheng, "Educational Mobility and Transnationalization."

${ }^{12}$ Kezar, How Colleges Change, 24-25.
} 
which school of change and which tactics are deployed depends on the decision-making context of the given institution. In addition, strategic leadership in this context requires key relationships to be leveraged where there is agency to do so. Does a given committee or individual have the agency for providing incentives and rewards for curricular change, physical space change, and pedagogical innovations? These are the questions to ask when addressing which process of change best suits the diversity and inclusion goals being developed and what actions are to be deployed. Practitioners can rely on multiple theories of change and corresponding tactics. In the next section action items that can integrate these change tactics are shared.

\section{Action Items to Adapt Your Institution FOR DIVERSITY AND INCLUSION AND THE APPLICATION of Change Tactics}

Applying the strategic change model that best fits the distinctive institutional context of a given university is the first step. Once this is done there are several different areas for change highlighted here that can be action items to work toward. There should be a diversity plan and mandate from somewhere within the institutions-often this comes from the student body more than the leadership - to drive change. Asking what the distinctive areas of concern within the institution are ${ }^{13}$ and how will addressing them improve learning is helpful. Below is a collection of some of the areas that can be engaged for strategic academic development of diversity and inclusion in higher education institutions across Asia.

\section{Physical Spaces}

Where there is a means and inclination to do so, a mandate to address learning spaces for diversity and inclusion is ideal. As there are hundreds of new universities being built across Asia at the moment, ${ }^{14}$ there is a

${ }^{13}$ Alice M. Cruz, "Intentional Integration of Diversity Ideals in Academic Libraries: A Literature Review," The Journal of Academic Librarianship 45, no. 3 (2019): 220.

${ }^{14}$ Schleicher, "China Opens a New University Every Week"; Mok, "Massive Expansion of Universities in Asia Raises Tough Questions on Social Mobility"; UNESCO, Higher Education in Asia. 
unique opportunity to take advantage of this boom for diversity and inclusion. Whereas in the west higher education is not expanding, across Asia, the hundreds of new buildings and campuses popping up can be purposebuilt for inclusion and impactful learning.

There are many ways to develop inclusive buildings that acknowledge and integrate diversity. The most apparent is to design builds that are accessible to all types of students and their abilities. The buildings should be accessible to the sight-impaired, the hearing impaired, and for those with non-chronic and chronic conditions. They should also include furniture and artwork that is representative of the regional context but also inclusive. This proximity between students and administrators lends itself to an inclusive community environment.

To give student voice to the design and function of the buildings, leaders can allow students to choose the artifacts that decorate the walls. And the design of administrative and student affairs office can be integrated to incorporate the students more literally into the decision-making structures of the institution. In addition, flexible classrooms with movable furniture and tables allow each instructor to devise a learning context that is appropriate to their classroom context. This enables what has traditionally been fixed roles between the instructor and the students to shift, allowing student-to-student learning that is invaluable for sharing a diverse set of perspectives on a given topic.

Which change process and tactics one can apply through strategic leadership for physical spaces depends on your context and timeframe. If the campus is in the design-phase, then there is endless possibility for inclusivity. If you are adapting an existing building or area of the campus, then the tactics will be different. The Evolutionary Method and the Scientific Method apply best to infrastructure given the permanence of building. The difference is in time frame. The evolutionary method is "rational, linear, and purposeful," and occurs because leaders and the internal environment demand it. ${ }^{15}$ The Evolutionary Method of change occurs because of an external environmental issue. ${ }^{16}$ The timeframe is different, slower. The process of change for the Evolutionary Method involves adaption

\footnotetext{
${ }^{15}$ Kezar, How Colleges Change, 24.

${ }^{16}$ Kezar, How Colleges Change, 24.
} 
and is "slow; gradual; [and] un-intentional." 17 The adaption of an existing campus to diversity and inclusion needs may follow this change process. Combining the Evolutionary Method with the Political Method of change tactics can also be useful with physical plant adaptions that are costly. As noted above, the Political Method involves creating coalitions and identifying allies and fostering a collective vision of change. This can address the un-intentional aspects of the evolutionary method that could produce suboptimal results for infrastructure.

\section{Chief Diversity Officers}

The role of Chief Diversity Officer is a relatively new role in higher education leadership, but some schools in Asia are hiring in this area. In nearly all universities this role faces issues of autonomy, but nonetheless, there is important work that can be done to enhance learning and equity on a given campus. A tangible change that can be pursued for an institution is to hire a new strategic change leader in the area of diversity and inclusion. In the United States, the National Association of Diversity Officers in Higher Education developed a Chief Diversity Officer Standards of Practice; this can be useful as a starting ground for universities attempting to craft job descriptions and keep performance indicators for a new role within their institution. ${ }^{18}$ As Yvette M. Alex-Assensoh noted in June 2018 , it is important to level-set expectations, and to be realistic about how much one person can do across a campus on such a broad issue. ${ }^{19}$ Collaboration across units and empowerment in the role are key. With this in mind, it is important that Chief Diversity Officers have regular access to senior leadership across the curriculum and residential life. ${ }^{20}$

The strategic leadership needed to create a Chief Diversity Officer role is one aspect of change that needs to be addressed. A key question to ask

${ }^{17}$ Kezar, How Colleges Change, 24.

${ }^{18}$ National Association of Diversity Officers in Higher Education put out the NADOHE CDO Standards of Practice, creating standards of practice of UBCDOs.

${ }^{19}$ Alex-Assensoh, "Hiring a Diversity Officer Is Only the First Step. Here Are the Next 7," Chronicle of Higher Education, June 5, 2018, https://www.chronicle.com/article/ Hiring-a-Diversity-Officer-Is/243591.

${ }^{20}$ Alex-Assensoh, "Hiring a Diversity Officer Is Only the First Step. Here Are the Next 7." 
is, what are the issues a person in this role could address for the institution and how would it enhance student learning relative to other initiatives and programs? The change approaches most relevant to a change of this nature are the Scientific Method of change and the Political Method of change. This is due in part because of the anticipated outcomes of the change. For the Scientific Method, the outcomes are new structures and organizational principles. ${ }^{21}$ For the Political Method, the outcome is a new organizational ideology. In this case, it would be freshly embracing a fresh or new commitment to diversity and inclusion. As noted above, there are differing tactics to enable this change. Whether you are developing coalitions to support the creation of the role or creating the infrastructure to make it possible (this may be building a new office space or unity house of some sort for example) this is a tangible outcome for those seeking to enhance the visibility and availability of diversity and inclusion efforts on a given campus.

\section{Changing Role of Curriculum Committees and Teaching and Learning Committees}

When properly empowered to do so, curriculum committees play an important role within higher education institutions. Typically, versions of this body are mandated to address academic programming within an institution. This includes reviewing course proposals, approving or rejecting program changes and the addition or deletion of programs. Such committees also develop policies that relate to teaching and learning assessment and effectivness. Ideally, committee members have mastery of curriculum procedures and evidence-based best practice training in course design or subject matter.

Strategic leadership on a curriculum committee can be extremely impactful in integrating diversity and inclusion of the teaching and learning in a given institution. At the micro level, course reviews can look to sample reading lists for diversity of authors, regions, and views. They can look to assessment assignments in a course proposal to ensure that there is a variety of ways in which a given student can demonstrate their understanding of the material. At the macro level, curriculum committees can review programs from top to bottom. Does a given program have

${ }^{21}$ Kezar, How Colleges Change, 24. 
a diverse set of faculty teaching into it? Does that program have broad regional representation in its courses where that is disciplinarily relevant. Does that program complement the diversity of programs already on offer or is one area being over emphasized relative to a marginalized population? These are the sorts of issues a curriculum committee leader can take up when given the mandate to do so.

Teaching and Learning committees can address issues such as gender bias in student course evaluations and their questions; grading, assessment, and feedback norms; syllabus template policies; and peer observation practices that might emphasize inclusivity in the classroom. They can also weave criteria related to inclusive teaching into teaching recognition awards, tenure and promotion criteria, and bonus structures. Finally, such committees can work closely with academic technology units to explore new software purchases that impact the entire campus. For example, playing a role in the learning management system to ensure that it is user friendly for less digitally literature students, or if such skills are needed, ensuring that the university supplies student support for becoming comfortable with the new software. Or ensure there are funds available to buy ability enabling software for those with visual or learning impairments.

Working from the perspective that change in this area comes from a committee chair, the strategic academic leadership needed is distinctive to a given personality but also the change context. Change can come about through the Social Cognition Method for this purpose. Here the change occurs because of the cognitive dissonance and the appropriateness of the changes being proposed. The needs to facilitate the change through learning and altering the complex paradigm or lens that colleagues on the committee are applying to diversity and inclusion. The change is individual in focus and involves a new frame of mind. ${ }^{22}$ The benefit of this approach is that it emphasizes the individual's beliefs as barriers that can be addressed by helping them adapt to the change. ${ }^{23}$

The Evolutionary method of change can also be effectively applied to this action area for diversity and inclusion. Here the change outcome is to develop new structures and processes. Although the timeframe is gradual and nonlinear, most of the work done by academic committees is slow. A combination of the Evolutionary Method with the Social Cognition

\footnotetext{
${ }^{22}$ Kezar, How Colleges Change, 29.

${ }^{23}$ Kezar, How Colleges Change, 24.
} 
method deployed in a higher education setting would be ideal for using committee work to integrate new structures and policies for diversity and inclusion. For example, developing a check list for necessary characteristics of a syllabus, and developing workshops for faculty to learn how best to design courses for inclusion.

Where the culture is much more hierarchical, this process would run even more smoothly. Implementation would then be the challenge. As noted by Lucy LePeau, "the leaders set the tone for making commitments to diversity, but the actual implementation came from the participants across campus; people already committed to diversity goals enacted the plans." 24 Committee leadership needs to follow-up on the implementation of the policies to ensure the vision and implementation align. This involves reaching out to IT departments to ensure the necessary tracking and electronic implementation is done. This also involves reaching out to Human Resources to address tenure and promotion or bonus structures. This involves reaching out the faculty themselves, multiple times a year, on these issues. Here the tactic of developing new policies through committees should be coordinated with academic development units as well. The next section addresses strategic academic leadership for diversity and inclusion in academic development units.

\section{Academic Support Units-Libraries, Writings Centres, and Centers for Teaching and Learning}

In universities around the world there is a coming together of libraries, writing centers, and teaching and learning centers. The roles within a given higher education context vary, but regardless of specific context, together these three units support learning and teaching outside of the classroom that is essential to an impactful learning experience. How we research and understand information literacy is a key teaching point for librarians. How we communicate ideas and develop critical thinking skills, while also addressing language barriers, is a key function of writing centers. And how we deliver peer tutoring support, learning accommodations, graduate student teaching training, and faculty development are all key roles of centers for teaching and learning. Together these three

${ }^{24}$ LePeau, "A Grounded Theory of Academic Affairs and Student Affairs Partnerships for Diversity and Inclusion Aims," The Review of Higher Education 39, no. 1 (2015): 110. 
units impact each student on campus. Strategic leadership for diversity and inclusion can be effectively guided through these units to buttress classroom curriculum and experiential learning.

Alice Cruz has provided a detailed review of the ways in which libraries embed diversity through staffing, culture, collections, services, and programming. ${ }^{25}$ When addressing the diversity of collections, the library staff can work with faculty and students to not only ensure that the collection includes a variety of voices and perspective, but also that the collection has sources in a many different forms to allow for physical and learning differences that benefit from oral histories, videos, and other multimedia sources. ${ }^{26}$ Programming that aligns with international curriculum and coordinates with the values of various student groups and local issues can be very powerful when done well. Where the legal and regulatory environment permits, there is a leadership opportunity for libraries in creating a display and programming space for discussion with and about underrepresented communities on campus. Librarians can be the strategic leadership needed, or they can work across the academic support units to share diverse viewpoints inside and outside the classroom as a piece of a larger effort.

Centers for teaching and learning play a key role in the development of academics on campus, working with them on course design, pedagogy, and grading and assessment.

The International Journal for Academic Development publishes a rich collection of papers that detail the ways in which academic developers are change agents within their higher education context. These centers can also ensure that they themselves are inviting a broad spectrum of practitioners for their events and programming. The resources and workshops they provide faculty members and instructors can speak directly to diversity and inclusion in the classroom. Indeed, other chapters in this edited volume speak to such tactics directly.

\section{Being Accountable}

It is important to develop objective measures of performance and success for diversity and inclusion in order to hold the institution to account

\footnotetext{
${ }^{25}$ Cruz, "Intentional Integration of Diversity Ideals in Academi Libraries."

${ }^{26}$ Cruz, "Intentional Integration of Diversity Ideals in Academic Libraries," 223.
} 
for the vision and programs they have put in place. ${ }^{27}$ It is one thing to determine the best way to pursue strategic change, it is another to determine how you will measure the efforts and their results. Strategic academic leadership requires the articulation of what success for inclusion and underrepresented groups on campus would look like in a given context. Additionally, leadership needs to build in accountability mechanisms. Measuring success can be challenging because the changes may not all be tangible. In some contexts, efforts will be around improved tolerance for difference. In others, it is about acceptance of difference. And in some, it is about full integration and community learning around diversity and inclusion. Legal and regulatory laws may not allow explicit acknowledgment of some groups, but the university policies and practices implemented can still benefit everyone's learning regardless of difference.

It can be challenging to measure the success of initiatives aimed at improving inclusive curriculum, pedagogy, and residential life practices. Patton et al. have document the resistance to change by leadership in the United States over the 60 years $^{28}$ and much of what they describe can be applied to experiences in Asia as well. Unfortunately, they find, that in the United States, "the number and focus of articles that analyze specific initiatives is lacking at best." ${ }^{29}$ They go so far as to conclude that the "lack of research on specific initiatives is potentially supporting institutional resistance towards transformative change."30

Being accountable means funding and valuing research on student learning. Strategic leadership in this space can support highering expertise in this area, or promoting from within. Lacking evidence-based best practice in how to measure the outcomes of diversity and inclusion initiatives on campus also remains a challenge for accountability.

Developing tactics for how best to be accountable within an institution is nonetheless important. The various change theories developed by Kezar provide some guidance on ways forward. In the context of accountability for diversity and inclusion programs and initiatives, no one change

\footnotetext{
${ }^{27}$ Alex-Assensoh, "Hiring a Diversity Officer Is Only the First Step. Here Are the Next 7."

${ }^{28}$ Lori D. Patton, Berenice Sánchez, Jacqueline Mac, and D-L Stewart, "An Inconvenient Truth About 'Progress': An Analysis of the Promises and Perils of Research on Campus Diversity Initiatives," The Review of Higher Education 42, no. 5 (2019): 179.

${ }^{29}$ Patton, Sánchez, Mac, and Stewart, “An Inconvenient Truth About 'Progress', 188.

${ }^{30}$ Patton, Sánchez, Mac, and Stewart, “An Inconvenient Truth About "Progress', 189.
} 
school addresses the systemic alterations necessary. Strategic academic development that involves holding faculty, staff, and students accountable for diversity and inclusion in classroom, curriculum, and residential life requires cognitive, cultural, and scientific management change. And such changes are likely to proceed slowly over time, which requires the tactics of the Evolutionary methods as well. Accountability is systemic and no theory of change school will sufficiently address the many types of change needed for this final step to take place.

\section{CONCLUSION}

This chapter has highlighted the changing diversity within higher education institutions across Asia and provided suggestions for how to identify the best avenues for strategic leadership around diversity and inclusion. With Kezar showcasing different mechanisms and approaches institutional leadership and change, the article also provides a summary of actionable strategic changes within an institution. A review of five possible actions that can be taken for strategic academic leadership are shared. These are the development of: (1) new physical spaces on a given campus; (2) the hiring of a chief diversity officer; (3) the changing role of curriculum committees and teaching and learning committees; (4) Engagement with academic support Units-libraries, writings centers, centers for teaching and learning; (5) and developing policies and mechanism for accountability around diversity and inclusion.

This chapter has spoken to a broader perspective on diversity and inclusion than the other chapters of this book, bringing together the ways in which the ideas in this book can be enacted in different higher education contexts. Collectively, this edited volume illuminates the many ways in which being cognizant of students' diverse experiences and backgrounds and designing curricula and courses with that diversity in mind, faculty can maximize student learning. Students will look to faculty and staff for leadership-intellectual and moral—in difficult and uncomfortable situations. The more we know about our students and their educational background the better we can anticipate challenges that will arise and respond in ways that achieve deep learning and avoid harm. This book provides practical advice on how to manage these issues within higher education across Asia. 


\section{Summary of the Volume}

The contributors here have addressed a dearth in the literature about the learner in Asia and academic leaders who are new to teaching in the Asian context. As the higher education industry expands across Asia, the issues of diversity and inclusion in pedagogy, curriculum, and institution have come to the fore with new intensity.

The first part of this book, Part I: Pedagogy for Inclusion, provides insights into the classroom techniques available for improving every students' learning in a given classroom. A particular benefit of the book is that it speaks to the varied learning contexts across Asia but within international education settings. This first section speaks to the nuts and bolts of teaching in the Asia context-pedagogy for inclusion, diversifying curricular design, preparing culturally fair rubrics for assessment, exploring the pedagogy of service-learning to address socio-economic difference, and decolonizing the curriculum in the Asian context. An important demographic trend distinctive to Asia in some ways is the aging population, combined with the shifts in employment caused by the automation economy, which means integrating adult learners into our classrooms is also very important. The discussion of diversity and how best to leverage it for impactful learning are relatively new in the literature for the higher education in Asia context. Whether you are interested in learning more about your own implicit bias and how grading can be done more fairly, or you are interested in learning about confusion heritage and its potential influence on learners, these chapters offer distinctive insights for learning and teaching in the region.

The second part of the book, Part II: Liberal Arts Curricula in Asia Through the Diversity and Inclusion Lens, offers insights in ways of change for international liberal education in Asia. Diversifying the curriculum, service-learning that can help address socio-economic difference, and the support for multilingual writers through the development of writer's centers. Together these three chapters represent key areas in which diversity and inclusion are playing out in higher education institutions across Asia.

In the third part, Part III: Supporting Historically Marginalized Populations, the authors review to different groups that have not yet been fully integrated into the higher education classroom in some countries within Asia, namely the LBGTQ+ community of learners, and in some contexts women and girls. There are varying cultural norms and legal precedents 
influencing the inclusion of both groups. Regardless of the higher education context, as educators, and strategic academic leaders, there are ways we can ensure they have an equal learning opportunity. These chapters seek to shed light on the current status of these groups and how we can engage them in the classroom for deeper learning for all.

\section{BIBLIOGRAPHY}

Alex-Assensoh, Yvette M. "Hiring a Diversity Officer Is Only the First Step. Here Are the Next 7." Chronicle of Higher Education, June 5, 2018. https://www. chronicle.com/article/Hiring-a-Diversity-Officer-Is/243591.

Antonio, Anthony L., Mitchell J. Chang, Kenji Hakuta, David A. Kenny, Shana Levin, and Jeffery F. Milem. "Effects of Racial Diversity on Complex Thinking in College Students." Psychological Science 15, no. 8 (2004): 507-510.

Aoun, Joseph. Robot Proof. Cambridge: MIT Press, 2017.

Chun, Edna Breining. Conducting an Institutional Diversity Audit in Higher Education: A Practitioner's Guide to Systematic Diversity Transformation. Dulles: Stylus Publishing, 2019.

Clauson, Caitlyn, and John McKnight. "Welcome to Campus: Planning for Diversity, Inclusion, and Equity." Planning for Higher Education 47, no. 1 (2018).

Clegg, Sue. "Forms of Knowing and Academic Development Practice." Studies in Higher Education 34, no. 4 (2009): 403-416. https://doi.org/10.1080/ 03075070902771937.

Cruz, Alice M. "Intentional Integration of Diversity Ideals in Academic Libraries: A Literature Review." The Journal of Academic Librarianship 45, no. 3 (2019): 220-227.

Gleason, Nancy, ed. Higher Education in the Era of the Fourth Industrial Revolution. Singapore: Palgrave, 2018.

Herring, Cedric. "Does Diversity Pay?: Race, Gender, and the Business Case for Diversity." American Sociological Review 74, no. 2 (2009): 208-224.

Hode, Marlo G., Elizabeth Beh-Morawitz, and Alexie Hays. "Testing the Effectiveness of an Online Diversity Course for Faculty and Staff." Journal of Diversity in Higher Education 11, no. 3 (2017): 347-365.

Kezar, Adrianna. How Colleges Change: Understanding, Leading, and Enacting Change. New York: Routledge, 2014.

- "Theories of Change: Change Agent Guides." The Review of Higher Education 39, no. l (2015): 167-170.

LePeau, Lucy. "A Grounded Theory of Academic Affairs and Student Affairs Partnerships for Diversity and Inclusion Aims." The Review of Higher Education 39, no. l (2015): 97-122. 
McLeod, Jack M., Katie Daily, Zhongshi Guo, William P. Eveland, Jan Bayer, Seungchan Yang, and Hsu Wang. "Community Integration, Local Media Use, and Democratic Processes." Communication Research 23, no. 2 (1996): 179209.

Ministry of Education Singapore. Education Statistics Digest 2018. Singapore: Ministry of Education Singapore, 2018. https://www.moe.gov.sg/docs/ default-source/document/publications/education-statistics-digest/esd_2018. pdf.

Mok, Joshua Ka-ho. "Massive Expansion of Universities in Asia Raises Tough Questions on Social Mobility.” March 8, 2016. http://theconversation.com/ massive-expansion-of-universities-in-asia-raises-tough-questions-on-socialmobility-54680.

Mok, Ka-ho, and Jin Jiang. "Massification of Higher Education and Challenges for Graduate Employment and Social Mobility: East Asian Experiences and Sociological Reflections." International Journal of Educational Development 63 (2018): 44-51.

OECD. "Enrolment rate." https://data.oecd.org/eduatt/enrolment-rate.htm.

Patton, Lori D., Berenice Sánchez, Jacqueline Mac, and D-L Stewart. "An Inconvenient Truth About 'Progress': An Analysis of the Promises and Perils of Research on Campus Diversity Initiatives." The Review of Higher Education 42 , no. 5 (2019): 173-198.

Schleicher, Andreas. "China Opens a New University Every Week." March 16, 2016. https://www.bbc.com/news/business-35776555.

Sng, Bee Bee. "Surface or Deep Change? How Is a Curriculum Change Implemented at Ground Level?" International Journal of Educational Management 22, no. l (2008): 90-106.

Stanley, Christine A., Karan L. Watson, Jennifer M. Reyes, and Kay, S. Verela. "Organizational Change and the Chief Diversity Officer: A Case Study of Institutionalizing a Diversity Plan." Journal of Diversity in Higher Education (2018). http://dx.doi.org/10.1037/dhe0000099.

UNESCO. Higher Education in Asia: Expanding Out, Expanding Up. Montreal: UNESCO, 2014. http://uis.unesco.org/sites/default/files/ documents/higher-education-in-asia-expanding-out-expanding-up-2014-en. pdf.

Wilson, Jeffrey L. "Presidential Plans: New College Presidents and Diversity Efforts." Planning for Higher Education 44, no. 1 (2015): 76-86.

World Bank. "School Enrolment, Tertiary (\% Gross)." https://data.worldbank. org/indicator/se.ter.enrr.

Worthington, Roger L., Christine A. Stanley, and William T. Lewis. "National Association of Diversity Officers in Higher Education Standards of Professional Practice for Chief Diversity Officers." Journal of Diversity in Higher Education 7, no. 4 (2014): 227-234. 
Wu, Alfred M., and John N. Hawkins. Massification of Higher Education in Asia. New York: Springer, 2018.

Zou, Tracy X. P., and Janet Yu. "Intercultural Interactions in Chinese Classrooms: A Multiple-Case Study." Studies in Higher Education (2019). https:// doi.org/10.1080/03075079.2019.164741.

Open Access This chapter is licensed under the terms of the Creative Commons Attribution 4.0 International License (http://creativecommons.org/licenses/ by $/ 4.0 /)$, which permits use, sharing, adaptation, distribution and reproduction in any medium or format, as long as you give appropriate credit to the original author(s) and the source, provide a link to the Creative Commons license and indicate if changes were made.

The images or other third party material in this chapter are included in the chapter's Creative Commons license, unless indicated otherwise in a credit line to the material. If material is not included in the chapter's Creative Commons license and your intended use is not permitted by statutory regulation or exceeds the permitted use, you will need to obtain permission directly from the copyright holder.

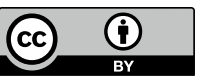

